\title{
On improving education opportunities
}

\author{
Citation for published version (APA):
}

Bernal N., G. L. (2021). On improving education opportunities: Preferences and performance of High School students in response to scholarships, information, and co-education. [Doctoral Thesis, Maastricht University]. Boekenplan. https://doi.org/10.26481/dis.20210623gn

\section{Document status and date:}

Published: 01/01/2021

DOI:

10.26481/dis.20210623gn

Document Version:

Publisher's PDF, also known as Version of record

\section{Please check the document version of this publication:}

- A submitted manuscript is the version of the article upon submission and before peer-review. There can be important differences between the submitted version and the official published version of record.

People interested in the research are advised to contact the author for the final version of the publication, or visit the DOI to the publisher's website.

- The final author version and the galley proof are versions of the publication after peer review.

- The final published version features the final layout of the paper including the volume, issue and page numbers.

Link to publication

\footnotetext{
General rights rights.

- You may freely distribute the URL identifying the publication in the public portal. please follow below link for the End User Agreement:

www.umlib.nl/taverne-license

Take down policy

If you believe that this document breaches copyright please contact us at:

repository@maastrichtuniversity.nl

providing details and we will investigate your claim.
}

Copyright and moral rights for the publications made accessible in the public portal are retained by the authors and/or other copyright owners and it is a condition of accessing publications that users recognise and abide by the legal requirements associated with these

- Users may download and print one copy of any publication from the public portal for the purpose of private study or research.

- You may not further distribute the material or use it for any profit-making activity or commercial gain

If the publication is distributed under the terms of Article $25 \mathrm{fa}$ of the Dutch Copyright Act, indicated by the "Taverne" license above, 


\section{On Improving Education Opportunities: Preferences and Performance of High School Students IN Response to Scholarships, INFORMATION, AND Coeducation}


@2021 Gloria L. Bernal

ISBN is 9789086665303

Publisher: Boekenplan, Maastricht

http://www.boekenplan.nl

All rights reserved. No part of this publication may be reproduced, stored in a retrieval system, or transmitted in any form, or by any means, electronic, mechanical, photocopying, recording, or otherwise, without the prior permission in writing, from the author. 


\title{
On Improving Education Opportunities: Preferences And Performance of High SCHOOL STUDENTS IN Response to SCHOlarships, INFORMATION, AND Coeducation
}

\begin{abstract}
Dissertation
to obtain the degree of Doctor at the Maastricht University, on the authority of the Rector Magnificus Prof.dr. Rianne M. Letschert in accordance with the decision of the Board of Deans, to be defended in public on Wednesday 23rd of June 2021 at 16.00 hours
\end{abstract}

By:

Gloria L. Bernal N. 


\section{Supervisor}

Prof. Dr. Kristof De Witte

University of Leuven KU Leuven/Maastricht University.

\section{Co-Supervisor}

Dr. Mindel van de Laar

\section{Assesment committee}

Prof. Dr. Wim Groot (Chair)

Prof. Dr. Tommaso Agasisti

Politecnico di Milano, School of Management. Milano, Italy.

Prof. Dr. Trudie Schils

Dr. Monica Hernandez

Universidad Eafit, Departamento de Economía. Medellín, Colombia. 


\section{Acknowledgements}

I wish to thank some of the many people who supported me in this accomplishment.

I wish to express my deepest gratitude to my supervisor, Prof. Kristof de Witte whose outstanding work in Economics of Education research motivated and influenced my current work. I am very thankful for his consistent help, and rigorous revisions to this project. To my co-supervisor, Dr. Mindel van de Laar for her support even before starting the program; for nominating me to the NUFFIC scholarship, for her comments, for expressing encouraging over the practical scope of this work and for guiding me with patience during this journey.

I would like to express my special regards to the assessment committee members Prof. Wim Groot, Prof. Tommaso Agasisti, Prof. Trudie Schils, Dr. Monica Hernandez, and the opponents Dr. Carla Haelermans and Dr. Silvia Gomez for the generous time they dedicated to reading my research and giving me valuable comments. Their reviews and recommendations, coming from such experts, are of immense importance for me to improve and continue growing in this field. I also wish to extend my special thanks to my friend Jeffrey Penney, who patiently read every word of my work checking for grammatical mistakes, and who took the time to explain to me my (not few) grammatical errors.

I would also like to thank the $\mathrm{GPAC}^{2}$ team. The comments from the coordinators (Shivani and Cristina) and all the assistants to my presentation during the seminars at UNU-MERIT helped to enrich this research. I express my gratitude to my amazing colleagues at the program who I wish all the best in their careers: Anna, Carlos, Eliana, Fernanda, Karen, María Antonietta, Nasir, Paolo and Ricardo. I want to thank Leanna Stiefel, who gave me a recommendation for this $\mathrm{PhD}$ program and whose course in Economics of Education at NYU awakened my interest in this field. I am also very grateful to my Ph.D. sponsor NUFFIC, the Dutch organization for internationalization in education.

Moreover, I am indebted to my employer Javeriana University and my work team. I am very thankful to Andres Rosas, who encouraged and supported me to pursue a Ph.D since he was my previous academic men- 
tor. To Luz Karime Abadía, my partner in the Laboratory of Economics of Education, which already serves to spur changes in the Colombian educational system. From her experience I had learned immensely. I am also indebted to many people at my work team whose commitment to their endeavors made mine easier to carry: Andrés Giraldo, Dora Guerrero, Gloria Gutierrez, Jeff Brown, Juliette Martinez, Juan Eduardo Coba, Luis José Tarazona, Omar Garzón and Pamela Amaya.

Finally, I dedicate this dissertation to my family. To my mother Martha and my aunt Stella, whose generosity and empowerment has been a model to me. They provided me with education, the most valuable asset I could ever get in my life, and always put service to others above their own needs. To my father Fernando for his kind and comforting words that he delivers to me literally every day in life. He declared himself to be my number one fan regardless of the size of the milestone I reach. To my three brothers, Oscar, Camilo and Felipe for their honest talks and for being always willing to give a hand to help in whatever issue I asked for in the busiest or oddest times. To my husband, Lope, who has been my rock: with his wisdom he stood by me and the kids through all challenging situations. Without him by my side and his love, maintaining the balance would not have been possible. To my children, Santiago and María Lucía, for their love: you have made me stronger, better and happier than I could have ever imagined. You inspire me every day to become a better person. I love you with my all heart. 


\section{Contents}

1 Introduction 15

1.1 Summary . . . . . . . . . . . . . . . . 15

1.2 Opportunities . . . . . . . . . . . . . . 16

1.3 The role of (higher) education in middle-income economies 19

1.4 Overview of the literature on higher-education scholarships and the role of information . . . . . . . . . 22

1.4.1 Scholarships for higher achieving low-income students . . . . . . . . . . . . . 22

1.4.2 Provision of Information . . . . . . . . . . . 24

1.5 Research setting: Colombia . . . . . . . . . . 26

1.5.1 Higher education in Colombia . . . . . . . . . 27

1.5.2 Academic gender gap . . . . . . . . . . . . . . . . 30

1.6 Overview of dissertation . . . . . . . . . . . . . . 30

2 Scholarships And Student Effort: Evidence From Colombia's Ser Pilo Paga Program 43

2.1 Introduction . . . . . . . . . . . . . . . 45

2.2 Institutional background . . . . . . . . . . . . . . . . . . . . . . . . . . . . . . .

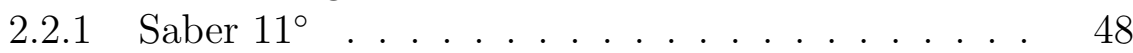

2.2.2 Ser Pilo Paga . . . . . . . . . . . . . . . . . . . . . . . . . 49

2.2 .3 Socioeconomic status . . . . . . . . . . . 50

2.3 Data . . . . . . . . . . . . . . . 52

2.4 Empirical analysis . . . . . . . . . . . . . . . . . . 56

2.4.1 Timeline . . . . . . . . . . . . . . 56

2.4 .2 Empirical strategy . . . . . . . . . . . . 56

2.4 .3 Results and discussion . . . . . . . . . . . . . 59

2.4.4 Robustness . . . . . . . . . . . . . 63

2.4.5 Distribution of top test performers . . . . . . 65

2.5 Survey evidence . . . . . . . . . . . . . 66 
2.6 Policy discussion . . . . . . . . . . . . . . . . . . . . 69

3 Can Information Change Preferences For Higher Education? Evidence From a Randomized Experiment in Colombia

3.1 Introduction . . . . . . . . . . . . . . 76

3.2 Context . . . . . . . . . . . . . . . . . 79

3.3 Methods .................... . . 81

3.3.1 Experimental Design . . . . . . . . . . . . . 81

3.3.2 Econometric analysis . . . . . . . . . . . . 86

3.4 Results . . . . . . . . . . . . . . . . . . . 89

3.4.1 Descriptive analysis . . . . . . . . . . . . 89

3.4.2 Effect of information on student preferences . . . 93

3.4.3 Heterogeneous effects . . . . . . . . . . . . . . . 98

3.5 Discussion and conclusion . . . . . . . . . . . . . 103

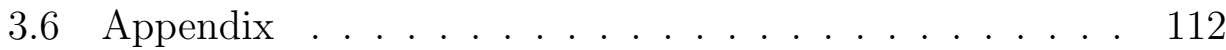

4 When Chances For Higher Education Drop: The Cancellation Of Ser Pilo Paga Scholarship On Student Preferences For Higher Education

4.1 Introduction . . . . . . . . . . . . . . . . . 120

4.2 Context and Setting . . . . . . . . . . . . . . 123

4.2.1 The Ser Pilo Paga Program . . . . . . . . . . . . 124

4.2.2 Exogenous shock . . . . . . . . . . . . . . 126

4.3 Methods . . . . . . . . . . . . . . . . . . 128

4.4 Data . . . . . . . . . . . . . . . . 133

4.5 Result . . . . . . . . . . . . . . . . 136

4.6 Discussion and conclusions . . . . . . . . . . . . . . . . . 142

4.7 Appendix . . . . . . . . . . . . . . . . 149

5 The Effect Of Converting Single-sex Schools To Coeducational: Quasi-experimental Evidence From Colombia 155

5.1 Introduction . . . . . . . . . . . . . . . 156

5.2 Literature review . . . . . . . . . . . . . . . . . . . . . 159

5.3 Institutional background . . . . . . . . . . . . . . . . . . . . . . . . . . . . . . 163

5.4 Data and Method . . . . . . . . . . . . . 163

5.5 Results . . . . . . . . . . . . . . . . 172

5.5.1 Effect of conversion from single-sex school to coed on performance ............... . . 172 
5.5.2 Intensity Effect and Marginal effects . . . . . . . 174

5.5.3 Sub-analysis for females in ex-male schools and males in ex-female schools . . . . . . . . . . . 176

5.6 Robustness checks . . . . . . . . . . . . . . . . 182

5.7 Discussion and conclusions . . . . . . . . . . . . . . 182

5.8 Appendix . . . . . . . . . . . . . . . . . . 193

6 Conclusion and Discussion $\quad 195$

6.1 Overview . . . . . . . . . . . . . . . 195

6.2 Findings and conclusions of each chapter . . . . . . . . . . . . . . . . 197

6.3 Summary of the findings . . . . . . . . . . . . . . . . . . . . . . . . . . 201

6.4 Policy implications . . . . . . . . . . . . . . . . 202

6.5 Directions for future research . . . . . . . . . . . . 204

$\begin{array}{ll}\text { Appendix } & 207\end{array}$

Bio

213 


\section{List of Figures}

1.1 PISA 2018 result by country . . . . . . . . . . . . 21

1.2 Colombian population distribution by sex and age range 26

1.3 Number of enrolled in the first year per semester in higher education (undergraduate) . . . . . . . . . 28

1.4 Education spending as a percentage of GDP in Colombia 29

1.5 Overview of dissertation . . . . . . . . . . . . 31

2.1 Strata and Sisben score . . . . . . . . . . . . 54

2.2 Histogram of the running variable by area . . . . . . . 55

2.3 Effect of SPP scholarship introduction on high school exit exam scores . . . . . . . . . . . . . 60

2.4 Regression discontinuity graph . . . . . . . . . . . 61

2.5 Placebo regression discontinuity graph . . . . . . . . 64

3.1 Activity instructions to the students before starting the DCE and an example of a DCE choice set. (Original text in Spanish) . . . . . . . . . . . . 83

3.2 Attributes and levels in the discrete choice experiment . 86

3.3 Sample distribution . . . . . . . . . . . . . . 87

3.4 Effect of information on stated preferences for higher education attributes. Treatment 1: returns \& access. Treatment 2: credits \& costs. . . . . . . . . . . . . .

3.5 Willingness to give up (WTGU) as a proportion of a full tuition scholarship. Coefficients of attributes and attributes*treatment 1 (returns \& access) . . . . . . . . . . . . . 96

3.6 Willingness to give up (WTGU) as a proportion of a full tuition scholarship. Coefficients of attributes and attributes*treatment 2 (credits \& costs) . . . . . . . . . . . 97 
3.7 Heterogeneous effect of provision of information on student's preferences, by subgroups. Treatment 1: returns \& access. Treatment 2: credits \& costs. . . . . . . . . . . . 99

3.8 Survey sections . . . . . . . . . . . . . . . . . . 116

3.9 Robustness check . . . . . . . . . . . . . . . . . . 118

4.1 Timeline of electoral year in Colombia and survey administration . . . . . . . . . . . . 126

4.2 Google trends exploration on 'ser pilo paga' searches . . 127

4.3 Attributes and levels in the discrete choice experiment . 130

4.4 Activity instructions to the students before starting the DCE and an example of a DCE choice set. (Original text in Spanish) . . . . . . . . . . . . . .

4.5 Robustness checks - Testing time discontinuity in variables related to aspirations for higher education (Raw dataset) 141

4.6 Robustness checks - Testing time discontinuity in variables unrelated to aspirations for higher education (Raw dataset) . . . . . . . . . . . . . .

5.1 Number of single-sex schools that converted to coeducational observed in exit examination over time. . . . . . . 165

5.2 Example of a boys-only school that converts to coeducational in $\mathrm{K}$ grade, observed in 11th grade at t period. . . 168

5.3 Example of a boys-only school that converts to coeducational in $\mathrm{K}$ grade, observed in 11th grade at t period. . . 169

5.4 Parallel trend assumption . . . . . . . . . . . . . 175

5.5 Intensity effect: changes in the share of students from the opposite sex in schools converted from single-sex to coed

5.6 Robustness checks: parallel trend assumption using control variables . . . . . . . . . . . . . . . 186 


\section{List of Tables}

1.1 Sustainable Development Goal 4: Quality Education . . 17

2.1 Summary statistics . . . . . . . . . . . . . . 53

2.2 Timeline . . . . . . . . . . . . . . . 56

2.3 Heterogeneous effects of SPP scholarship introduction on test scores . . . . . . . . . . . . . . . 62

2.4 Quantile effects of SPP scholarship introduction on test scores .................... 63

2.5 Placebo checks . . . . . . . . . . . . . . 64

2.6 Distribution of top performers on the SABER $11^{\circ} \ldots .65$

2.7 Importance of studying for the Saber $11^{\circ} \ldots . . . . .667$

2.8 Hours of study for the Saber $11^{\circ}$ by method . . . . . . . 68

2.9 Method of studying used for the Saber $11^{\circ} \ldots \ldots$

3.1 Covariate balance by treatment- table A- school level . . 90

3.2 Covariate balance by treatment-B Individual level . . . . 91

3.3 Percentage of correct answers for each one of the statements showed to treatment groups . . . . . . . . 92

3.4 Heterogeneous effect of provision of information on student's preferences, by their level of (miss)information on the statements . . . . . . . . . . . . . 100

3.5 Effect of treatment on the types of information requested by students at the end of the survey . . . . . . . . . . 102

3.6 A - Intervention: statements provided to students in treatment 1 and treatment 2 groups (Original text in Spanish) 112

3.7 B-Effect of information on student's preferences for higher education bundles. Willingness to give (WTGU) analysis. 116

4.1 Covariates balance of students in the sample and nonrespondents .................... 135 
4.2 Effects of the cancellation of SPP on students preferences, by subsample according to their Sisben poverty index level. CEM specification. . . . . . . . . . . . .

4.3 Effects of the cancellation of SPP on students preferences, by subsample according to their Sisben poverty index level. Raw data . . . . . . . . . . . . . .

4.4 Effects of the cancellation of SPP on students preferences, by subsample according to their Sisben poverty index level. More restricted CEM specification. . . . . . . . . . . . 151

4.5 Placebo checks using the exit examination in 2019 . . . 153

5.1 Summary statistics of the schools in the sample. Exit examination of senior cohorts 2000-2017. . . . . . . . 166

5.2 Effect on performance of single-sex schools converting to coeducational . . . . . . . . . . . . . 174

5.3 Observational analysis of females in ex-male schools and males in ex-female school part A . . . . . . . . . .

5.4 Observational analysis of females in ex-male schools and males in ex-female school- Part B . . . . . . . . . . . 180

5.5 Appendix A-Effect of conversion of single-sex schools under different controls-Part-A . . . . . . . . . . . 193

5.6 Appendix A-Effect of conversion of single-sex schools under different controls-Part-B . . . . . . . . . . . . . . 194

6.1 Selected literature - Scholarships provision . . . . . . 207

6.2 Selected literature - Provision of information . . . . . . . 209 


\section{Chapter 1}

\section{Introduction}

\subsection{Summary}

Educational opportunities are diverse, finite, and dependent on many factors. Public policy in education is constantly looking for ways to improve these opportunities and to increase students' performance in an effort to achieve a better society. The presence of inequality in access to (and the quality of) education is a main concern that requires public intervention. After setting the scene in Chapter 1, this dissertation explores the effect of introducing the merit-based Ser Pilo Paga (SPP) scholarship to lowincome students in Colombia on their subsequent academic performance and effort (Chapter 2). It also surveys low-income high school pupils to explore their preferences for higher education over different hypothetical scenarios, and tests whether the provision of basic information on financial aid and the returns to education could alter those preferences (Chapter 3). Furthermore, we exploit the SPP's sudden cancellation in 2018 to study the consequences of this shock on the higher education preferences of those who would have been eligible for the program based on the family's poverty index (Chapter 4). We find that the scholarship raised the level of effort of high achievers (particularly males and students living in urban areas). Moreover, we show that students' educational choices are markedly determined by scholarship opportunities: after the SPP was cancelled, eligible students' educational aspirations fell significantly; females and the lowest-income students were affected particularly hard. Prior research has concluded that financial opportunities for low-income students are a key driver of their effort and an important determinant of their decisions about whether to pursue higher 
education. Moreover, preferences for higher education can be mediated by the provision of information -particularly information about financial aid and the cost of tertiary education. Here, provision of information also benefited disproportionally more females than males, which shows a tool to alleviate academic gender inequalities perceived in several levels of education in Colombia, a country with one of the largest gender gaps in math and one of the smallest gender gaps in favor of girls in reading across PISA-participating countries (OECD, 2018).

Chapter 5 investigates the academic gender inequalities in Colombian secondary schools, which have been widely documented. This chapter explores gender peer effects, looking for insights as to how to increase academic performance in high school exit examinations, for female students in particular. In this chapter, we study how the conversion of single-sex schools into coeducational (coed) schools affected the academic achievement of incumbent students (Chapter 5). The results suggest that males in formerly male-only schools did not benefit, whereas females did so only marginally. The debate on the proper environment for students to maximize their learning is ongoing, although single-sex education is unlikely to return in many cases.

This study aims to provide new insights that can help students, parents, schools, and governments close the academic gap between low- and high-income students, as well as between females and males. This thesis provides evidence-based insights to pursue this aim and discuss the policy implications of those findings. The results have important implications for developing countries like Colombia, where academic achievement is highly dependent on opportunities, income, and sex, rather than individual academic potential.

\subsection{Opportunities}

Educational opportunities refer to the act of giving individuals the chance to develop the knowledge, skills, and attitudes that are required to perform within a society (UNESCO-UIS, 2011). Access to quality education brings intrinsic benefits to individuals and external benefits to society. For individuals, especially those from low-income families, educational opportunities lead to social mobility, access to better-paid jobs, better 
healthcare, and better decision-making skills, among other advantages (Powdthavee, Lekfuangfu \& Wooden, 2015). For society, more knowledgeable workers are more productive, and people tend to have better civic skills, and to be more informed and interested in participating in politics and voting (Verba, Schlozman \& Brady, 1995). Although there are significant advantages associated with providing educational opportunities to individuals, many students are denied the possibility of pursuing a high-quality education (Sawhill, 2013). This situation is particularly true for students in developing countries and for the tertiary education level. Therefore, evidence that explores the channels through which economically disadvantaged students can better afford higher education is needed to inform government efforts to achieve that goal.

Educational opportunities are a priority in the global policy agenda. The United Nations' Sustainable Development is to 'Ensure inclusive and equitable quality education and promote lifelong learning opportunities for all' (United Nations, 2017). This goal is measured by 11 indicators (see Table 1.1); this dissertation provides evidence that supports three of those indicators (in bold): to increase coverage and equity in (tertiary) education, to eliminate gender disparities to ensure equal access to all levels of education, and to expand the number of higher education scholarships available to developing countries. The former two targets are outcome oriented, whereas the last is a means of achievement target. That is, the efficient provision of high school scholarships, focusing on vulnerable groups - such as low-income students or those living in rural areas or females in unrepresented areas - can produce a virtual circle of access and inclusion in education. Higher education scholarships can also help prepare vulnerable individuals for employment, which is particularly important for increasing productivity and reducing income inequalities and poverty (Piketty, 2014).

Table 1.1: Sustainable Development Goal 4: Quality Education

\begin{tabular}{ll}
\hline Goal 4 & Indicators (summary) \\
\hline 4.1 & $\begin{array}{l}\text { Free, equitable and quality primary and secondary education. } \\
\text { Access to quality early childhood development, care and pre- } \\
\text { primary education }\end{array}$ \\
& $\begin{array}{l}\text { Access for all women and men to affordable and quality techni- } \\
\text { cal, vocational and tertiary education, including university }\end{array}$ \\
& $\begin{array}{l}\text { Substantially increase the number of youth and adults who have } \\
\text { relevant skills for employment, decent jobs and entrepreneurship. }\end{array}$
\end{tabular}


Table 1.1 continued from previous page

\begin{tabular}{|c|c|}
\hline Goal 4 & Indicators (summary) \\
\hline 4.5 & $\begin{array}{l}\text { Eliminate gender disparities in education and ensure equal access } \\
\text { to all levels of education }\end{array}$ \\
\hline 4.6 & $\begin{array}{l}\text { Ensure that all youth and a substantial proportion of adults, } \\
\text { both men and women, achieve literacy and numeracy }\end{array}$ \\
\hline 4.7 & $\begin{array}{l}\text { Ensure that all learners acquire the knowledge and skills needed to } \\
\text { promote sustainable development. }\end{array}$ \\
\hline 4.a & $\begin{array}{l}\text { Build and upgrade education facilities that are child, disability and } \\
\text { gender sensitive and provide safe, non-violent, inclusive and effective } \\
\text { learning environments for all. }\end{array}$ \\
\hline 4.b & $\begin{array}{l}\text { Substantially expand globally the number of scholarships available to } \\
\text { developing countries, ( } \ldots) \text { for enrollment in higher education. } \\
\text { Substantially increase the supply of qualified teachers, including }\end{array}$ \\
\hline 4.c & $\begin{array}{l}\text { through international cooperation for teacher training in developing } \\
\text { countries. }\end{array}$ \\
\hline
\end{tabular}

Source: United Nations, Sustainable Development Goals (2015, p.21)

Empirical evidence has demonstrated the positive impact of meritbased scholarships on the higher education enrollment and social mobility of those low-income students (Cornwell, Lee \& Mustard, 2006). Given the relatively scarce resources to fund such scholarships in most developing countries, policymakers and researchers explore how to create more effective and efficient financial aid programs for higher education. How can more students benefit from a given educational budget? What channels best motivate students to pursue higher education? Which population groups will react most and least strongly to the provision of financial aid? Do scholarships only benefit those who receive them?

Recent studies have focused on the role of information in formulating more efficient higher education policies. The provision of information can modify perceptions and thus student's decision-making (Jensen, 2010), reduce mismatching and increase the welfare gains from informed decisions (Matthew, Wiswall \& Zafar, 2015). Moreover, the provision of information is a low-cost measure that can vary in its complexity, for instance from publicizing available scholarships to personalizing information on the earning distribution according to each student's aptitude and preferred major (Hastings, Neilson \& Zimmerman, 2015). These studies are based on the premise that well-informed students will reduce educational mismatch, and take better advantage of educational opportunities.

This dissertation focuses on the role of information regarding higher education on students' outcomes, particularly on pre-college low socioe- 
conomic status (SES) students. The exogenous shock of information described in Chapters 2 and 4 was the creation, and cancellation (respectively), of a nation-wide merit- and income-based scholarship program in Colombia. In Chapter 3 the provision of basic information about higher education was recreated in experimental conditions. Although Chapter 2 assesses the impact of information on performance and effort, Chapters 3 and 4 employ an innovative outcome: we elicited students' preferences for higher education. These three chapters inspect heterogeneous effects of the most vulnerable in terms of academic achievement (i.e. students in rural areas, poorest and females). In Chapter 5 we explore gender peer effects in former female-only and male-only schools. Here, the SES resulted to be a significant determinant of students' performance.

The remainder of the chapter proceeds as follows. Section 1.3 provides a brief overview of the role of (higher) education in middle-income economies as all chapters are developed in the context of a developing country. Section 1.4 outlines the literature on higher education scholarships and the role of information, focusing on higher education. Section 1.5 describes the research setting, and Section 1.6 outlines the study.

\subsection{The role of (higher) education in middle- income economies}

Education is a leading determinant of a country's prosperity. It can reduce poverty and social exclusion, and generate growth and employment (Woessman, 2015). Investing in education can have a multiplicative effect. Globally, one extra year of schooling generates a $9 \%$ increase in hourly earnings (Psacharopoulos \& Patrinos, 2018). In developing countries, every 1USD invested can generate 10-15USD in economic growth (UNESCO, 2012). Making effective investments in education is crucial for human capital accumulation and economic growth.

Access to education involves creating a safe environment that allows learning to take place, and opportunities to learn that are equitably distributed (Lewin, 2015). Enrollment has increased in recent decades. In 2020, the global coverage rate reached $92 \%$ for primary, $66 \%$ for secondary and 39\% for tertiary education (World Bank, 2020c). For middleincome economies coverage differs less from the worldwide mean. The 
gender access gap has been reduced over time, although females remain disadvantage compared to males (World Bank, 2018). Likewise, lowincome students and those living in rural areas are enrolled in education at significantly below-average rates. Access gaps among students from different socioeconomic statuses are high and persistent in developing economies (Sawhill, 2013) Access is a necessary but not sufficient condition for capital accumulation. Quality is key for learning. According to UNICEF (2000), quality in education includes at least four characteristics: I) learners who are healthy and well nourished; II) environments that are healthy, safe, protective and gender sensitive, and provide adequate resources and facilities; III) educational programs that allow differential access; and IV) educational outcomes articulated with the labor market and the country's economy. Developing countries have been less successful than their developed counterparts in achieving quality education systems. The Program for International Student Assessment (PISA) shows that developing countries consistently rank below the average among Organization for Economic Co-operation and Development (OECD) countries (see Figure 1.1). Within countries, children from poorer families generally receive a lower-quality education, which exacerbates inequalities among children from different backgrounds.

Higher education can help overcome the persistent barriers to social mobility. Improving attendance and quality in tertiary education therefore benefits both individuals and society as a whole. Completing tertiary education is associated with higher wages, health, political engagement, and children's educational attainments (Chan, 2016). Yet many students cannot afford to pursue higher education. In Latin America, enrolment entails significant private costs that average $60 \%$ of GDP per capita (UNESCO, 2009), which results in significantly lower enrolment possibilities for low-SES students. Providing educational opportunities that are financially feasible and sustainable, such as higher education scholarships, can help reduce income inequalities. Moreover, providing reliable information can boost these outcomes. 
Figure 1.1: PISA 2018 result by country

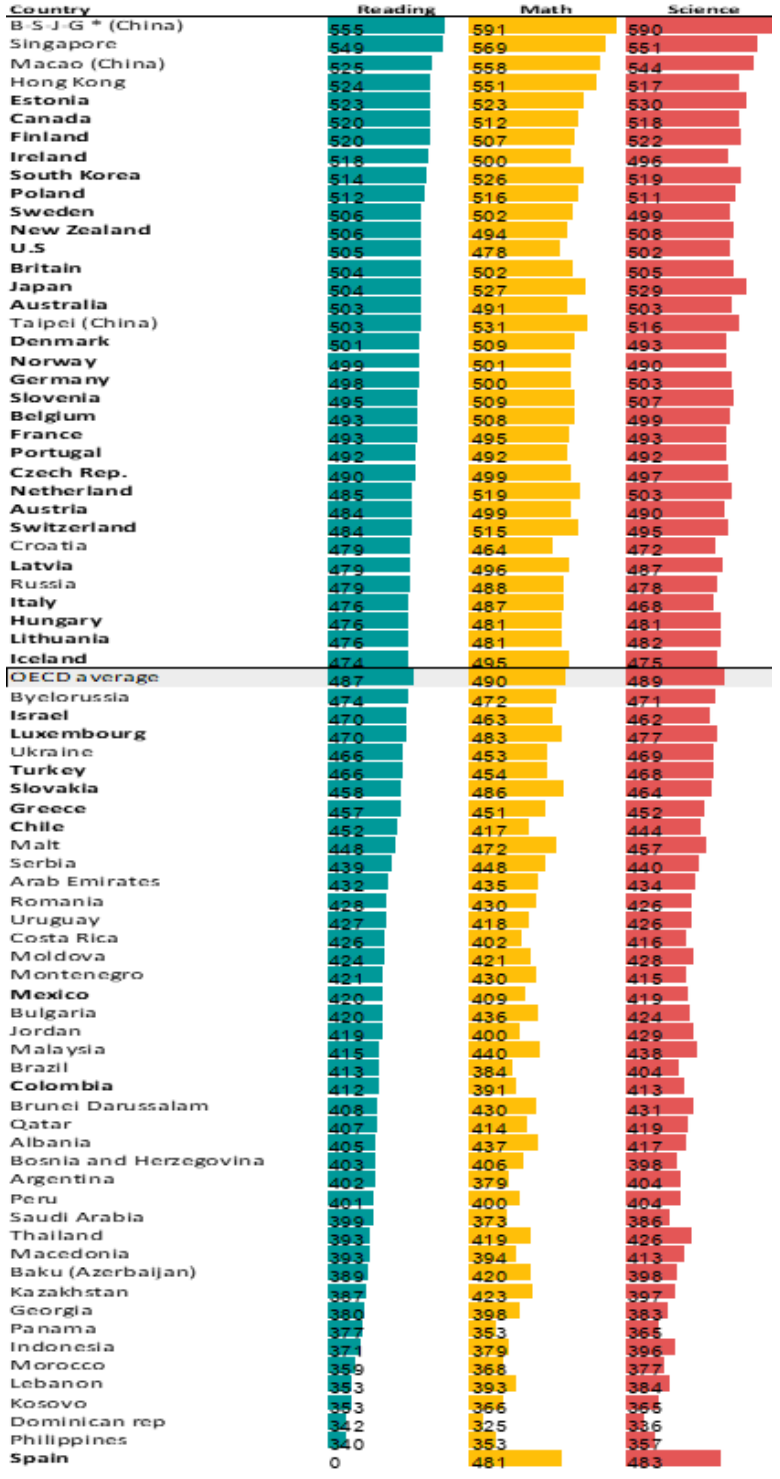

Data source: OECD, 2018. Own elaboration 


\subsection{Overview of the literature on higher- education scholarships and the role of information}

Progress in guaranteeing access, quality, gender equity, inclusion, and basic spending at the elementary and secondary levels generates favorable conditions to maximize quality and inclusion at the higher education level. However, these conditions are not entirely met for poor and minority students, who are disproportionately educated in lower-performing schools (Quintana \& Mahgoub, 2016). This, combined with the fact that these individuals are less able to pay for college (tuition fees and accommodation expenses), results in these students' underrepresentation in tertiary education. Knowledge of higher education opportunities and advantages is also unequally spread among students from less-educated families (Lawrence, 2016). Many low-income students cannot access tertiary education even when they have the ability and desire to do so. Therefore, extra incentives, such as (partial) scholarships for high school targeting low-income students, can serve as an effective channel to partly compensate for the underrepresentation of economically disadvantaged students and to promote social mobility. Furthermore, proper information of the higher education system accompanying these opportunities could improve the recipients' assignation, efficiency, and benefits, and can have a positive impact on non-recipients' educational aspirations and attainment. A virtual circle for individuals and society can emerge from widening access to and inclusion in higher education, which has many positive consequences for the next generation.

\subsubsection{Scholarships for higher achieving low-income students}

Among high achievers, low-income students are less likely to apply to highly selective colleges than high-income students (Hoxby \& Avery, 2012; Dillon \& Smith, 2017). In some cases, by giving scholarships and financial aid to underprivileged groups, these students could lower their educational costs (Cohodes \& Goodman, 2014; Sneyers, Agasisti, De Witte \& Graziosi, 2021) by enrolling in a high-quality university, and increase their expected returns (Hoekstra, 2009; Zimmerman, 2014). 
Initiatives that provide need-based financial aid to help students enroll in selective universities usually report positive outcomes on performance, enrollment, and/or school competition. Prior studies show that such aid represents an effective mechanism to increase the representation of low-income students in college. Cornwell, Lee \& Mustard (2005) and Sridhar (2006) examined the effects of the HOPE scholarship program administered by the US state of Georgia on enrollment and course load. The program grants scholarships to public or private post-secondary institutions within the state to students who excel academically in high school. It has been shown to increase total college enrollment by $5.9 \%$, mostly in 4-year colleges.

Scott-Clayton (2011) examined the US state of West Virginia's promise scholarship program, which has similar academic performance requirements as the HOPE program. The PROMISE program offers free tuition to students with good academic performance who achieve a minimum standardized test score (21 on the ACT or 1000 on the SAT) and who remain enrolled full time. The authors found that recipients completed slightly more than one additional course during the 4-year period, their GPA increased by about 0.1 during the 4 -year period, and they were more likely to finish their Bachelor's degree than their non-awarded peers. Full-time enrollment was 20-25\% higher in the PROMISE program compared to the HOPE program when awardees were compared to non-recipients of the scholarships.

Other programs combine merit-based scholarships with income-based requirements. For instance, participants in the Opening Doors Scholarship program in Louisiana were randomly assigned to either an experimental group or a control group (Brock \& Ritchburg-Hayes, 2006). The treatment group was offered 1,000USD per semester for half-time enrollment and required recipients to maintain a minimum $\mathrm{C}$ average. Participants in the treatment group were about 9 percentage points more likely to be enrolled full time, 7 percentage points less likely to withdraw from a course, 12 percentage points more likely to pass their registered course, and earned on average 1.1 additional credits in the first semester than those in the control group.

Few studies have assessed the causal heterogeneous effects of grants across sub-groups of students and universities, or their long-term and 
spillover effects. Sneyers, Agastisti, De Witte \& Graziosi (2021) estimate the impact of receiving a need-based grant on the performance of students in five Italian universities. They showed that grants have a positive effect on students' performance and competition. They concluded that the impact of the program is heterogeneous across universities and across some subgroups of students.

Finally, a growing literature has tested the combination of scholarships for low-income, high-achieving students with the provision of information. Dynarski et al. (2018) conducted a randomized controlled trial to test whether an inexpensive, targeted, personalized outreach campaign (called the High Achieving Involved Leader Scholarship) was effective at changing low-income students' decisions about whether to attend college. Treated students were reached by mail and encouraged to apply to the highly selective University of Michigan. Their parents and principals were also made aware of the opportunity. The information provided announced four years of free tuition and fees if admitted to the program, with no obligation to complete any financial aid forms. The study found that the likelihood of applying to and enrolling in the University of Michigan more than doubled in the group that received this information ( $26 \%$ vs. $67 \%$ and $27 \%$ vs. $12 \%$, respectively). The authors concluded that income gaps in college choices can be closed by combining financial aid, provision of information and simplicity in the college application. In general, previews literature has shown positive effects of scholarships on the outcomes (e.g. performance, application or enrollment) of targeted students.

\subsubsection{Provision of Information}

The provision of financial aid to increase the inclusion of low-income students in tertiary education can be boosted by the provision of information to those students (Jensen, 2010; Bettinger et al., 2012). Students from low-socioeconomic backgrounds are generally more misinformed than their counterparts in terms of financial aid, the returns on education, and the general process of applying for higher education (Baker, Bettinger, Jacob \& Marinescu, 2018). Therefore, the aspirational and actual attainment gap, as well as proper assignation in undergraduate programs, can be reduced by providing information (Jensen, 2010). The importance of providing information to high school students has been 
empirically tested. For instance, Mizala \& Urquiola (2013) found that knowledge about higher education and its returns can reduce market failures from students' misconceptions and increase educational equity and efficiency at a lower cost. The provision of information has also been shown to effectively increase low-income students' enrollment in selective colleges in some contexts. For example, the USA has rapidly tested the efficacy of information (Bettinger, Long, Oreopoulos \& Sanbonmatsu, 2012; Dynarski, Michelmore, Libassi \& Owen, 2018; Bleemer \& Zafar, 2018), and several studies have been developed for Chile (Dinkelman \& Martínez, 2014; Hastings, Neilson, Ramirez \& Zimmerman, 2016).

Different sets of information have been randomly provided to students. Two of the most popular provisions regard further salaries and credit options (e.g. Booij, Leuven \& Oosterbeek, 2012; Fryer, 2016; Hastings, Neilson \& Zimmerman, 2015). The outcomes usually test the students' choices of college. Although the absorption of the information is usually not a limitation in such studies, the efficacy of such information on students' decisions is not precise. Successful impacts usually depend on the context and the methods used to reach students. Whereas a definitive conclusion cannot be drawn from the previous literature, a general standard is that providing information on available financial aid tends to be more effective at influencing enrollment in higher education (e.g. Herber, 2018; Dinkelman et al., 2014; Bonilla-Mejía, Bottan \& Ham, 2019; Loyalka, Song, Wei, Zhong \& Rozelle, 2015). The provision of information on returns has mixed results on enrollment (e.g. Avitabile \& De Hoyos; Navarro, 2018; Fryer, 2016; Rao, 2016; Kerr, Pekkarinen, Sarvimäki \& Uusitalo, 2020; Peter \& Zambre, 2017; Busso, Dinkelman, Martínez \& Romero, 2017; Jensen, 2010). Most recently, interventions have sought to mix the provision of information and scholarship opportunities, which has had positive effects on enrollment (Dynarski et al., 2020). These positive effects appear to depend on students' socio-economic characteristics.

Moreover, information has proven effective at modifying the aspirations of students from families with low levels of education (Lergetporer, Werner \& Wößmann, 2021). Changes in aspirations, even in hypothetical scenarios, have been shown to be a strong predictor of actual future educational and labor market choices (e.g., Mas \& Pallais, 2017; Wiswall \& Zafar, 2018). Therefore, information can be a strong and low-cost chan- 
nel to optimize higher education decision-making processes for students, and to reduce inequality in society.

\subsection{Research setting: Colombia}

This dissertation focusses on Colombia, which has a 210-year history of republican political life and has suffered internal violent conflicts for more than 50 years. The most important sectors of the country's economy are mining, financial services, construction, and agriculture. In 2018, Colombia had a population of 48 millions (DANE, 2018) and a per capita income of 15.64USD purchasing power parity in 2019 (World Bank, 2020e). Figure 1.2 presents the distribution of the population by age and gender.

Figure 1.2: Colombian population distribution by sex and age range

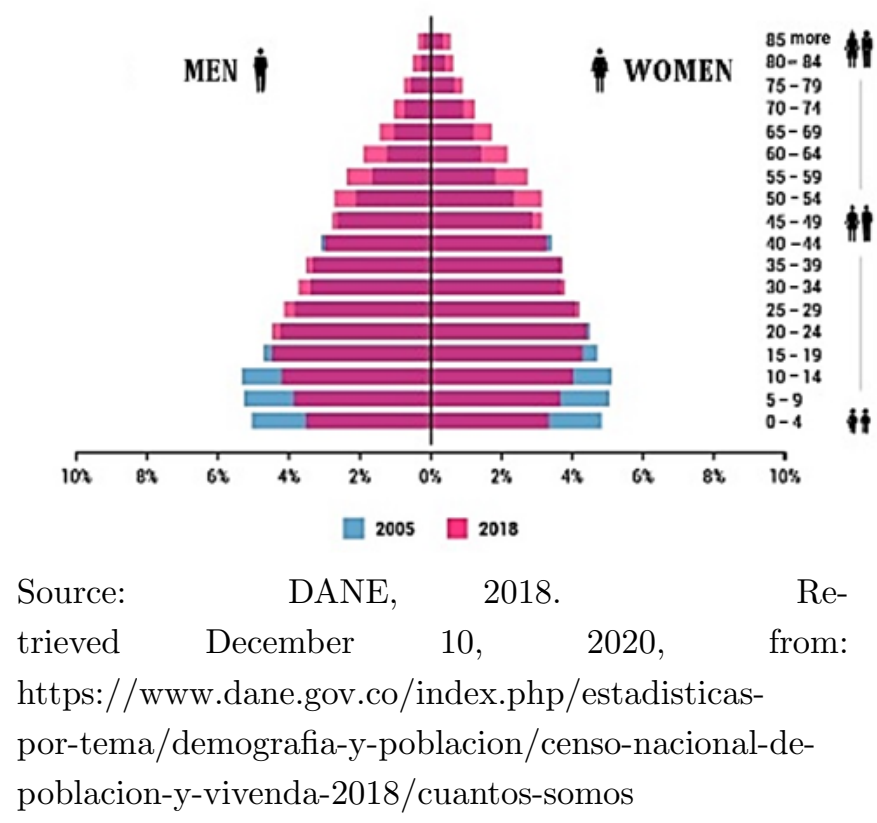

Education in Colombia is regulated by the National Ministry of Education. The ministry provides guidelines to the 96 territorial units to manage primary and secondary education, but directly controls higher education throughout the country. 
Secondary and preparatory education in Colombia include six years of training (grades 6 to 11). This is a fundamental right enshrined in article 67 of the constitution. The law specifies three ways in which students can obtain a high school degree: i) pass the requirements in the six grades of secondary school, ii) pass the ICFES high school exit examination, of iii) take and pass the accelerated high school option in which two grades are completed in one year. Only two-third of students who start primary education manage to finish secondary school.

Although dropout rates are still high in Colombia, its education system has improved during the last two decades in access, financing, and quality. The percentage of students entering primary school increased from $88 \%$ in 1999 to $96 \%$ in 2019 . Access to secondary school has also improved but is still insufficient. In 2019 the net coverage rate was only $63.3 \%$, with rural areas falling below $50 \%$.

The Colombian education system is nearly equally divided into public and private: $49.9 \%$ of schools were public (with 7.35 million enrolled students) and $50.1 \%$ were private (with 1.95 million students) in 2019. Public resources finance public education while private institutions mainly finance on their own education. Students in private schools usually hold higher socioeconomic status than those in public schools; $66.7 \%$ of students in public schools belong to the lowest two of six SES levels.

In 2011, all public schools in Colombia were required to abolish tuition fees under Decree 4807; private school fees vary from US\$14-908 per month (2018 USD). Private school students' scores on the national standardized test, Saber11, are 1.5 standard deviations higher than those of public school students. This thesis focuses on the academic expectations and performance of low-income students who usually study in public and lower-quality schools, and obtain lower academic achievements and attainment than their high-income counterparts.

\subsubsection{Higher education in Colombia}

Colombia's constitution defines higher education as a "cultural public service" (Law 30 of 1992); education funding is considered social public spending according to articles 350 and 366 . The sector is governed based on quality and coverage. 
However, few have access to higher education. Nearly $70 \%$ of students who graduate from high school are low income. Most of them have low chances of being admitted to public universities and cannot afford private universities. Unconditional on quality, higher education coverage rates are low in Colombia compared to its peers. In 2018 its gross coverage rate in higher education was $54 \%$, which is below the average rate for Latin America (57.9\%) and the OECD average rate $(75.1 \%)$ (Private Competitiveness Council, 2020).

In Colombia, higher education programs include technical, technological, bachelor (undergraduate) and graduate degrees. Roughly $37 \%$ of freshman in higher education are enrolled in technical and technological programs, which consist of $4-6$ semesters of training in vocational skills. The rest are enrolled in undergraduate programs. Figure 1.3 illustrates that the enrollment rates in university education display an inverse $U$ shape, with a peak in 2015-2018, when the nation-wide merit-based SPP scholarship (which roughly translates as "it pays to be smart") was available. The scholarship program was cancelled in September 2018 due to cost overruns after funding approximately 40,000 students; by 2019 the number of students enrolled had returned to the 2013 level.

Figure 1.3: Number of enrolled in the first year per semester in higher education (undergraduate)

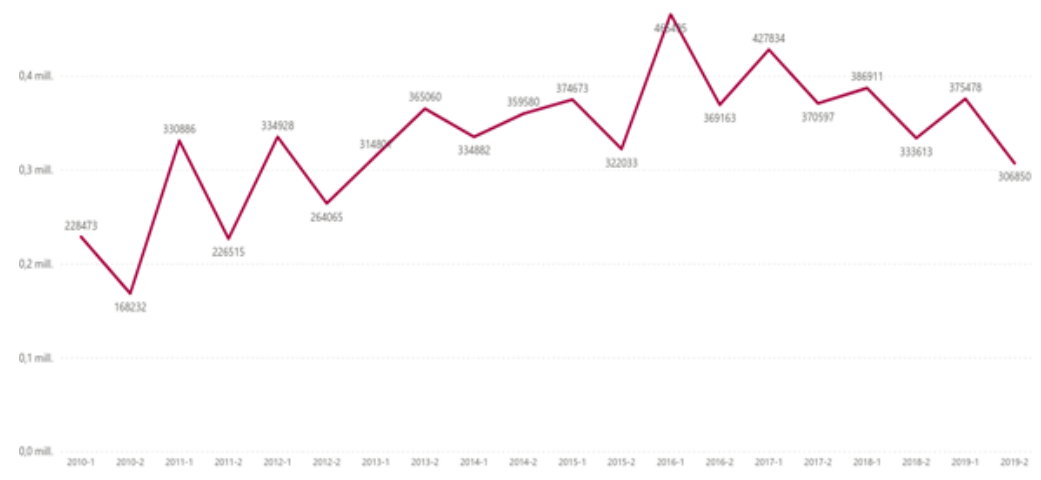

Source: Author's calculation based on National Ministry of Education (2020)

Colombia increased its investment in education as a percentage of 
Gross National Product from 3.5\% in 2000 to $4.5 \%$ in 2018 (Figure 1.4) (World Bank, 2020b). The most important investments in primary, secondary, and tertiary education were made in 2009 and 2013, when the policy of total free enrollment began. In 2014, the nation-wide and meritbased SPP scholarship program was launched, which provided full scholarships to any accredited (high-quality) university in the country to lowincome high achievers (high school students who performed above the 90th percentile on the exit examination score).

Figure 1.4: Education spending as a percentage of GDP in Colombia

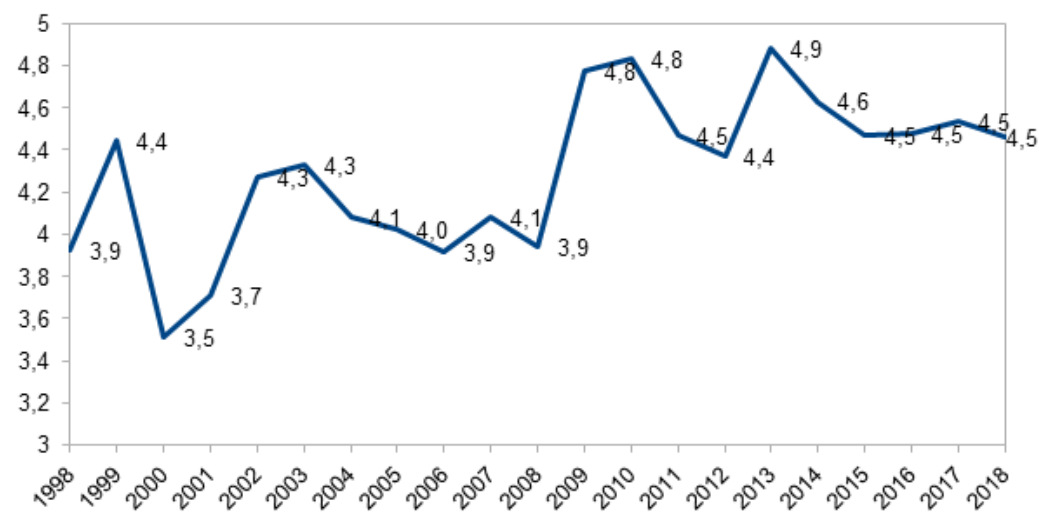

Data Source: World Bank 2020b. Own elaboration.

The SPP program is key to the development of this dissertation for three reasons. First, the program's eligibility criteria create a natural experiment that we use to measure its effects among eligible students who still are in high school (Chapter 2). Second, it allows us to explore both (1) vulnerable high school students' knowledge about basic aspects of higher education in Colombia and (2) the trade-offs these students are likely to make in the context of higher education decisions. Third, the sudden cancelation of the SPP allows us to test the counter effect it would have had among income-eligible students. The reactions of those low-income students to changes (real or hypothetical) to this nation-wide program shed light on the consequences of introducing and cancelling scholarship opportunities in higher education. The three first chapters of the dissertation focus on opportunities and inclusion, seen in the context of the existence and termination of the SPP scholarship program. 


\subsubsection{Academic gender gap}

In addition to socioeconomic inclusion policies, Colombia has also pursued gender inclusion policies. Since the mid-twentieth century, singlesex schools have become mixed more often to offer parents more options for their (mainly female) children to study. Currently, gender academic disparities are not high in terms of coverage, but they remain historically high in terms of performance. The academic gender gap in Colombia is among the largest in the world according to the PISA assessment: males outperform females in math by the widest margin, but girls outperform boys in reading by the lowest margin (OECD, 2018). PISA test results also reveal that Colombia underperforms most countries in math, reading and science, which calls into question the role played by the gender peer effect in educational environments. Chapter 5 explores whether ongoing opportunities to vary the gender composition of schools, from single sex to coed, have repercussions on student performance.

Altogether, using different analytical approaches, this thesis explores ways in which high school students can be encourage to pursue better higher education (tertiary education) options and how such efforts can be more efficient. It also investigates the effects of coeducational over singlesex education, which can be instrumental to learning about gender gaps in the country.

\subsection{Overview of dissertation}

This thesis provides causal evidence of the effect of particular policies, information or measures promoted by the government or schools on students' outcomes. Figure 1.5 presents an overview of the study. This section describes the objectives of the dissertation, provides an overview of the specific research questions and hypotheses that were formulated for each chapter, and briefly discusses the empirical methods used to answer these questions. 


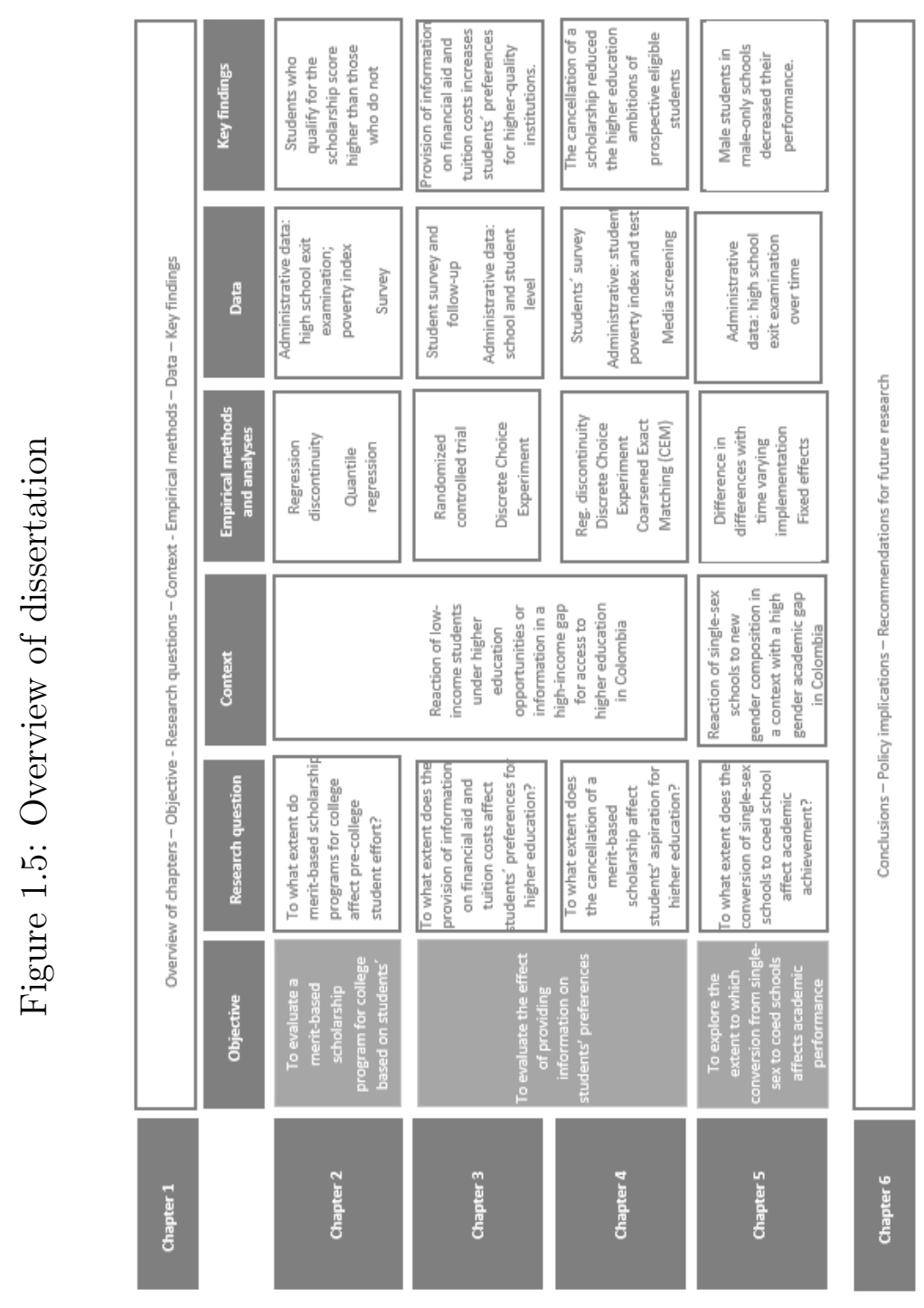


The second chapter evaluates the SPP merit-based scholarship program's impact on student effort using national-level government administrative data from 2014 and 2015. This nationwide scholarship is without precedent in Colombia. It was a clear opportunity for high-achieving, low-income students to enroll in high-quality colleges. Previous studies have demonstrated that opening educational opportunities for college produces spillover effects on pre-college students (Bartik \& Lachowska, 2014) that can eventually determine enrollment in higher education. The present study is one of the first to investigate whether achievement on a standardized test increases in the presence of additional incentives (i.e. a valuable competitive scholarship awarded to students who perform well on the test), and the potential channels through which the increases occur. Chapter 2 examines the following hypothesis:

Hypothesis 1: Merit-based scholarship programs for college increase pre-college student academic performance and effort.

The third chapter examines the role of information provision on students' preferences for higher education. We conducted a randomized controlled trial among 2,652 students where the outcomes were measured using a discrete choice experiment. Students were treated with information on the returns to higher education, enrollment rates, and financial aid and tuition costs at high-quality universities. The hypothetical scenarios were context based using the features of the SPP scholarship to better resemble real scenarios of higher education package decisions. Although the literature on testing information on educational outcomes education is rapidly growing (e.g. Herber, 2018; Dinkelman et al., 2014; BonillaMejía, Bottan \& Ham, 2019; Loyalka, Song, Wei, Zhong \& Rozelle, 2015), this is the first chapter to focus on the decision making of low-income students, who are usually not included in traditional choice records because they rarely attend college. Chapter 3 examines the following hypothesis:

Hypothesis 2: Providing information on financial aid and tuition costs affects students' preferences and aspirations for higher education.

The fourth chapter seeks to quantify the impact of the cancellation of the SPP scholarship on low-income students' preferences for higher education. This is of particular importance as this population is especially sensitive to the uncertainty of financial aid opportunities (Hastings, Neil- 
son \& Zimmerman, 2012). Using a sample of 980 low-income 10th grade students and a regression discontinuity design, we exploit the unanticipated cancellation of the nationwide merit- and need-based scholarship, along with the sharp eligibility criteria for this program. We study the consequences of ending this inclusive program on students' preferences for higher education. Preferences are measured with a discrete choice experiment administered to senior high school students in 2018. Chapter 4 examines the following hypothesis:

Hypothesis 3: Cancelling a merit-based scholarship affects students' aspirations for higher education.

Chapter 4 seeks to quantify the impact of the cancellation of the SPP scholarship on low-income students' preferences for higher education. This is of particular importance as this population is especially sensitive to the uncertainty of financial aid opportunities (Hasting, Neilson \& Zimmerman, 2012). Using a sample of 980 low-income 10th grade students and a regression discontinuity design, we exploit the unanticipated cancellation of the nationwide merit- and need-based scholarship, along with the sharp eligibility criteria for this program. We study the consequences of ending this inclusive program on students' preferences for higher education. Preferences are measured with a discrete choice experiment administered to senior high school students in 2018.

Hypothesis 4: Converting single-sex schools into coeducational schools increase academic achievement for both females and males.

Exploiting quasi-experimental evidence from Colombia, Chapter 5 examines the effects of converting single-sex schools into coed schools on students' performance. Using a time-varying difference-in-differences strategy, we exploit the conversion of 78 male-only and 168 female-only schools into coed schools over a period of 17 years. We also exploit the unique significant variation in the share of opposite-sex students across cohorts within the same school and among former single-sex schools. Using this natural experiment, we contribute to the debate on the effect on performance of having separated or joint classes for the two genders. In this regard, there are hypotheses favoring (Schneeweis \& Zweimuller, 2012; Booth \& Nolen, 2012) and contradicting (Halpern et al., 2011; Hilliard et al., 2010 \& Liben, 2010) the convenience of single- 
sex school environment to increase performance. This paper contributes to the ongoing debate about the effect of coed settings on pupils' academic achievement. Chapter 5 is connected to the previous ones, the theme of which is the importance of studying gender peer effects on high school exit examination scores, which affects the set of opportunities for higher education among high school students (Chapters 2-4). This study also provides insights as to how to possibly moderate the large gender gap in these standardized examinations. It is thought that these gaps disproportionately lessen female opportunities in higher education.

The Chapter 6 presents the main conclusions, broken down by the research questions. This approach helps identify promising collaborative practices and approaches that can influence academic achievement. It also discusses the study's limitations, as well as the implications of the findings for future research and policy. 


\section{References}

[1] Avitabile, C., \& de Hoyos, R. (2018). The heterogeneous effect of information on student performance: Evidence from a randomized control trial in Mexico. Journal of Development Economics, 135, 318-348. https://doi.org/10.1016/j.jdeveco.2018.07.008

[2] Baker, R., E. Bettinger, B. Jacob \& I. Marinescu. (2018). "The Effect of Labor Market Information on Community College Students' Major Choice." Economics of Education Review 65: 18-30.

[3] Bartik, T. J., \& Lachowska, M. (2014). The short-term effects of the KALAMAZOO promise SCHOLARSHIP on student outcomes. New ANALYSES of worker well-being. Emerald Group Publishing Limited. 37-76.

[4] Bettinger, E. P., Long, B. T., Oreopoulos, P., \& Sanbonmatsu, L. (2012). The Role of Application Assistance and Information in College Decisions: Results from the H\&R Block Fafsa Experiment. The Quarterly Journal of Economics, 127(3), 1205-1242. https://doi.org/10.1093/qje/qjs017

[5] Bleemer, Z., \& Zafar, B. (2018). Intended college attendance: Evidence from an experiment on college returns and costs. Journal of Public Economics, 157, 184-211. https://doi.org/10.1016/j.jpubeco.2017.11.002

[6] Bonilla-Mejía, L., Bottan, N. L., \& Ham, A. (2019). Information policies and higher education choices experimental evidence from Colombia. Journal of Behavioral and Experimental Economics , 83, 101468. https://doi.org/10.1016/j.socec.2019.101468

[7] Booij, A. S., Leuven, E., \& Oosterbeek, H. (2012). The role of information in the take-up of student 
loans. Economics of Education Review, 31(1), 33-44. https://doi.org/10.1016/j.econedurev.2011.08.009

[8] Booth, A., \& Nolen, P. (2012). Choosing to compete: How different are girls and boys? Journal of Economic Behavior and Organization, 81(2), 542-555. https://doi.org/10.1016/j.jebo.2011.07.018

[9] Brady, H. E., Verba, S., \& Schlozman, K. L. (1995). Beyond SES: A resource model of political participation. American political science review, 271-294.

[10] Brock, T., \& Richburg-Hayes, L. (2006). Paying for Persistence Early Results of a Louisiana Scholarship Program for Low-Income Parents Attending Community College. In MDRC. MDRC, 16 East 34th Street, 19th Floor, New York, NY 10016-4326. Tel: 212-532-3200; Fax: 212-684-0832; e-mail: publications@mdrc.org. www.mdrc.org.

[11] Busso, M., Dinkelman, T., Claudia Martínez, A., \& Romero, D. (2017). The effects of financial aid and returns information in selective and less selective schools: Experimental evidence from Chile. Labour Economics, 45, 79-91. https://doi.org/10.1016/j.labeco.2016.11.001

[12] Chan, R. Y. (2016). Understanding the purpose of higher education: An analysis of the economic and social benefits for completing a college degree. Journal of Education Policy, Planning and Administration, 6(5), 1-40.

[13] Cohodes, S. R. \& Goodman, J. S. (2014). Merit aid, college quality, and college completion: Massachusetts' Adams scholarship as an in-kind subsidy. American Economic Journal: Applied Economics, $6(4): 251-85$.

[14] Cornwell, C. M., Lee, K. H., \& Mustard, D. B. (2005). Student responses to merit scholarship retention rules. Journal of Human Resources, 40(4), 895-917. https://doi.org/10.3368/jhr.xl.4.895

[15] Cornwell, C., Mustard, D. B., \& Sridhar, D. J. (2006). The enrollment effects of merit-based financial aid: Evidence from Georgia's HOPE Program. Journal of Labor Economics, 24(4), 761-786. https://doi.org/10.1086/506485 
[16] DANE.

(2018).

¿Cuántos

somos?

https://www.dane.gov.co/index.php/estadisticas-por-

tema/demografia-y-poblacion/censo-nacional-de-poblacion-y-

vivenda-2018/cuantos-somos

[17] Dillon, E. W. \& Smith, J. A. (2017). Determinants of the match between student ability and college quality. Journal of Labor Economics, 35(1):45-66.

[18] Dinkelman, T., \& Claudia Martínez, A. (2014). Investing in schooling in Chile: The role of information about financial aid for higher education. Review of Economics and Statistics, 96(2), 244-257. https://doi.org/10.1162/REST_a_00384

[19] Dynarski, S., Libassi, C. J., Michelmore, K., \& Owen, S. (2018). Closing the gap: The effect of a targeted, tuition-free promise on college choices of high-achieving, low-income students (No. w25349). National Bureau of Economic Research.

[20] Fryer Jr, R. G. (2016). An empirical analysis of racial differences in police use of force (No. w22399). National Bureau of Economic Research.

[21] Graziosi, G., Sneyers, E., Agasisti, T., \& De Witte, K. (2021). Can Grants Affect Student Performance? Evidence from Five Italian Universities. Journal of Higher Education Policy and Management 43 (1), 24-48.

[22] Halpern, D. F., Eliot, L., Bigler, R. S., Fabes, R. A., Hanish, L. D., Hyde, J., Liben, L. S., \& Martin, C. L. (2011). Education: The pseudoscience of single-sex schooling. In Science (Vol. 333, Issue 6050, pp. 1706-1707). American Association for the Advancement of Science. https://doi.org/10.1126/science.1205031

[23] Hanushek, E. A., \& Woessmann, L. (2015). The knowledge capital of nations: Education and the economics of growth. MIT press.

[24] Hastings, J., Neilson, C., \& Zimmerman, S. (2012). The Effect of School Choice on Intrinsic Motivation and Academic Outcomes. NBER Working Paper No. 18324. National Bureau of Economic Research. https://doi.org/10.3386/w18324 
[25] Hastings, J., Neilson, C. A., \& Zimmerman, S. D. (2015). The effects of earnings disclosure on college enrollment decisions (No. w21300). National Bureau of Economic Research.

[26] Hastings, J. S., Neilson, C. A., Ramirez, A., \& Zimmerman, S. D. (2016). (Un)informed college and major choice: Evidence from linked survey and administrative data. Economics of Education Review, 51, 136-151. https://doi.org/10.1016/j.econedurev.2015.06.005

[27] Hemelt, S. W., Schwartz, N. L., \& Dynarski, S. M. (2020). DualCredit Courses and the Road to College: Experimental Evidence from Tennessee. Journal of Policy Analysis and Management, 39(3), 686-719. https://doi.org/10.1002/pam.22180

[28] Herber, S. P. (2018). The role of information in the application for highly selective scholarships: Evidence from a randomized field experiment. Economics of Education Review, 62, 287-301. https://doi.org/10.1016/j.econedurev.2017.12.001

[29] Hilliard, L. J., \& Liben, L. S. (2010). Differing Levels of Gender Salience in Preschool Classrooms: Effects on Children's Gender Attitudes and Intergroup Bias. Child Development, 81(6), 1787-1798. https://doi.org/10.1111/j.1467-8624.2010.01510.x

[30] Hoekstra, M. (2009). The effect of attending the flagship state university on earnings: A discontinuity-based approach. Review of Economics and Statistics, 91(4), 717-724. https://doi.org/10.1162/rest.91.4.717

[31] Hoxby, C. M. \& Avery, C. (2012). The missing "one-offs": The hidden supply of high-achieving, low income students. NBER Working Paper No. 18586, National Bureau of Economic Research, Cambridge, MA.

[32] Kerr, S. P., Pekkarinen, T., Sarvimäki, M., \& Uusitalo, R. (2020). Post-secondary education and information on labor market prospects: A randomized field experiment. Labour Economics, 66, 101888. https://doi.org/10.1016/j.labeco.2020.101888

[33] Lergetporer, P., Werner, K., \& Wößmann, L. (2018). Does Ignorance of Economic Returns and Costs Explain the Educational Aspiration Gap?. 
[34] Jensen, R. (2010). The (perceived) returns to education and the demand for schooling. The Quarterly Journal of Economics, 125(2), $515-548$.

[35] Lawrence, M. (2016). Unequal Advantages: The Intergenerational Effects of Parental Educational Mobility. American Educational Research Journal, 53(1), 71-99. https://doi.org/10.3102/0002831215621162

[36] Lewin, keith M. (2015). Educational access, equity, and development: Planning to make rights realities. Fundamentals of Educational Planning, 154. https://unesdoc.unesco.org/ark:/48223/pf0000235003 /PDF/235003eng.pdf.multi

[37] Loyalka, P., Wei, J., Song, Y., Zhong, W., \& Chu, J. (2015). The impacts of building elite high schools for students from disadvantaged areas. Economic Development and Cultural Change, 63(2), 393-422. https://doi.org/10.1086/678992

[38] Mas, A., \& Pallais, A. (2017). Valuing alternative work arrangements. American Economic Review, 107(12), 3722-59.

[39] Mizala, A., \& Urquiola, M. (2013). School markets: The impact of information approximating schools' effectiveness. Journal of Development Economics, 103(1), 313-335. https://doi.org/10.1016/j.jdeveco.2013.03.003

[40] OECD.(2018). Programme for international students assessment (PISA) Results from PISA 2018. https://www.oecd.org/pisa/publications/PISA2018_CN_COL_ESP .pdf

[41] Peter, F. H., \& Zambre, V. (2017). Intended college enrollment and educational inequality: Do students lack information? Economics of Education Review, 60, 125-141. https://doi.org/10.1016/j.econedurev.2017.08.002

[42] Piketty, T., \& Saez, E. (2014). Inequality in the long run. Science, 344(6186), 838-843. 
[43] Powdthavee, N., Lekfuangfu, W. N., \& Wooden, M. (2015). What's the good of education on our overall quality of life? A simultaneous equation model of education and life satisfaction for Australia.Journal of behavioral and experimental economics,54, 10-21.

[44] Psacharopoulos, G., \& Patrinos, H. A. (2018). Returns to investment in education: a decennial review of the global literature. Education Economics, 26(5), 445-458.

[45] Quintana, S. M., \& Mahgoub, L. (2016). Ethnic and racial disparities in education: Psychology's role in understanding and reducing disparities. Theory Into Practice, 55(2), 94-103.

[46] Rao, M. B. (2016). Motivation of teachers in higher education. Journal of Applied Research in Higher Education, 8(4), 469-488.

88 errors13 warnings https://doi.org/10.1108/JARHE-08-2015-0066

[47] Sawhill, I.V. (2013). Higher Education and the Opportunity Gap. Brookings. Retrieved from https://www.brookings.edu/research/higher-education-and-theopportunity-gap/

[48] Schneeweis, N., \& Zweimuller, M. (2012). Girls, girls, girls: Gender composition and female school choice. Economics of Education Review, 31(4), 482-500. https://doi.org/10.1016/j.econedurev.2011.11.002

[49] Scott-Clayton, J. (2011). On money and motivation: A quasi-experimental analysis of financial incentives for college achievement. Journal of Human Resources, 46(3), 614-646. https://doi.org/10.3368/jhr.46.3.614

[50] UNESCO. (2009). Trends in Global Higher Education: Tracking an Academic Revolution. http://atepie.cep.edu.rs/public/Altbach,_Reisberg,_Rumbley _Tracking_an_Academic_Revolution,_UNESCO_2009.pdf

[51] UNESCO UIS. (2011). TVETipedia Glossary. GLOBAL. https://unevoc.unesco.org/home/TVETipedia+Glossary/lang=en $/ \mathrm{id}=170$ 
[52] UNESCO. (2012). Reuniones co-organizadas por la sección del Patrimonio Cultural Inmaterial, disponible en:http://www.unesco.org/culture/ich/index.php?lg=esmeeting id $=00057$

[53] UNICEF. (2000). Defining Quality in Education. Improving Educational Quality Project, 1-44. $\quad$ https://unstats.un.org/sdgs/report/2017/goal04/: :text=SDG\%20Goals-,Goal\%204\%3A\%20Ensure\%20inclusive $\% 20$ and $\%$ 20equitable \%20quality\%20education\%20and\%20promote, the\%20realization\%20of\%20sustainable \%20development.

[54] United Nations. (2015). Goal 4: Ensure inclusive and equitable quality education and promote lifelong learning opportunities for all. page. 21. https://sustainabledevelopment.un.org/content/documents/21252 030\%20Agenda\%20for \%20Sustainable\%20Development\%20web.pdf

[55] United Nations. (2017). Goal 4: Ensure inclusive and equitable quality education and promote lifelong learning opportunities for all. https://unstats.un.org/sdgs/report/2017/goal04/\#::text=SDG\%20Goals-,Goal\%204\%3A\%20Ensure\%20inclusive $\% 20$ and $\% 20$ equitable\%20quality \%20education\%20and\%20promote ,the\%20realization $\% 20$ of\%20sustainable\%20development.

[56] Upton, G.B. (2016). The Effects of Merit-Based Scholarships on Educational Outcomes.J Labor Res 37, 235-261. https://doi.org/10.1007/s12122-016-9222-7

[57] Wiswall, M., \& Zafar, B. (2015a). Determinants of college major choice: Identification using an information experiment. The Review of Economic Studies,82(2), 791-824.

[58] Wiswall, M., \& Zafar, B. (2018). Preference for the workplace, investment in human capital, and gender. The Quarterly Journal of Economics, 133(1), 457-507.

[59] World Bank.

(2018).

Women

Economic Empowerment Study. In World Bank. http://documents1.worldbank.org/curated/en/861491551113547855 /pdf/134846-WP-PUBLIC-march-2-WB-Women-Study-EN.pdf 
[60] World Bank. (2020b). Government expenditure on education (\% of government expenditure). 6(6), 35-37. https://data.worldbank.org/indicator/SE.XPD.TOTL.GD.ZS

[61] World Bank. (2020c). Primary education, pupils (\% female) Data. https://data.worldbank.org/indicator/SE.PRM.ENRL.FE.ZS? locations $=\mathrm{ET}$

[62] World Bank. (2020d, February). GDP per capita (current US\$) Data. https://data.worldbank.org/indicator/NY.GDP.PCAP.CD

[63] Zimmerman, S. D. (2014). The returns to college admission for academically marginal students. Journal of Labor Economics,32(4), 711-754. 


\section{Chapter 2}

\section{Scholarships And Student Effort: Evidence From Colombia's Ser Pilo Paga Program * $\dagger$}

*Published paper: Bernal, G. \& Penney, J.(2019) Scholarships and Student effort: Evidence from Colombia's Ser Pilo Paga Program. Economics of Education Review, 2019, vol. 72, p. 121-130.

${ }^{\dagger}$ Acknowledgements: We are grateful to the ICFES for their constant support in this research. Santiago Gómez, Juan Eduardo Coba, and Nicolás Niño provided excellent research assistance. We acknowledge financial support for this research by ICFES through grant \#465-2016. The analysis, views, and opinions expressed in this article are those of the authors and do not necessarily represent those of ICFES. 


\section{Abstract}

Launched in 2014, Colombia's Ser Pilo Paga program aimed to increase college enrollment for low income students by providing 10,000 means-tested scholarships annually to the highest performers on the country's high school exit exam. We theorize that the introduction of the scholarship incentivized these students to better prepare for this exam. Exploiting the SES thresholds for eligibility using a regression discontinuity design, we find that students who qualify for the scholarship score about 0.09 test score standard deviations higher than those who do not. We also find that the program increased the repr of the poorest students in the top $9 \%$ of test takers. Survey evidence suggests that students spent more time and money preparing for the test. 


\section{$2.1 \quad$ Introduction}

According to the World Bank, the prohibitive cost of tertiary education is one of the primary drivers of the substantial inequalities with regards to its access in Colombia (World Bank, 2012). In 2017 constant dollars, the average annual cost of tuition at a public university in Colombia was almost $\$ 900$ US Dollars, while for private universities it is approximately $\$ 7,300$; the latter figure is over $40 \%$ of per adult national income (Ministry of Education, 2016; The World Inequality Database, 2019). ${ }^{1}$ Attendance at tertiary institutions shows a clear pattern by income quintile. The composition of students is approximately $8.6 \%$ in the first quintile, $9.5 \%$ in the second, but over $44 \%$ for those in the fifth (OECD \& World Bank, 2012, p.106). The rewards for attending college in Colombia are substantial: bachelor's degree holders earn on average 3.5 times more than those with only a high school degree (World Bank, 2013).

To help combat the inequality of access, the government has developed programs aimed at the poor for secondary and tertiary education, ${ }^{2}$ and in the second half of 2014, launched a new initiative to expand college access to low income students called Ser Pilo Paga (henceforth SPP), which roughly translates to "it pays to be smart". Scholarships from this program were allocated based on both need and merit, awarding tuition and living expenses to students of low socioeconomic status who were the highest performers in the country's high school exit exam, the Saber $11^{\circ}$. The SPP program appears to have been unique in that it was possibly the first competitive large-scale university scholarship program where very high performance on a standardized test was required yet only students of low socioeconomic status were eligible, with 10,000 scholarships having been awarded annually. ${ }^{3}$ The scholarship program stopped distributing new awards after 2018.

In this study, we examine the extent to which students increased their

\footnotetext{
${ }^{1}$ These figures are adjusted for purchasing power parity.

${ }^{2}$ Some examples of these initiatives include the PACES program, which provided over 125,000 pupils with vouchers covering more than half the cost of private secondary school between 1991 and 1997, and the ACCES program, which from 2002 onward has provided almost 300,000 low-income students with subsidized loans to enroll in higher education.

${ }^{3}$ In 2014 and 2015, approximately 250,000 students were eligible to compete for the scholarship.
} 
performance on the high school exit exam as a result of the introduction of the SPP program, and seek to determine the channels through which any performance gains were obtained. Using administrative data from the government of Colombia's education and socioeconomic agencies for the years 2014 and 2015, we exploit the sharp discontinuity in the SES measure of eligibility for SPP (the Sisben score) to examine the causal effect of the scholarship's introduction on Saber $11^{\circ}$ test scores, and then observe whether the socioeconomic composition of the top $9 \%$ of test takers changes. Lastly, we overview the results of a large-scale survey at one of Colombia's top-ranked private tertiary institutions to probe whether and how students reacted to the introduction of the SPP in terms of preparation and other measurable dimensions.

The following is an outline of the main findings of the empirical analysis. Examining the difference in test scores at the SES eligibility threshold, we determine that the causal effect of the scholarship is approximately 0.09 standard deviations, which is rather sizable in magnitude. These gains appear to be driven by students at the top of the ability distribution, with those at the 90th percentile of test scores experiencing increases in the neighbourhood of 0.17 test score standard deviations. The distribution of top performers before and after SPP was introduced changes: in 2015, students of the lowest social class have $18 \%$ increased odds of appearing in the top $9 \%$ of test takers relative to 2014 . Survey evidence suggests that students spent about $9.8 \%$ more money to prepare for the test after the introduction of the SPP, and that they were more likely to take private in-person and virtual courses in order to prepare for the Saber $11^{\circ}$. The SPP also appeared to increase the subjective desires for high scores and the need to obtain a high score in order to earn a scholarship.

This study contributes to the literature in several ways. It appears to be one of the first to investigate whether performance on a standardized test increases in the wake of additional incentives in the form of a valuable competitive scholarship program that uses the test to allocate the recipients, and the potential channels through which the increases occur. ${ }^{4}$ Perhaps the first paper to examine this question was that of Pal-

\footnotetext{
${ }^{4}$ We note the existence of another working paper examining the test score effects of SPP by Laajaj et al. (2018). We use a different empirical approach than these authors, and we pay particular attention to heterogeneous effects.
} 
lais (2009), who examines the effect of the introduction of Tennessee's HOPE merit scholarship on ACT standardized test scores. Scores below the cut-off point to qualify for the reward were increased, but those above the cut-off saw no effect. There are several important differences between the SPP program and the HOPE scholarship. The first is that there were two different ways to qualify for HOPE, either through performance on a standardized test or through one's high school GPA; qualifying for SPP could only be done via performance on a standardized test. The second is that the test score cut-off to qualify for HOPE is closer to the median of the distribution, ${ }^{5}$ while the SPP scholarship was awarded for students in approximately the top decile. The third is that financial need is not considered for HOPE, whereas for SPP, only students of low socioeconomic status are eligible. Lastly, the HOPE scholarship awarded an amount that is less than tuition, while SPP also covered living expenses (which can be considerable in Colombia's larger cities).

Another paper that looks at ex ante outcomes due to the introduction of a scholarship is Bartik \& Lachowska (2014). They examine the effect of the surprise announcement of the Kalamazoo promise scholarship, which pays a certain percentage of tuition depending on how long students have attended Kalamazoo Public Schools, a mid-sized school district with approximately 10,000 students from a range of different racial and economic backgrounds. The scholarship covers between $65 \%$ and $100 \%$ of college tuition, depending on how long the student had been enrolled at schools inside the district. Unlike SPP and HOPE, there were no GPA or test score requirements: the student need only enroll in higher education. Bartik \& Lachowska (2014) find that the program increased high school GPA, but only for black students. However, school suspensions in the district decreased by a substantial fraction for the overall student population. The authors conjecture that improved behaviour is a channel through which the increase in high school GPA occurred.

Most papers examining the effects of competitive university scholarships focus on ex post outcomes, such as graduation rates and college grades. Research on the ex post effect of scholarship programs (such as on grades and graduation rates) has been conducted regarding Geor-

${ }^{5}$ The ACT requirement to qualify during the time period examined in Pallais (2009) was 19; this corresponds to approximately the 41st percentile of ACT scores in 2011. 
gia's HOPE scholarship program by Cornwell et al. (2005, 2006), West Virginia's PROMISE program by Scott-Clayton (2011), and Louisiana's Opening Doors program by Richburg-Hayes et al. (2009). There is much research on the effect of short-term incentives on test score performance; Gneezy et al. (2017) provide an extensive review. One paper examines the effect of the Ser Pilo Paga program on college enrollment, stratification, and student diversity (Londoño-Veléz et al., 2018). A comparison chart of the relevant literature regarding the impact of higher education scholarships on student's outcomes can be found in the appendix of this dissertation (Appendix, Table 6.1).

The remainder of the study is organized as follows. We conduct a brief overview of the Saber $11^{\circ}$ high school exit exam and the SPP program in Section 2. We outline the data and conduct some initial analysis in Section 3. In Section 4, we estimate the causal effect of the introduction of the SPP program using a sharp regression discontinuity design and investigate the robustness of the results, and then examine how the distribution of students in the top $9 \%$ of test takers has changed. Section 5 overviews the results of a survey given to students at a top private university in Colombia that graduated from high school between 2013 and 2016. The study concludes with a discussion of the public policy implications in Section 6.

\subsection{Institutional background}

\subsubsection{Saber $11^{\circ}$}

The Saber $11^{\circ}$ high school exit exam was first established in 1968 in order to provide support to universities and other higher education institutions in their admissions processes; it became compulsory in 1980. Currently, the Saber $11^{\circ}$ is considered an important indicator of student skills and is also the main criterion for admission to higher education and the grant of scholarships in Colombia (ICFES, 2010). The exam can be thought of as analogous to the SAT and ACT exams in the United States. The Saber $11^{\circ}$ is administered by ICFES, a Colombian governmental agency in charge of measuring the quality of education. ${ }^{6}$ Every year, hundreds of

\footnotetext{
${ }^{6}$ The ICFES acronym stands for "Instituto Colombiano para el Fomento de la Educación Superior".
} 
thousands of students across the country take the exam; the compliance rate for senior high school students taking the exam is approximately 97\%. It is given twice per year; most students (approximately 95\%) sit the exam in August (the fall), ${ }^{7}$ while the remainder take it in March (the spring). The exam is given at the exact same time nationwide on both of these dates. As of 2014, the exam is divided into five subject areas: mathematics, language skills (in Spanish), social science, natural science, and English language skills; students are given a separate score for each section. $^{8}$ An overall score, which we refer to here as a global score, is calculated as a function of all the different subject area scores. ${ }^{9}$ Each of the five areas has a possible score of between 0 and 100; the test is tuned so that each of these five components are targeted to have a mean of approximately 50 and a standard deviation of about 10 . The overall score ranges between 0 and 500, and the scaling is constructed using Item Response Theory. All questions on the test are multiple choice, and it is administered over two separate sessions of four hours and 30 minutes each. In addition to the data on test scores, students taking the Saber $11^{\circ}$ are also asked a small number of questions concerning their demographic and socioeconomic characteristics. Students interested in familiarizing themselves with the exam can take the Pre Saber, a test administered by ICFES that simulates the Saber $11^{\circ}$. The cost of the test is approximately $\$ 30 \mathrm{USD}$, which is rather expensive for students from low income families. It is conducted on the same day as the Saber $11^{\circ}$.

\subsubsection{Ser Pilo Paga}

Ser Pilo Paga was a scholarship program intended to help low income students access higher education. Announced on October 1st of 2014 by President Santos's administration, the scholarship included tuition (which was paid directly to the institution) and additional monetary support of between 1 and 4 times the legal minimum wage in each semester based on where the student lives and where the student goes to school;

\footnotetext{
${ }^{7}$ In 2014, the exam was given on August 3rd; in 2015, the exam took place on August 2nd.

${ }^{8}$ Before this time, the test consisted of eight subject areas. A number of sections were combined in 2014, reducing the number of subject scores down to five.

${ }^{9}$ The equation is global $=(($ math $\times 3+$ language $\times 3+$ social $\times 3+$ natural $\times 3+$ English)/13) $\times 5$.
} 
schools had the option to provide additional benefits to awardees. Technically, the support provided by SPP came in the form of a loan that is forgiven upon graduation within a stipulated period. The student was only permitted to use the scholarship to attend an institution "Alta Calidad" (high quality). ${ }^{10}$ One month after Colombian president Iván Duque was elected in 2018, the minister of education announced that the program was no longer going to award additional scholarships, but that existing recipients would continue to benefit from the program as per normal. The program ultimately enrolled approximately 40,000 students over 4 years, from 2015 to 2018 . The program has been criticized by the newly-elected government for its focus on only a small number of people and its high cost (Barrientos \& Castañeda, 2018).

To have qualified for the scholarship, students must (i) have a Sisben score (a proxy for social class) below a set threshold, the maximum qualifying score of which varies whether they live in one of 14 major cities (57.21), live in another metropolitan area (56.32), or live in a rural area (40.75); $;^{11}$ and (ii) score sufficiently high on the Saber $11^{\circ}$ exam, the minimum score of which varies every year. In 2014, the cut-off score was 310 ; in 2015, the score was 318 . The cut-off is set at approximately the 91st percentile of the overall distribution of test scores for each year, so the cut-off is not known in advance of taking the test.

\subsubsection{Socioeconomic status}

The government of Colombia uses two measures of socioeconomic status in its administration of public policy: strata and Sisben. We discuss each in turn.

Strata (in Spanish, "estrato") is a measure of socioeconomic status used primarily to determine the cost of public utilities and services such as energy, water and basic sanitation, although some private firms use it to set pricing for various services (such as cable television and internet access). The modern incarnation of the strata system comes from a law passed by the Colombian Congress in July of 1994. The govern-

\footnotetext{
${ }^{10}$ In 2014, there were 33 such universities; in 2015, there were 39.

${ }^{11}$ The 14 cities are as follows: Barranquilla, Bogota, Bucaramanga, Cali, Cartagena, Cucuta, Ibague, Manizales, Medellin, Monteria, Pasto, Pereira, Santa Marta, and Villavicencio.
} 
ment classifies people into six different categories: two lower classes (1 "lower-lower" and 2 "lower"), three middle classes (3 "lower-middle", 4 "middle", and 5 "upper-middle"), and one upper class (6 "upper"). ${ }^{12}$ The system is designed so that strata 1,2 , and 3 receive subsidies from strata 5 and 6 ; strata 4 neither receives nor pays for any subsidies. A person's strata is determined strictly by the geographic location of their primary domicile. The strata of a neighbourhood is derived using a formula that includes the physical characteristics of the dwellings and the environment located in the area. ${ }^{13}$ The income level of those who reside in the area is not taken into account. Strata can vary enormously even within small distances (for example, it is possible for a strata 1 area to border a strata 5 area), although this is uncommon. Strata plays a large role in Colombian society, and people often identify themselves as being members of a particular strata (Jessel, 2017).

The second measure of a person's socioeconomic status is their Sisben score (in Spanish, "Sisbén"). This measure is used by the government to direct personalized services, such as health and education programs. The version used for the data in this study is Sisbén III. ${ }^{14}$ It is determined by a secret formula using variables at household level that were meant to proxy housing and public services, health, education, and vulnerability. The formula does not include measures of family income and potential income. ${ }^{15}$ Strata is also excluded as a variable in this calculation; however, people that live in strata 4 or higher neighbourhoods are ineligible to receive a Sisben score. The Sisben score varies from 0 to 100, and fractional values are possible. On this scale, lower numbers correspond to being of a lower social class. The scores for most people were determined in an initial assessment phase from 2009 to 2011; new households and revision requests occurred afterwards. The Sisben score for a household does not expire until a new version of the Sisben is released, despite changes in circumstances: for example, a household could move into a strata 6 neighbourhood and keep their same Sisben score despite being ineligible to have a Sisben score because of their new strata.

\footnotetext{
${ }^{12}$ Much of the information about strata in this section is found in a government FAQ; see DANE (undated).

${ }^{13} \mathrm{~A}$ law passed in 2002 legislates that Indigenous Colombians are considered to be strata 1.

${ }^{14}$ The Sisben system has since been updated to Sisbén IV, which was launched in January 2017.

${ }^{15}$ Sisbén IV includes both family income and potential income in its calculation.
} 
The process for obtaining a Sisben score after the initial sign-up period is as follows. First, a person heads to their local Sisben office and asks to be surveyed; there is no cost to make this request. The request must be made by an adult over the age of 18, and they are asked to provide identification and the address of their residence. An appointment is made for an employee to visit the residence. During the visit, the necessary information is gathered and the head of the household is questioned; the declarations of the head of household are made under oath. The information is then forwarded to the municipality, which in turn sends it to the DNP, a government agency responsible for public and economic policy (in Spanish, the acronym is "Departamento Nacional de Planeación)". The DNP validates the information and calculates the index. The citizen is then notified of their score. While there is no official timeline for this process, anecdotal evidence suggests that requests to revise Sisben scores take a minimum of 6 months. Further, revision of Sisben scores are said to have been quite rare until the announcement of the SPP program.

\subsection{Data}

The analysis of this study uses a data set combining data from ICFES (Colombia's education agency) and the DNP for the years 2014 and 2015. ${ }^{16}$ The DNP and the Ministry of Education sent the data to ICFES to perform the necessary linkages. The database was cleaned to remove cases of fraud and then anonymized for use by the authors.

The summary statistics of the sample of test takers are displayed in Table 2.1. In order to examine differences in test preparation behaviour across cohorts, we examine the proportion of those who took the Pre Saber in the March iteration of the test and then took the Saber $11^{\circ}$ in August of the same year. ${ }^{17}$ From 2014 to 2015, the number of students who took the Pre Saber increased more than $60 \%$; this increase is statistically significant $(p<0.01)$. An increase is anticipated because the SPP program was announced only after testing in 2014 was completed and

\footnotetext{
${ }^{16}$ We use the data from the August waves of the test; the March wave tends to be a self-selected group of students in international schools, students of high social classes, and the like.

${ }^{17}$ This is to allow for an apples-to-apples comparison: for example, the number of students who took the Pre Saber in 2014 to help prepare for 2015 would not interest us, as it was not administered in 2014 before SPP was announced.
} 
Table 2.1: Summary statistics

\begin{tabular}{lcccc}
\hline & \multicolumn{2}{c}{2014} & \multicolumn{2}{c}{2015} \\
& Mean & St. dev. & Mean & St. dev. \\
\hline Age & 17.203 & $(1.958)$ & 17.198 & $(1.945)$ \\
Female & 0.546 & $(0.498)$ & 0.544 & $(0.498)$ \\
Eligible for SPP & 0.813 & $(0.390)$ & 0.833 & $(0.373)$ \\
Sisben score $^{\dagger}$ & 37.067 & $(18.219)$ & 35.171 & $(18.366)$ \\
Saber global score & 251.170 & $(42.606)$ & 251.331 & $(46.764)$ \\
Took Pre Saber & 0.033 & $(0.179)$ & 0.053 & $(0.225)$ \\
Strata 1 & 228,579 & & 237,904 & \\
Strata 2 & 189,253 & & 187,479 & \\
Strata 3 & 97,087 & & 91,192 & \\
Strata 4 & 19,782 & & 18,272 & \\
Strata 5 & 5,737 & & 5,330 & \\
Strata 6 & 2,229 & & 2,029 & \\
N & 542,667 & & 542,206 & \\
\hline
\end{tabular}

Notes: Numbers calculated from sample data. $\dagger$ Based on those with valid Sisben scores only. The "Took Pre Saber" variable refers to those who took the Pre Saber in March and took the Saber exam in August of the same year.

the increased incentive of the SPP program may have caused students to prepare more for the 2015 iteration of the test, an issue we investigate later on in this research. A drop in the average Sisben score results in the percentage of those eligible for SPP increasing two percentage points; looking at the breakdown by strata, this appears to be driven by the 2015 cohort being of a lower strata on average compared to 2014. Otherwise, there do not appear to be any meaningful differences between the two waves.

Figure 2.1 shows the distribution of Sisben scores by strata. As we can see, there appears to be a correlation between Sisben and strata, but the correlation is low. The distributions for strata 1 and 2 exhibit substantial overlap, and strata 3,4 , and 5 exhibit very similar curvatures. Strata 6 has an odd distribution, but the number of observations in this category is low because very few strata 6 students have Sisben scores. It is clear from this figure that these two measures of socioeconomic status do not measure the same information. 
Figure 2.1: Strata and Sisben score

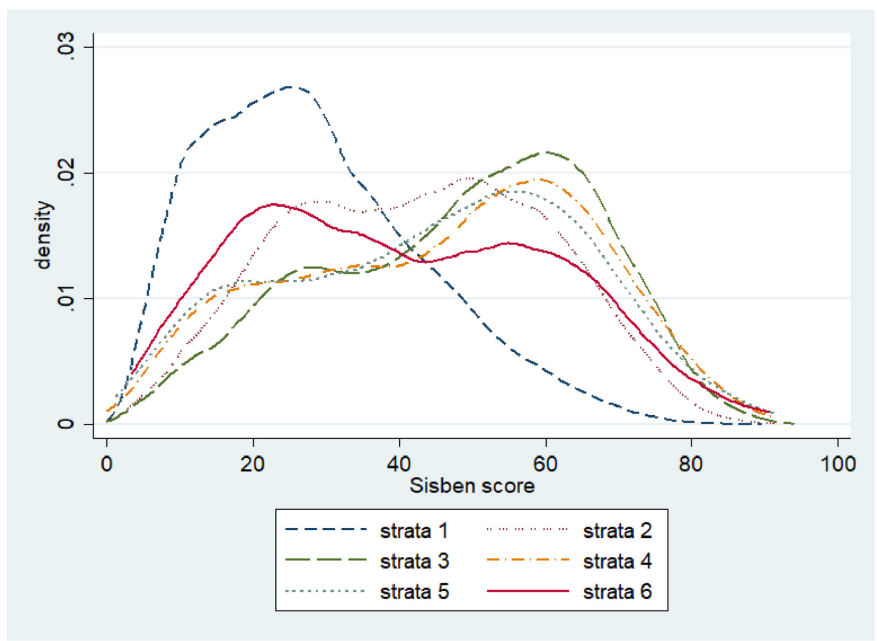

Notes: Authors' calculations from sample data (ICFES, 2015).

Since eligibility for the Ser Pilo Paga program is based on a numerical cutoff in the Sisben score, it is necessary to examine whether scores have been precisely manipulated before we commence with the empirical analysis because manipulated scores may cause the coefficient estimates to be contaminated by selection bias. ${ }^{18}$ Because the Sisben score cutoffs for SPP eligibility vary by whether someone lives in a rural region, a city, or one of 14 designated cities, it is necessary to investigate the cutoffs for each of these categories.

We begin with a visual inspection of the histograms of the densities for each of the categories, which we display on Figure 2.2. For urban and rural residents, the distribution of Sisben scores seems to spread evenly across the Sisben cutoff. However, there does seem to be a rise in scores just above the cutoff for residents of the 14 major cities. To investigate further, we employ a recently developed test by Cattaneo et al. (2017) to examine whether there is any evidence of discontinuities in the density of the running variable near the cutoffs, which would be suggestive of the possibility of manipulation. ${ }^{19}$ We find that the 14 cities subsample rejects

\footnotetext{
${ }^{18}$ Regression Discontinuity designs may still be valid in the case of manipulation that is less than perfect; see Lee \& Lemieux (2010) for a discussion.

${ }^{19}$ This test innovates on the McCrary (2008) test in that it has improved size and
} 
Figure 2.2: Histogram of the running variable by area
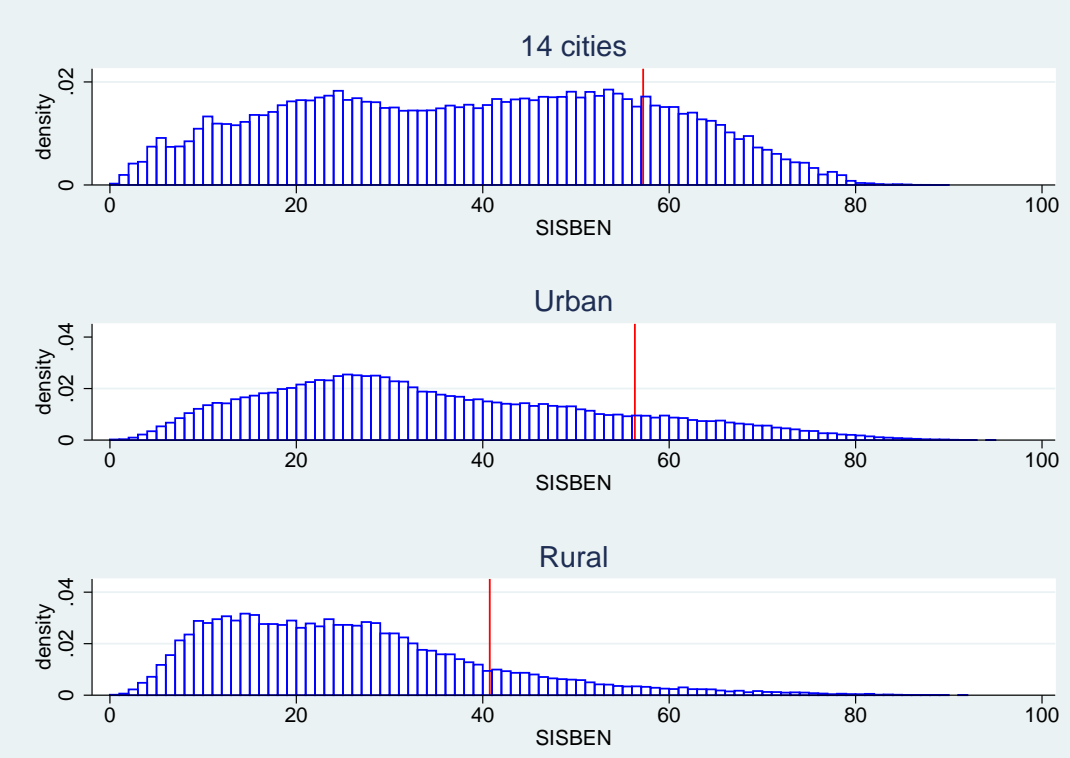

Notes: Histogram of the running variable (Sisben) by area. The red line represents the Sisben cutoff by area (students are eligible if Sisben score is lower than the cutoff). Authors' calculations from sample data (ICFES, 2015).

the null and detect a potential discontinuity at the cutoffs, while the null hypotheses of no manipulation for the rural and urban samples are not rejected. We believe the rejection of the null for the 14 cities sample is a statistical artifact and is not due to precise manipulation for several reasons. First, the discontinuity tests show greater mass above the cutoff for the qualification: a slightly higher mass of people are out of reach of the scholarship rather than in - any fine manipulation of the Sisben score by the people who would seek to benefit from it (the parents of the students attempting to obtain the SPP scholarship) would be in the other direction. Second, as mentioned previously, Sisben scores cannot be precisely manipulated by the public because they are determined by a government agency whose method of scoring is secret and as such the lack of precise manipulation means that a regression discontinuity design would still be valid, and obtaining or changing one's score is a time

power properties. 
consuming bureaucratic process, so most people did not have enough time to attempt to manipulate the score for the 2015 year even if fine manipulation were possible.

\subsection{Empirical analysis}

\subsubsection{Timeline}

To identify the effects of Ser Pilo Paga on student achievement and to argue that the results are robust, we illustrate the timeline of the events leading up to and after its introduction in the table below.

Table 2.2: Timeline

\begin{tabular}{|c|c|}
\hline Date & Event \\
\hline August 3rd, 2014 & Saber $11^{\circ}$ exam takes place for the 2014 cohort \\
\hline October 1st, 2014 & Ser Pilo Paga scholarship announced \\
\hline August 2nd, 2015 & Saber $11^{\circ}$ exam takes place for the 2015 cohort \\
\hline
\end{tabular}

Because the program was announced after the 2014 exam took place, the scores for this cohort were unaffected by the announcement. We can therefore use this cohort for placebo checks. Meanwhile, there is an adequate lag between the announcement of SPP and the 2015 exam, so there was sufficient time for people to become aware of the program and begin to change their behaviour in their preparing for the exam.

\subsubsection{Empirical strategy}

We use a regression discontinuity approach to estimate the effects of the Ser Pilo Paga program's introduction on student achievement. Because the Sisben score cutoffs for SPP eligibility vary by whether someone lives in a rural region, a city, or one of 14 designated cities, it is necessary to normalize them for use in the empirical analysis. Define $x$ as the distance to the eligibility cutoff, with positive scores being below the cutoff and therefore eligible to compete for the scholarship, and negative scores being above the cutoff. 
We first use the $r d$ program by Nichols (2011) to produce a nonparametric estimate of the jump at $x=0$. The estimate is generated by fitting a degree zero local polynomial regression with a triangle kernel on each side of the discontinuity and then calculating the difference in height at $x=0$. The Imbens \& Kalyanaraman (2009) bandwidth selection procedure is employed ${ }^{20}$ we also vary the bandwidth by 50 percentage points in each direction to examine the sensitivity to its selection. ${ }^{21}$

Next, we use two forms of quantile regression to examine the effects of Ser Pilo Paga at the different points in the distribution of student ability, again using the Imbens \& Kalyanaraman (2009) bandwidth. In essence, the estimators we use answer the following question: suppose a student is at the Nth percentile of the test score distribution for those who do not qualify for SPP. How much higher would their score be if they instead qualified? This is an important question to answer, because important heterogeneities may be present at the different points in the distribution of ability. It is possible, for example, that a zero average effect obtained by OLS may be the result of positive effects and negative effects at different points in the distribution cancelling each other out.

A local linear regression model is employed here for the unconditional quantile regression (Firpo et al., 2009); we do this because using higher order terms has been shown to cause significant problems because, inter alia, higher order terms place more weight on observations away from the cutoff (Gelman \& Imbens, 2018). ${ }^{22}$ The regression equation is:

$$
\text { score }_{i t}=\beta_{0}+\beta_{1} d_{i t}+\beta_{2} x_{i t}+\beta_{3} d_{i t} \times x_{i t}+\epsilon_{i t}
$$

where score $_{i t}$ is the standardized Saber $11^{\circ}$ test score of the student $i$ in year $t, d$ is a dummy equal to 1 if the student qualifies for the scholarship, and $x$ is the adjusted Sisben score of the student. The interpretation of the $\beta_{3}$ term is slightly different than in a normal ordinary least squares regression, as the latter examines the effect of the policy at the unconditional mean, while the former looks at the unconditional quantiles. Chernozhukov et al. (2013) show that a dummy coefficient in

\footnotetext{
${ }^{20}$ The bandwidths chosen are displayed in the relevant tables.

${ }^{21}$ The mean of the running variable for the year 2015 is 19.252 and its standard deviation is 17.991 .

${ }^{22}$ Global regressions in regression discontinuity design are also fraught with problems; see (Gelman \& Imbens, 2018).
} 
an unconditional quantile regression is a first order approximation to the following expression:

$i n f_{y \in Y}\left[\int_{\chi_{1}} F_{Y_{0} \mid Q_{0}}(y \mid q) d F_{Q_{1}}(q) \leq \tau\right]-i n f_{y \in Y}\left[\int_{\chi_{0}} F_{Y_{0} \mid Q_{0}}(y \mid q) d F_{Q_{0}}(q) \leq \tau\right]$

where $y$ is an arbitrary value of the response variable, $Y$ is the set of values $y$ can take, $Y_{i}$ is the set of values for group $i=0,1, q$ is an arbitrary set of values for the set of control variables, $Q_{i}$ is the set of characteristics for group $i$ with $\chi_{i}$ as its support, $F$ is a cumulative distribution function, and $\tau$ is the quantile of interest. Thus, the first term of this difference is the counterfactual quantile $\tau$ for the group of interest, while the second term is the definition of the quantile of the baseline group. Defining $Q_{1}=Q_{0}$ for all controls except the dummy, we can interpret the coefficient of interest $\beta_{3}$ as the difference at quantile $\tau$ if the group of interest had the same distribution of coefficients as the baseline group. In the case of this study, the coefficient $\beta_{3}$ in the above regression at quantile $\tau$ indicates the difference between the SPP eligible and ineligible students at that quantile of their distributions of test scores if the former had the same distribution of control variables as the latter.

The second method by Frandsen et al. (2012) estimates quantile treatment effects using nonparametric regression. The interpretation of the coefficients is somewhat different than the above method of Firpo et al. (2009): it estimates a local quantile treatment effect, that is, the difference in the unconditional distributions of potential outcomes for compliers at the threshold of the running variable at the quantile of interest. ${ }^{23}$ This is analogous to the estimation of the average effect of a policy on a "local group" in instrumental variables estimation (the local average treatment effect). The strength of this method is that the estimates are still valid even if selection into treatment is endogenous. ${ }^{24}$

It is important to note that both quantile regression methods employed here examine the causal effects of the intervention on the quan-

${ }^{23}$ By contrast, the method of Firpo et al. (2009) does not limit its attention to compliers.

${ }^{24}$ The estimator allows for endogenous treatment selection in the neighborhood of the threshold, and thus has an instrumental variables interpretation (Frandsen et al., 2012). 
tiles of the distribution of the response variable, which are policy relevant. Traditional quantile regression introduced by Koenker \& Basett (1978) look at the conditional quantiles; that is, the quantiles of the error term. Borah \& Basu (2013) argue that this methodology is at times problematic in producing policy relevant effects.

\subsubsection{Results and discussion}

We use a sharp regression discontinuity design to estimate the causal effect of SPP eligibility on 2015 Saber $11^{\circ}$ test scores for students of low social class. Including students of all six different strata, we estimate a positive effect of 0.044 standard deviations; however, it is not statistically significant $(\mathrm{p}=0.209)$. Examining the subsamples by gender and by whether they live in a rural area, we similarly have no statistically significant results. We similarly have no statistically significant results using the quantile regression approaches. The estimates are consistently positive, indicating that there may be a small positive effect to the program, but the possibility that there is an overall zero effect in the general population cannot be ruled out. While the sample sizes used in this study number in the hundreds of thousands, the number of observations near the thresholds are not nearly as large, so effects that are very small but positive likely lack sufficient power to precisely estimate. It is clear, however, that we can safely rule out large effects at the threshold of these programs. ${ }^{25}$

We thus turn our attention on the subsample of strata 1 and 2 students (lower class as defined by the government) for the remainder of this analysis for two reasons. The first is that the effect of the program likely varies by socioeconomic status because of differing family income and neighbourhood effects (both of which improve as one goes up the ladder), and that Sisben scores do not do a sufficiently good job of determining it. The Sisben scores for families of the vast majority of students in the sample were determined between 2009 and 2011, meaning that the Sisben scores of those students taking the exam in 2015 are likely 4 to 6 years out of date. By contrast, strata is a contemporaneous measure of socioeconomic status (as it changes instantly when residency changes)

\footnotetext{
${ }^{25}$ It is important to note that at no point that we estimate a precise zero for the effect of the program; the confidence intervals for the estimates are in many cases at least 0.10 standard deviations wide.
} 
and is thus the best approximation of a student's family resources at the time they are writing the exam. Higher strata students are more likely to have higher family resources, decreasing the incentive to study hard for the Saber $11^{\circ}$ exam. While attending a private university is expensive in Colombia, attending a public postsecondary institution is much more affordable, and the budget constraints are considerably less binding for those of higher strata.

Figure 2.3: Effect of SPP scholarship introduction on high school exit exam scores

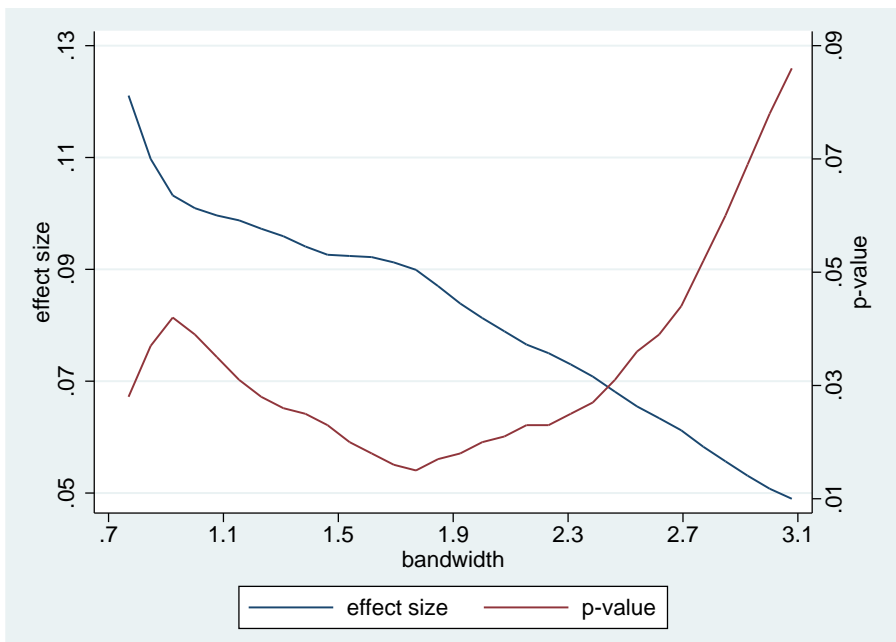

Notes: Regression discontinuity estimates wherein the bandwidth is varied from $50 \%$ to $200 \%$ of the Imbens and Kalyanaraman (2009) bandwidth of 1.539. $\mathrm{N}=$ 257,469 observations.

The second reason we focus attention on lower strata students is the big fish-small pond effect described by Elsner \& Isphording (2017) wherein, holding ability constant, a student of a higher ordinal rank in their classroom cohort is more likely to finish high school, attend college, and finish a 4 year degree. It is likely that high achieving students on the Saber $11^{\circ}$ of lower strata are more likely to be of a higher class rank because performance is highly correlated with strata, all else equal. ${ }^{26}$ These students, highly ranked within their cohorts, receive more support

\footnotetext{
${ }^{26}$ In 2015 , the average test score on the Saber $11^{\circ}$ for a strata 1 student was 234 ; strata 2, 255; strata 3, 274; strata 4, 302; strata 5, 313; strata 6, 322 .
} 
from their teachers, have higher expectations about their future career, and have higher perceived intelligence (Elsner \& Isphording, 2017). They are therefore much more motivated to prepare for the Saber $11^{\circ}$ exam compared to students of similar ability at higher strata.

Figure 2.4: Regression discontinuity graph

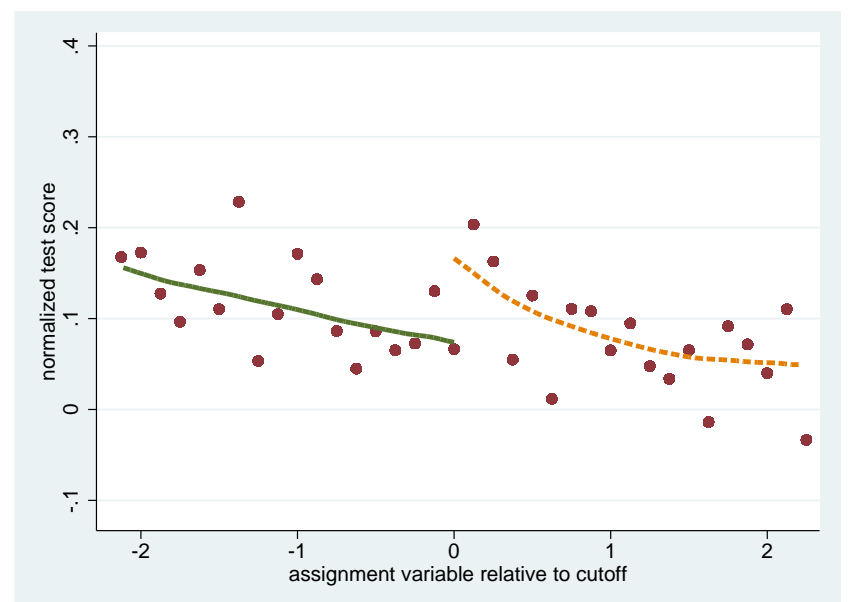

Source: Own elaboration

The regression results are displayed on Figure 2.3. The effect size at the Imbens \& Kalyanaraman (2009) bandwidth is 0.092 standard deviations ( $\mathrm{p}$-value $=0.02$ ), which is sizeable: a gap of this magnitude is approximately one-third of the retake effect on SAT scores (Goodman et al., 2018). Varying the bandwidth between $50 \%$ and $200 \%$ of the optimal level, we note the following. The effect size maintains economic significance across the range of values, being between approximately 0.05 and 0.12 test score standard deviations. For statistical significance, it remains under $\mathrm{p}=0.05$ until about $180 \%$ of the optimal bandwidth, and stays under $\mathrm{p}=0.10$ for the rest of the range.

Figure 2.4 illustrates the nonparametric regression in the neighbourhood of the discontinuity. We see that, as $x$ increases, the predicted score generally goes down: this makes sense because low income students tend to perform worse academically. However, we do see an almost parallel shift upwards of the downward sloping line after the cutoff point, showing that there is a slight bump in predicted test score performance as a result of the SPP scholarship for those who qualified to compete for it.

We now investigate the heterogeneous effects of the program, which 
Table 2.3: Heterogeneous effects of SPP scholarship introduction on test scores

\begin{tabular}{lcccc}
\hline Regression & \multicolumn{3}{c}{ Bandwidth } & $\mathrm{N}$ \\
& Optimal & Minus 50\% & Plus 50\% & \\
\hline Men & $0.149^{\dagger}$ & 0.129 & $0.107^{\dagger}$ & 111,451 \\
& $(0.058)$ & $(0.081)$ & $(0.048)$ & \\
\multirow{4}{*}{ Women } & {$[1.822]$} & {$[0.911]$} & {$[2.732]$} & \\
& 0.049 & 0.082 & 0.030 & 146,018 \\
& $(0.047)$ & $(0.065)$ & $(0.038)$ & \\
City & {$[1.796]$} & {$[0.898]$} & {$[2.693]$} & \\
& $0.088^{\dagger}$ & $0.127^{\dagger}$ & $0.067^{\dagger}$ & 216,293 \\
& $(0.041)$ & $(0.057)$ & $(0.034)$ & \\
Rural & {$[1.624]$} & {$[0.812]$} & {$[2.436]$} & \\
& 0.033 & -0.018 & 0.023 & 41,176 \\
& $(0.080)$ & $(0.116)$ & $(0.064)$ & \\
\hline
\end{tabular}

Notes: The table contains the estimates of the jump at $x=0$. Standard errors corrected for heteroskedasticity are in parentheses. ${ }^{\dagger}$ denotes statistical significance at the the $5 \%$ level. Bandwidths chosen using the method described in Imbens \& Kalyanaraman (2009) are in square brackets.

are displayed in Table 2.3. Examining the results by gender, men appear to be far more affected by the scholarship's introduction than women. Moreover, students located in cities also appear to be more significantly driven to increase their scores compared to their rural counterparts; not only is the effect on rural residents not statistically significant, it can be argued that it is economically insignificant as well. Perhaps these people were significantly less aware of the program compared to those living in urban areas, or perhaps they were much less likely to pursue postsecondary studies in the first place. Not displayed are results comparing students who graduate "on-time" (are 17 years old or less at the time of the test) to older students: both groups have similar results (about 0.09 test score standard deviations), but the results for older students are not statistically significant, possibly owing to their relative scarcity.

Table 2.4 displays the effects of the policy at the different quantiles of the distribution of ability using the two different methodologies. We see that most of the effect appears to be driven by the very best students 
(those at the 0.9 decile); while there may have been test score increases at lower quantiles, they are either weakly or not statistically significant. The consistent pattern of positive coefficients at the lower quantiles suggests that there is a good chance that there was a positive but likely small effect in the lower parts of the distribution.

Table 2.4: Quantile effects of SPP scholarship introduction on test scores

\begin{tabular}{lcccr}
\hline \multicolumn{3}{c}{ Quantile RD } & \multicolumn{2}{c}{ UQR } \\
\hline 0.1 & $0.107^{*}$ & $(0.055)$ & 0.072 & $(0.051)$ \\
0.2 & 0.064 & $(0.054)$ & 0.065 & $(0.048)$ \\
0.3 & $0.086^{*}$ & $(0.049)$ & 0.064 & $(0.045)$ \\
0.4 & $0.086^{*}$ & $(0.048)$ & 0.065 & $(0.045)$ \\
0.5 & $0.086^{*}$ & $(0.046)$ & 0.074 & $(0.046)$ \\
0.6 & 0.000 & $(0.047)$ & 0.060 & $(0.047)$ \\
0.7 & 0.043 & $(0.051)$ & 0.051 & $(0.052)$ \\
0.8 & 0.064 & $(0.062)$ & 0.057 & $(0.057)$ \\
0.9 & $0.171^{\ddagger}$ & $(0.066)$ & $0.149^{\dagger}$ & $(0.072)$ \\
$\mathrm{N}$ & 257,469 & & 257,469 & \\
\hline
\end{tabular}

Notes: The table contains the quantile regression discontinuity estimates of the jump at $x=0$. Standard errors corrected for heteroskedasticity are in parentheses. $*$ denotes statistical significance at the $10 \%$ level, $\dagger$ the $5 \%$ level, and $\ddagger$ at the $1 \%$ level. Quantile RD refers to the method outlined in Frandsen et al. (2012), and UQR to Firpo et al. (2009). The Imbens \& Kalyanaraman (2009) bandwidth is used.

\subsubsection{Robustness}

The results of these regressions are displayed in Table 2.5.

\section{Placebo test with 2014 scores}

There are several reasons why we would like to examine a placebo test with the 2014 test scores. First, because students were not aware of the SPP program when they took the test in 2014, then there should ostensibly be no discontinuities at the eligibility thresholds of the Sisben scores. Second, there are a number of other programs with the exact same cutoffs as for SPP, all of which (save one) that began before 2015 
Table 2.5: Placebo checks

\begin{tabular}{lcccc}
\hline Regression & \multicolumn{3}{c}{ Bandwidth } & $\mathrm{N}$ \\
& Optimal & Minus 50\% & Plus 50\% & \\
\hline 2014 scores & -0.023 & -0.024 & -0.016 & 289,252 \\
& $(0.032)$ & $(0.045)$ & $(0.026)$ & \\
female & {$[2.121]$} & {$[1.061$} & {$[3.182]$} & \\
& 0.018 & -0.015 & 0.017 & 257,469 \\
& $(0.021)$ & $(0.029)$ & $(0.017)$ & \\
age & {$[1.865]$} & {$[0.933]$} & {$[2.798$} & \\
& -0.017 & -0.034 & 0.016 & 257,469 \\
& $(0.039)$ & $(0.053)$ & $(0.033)$ & \\
\hline
\end{tabular}

Notes: The table contains the estimates of the jump at $x=0$. Standard errors corrected for heteroskedasticity are in parentheses. ${ }^{\dagger}$ denotes statistical significance at the $5 \%$ level. Bandwidths chosen using the method described in Imbens \& Kalyanaraman (2009) are in square brackets.

Figure 2.5: Placebo regression discontinuity graph

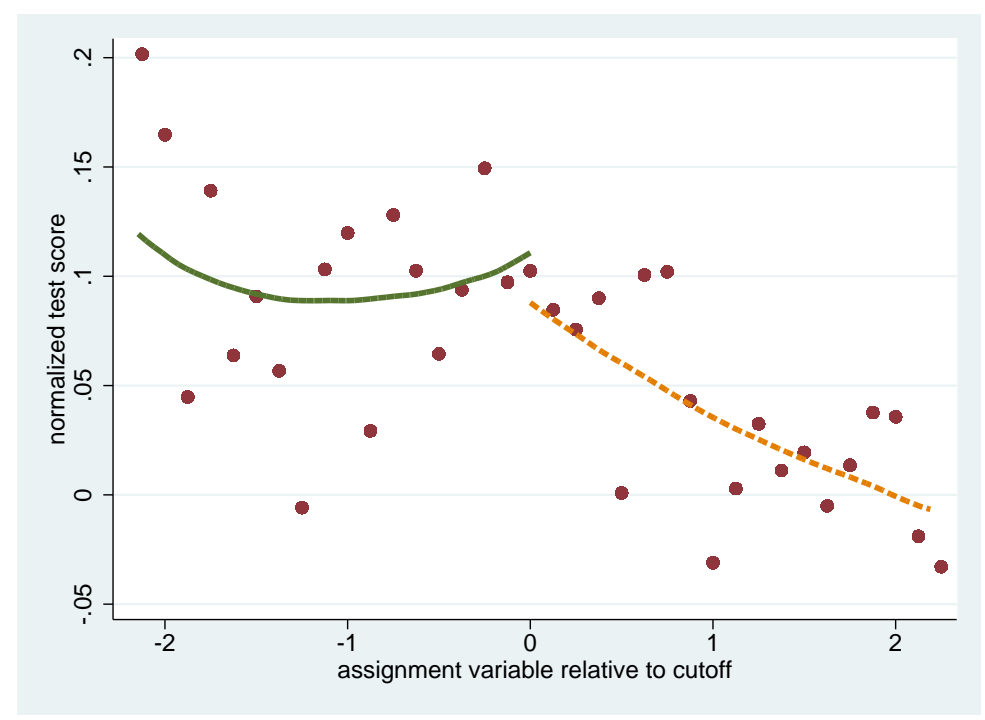

(Laajaj et al., 2018). ${ }^{27}$ We repeat the analysis of the previous section

\footnotetext{
${ }^{27}$ The one program with the same cutoffs that started in 2015 was a savings program targeted towards the elderly, and thus is very unlikely to have affected Saber $11^{\circ}$ high school exit examination test scores.
} 
while substituting the 2014 Saber $11^{\circ}$ scores for the 2015 scores, and see that none of the estimates are statistically significant. Therefore, we can attribute the gains in 2015 to the introduction of the SPP program. A graphical illustration of this null result is displayed in Figure 3.4.

\section{Placebo test with other variables}

The introduction of the SPP scholarship should have no effect on the average age or gender of test takers; we substitute these variables into the response variable below. As above, there are no statistically significant results.

\subsubsection{Distribution of top test performers}

The scores needed to earn the SPP scholarship are at approximately the 91st percentile of the overall Saber $11^{\circ}$ test score distribution. To examine the extent to which the SPP scholarship motivated students of different backgrounds to increase their scores, we look at the composition in terms of the Sisben level of test takers in 2014 and 2015 that earned the top $9 \%$ of scores on Table 2.6 .

Table 2.6: Distribution of top performers on the SABER $11^{\circ}$

\begin{tabular}{ccccccc}
\hline & \multicolumn{2}{c}{2014} & \multicolumn{2}{c}{2015} & \multicolumn{2}{c}{ Odds ratios } \\
Strata & Overall & Top 9\% & Overall & Top 9\% & Coef. & Std. dev. \\
\hline 1 & $42.3 \%$ & $12.0 \%$ & $44.0 \%$ & $14.8 \%$ & $0.173^{\ddagger}$ & $(0.017)$ \\
2 & $34.9 \%$ & $30.3 \%$ & $34.6 \%$ & $31.2 \%$ & $0.042^{\ddagger}$ & $(0.012)$ \\
3 & $17.8 \%$ & $34.9 \%$ & $16.7 \%$ & $32.8 \%$ & 0.001 & $(0.012)$ \\
4 & $3.6 \%$ & $15.1 \%$ & $3.3 \%$ & $14.2 \%$ & 0.022 & $(0.021)$ \\
5 & $1.0 \%$ & $5.3 \%$ & $1.0 \%$ & $4.9 \%$ & -0.014 & $(0.038)$ \\
6 & $0.4 \%$ & $2.4 \%$ & $0.4 \%$ & $2.2 \%$ & 0.016 & $(0.061)$ \\
\hline
\end{tabular}

Notes: Standard errors corrected for heteroskedasticity are in parentheses. $\ddagger$ denotes statistical significance at the $1 \%$ level. Odds ratios are calculated using a logistic regression where the response variable is a dummy variable equal to 1 if in the top $9 \%$ of test takers and 0 otherwise, and the explanatory variable is a dummy equal to 1 for the year 2015 and 0 for the year 2014 .

Examining the odds ratios, we see that strata 1 experiences a $17.3 \%$ increase in its representation in the top $9 \%$, strata 2 sees a much smaller $4.2 \%$ increase, and those in the higher strata experience changes that are 
not precisely estimated. Taken together, this implies that the decrease in representation from the higher strata due to the increase in representation from strata 1 and strata 2 was likely not concentrated in any one category. It appears that the SPP scholarship has incentivized low income students to sufficiently improve their academic performance on the SABER $11^{\circ}$ high school exit exam that higher income students have been displaced from the top $9 \%$ of test takers.

\subsection{Survey evidence}

What remains to be determined is how the test scores were increased as a result of the SPP program's introduction. Using a survey of 1938 students at one of Colombia's top private universities, we asked broad range of questions concerning the choice of major, method of financing, Saber $11^{\circ}$ preparation, and other topics. ${ }^{28}$ We divided the sample into two parts: students who wrote the high school exit exam in 2013 and 2014, which we call the pre-period, and those that took it in 2015 and 2016, the post-period; students who wrote the Saber $11^{\circ}$ in other periods were excluded from the sample. Since students in the first group were not aware of the SPP program at the time of writing the exam, we can compare their study habits and attitudes to see the effect of the program on their motivation and effort to do well on the Saber $11^{\circ}$.

${ }^{28}$ The survey was conducted in Spanish; the original wording of the questions is available by request. 
Table 2.7: Importance of studying for the Saber $11^{\circ}$

$\begin{array}{lllll}2013 \& 2014 & 2015 \& 2016 & \text { Difference } & \text { N } \\ \text { Mean St. dev. } & \text { Mean } & \text { St. dev. } & & \end{array}$

Importance of

Being admitted

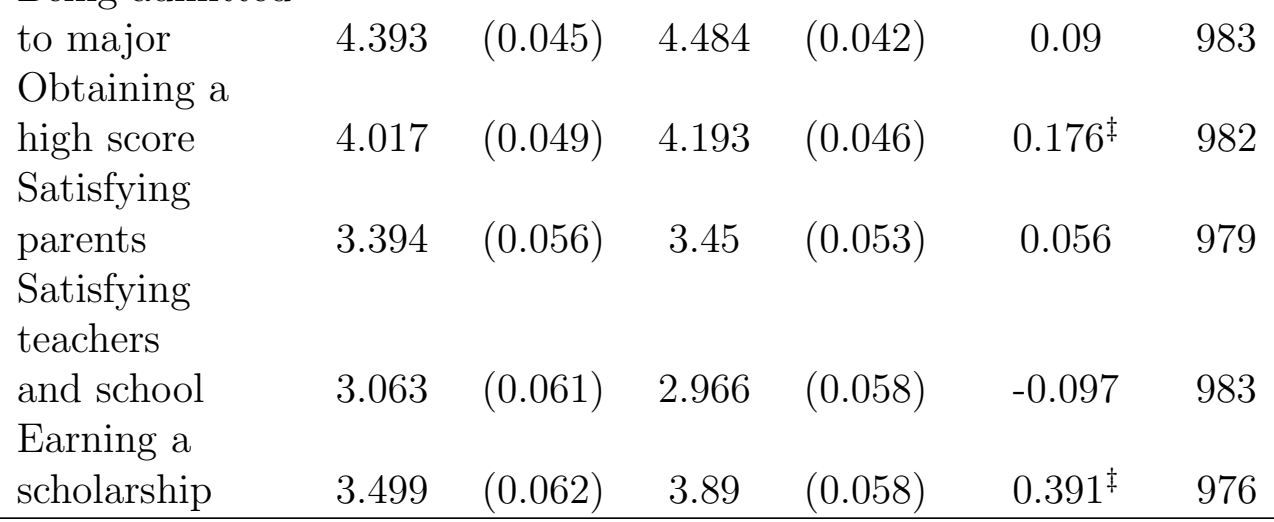

Notes: Authors' calculations. Attitudinal variables are on a 1 to 5 scale, with 1 being the lowest and 5 being the highest. Heteroskedasticity-robust standard errors are in parentheses. $N$ denotes the number of observations, and $\ddagger$ denotes statistical significance at the $1 \%$ level.

We find that students studied for the exam at roughly equal rates, about $87 \%$ in the pre-period versus $85 \%$ in the post period (Fisher exact p-value $=0.357)$. As part of the survey, students were asked to recall their attitudes before taking the SPP exam. The attitudinal variables are on a 1 to 5 scale, where 1 is not at all important and 5 is very important. These attitudinal variables are displayed on Table 2.7.

We see that the introduction of the SPP scholarship program affected attitudes in two dimensions: both the desire to obtain a high score and the desire to score well enough to obtain a scholarship increased at a statistically significant level, with the magnitude of the latter rising more than twice as much as the former. These results show that student motivation to perform well on the Saber $11^{\circ}$ increased markedly. Next, we examine the hours of study used to prepare for the exam through each method, conditional on using the method to prepare; see Table 2.8. There are no statistically significant increases or decreases in the number of hours studied, although it appears possible that teachers substituted 
preparing students for the exam outside of class hours for doing so during school hours.

Table 2.8: Hours of study for the Saber $11^{\circ}$ by method

\begin{tabular}{|c|c|c|c|c|c|c|c|}
\hline Method of & $2013 \&$ & 2014 & 20158 & 2016 & \multicolumn{2}{|c|}{ Difference } & $\mathrm{N}$ \\
\hline $\begin{array}{l}\text { During } \\
\text { school hours }\end{array}$ & 55.08 & $(3.36)$ & 62.48 & $(3.38)$ & 7.40 & 0.121 & 554 \\
\hline $\begin{array}{l}\text { Outside } \\
\text { school hours }\end{array}$ & 68.04 & $(4.23)$ & 59.68 & $(4.16)$ & -8.36 & 0.160 & 376 \\
\hline $\begin{array}{l}\text { Outside tutor } \\
\text {, at school }\end{array}$ & 71.91 & $(4.70)$ & 75.81 & $(4.18)$ & 3.89 & 0.536 & 332 \\
\hline $\begin{array}{l}\text { Private } \\
\text { courses }\end{array}$ & 78.54 & $(3.87)$ & 84.69 & (3.67) & 6.14 & 0.250 & 388 \\
\hline $\begin{array}{l}\text { Virtual } \\
\text { courses }\end{array}$ & 67.07 & $(6.40)$ & 64.99 & $(5.92)$ & -2.09 & 0.811 & 155 \\
\hline
\end{tabular}

Notes: Authors' calculations. Numbers are expressed in terms of proportions.During and outside school hours methods indicate the use of the student's usual teacher at the school. Heteroskedasticity-robust standard errors are in parentheses. $N$ denotes the number of observations.

Next, we consider whether students study in additional ways in order to prepare for the Saber $11^{\circ}$ exam. Examining Table 2.9, it appears that there are some gains on the order of 5 percentage points for private and virtual courses, but the estimates are mildly imprecise. Examining the coefficient differences, nearly all of them are positive, save for one that is negative at about a single percentage point. Overall, it appears that there is evidence that students used additional methods of preparation for the exam after SPP was introduced.

Another consideration is whether students spent additional money preparing for the exam as a result of the introduction of SPP. In current dollars, students spent an average of $\$ 406,000$ Colombian Pesos (COP) in $2013, \$ 393,000 \mathrm{COP}$ in $2014, \$ 477,000$ in 2015 , and $\$ 492,000 \mathrm{COP}$ in 2016. Adjusting for inflation and expressing the figures in 2013 COP, students spent an average of $\$ 394,000 \mathrm{COP}$ in 2013 and 2014, and an average of $\$ 433,000 \mathrm{COP}$ in 2015 and 2016, a $9.9 \%$ increase in spending. This result agrees with the previous point that students more often took private and online courses in order to prepare for the exam. 
Table 2.9: Method of studying used for the Saber $11^{\circ}$

\begin{tabular}{lcccccccc}
\hline $\begin{array}{l}\text { Method of } \\
\text { studying }\end{array}$ & $\begin{array}{l}2013 \text { \& } 2014 \\
\text { Mean }\end{array}$ & St. dev. & Mean & St. dev. & $\begin{array}{l}\text { Diffe- } \\
\text { rence }\end{array}$ & $\begin{array}{l}\text { P- } \\
\text { value }\end{array}$ & N \\
\hline $\begin{array}{l}\text { During school } \\
\text { hours }\end{array}$ & 0.610 & $(0.022)$ & 0.626 & $(0.021)$ & 0.017 & 0.586 & 1012 \\
$\begin{array}{l}\text { Outside school } \\
\text { hours }\end{array}$ & 0.451 & $(0.023)$ & 0.442 & $(0.021)$ & -0.009 & 0.772 & 1012 \\
$\begin{array}{l}\text { Outside tutor, } \\
\text { at school }\end{array}$ & 0.386 & $(0.022)$ & 0.429 & $(0.021)$ & 0.043 & 0.162 & 1012 \\
$\begin{array}{l}\text { Private courses } \\
\text { Virtual courses }\end{array}$ & 0.420 & $(0.023)$ & 0.472 & $(0.022)$ & 0.052 & 0.095 & 1012 \\
\hline
\end{tabular}

Notes: Authors' calculations. Numbers are expressed in hours of study. During and outside school hours methods indicate the use of the student's usual teacher at the school. Heteroskedasticity-robust standard errors are in parentheses. $N$ denotes the number of observations.

\subsection{Policy discussion}

This study provides evidence that valuable merit-based scholarship programs generally increase the effort input on tests that are used to allocate the scholarships, as predicted by economic theory. While much of this effort increase appears to be driven by students at the top of the distribution of student ability, the statistically significant average gains that are of a non-trivial magnitude showcase that students at other points in the distribution increase effort as well. If this effort in preparing for the Saber $11^{\circ}$ exam translates into additional human capital in the economy (that is, studying for the test increases one's ability to produce and not just the ability to take the test), we can consider this phenomenon to be a positive spillover effect of the program. Whether future generations of students will learn and eventually adjust their expectations downward remains to be seen.

Should these spillovers to lower ability students be permanent, there may be reason to believe that similarly-designed scholarship programs can be developed and employed at different levels of education for similar benefits. For example, perhaps a exam similar to the Saber $11^{\circ}$ can be 
given at a certain point (before the end of high school) that provides scholarships to high quality private schools for low income students that perform well on the test. 


\section{References}

[1] Barrientos, J. \& Peña C. "El fin de Ser Pilo Paga: ¿y ahora qué?." El Tiempo. Retrieved from https://www.eltiempo.com/vida/educacion/lo-que-podria-ocurrirdespues-del-fin-de-ser-pilo-paga-265972 (accessed March 31st, 2019).

[2] Bartik, T. \& Marta L. (2014). The short-term effects of the Kalamazoo Promise scholarship on student outcomes. New Analyses of Worker Well-Being. Emerald Group Publishing Limited. 37-76.

[3] Borah, J. \& Anirban B. (2013). "Highlighting differences between conditional and unconditional quantile regression approaches through an application to assess medication adherence." Health Economics, vol. 22: 1052-1070.

[4] Cattaneo, M. D., Jansson, M., \& Ma, X. (2020). Simple Local Polynomial Density Estimators. Working paper, University of Michigan. 2017.

[5] Cornwell, C., David B. \& Kyung Hee Lee. (2005). "Student Responses to Merit Scholarship Retention Rules." Journal of Human Resources, vol. 40: 895-917.

[6] Cornwell, C., Mustard, D. B., Sridhar, D. J., \& Deepa J. Sridhar. (2006). "The Enrollment Effects of Merit-Based Financial Aid: Evidence from Georgia's HOPE Program." Journal of Labor Economics, vol. 24: 761-786.

[7] El Departamento Administrativo Nacional de Estadística (DANE). Undated. Preguntas frecuentes estratificacion. Retrieved from https://www.dane.gov.co/files/geoestadistica/Preguntas_frecuentes _estratificacion.pdf (accessed April 1st, 2019). 
[8] Elsner, B., \& Isphording, I. E. (2017). "A big fish in a small pond: Ability rank and human capital investment." Journal of Labor Economics, vol. 35(3): 787-828.

[9] Firpo, S., Fortin, N. M., \& Lemieux, T. (2009). "Unconditional quantile regressions." Econometrica, vol. 77(3): 953-973.

[10] Frandsen, B. R., Frölich, M., \& Melly, B. (2012). "Quantile treatment effects in the regression discontinuity design." Journal of Econometrics, vol 168(2): 382-395.

[11] Gelman, A., \& Imbens, G. (2018). "Why High-Order Polynomials Should Not Be Used in Regression Discontinuity Designs." Journal of Business and Economic Statistics, forthcoming.

[12] Gneezy, U., List, J. A., Livingston, J. A., Qin, X., Sadoff, S., \& Xu, Y. (2019). Measuring Success in Education: The Role of Effort on the Test Itself. JAmerican Economic Review: Insights 1(3), 291-308.

[13] Goodman, J., Gurantz, O., \& Smith, J. Take two! SAT retaking and college enrollment gaps. No. w24945. National Bureau of Economic Research, 2018.

[14] Imbens, G., \& Kalyanaraman, K. (2012). "Optimal bandwidth choice for the regression discontinuity estimator" Review of Economic Studies, vol. 79(3): 933-959.

[15] Instituto Colombiano para la Evaluación de la Educación - ICFES. Instituto Colombiano para el Fomento de la Educación Superior Orientaciones para el Examen de Estado de la Educación Media (pp. 30). Bogota: Instituto Colombiano para la Evaluación de la Educación (ICFES). 2010.

[16] Jessel, E. 'If I'm stratum 3, that's who I am': inside Bogotá's social stratification system. The Guardian. Retrieved from https://www.theguardian.com/cities/2017/nov/09/bogotacolombia-social-stratification-system (accessed June 18th, 2018).

[17] Koenker, R. \& Bassett, G. (1978). "Regression Quantiles." Econometrica, vol. 46(1): 33-50. 
[18] Laajaj, R., Moya, A. \& Sánchez, F. "Equality of Opportunity and Human Capital Accumulation: Motivational Effect of a Nationwide Scholarship in Colombia." Number 2018-26. May 2018.

[19] Londoño-Veléz, J., Rodríguez, C \& Sánchez, F. "Upstream and Downstream Impacts of College Merit-Based Financial Aid for LowIncome Students: Ser Pilo Paga in Colombia." Working paper, version September 2018.

[20] Lee, D. S. \& Lemieux., T. (2010). "Regression Discontinuity Designs in Economics." Journal of Economic Literature, vol. 48: 281-355.

[21] McCrary, J. (2008). "Manipulation of the running variable in the regression discontinuity design: A density test," Journal of Econometrics, vol. 142(2): 698-714.

[22] Ministry of Education of Colombia. (2016). Resumen de Educación Superior. Subdirección de desarrollo sectorial.

[23] Nichols, A. (2011). rd 2.0: Revised Stata module for regression discontinuity estimation. Available at http://ideas.repec.org/c/boc/bocode/s456888.html.

[24] OECD \& World Bank. (2012). Tertiary Education in Colombia. Reviews of National Policies for Education. Paris: OECD Publishing. (C) OECD and World Bank. Available at https://openknowledge.worldbank.org/handle/10986/27434.

[25] Pallais, A. (2009). "Taking a Chance on College: Is the Tennessee Education Lottery Scholarship Program a Winner?," Journal of Human Resources, vol. 44(1): 199-222.

[26] Richburg-Hayes, L., Brock, T., LeBlanc, A., Paxson, C. H., Rouse, C. E., \& Barrow, L. Rewarding Persistence: Effects of a PerformanceBased Scholarship Program for Low-Income Students. MDRC research paper, January 2009.

[27] Scott-Clayton, J. (2011). "On Money and Motivation: A QuasiExperimental Analysis of Financial Incentives for College Achievement," Journal of Human Resources, vol. 46: 614-646.

[28] The World Inequality Database. Colombia. https://wid.world/country/colombia/ (accessed April 9th, 2019). 
[29] World Bank. Colombia's Goal: More Success in Higher Education, More Opportunities for Youth. Retrieved from http://www.worldbank.org/en/news/feature/2013/01/24/colombiamore-success-in-higher-education-more-opportunities-for-youth (accessed April 3rd, 2019). Published January 24, 2013.

[30] World Bank. Reviews of national policies for education: Tertiary education in Colombia. Washington, D.C. 2012. 


\section{Chapter 3}

\section{Can Information Change Preferences For Higher Education? Evidence From a Randomized Experiment In Colombia $^{* \dagger}$}

\section{Abstract}

To examine the role of information provision on students' preferences for higher education, this study conducts a randomized controlled trial where the outcomes are measured by a discrete choice experiment. Low-income, 10th-grade students were randomly assigned to two intervention groups and one control group. Students were treated with information on the

* Based on working paper: Bernal, G., Abadía, L.K., Arango, S. \& De Witte, K., (2020): Can information change preferences for higher education? Evidence from a randomized experiment in Colombia. This study is registered in the AEA RCT Registry under identifier AEARCTR-0003726.

$\dagger$ Acknowledgements: we would like to thank to ICFES for their collaboration in this project. The analysis, views, and opinions expressed in this article are those of the authors and do not necessarily represent those of ICFES. We are also grateful to Mindel van de Laar, Wim Groot, and the seminar participants at the 44th AEFP Annual Conference, the 24th LACEA meeting, the 5th LEER Workshop the UNUMERIT workshop, the Banco de la República seminar, and the $10^{\circ}$ ICFES seminar, for their valuable comments. 
returns to higher education, enrollment rates, financial aid and tuition costs in high-quality universities. The results show that, first, the information provision reduces students' preferences for public institutions. Second, treated with information on financial aid and tuition costs, students increased their preferences for higher-quality institutions. Third, sub-groups of students who are most likely to change their decisions by means of information are lowest SES, female, present-oriented or those who overestimate the returns. Fourth, students are willing to give up between 24\% - 36\% of a 100\% scholarship in order to switch from a lowquality institution to a high-quality institution.

\subsection{Introduction}

Programs using information to increase low-income students' enrollment in selective colleges are popular in various countries, such as the USA (Bettinger, Long, Oreopoulos \& Sanbonmatsu, 2012; Dynarski, Michelmore, Libassi \& Owen, 2018; Bleemer \& Zafar, 2018) and Chile (Dinkelman \& Martínez, 2014). Earlier literature has studied the effect of providing key information, such as the returns to higher education or credits options, on student choices for college (e.g. Booij, Leuven \& Oosterbeek, 2012; Fryer, 2016; Hastings, Neilson \& Zimmerman, 2015). This work has been conducted under the hypothesis that information can reduce market failures from students' misconceptions and increase educational equity and efficiency at a low cost (Mizala \& Urquiola, 2013). The present study supplements previous work by measuring the causal effect of the provision of information on students' preferences for higher education, and by examining the underlying mechanisms of students' decisions. Using a unique combination of a randomized controlled trial (RCT) with a discrete choice experiment, we observed the decision making of low-income students, who are usually not included in traditional choice records because they rarely reach college. We contribute to the literature by estimating the causal influence of provision of information on student preferences for higher education, which leads to a better understanding of determinants of choices, trade-offs and decision-making process. This ultimately serves the formulation of more cost-effective and inclusive education programs.

Our study fits in two strands of the existing literature. First, it re- 
lates to previous studies that use RCTs to test the effect of information provided to high school seniors on their college enrollment decisions (or intentions to enroll). Various studies have assessed whether information on returns and available financial aid affect students' higher education choices. Although differences in context and methods make it difficult to establish definite conclusions across studies, it generally appears that provision of information on available financial aid might increase enrollment in higher education (e.g. Herber, 2018; Dinkelman et al., 2014; BonillaMejía, Bottan \& Ham, 2019; Loyalka, Song, Wei, Zhong \& Rozelle, 2015). By contrast, provision of information on returns has either no effect on enrollment (e.g. Avitabile \& De Hoyos Navarro, 2018; Fryer, 2016; Rao, 2016; Kerr, Pekkarinen, Sarvimäki \& Uusitalo, 2020; Peter \& Zambre, 2017; Busso, Dinkelman, Martínez \& Romero, 2017), or a substantial positive effect (Hastings, Neilson, Ramirez \& Zimmerman, 2016; Oreopoulos \& Dunn, 2013; Hurwitz \& Smith, 2018). It also appears that these positive effects depend on the socio-economic characteristics of students. Moreover, randomized studies concerning clarifications on enrollments rates, university quality and living/moving costs are scarce. In the appendix of this dissertation (Appendix, Table 6.2), there is a comparison chart of the relevant papers that, using RCT, assess the causal impact of provision of information to pre-college students on different student's outcomes.

Second, this study relates to studies using Discrete Choice Experiments (DCE) to elicit student preferences for higher education (Walsh, Flannery \& Cullinan, 2018; Moorhouse, Dunnett, \& Barry, 2015; Dunnett, Moorhouse, Walsh \& Barry, 2012; Czajkowski, Gajderowicz, Giergiczny, Grotkowska \& Sztandar-Sztanderska, 2020). This strand of research assesses the importance of attributes related to quality or reputation, location and fees of the higher education institutions (HEIs). Walsh et al. (2018) and Dunnett et al. (2012) observe quality/reputation as an important factor in students' decisions, and report evidence that students from a low-SES are more sensitive to higher fees. Czajkowski et al. (2020) find that the "salary after 5 years of graduation" weighs the most in students' choices.

The present study aims to estimate the causal effects of providing information about higher education on students' stated preferences by using a randomized controlled trial (RCT) combined with a discrete choice 
experiment (DCE). ${ }^{1}$ By combining the RCT and DCE approach, we are able to explore the underlying mechanisms in student decisions, and to estimate the causal impact of information on students' stated preferences.

Students in the treatment groups received seven statements with general facts about higher education. The information provided to students in a first treatment group emphasized the returns to and the enrollment rates in accredited universities, whereas the information in a second treatment group emphasized financial aid and tuition costs at accredited universities. No information was provided to the students in a control group. Randomization was performed at the school level. The outcomes of the RCT were measured in terms of student's preferences with and without the provision of information. The DCE methodology allows us to elicit students' preferences in terms of five higher education attributes: institution quality, location of the higher education institution, type of institution (public or private), the size of the awarded scholarship and the level of the living expense stipend. As the DCE introduces exogenous variation of the levels of the attributes presented to the students in hypothetical bundles, choice sets are orthogonal to students' characteristics. This solves concerns of endogeneity and collinearity that might be present in the records of higher education choices (Angrist \& Pischke, 2010; Freeman, Herriges \& Kling, 2014; Phaneuf \& Requate, 2016). Moreover, DCE studies have shown correlation between choosing under hypothetical scenarios and choice in real scenarios in several fields such as human capital (Wiswall \& Zafar, 2018; Mas \& Pallais, 2017; Maestas, Mullen, Powell, Von Wachter \& Wenger, 2018), and DCE surveys applied to children or young people (Hemsley-Brown, 2015; Lambooij, Harmsen, Veldwijk, de Melker, Mollema, van Weert \& de Wit, 2015; Kamargianni \& Polydoropoulou, 2013).

Participating students were Colombian low-income 10th-grade students, most of them income-eligible for governmental financial aid for tertiary education. Colombia provides an interesting research environment given its high levels of misinformation regarding the higher education system (Bonilla-Mejía et al., 2019). In addition, Colombian educational

\footnotetext{
${ }^{1}$ Stated preferences, as opposed to revealed preferences, are those that are elicited from offering hypothetical bundles rather than real. Hearth on we only use the term preferences.
} 
authorities usually lack information regarding preferences, potential demand or willingness to pay of low-income students. This likely prevents authorities and institutions from accurately predicting students' demand for higher education, which in turn may result in the formulation of unsustainable financial aid policies for low-income students. This study is well suited to analyze how facts can redirect students' preferences and where those preferences directing towards. Using these insights, this study provides a direct contribution to guide toward more efficiency and equity in the provision of higher education in general and higher education in developing countries in particular.

The present study unfolds as follows. Section 2 presents the context. The intervention and sample selection are discussed in Section 3, followed by the methodology in Section 4 . Section 5 presents the results. Section 6 discusses the results and concludes.

\subsection{Context}

The Colombian higher education system offers vocational (two-year) and academic (five-year) degrees across 55 different fields of study. There are 211 technical institutes and 86 universities all around the country. However, $68 \%$ of the total supply is located in the fourth main cities of the country (i.e. Bogotá, Medellín, Cali and Barranquilla). About 28\% of the higher education institutes are public whereas the rest are private, and only 52 higher education institutes (18\% of the total) are nationally accredited by the Ministry of Education (i.e. they fulfill national quality standards in terms of curriculum, professors, infrastructure, labor conditions of alumnae, etc.). Approximately, 37\% of the accredited universities (including six public and 13 private) are located in the capital, Bogotá.

The higher education institutes are heterogeneous in terms of costs and quality. For public universities, tuition fees are under a progressive system based on family income, and students can pay as low as about 28 USD per semester. ${ }^{2}$ Tuition cost per semester at private universities vary from 400 USD to 7750 USD. Financial aid is available through a governmental institution responsible for funding higher education known as ICETEX, which grants interest free loans to low-income students. Ac-

\footnotetext{
${ }^{2}$ Assuming an exchange rate of: 3000COP / USD.
} 
ceptance in higher education institutions is mainly based on performance on the high school exit examination.

Enrollment rates in tertiary education are low in Colombia. According to the OECD (2016), the level of tertiary education attainment among Colombians between 25 and 34 years old is $27.4 \%$, while the average for OECD countries is $42.1 \%$. Paradoxically, the percentage of students who expect to complete a university degree in Colombia is $76.3 \%$, one of the highest among PISA-participant countries (ranked second out of 52 countries) in 2015. For most low-income high school students in the country (about 360,000 every year), their desire to pursue tertiary education cannot be satisfied.

In an effort to increase college enrollment for low-income students, the program 'Ser Pilo Paga' (SPP) was introduced in 2014. Every year, it covered $100 \%$ of tuition fees (and in some cases living expenses and moving fees) to 10,000 low-income students in approximately the top 10th percentile of performance in the high school exit examination. Students were able to attend accredited institutions only, as the government considers these institutions to have better quality standards. For the first wave in 2014, only $60 \%$ of awardees accepted the offer, but this rate increased to $81 \%, 83 \%$ and $90 \%$ respectively in the following three following cohorts. Arguably, these differences are due to "lack of information" of the first wave students regarding the higher education system (DNP, CNC, \& UniAndes, 2016).

The Ser Pilo Paga program was shown to be effective in doubling the enrollment rate among eligible students and shifting high-skilled students from low-quality to accredited higher education institutions, and from public to private colleges (Londoño-Velez, Rodriguez \& Sanchez et al., 2017). Nevertheless, the unanticipated nature of student preferences led the intervention to be unexpectedly costly. About $83 \%$ of the beneficiaries chose private universities (which cost, on average, two times more than public institutions), and about one third moved in order to attend college. Those extra expenses were covered by the program. In July 2018 , the cost of the program reached approximately $50 \%$ of the national budget for higher education loans. The Ministry of Education claimed cost overruns led to the SPP's cancellation in September 2018. 


\subsection{Methods}

\subsubsection{Experimental Design}

To examine the role of information on higher education preferences, we used a one-time, online survey in the second semester of 2018. The first part of the survey provided information regarding higher education facts to the two treatment groups, whereas a following section of the survey assessed students' preferences for higher education. We also collected socio-economic information of the students as well as other factors such as future expectations and beliefs. The survey was administered and collected by the governmental Colombian agency in charge of assessing education: the Colombian Institute for Educational Evaluation (ICFES). ${ }^{3}$ Given that we targeted low-income students, some schools did not have internet access. Therefore, we designed a paper version of the survey. ${ }^{4}$

The sample selection. ICFES statistical office sampled schools among the schools that reported a percentage of income-based eligible students over $30 \%$. Using a stratified random sample, the sample was made broadly representative of the population of schools across geographic location (the 5 macro-regions in the country). Schools were randomized in three different groups (i.e. control group, treatment 1 and treatment 2). We checked the balance at baseline in schools' characteristics (i.e. percentage of eligible students for SPP program, proportion of female, full-day at school and conflict victim). ${ }^{5}$ Randomization was at the school level, rather than individual level, to best mimic a potential policy measure and to avoid spillover effects within schools. Nevertheless, we examine the effect of information at the individual level. This conducts to a lower probability of balancing covariates at the individual level, considering that the composition of the students within schools is usually non-random and the number of observations is high.

\footnotetext{
${ }^{3}$ Data was managed by ICFES under their pre-established confidentiality conditions. Data was first anonymized by ICFES and then passed to the researchers.

${ }^{4}$ In the empirical analysis, we add a dummy variable if students used the paper version.

${ }^{5}$ Before the sampling, we performed a power analysis estimating the minimum number of observations required in the experiment. With a planned number of 100 clusters, power parameter equal 0.9 and type I error of 0.05 , it is required to have on average 5 students per cluster. This also implies a minimum sample size of 196 students across all groups, as treatments are randomized at individual level.
} 
ICFES invited schools to participate through a phone call. If they accepted, a link with instructions, consents and surveys were send by email. Among the 331 invited schools 102 ended up completing the survey, which a participation rate of $31 \%$. Table 3.1 column 5 shows the difference in the statistics between compliers (column 1) and no complier schools. Except for a slightly higher proportion of public schools in the no compliers group (0.06), there is not systematic differences in observable characteristics between the two groups of schools. Based on observables, the final school sample is representative of the initially targeted schools.

The data collection. Both the information experiment and the discrete choice experiment took place within a survey that was sent by email directly to the students. The survey contains five different sections. ${ }^{6}$ In a first section, we asked for the student's consent. A second section, only for students in the treatment groups, comprised the information experiment. In particular, it included different statements with information on the higher education system. A third section measured students' pre-determined preferences and perceptions on higher education. Figure 3.1 illustrates both the instructions for the DCE and one (out of nine) of the choicest presented to students to elicit their preferences for higher education attributes. Between each pair of bundle, students must choose their preferred option. In particular, we included questions about their willingness to pursue higher education, about their preferred program-institution-city (either assuming their parents pay or some other entity pays), their assessment on tuition fees, questions on expected returns of higher education, and high school exit examination scores. The fourth part of the survey included the discrete choice experiment. There were nine choice sets, corresponding to higher education bundles, which were defined by three university attributes and two financial (scholarship) attributes. A fifth section of the survey collected socioeconomic information of students by asking for additional information of students which was contrasted with administrative data as well as used in the case that administrative datasets did not include a particular variable. Students could leave responses in blank. A final section of the survey collected data on the requests of students for further information on an orientation test, on the list of accredited universities, on the list of non-accredited universities, on the list of private and public universities, government loans (credit simulator), wages of different occupations, and

\footnotetext{
${ }^{6}$ See appendix Figure A for more details.
} 
enrollment fees in higher education programs. At the end of the survey, all students were presented links to official websites on higher education orientation and information. Neither schools nor students were made aware of the purposes or hypotheses being tested in order to minimize the potential for performance and expectancy bias. We matched the survey data with administrative records of students when they took the exit examination in August 2019.

The statements and attributes for the information experiment and the DCE relied on reviews of the factors influencing college choice (Bergerson, 2009; Hemsley-Brown, 2015), as well as data from the National Department of Planning, and interviews with representatives of two government agencies responsible for the programs involving higher education financial aid. We ran two small scale pilots of the discrete choice experiment, and a pilot of the full online survey administrated into two low-income schools across Colombia.

Figure 3.1: Activity instructions to the students before starting the DCE and an example of a DCE choice set. (Original text in Spanish)

ACTIVITY
In the next activity you have to choose the higher education
bundle that you would prefer (Bundle 1 or Bundle 2). The
scenarios are imaginary, and refer to institutions of higher
education (for example, universities or university of applied
sciences). Each option has 5 characteristics:
1. Quality of the Higher Education Institution: Where 5 stars
is the highest quality and 2 stars is the minimum quality.
The accredited higher education institutions have 4 or 5
stars and those not accredited have 2 or 3 stars.
2. Location of the higher education institution: This
represents the number of hours by bus that you would
have to take from your city of origin to the city where the
higher education institution is located.
3. Type of higher education institution: public or private.
4. Scholarship for tuition payment: This represents the
percentage that is given to subsidize your enrollment. If
the scholarship is NOT 100\%, you are supposed to pay the
rest of the tuition when you graduate and receive a
salary.
5. Support Subsidy: "YES" means that you are provided by a
subsidy of $\$ 312,000$ per month for transport, food and
housing expenses. "NO" means that you do not receive
extra money.

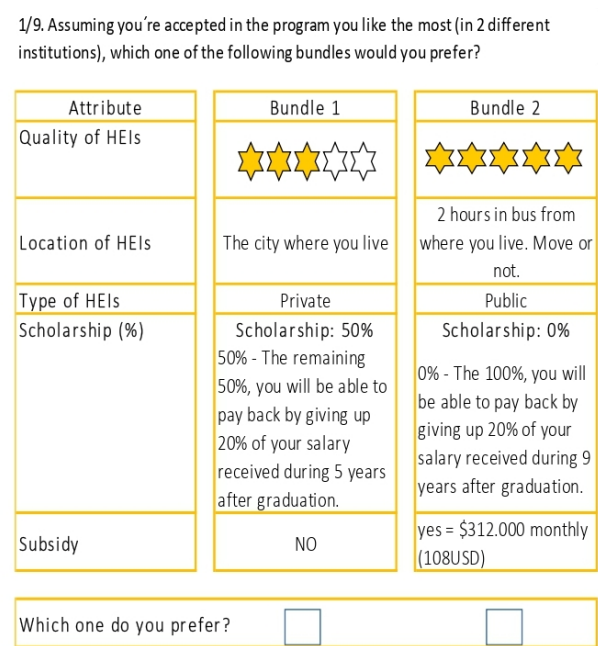

Note: After instructions, and according to their preferences, students must choose between the two possible bundles of higher education displayed in each of the nine choicest.

The information experiment. In both treatment groups, students in the randomly selected schools were provided with seven statements related to higher education. The statements contain information on the 
difference between university versus technical level of education, costs of moving, loans, enrollment rates in public and private universities, and cost of living. Next to the seven statements which are common to both treatment groups, two additional statements differed between the treatment groups. Using 2 extra statements, treatment group 1 was treated with information on return and access to accredited universities, whereas treatment 2 group received two statements on governmental loans and cost of accredited universities.

To increase the attention level of the students, and increasing the likelihood that students effectively absorb the information, the statements were provided to the students in a 'Myth or reality' format. Students were given a statement and then vote 'myth' or 'reality' according to their beliefs. Immediately after voting each item, students were informed if the answer is correct or not, and additional information and/or explanation of the statement was provided. For example, a statement reads as "Myth or reality? Less than 25\% of the credits given by the ICETEX -governmental entity in charge of credits for higher education- are given to low-income students." After a student voted, the following information appeared: "Myth! $69 \%$ of students beneficiated from ICETEX loans are low-income students".

The Discrete Choice Experiment. Using five attributes, we measured the multi-dimensional trade-off in student preferences for institution quality, location, type (public versus private), scholarship (tuition fee) and living expense stipend. The choices within the attributes (the levels) are made as realistic as possible. The attributes and levels included in the DCE are summarized in Figure 3.2 and discussed next.

1. Institution quality, which is represented by stars. The attribute ranges from 5 stars to 2 stars, where the 5 and 4 stars represent the accredited universities.

2. Location included 5 categories: 0, 2, 4, 10 and 14 (or more) hours from home. ${ }^{7}$ The length is set according to the most popular journeys students make to attend higher education. The information is based on averages hours that take to travel by bus from 5 important cities to the capital, Bogotá.

\footnotetext{
${ }^{7}$ Students are more familiar with the concept of time than distance.
} 
3. Type of universities: public or private provision of education.

4. Scholarship tuition fee ranged from $0 \%$ to $100 \%$, with intervals of $25 \% .^{8}$ The values of $25 \%$ and $75 \%$ coincide with the current ICETEX loan. The variable represents the percentage of tuition fee that students are hypothetically receiving. The values of salary and time students should give up in order to pay the remaining debt are calculated according to real information on returns combined with credits calculator from ICETEX. The lower the amount of the scholarship, the higher the level of discouragement of students from choosing a school is expected. This attribute is further defined as a continue variables to calculate the wiliness to pay.

5. Living expenses stipend, amounts to 312.000 COP (approximately 108 USD). This attribute was either 'yes' or 'no'. The value of the living expenses was calculated based on current stipend approved by the government to SPP students who moved to attend college.

Given the number of attributes and levels considered in our experiment, the number of all possible combinations of attribute levels, that is, the full factorial design matrix has 400 rows, which can be combined into 79800 pairs. Since these numbers of packages becomes unwieldy if all possible combinations are considered, we used a statistically efficient design, called D-efficient, to reduce the number of choice sets to a manageable amount for the respondents (fractional factorial design). This method ensures minimum variation around the parameter estimates by minimizing the estimated standard errors in a multinomial logit (MNL) model. We sample from the full factorial to produce 18 scenarios with an orthogonal main effects design, and then split them into two versions of 9 scenarios. To avoid fatigue in choosing the choice sets, each student answered only one of the blocks (i.e. 9 choice sets). This corresponds to a binary choice framework. As such, we asked respondents to pick their preferred bundle and assume admission among 2 possibilities, under each of 9 different conditions.

\footnotetext{
${ }^{8}$ We present percentages as supposed to monetary amounts because two reasons: first, financial aid programs are presented in percentages (i.e. $50 \%$ of tuition fees). Second, a bill 1911 of 2018 in course proposed that students with debts should give up $20 \%$ of their salary for 5 years regardless the amount of their future earnings. By having a percentage specification, results are not susceptible to monetary student's anchors.
} 
Figure 3.2: Attributes and levels in the discrete choice experiment

\begin{tabular}{|c|c|c|}
\hline Attribute & Categories & Level coding \\
\hline $\begin{array}{l}\text { University } \\
\text { quality }\end{array}$ & $\begin{array}{l}5 \text { stars (accredited) } \\
4 \text { stars (accredited) } \\
3 \text { stars (non-accredited) } \\
2 \text { stars (non-accredited) }\end{array}$ & $\begin{array}{l}5 \\
4 \\
3 \\
2\end{array}$ \\
\hline Location & $\begin{array}{l}\text { The city where your parents live. } \\
2 \text { hours by bus from where your parents live. You can choose to move or not. } \\
4 \text { hours by bus from where your parents live. You can choose to move or not. } \\
10 \text { hours by bus from where your parents live. You have to move. } \\
14 \text { hours or more by bus from where your parents live. You have to move. }\end{array}$ & $\begin{array}{l}0 \\
2 \\
4 \\
10 \\
14\end{array}$ \\
\hline University type & $\begin{array}{l}\text { Public } \\
\text { Private }\end{array}$ & $\begin{array}{l}1 \\
0\end{array}$ \\
\hline $\begin{array}{l}\text { Scholarship } \\
\text { (tuition fee) }\end{array}$ & $\begin{array}{l}\text { Scholarship of } 100 \% \text { of the tuition fee. } \\
\text { Scholarship of } 75 \% \text { of the tuition fee. The remaining } 25 \% \text {, you will be able to pay back } \\
\text { by giving up } 20 \% \text { of your salary received during } 3 \text { years after graduation. } \\
\text { Scholarship of } 50 \% \text { of the tuition fee. The remaining } 50 \% \text {, you will be able to pay back } \\
\text { by giving up } 20 \% \text { of your salary received during } 5 \text { years after graduation. } \\
\text { Scholarship of } 25 \% \text { of the tuition fee. The remaining } 75 \% \text {, you will be able to pay back } \\
\text { by giving up } 20 \% \text { of your salary received during } 7 \text { years after graduation. } \\
\text { No scholarship. You will be able to pay the costs back by giving up } 20 \% \text { of your salary } \\
\text { received during } 9 \text { years after graduation. }\end{array}$ & $\begin{array}{l}100 \\
75 \\
50 \\
25 \\
0\end{array}$ \\
\hline $\begin{array}{l}\text { Living expense } \\
\text { stipend }\end{array}$ & $\begin{array}{l}\text { Yes (COP } \$ 312.000 \text { monthly - about USD } \$ 100) \\
\text { No }\end{array}$ & $\begin{array}{l}1 \\
0\end{array}$ \\
\hline
\end{tabular}

Timing. Data collection dates from September 6 to December 31, 2018. Figure 3.3 describes the distribution of schools into the different trial groups. The final sample includes 2652 students in 102 schools (42, 35 and 25 schools in the control, treatment 1 and treatment 2 group, respectively). We exclude the 359 responses before September 6th, given the cancellation of Ser Pilo Paga program on September 6th, which could have changed their preferences for higher education (Bernal, Abadía, Alvarez \& De Witte, mimeo).

\subsubsection{Econometric analysis}

DCE allows measuring students' higher education preferences inspired on modern microeconomic consumer theory. Lancaster (1966) arguments that are the attributes of goods what determine the utility they provide. DCE relies on the random utility model (McFadden, 1974), therefore, to estimate the declared students' higher education preferences, it is necessary to transform the student choice responses to estimated parameters representing their preferences. Random utility theory states that utility $\mathrm{U}$ associated higher education bundle $\mathrm{i}$ for student $\mathrm{n}$ is additively and independently composed of two parts. First, the observable (deterministic) utility $V$ which is a function of the vector of alternative's attributes. Second, the random source $\varepsilon$ which is a function of unobserved higher education attributes and student variation in tastes (Ryan, Kolstad, Rockers \& Dolea, 2012). 
Figure 3.3: Sample distribution

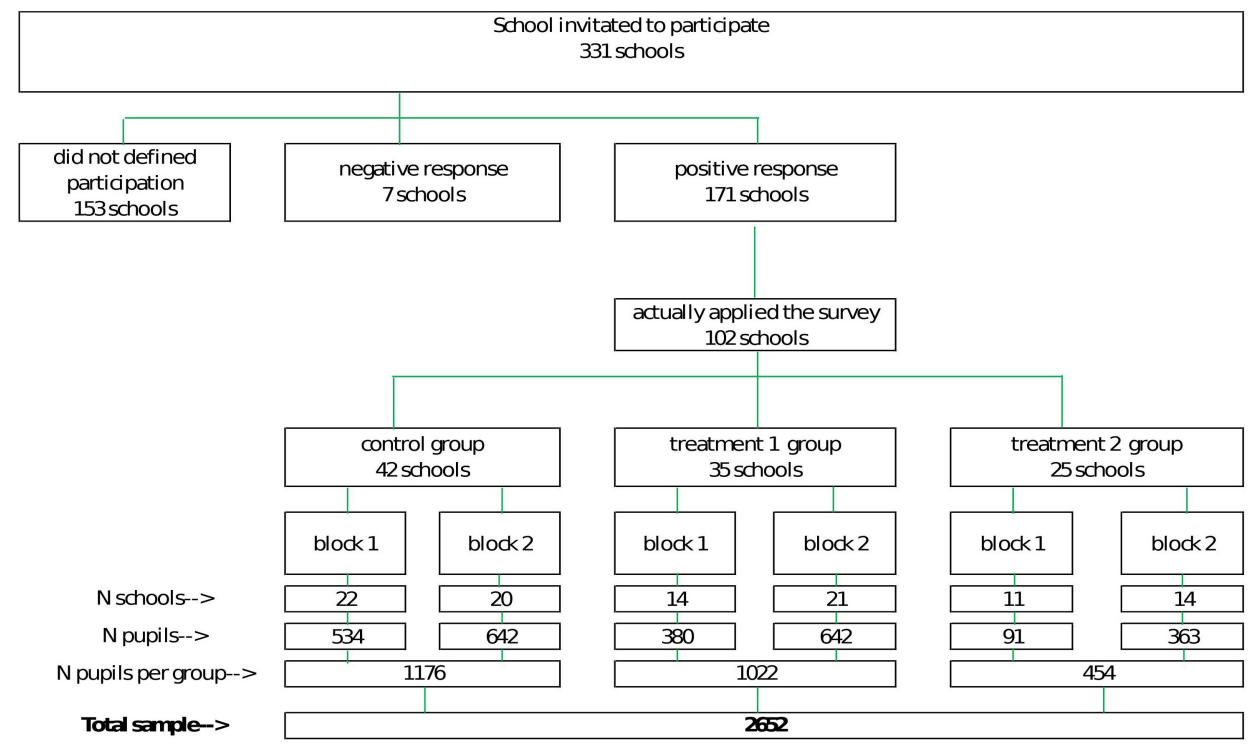

Note: The final sample consists of 2652 children in 102 schools.

$$
U=V+\varepsilon
$$

The observable utility is specified as a weighted expression with $j$ higher education institutions attributes $\left(A_{1}, \ldots A_{j}\right)$. We ask each student to choose one $\mathrm{HE}$ bundle from the two alternatives presented in each choice set (modelling a binary decision). Each bundle on offer is judged as a set of characteristics to be compared with the alternative 'bundle' on offer. No single bundle may represent the ideal HE bundle, and the random utility model assumes that in each choice set, respondents will choose the option that will provide them with the highest benefit (or utility). As utility $U$ is not directed observable because it includes an unobservable component, the students' choice behavior is modeled in terms of probabilities. Therefore, the probability $(P)$ student $n$ chooses higher education institution bundle $i$ over $m$ can be estimated as:

$$
P=\operatorname{Pr}\left[U>U_{m n} \mid \forall i \neq m\right]
$$

Although the evaluation of an RCT is straightforward, its interaction with a discrete choice experiment makes it more complicated. In the questions of the discrete choice experiment, students have to choose one 
higher education bundle (or leave it blank as outside option) from the two alternatives presented in each choice set (see Appendix 3.1). Each offered bundle of attributes is judged as a set of characteristics to be compared with the alternative offered bundle of attributes. No single bundle of attributes may represent the ideal higher education package for the student, but we assume that, in each choice set, respondents will choose the option that will provide them with the highest utility. As the level of attributes changes with the different choice sets, we can model the effect of each characteristic on the probability of a bundle being accepted.

Moreover, to examine the causal effect of information on the importance of each higher education attribute, we introduce interaction terms of each treatment with each attribute. The model is estimated by both linear regression and mixed logit model. For simplicity, and because the results are largely unchanged, we report the mixed logit model in Appendix $2^{9}$.

Statistical model. The underlying utility function combined with the two treatment interactions can be expressed as:

$U=V+\varepsilon=\beta_{0}+\sum_{x=1}^{18} \beta_{j k} A_{j k}+T_{1} \sum_{x=1}^{18}\left(\beta_{1 j k} A_{j k}\right)+T_{2} \sum_{x=1}^{18}\left(\beta_{2 j k} A_{j k}\right)+\gamma_{x}+\varepsilon$

Where $x$ denotes the choice set. The subscript $k$ refers to the attributelevel (each level in all five attributes, see Figure 3.2), sub-index 1 and 2 refer to treatment group 1 and treatment group 2, respectively. Likewise, $\gamma_{x}$ represents the choice set fixed effects to capture observed and unobserved heterogeneity at individual level, and $\varepsilon$ is the idiosyncratic term. ${ }^{10}$ To account for peer effects and randomization at school level, we cluster the standard errors at school level. The reference group for each attribute corresponds to a two-star university, same city as home,

${ }^{9}$ The latter allows for preference heterogeneity in the sample by treating the coefficients as random rather than fixed (Kruk et al., 2010). The mixed logit model estimates the standard deviation of the mean coefficients, thereby providing information on the extent to which students' preferences for characteristics differ. As a robustness test, we also estimate the model using the conditional logit model as developed by McFadden (1974)

${ }^{10}$ As a robustness test, we also include student fixed effects. 
public institution and no stipend. The reference group for $T_{1}$ and $T_{2}$ is the control group, which did not receive any information.

The estimated coefficients $\beta_{j k}$ represent the preferences for the level of each attribute $j$.A positive sign of the coefficient implies that the attribute has a positive impact on the take-up of a given higher education bundle, conditional on treatment effects. Higher coefficients indicate a higher importance of the attribute on the decision making. Interaction coefficients estimate the causal effect of information on student's choices for treatment group 1 ; whereas $\beta_{2 j k}$ estimate the causal effect of information on student's choices for treatment group 2. These coefficients identify the extent to which student preferences are influenced by the provided information (treatment 1 or 2) compared to the control group. Significant and positive coefficients on these interactions suggest that the treatment was effective in modifying the importance of the attributes in the choice for higher education packages.

To understand how students value different components of the HE bundles, we calculated the willingness to give up (i.e. the opposite of willingness to pay) for several attributes. Each coefficient has been divided by the scholarship coefficient to calculate how much percentage of the scholarship students' were willing to give up for a unit change in the characteristics. In other words, the willingness to pay answers the question such as "How much \% of the scholarship are individuals willing to sacrifice -and instead take a loan- in order to pass from a 3 stars HEI to a 4 stars HEI?".

\subsection{Results}

\subsubsection{Descriptive analysis}

The questionnaire was initiated by 3554 senior high school students. We restricted the sample to those schools with more than five completed surveys, following our power analysis which requires a minimum of six students per cluster. Moreover, we excluded 543 respondents because they have a large number of missing variables $(n=499)$ (i.e. more than $60 \%$ of questions were not answered) and/or did not complete the DCE section $(n=44)$. The proportion of non-response was relatively even across groups. 
In terms of internal validity, only 32 of respondents always chose "package A" or "package B" for all nine choices, and 9 failed a test of choice consistency (i.e. they did not select the package for which every attribute had levels superior to those of the other option). The 2652 respondents who remained in our dataset evaluated the 9 choice sets (with 2 bundle each), so that we have a panel with 47,736 observations $\left(2652^{*} 9^{*} 2\right)$. This represents a usable response rate of $74.6 \%$ of the 3,554 individuals who were surveyed and a $30.8 \%$ response rate of schools that were initially called to participate.

Table 3.1: Covariate balance by treatment- table A- school level

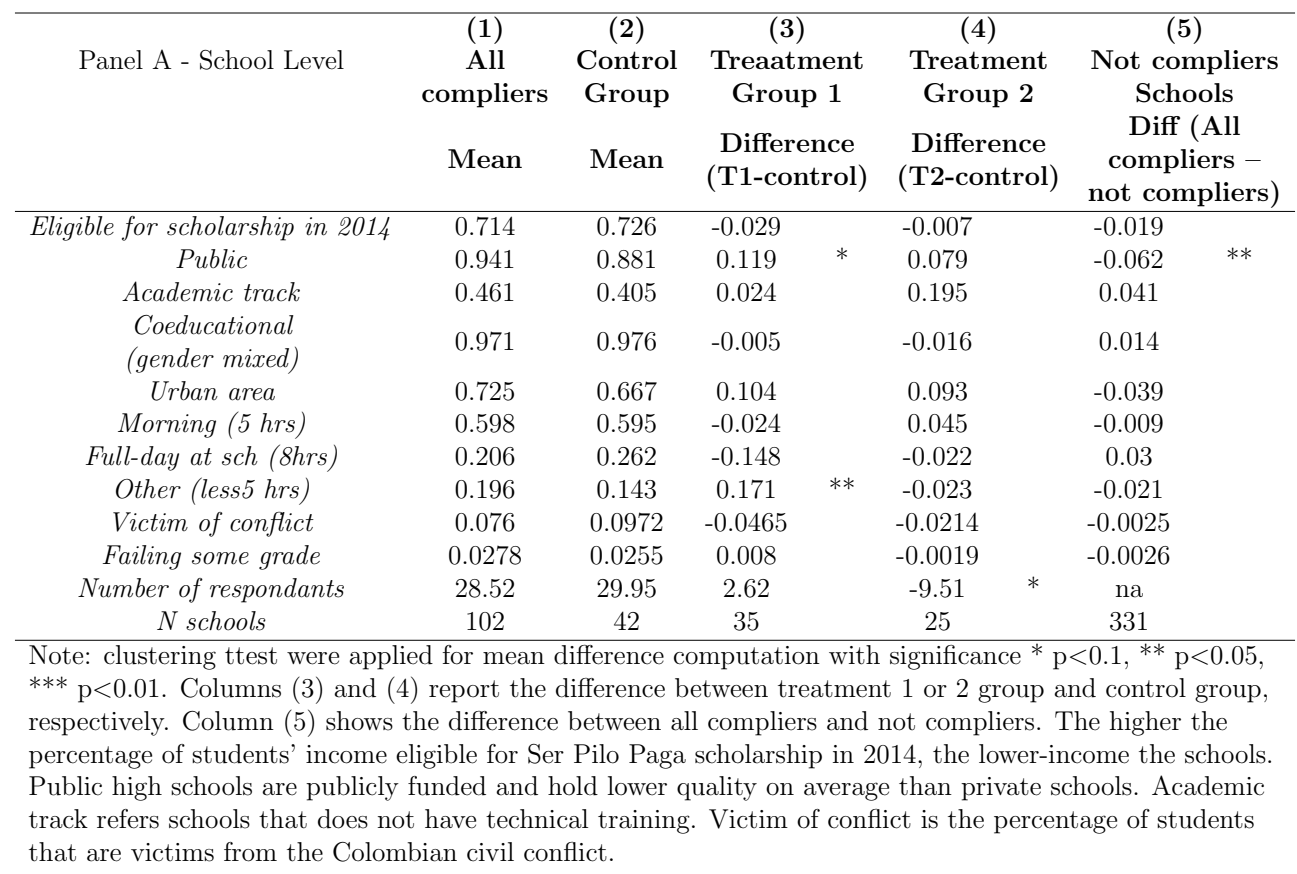

To obtain a rich set of covariates, we linked the survey with administrative data on the schools and students. Table 3.2a shows school-level descriptive statistics by treatment. Columns 2,3 and 4 show that randomization at the school level was in general achieved for the observable characteristics. There are only a few exceptions in treatment group 1, which has a higher proportion of public schools (12.0 percentage points) and higher proportion of schools with less than 5 hours of meeting time (17.1 percentage points) compared to the control group average. Overall, the sampled schools had a high population of low income children (with $71.4 \%$ income-eligible for governmental financial aid), were mainly pub- 
Table 3.2: Covariate balance by treatment-B Individual level

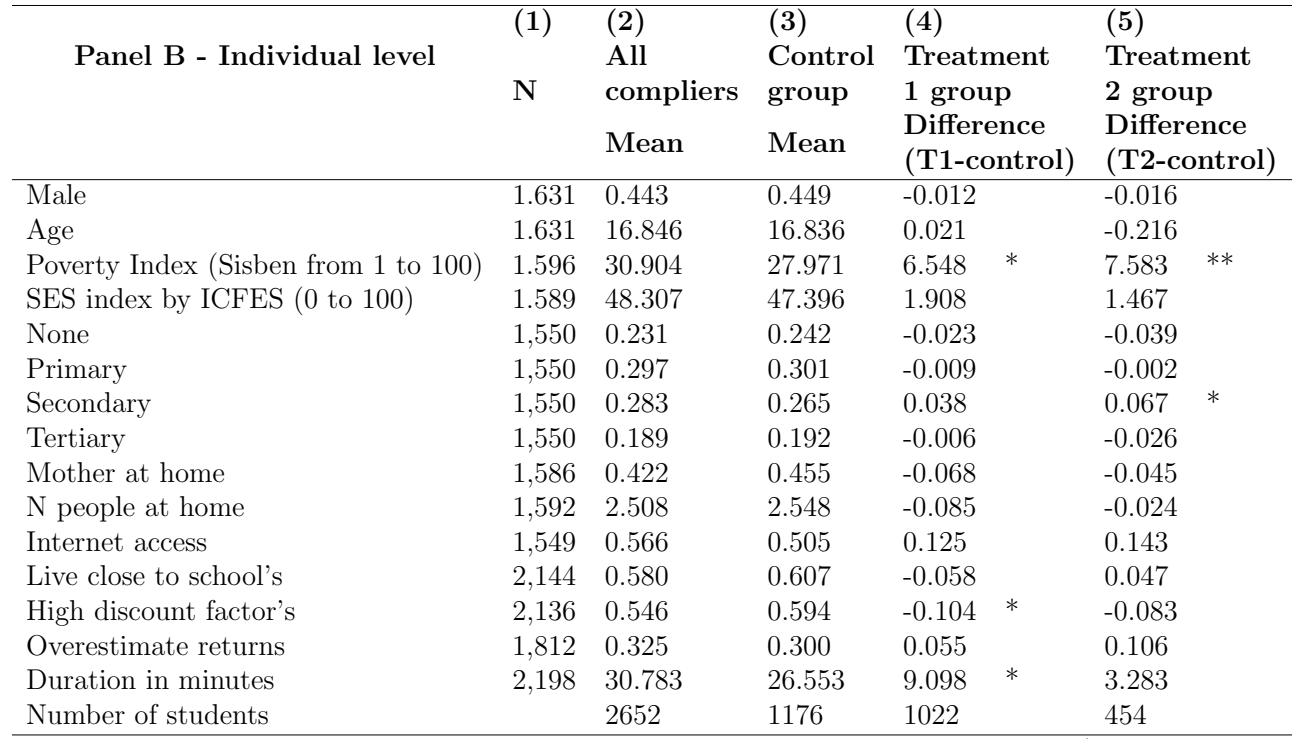

Note: clustering ttest were applied for mean difference computation with significance ${ }^{*} \mathrm{p}<0.1$,

${ }^{* *} \mathrm{p}<0.05,{ }^{* * *} \mathrm{p}<0.01$. Paper-based surveys do not register duration filling in the survey; they are excluded in "duration in minutes variable". These variables are not reported in administrative data, they are taken from the study survey.

lic $(94.1 \%)$, academic-oriented (46\%), coeducational (97.1\%), located in urban areas $(72.5 \%)$ and attended in the morning shift $(59.8 \%)$.

Table 3.2 displays the statistics at student level. ${ }^{11}$ In general, most covariates balance across groups, with one exception. Compared to the control group, the treatment groups score higher on the Sisben poverty index: 6.6 and 7.6 points over the control group on a scale that goes from 0 to 100 . This suggests that the treatment groups include students who are slightly less poor than students in the control group. Yet, students in all groups display low SES (average Sisben score of 31/100), ${ }^{12}$ a small percentage of mothers with tertiary education (19\%) and lack of internet access $(57 \%$ coverage). Moreover, a large share of participants are

\footnotetext{
${ }^{11}$ As randomization was not performed at the level of the individual, there exists the possibility that the covariates for several groups (such as males and socioeconomic status) are not balanced.

${ }^{12} 15.7 \%$ of students who do not have Sisben score. These missing can be students whose families do not classify in poverty index, and are likely in a higher SES compared to their peers. Percentage of missing on this variable does not differ across treatment groups.
} 
present-oriented $(54.6 \%)$, and many overestimate returns by more than 1 standard deviation (32.5\%). ${ }^{13}$ Finally, as expected due to the information treatment, it took treatment groups more time to complete the survey (9.1 and 3.3 minutes, respectively).

Table 3.3 shows the proportion of correct answers for each statement presented in the format of "mark as myth or reality" to students in treatment group 1 and 2 (see appendix, Table 3.6 for the full version of the statements). The share of correct answers to each statement was similar between the treatment groups. The far from perfect scores in classifying the statements as myth or reality indicates that there is room to improve students' basic conceptions of higher education. The two specific statements for treatment 1 and 2 reveal a lack of knowledge regarding accredited (high standard) institutions. About $50 \%$ of the respondents do not think that, on average, graduates from accredited universities earn more than those from non-accredited institutions, and $45 \%$ assume the percentage of low income students in accredited universities is less than $10 \%$ (it is actually $38 \%$ ). Expectations about loans evaluated in treatment 2 are more realistic: $71 \%$ think there is preferential access to those who enroll in accredited universities (true), whereas $37 \%$ of students wrongly mark as true that tuition fees of accredited HEI cost more than COP $\$ 5,000,000$ per semester.

Table 3.3: Percentage of correct answers for each one of the statements showed to treatment groups

\begin{tabular}{|c|c|c|c|}
\hline $\begin{array}{l}\text { Statement } \\
\text { (reduced version) }\end{array}$ & $\begin{array}{l}\text { Treat. } \\
1\end{array}$ & $\begin{array}{l}\text { Treat. } \\
2\end{array}$ & $\begin{array}{l}\begin{array}{l}\text { Difference } \\
(\mathrm{T} 2-\mathrm{T} 1)\end{array} \\
\end{array}$ \\
\hline $\begin{array}{l}\text { Types of degree are University, } \\
\text { technical or technological (reality) }\end{array}$ & 0.924 & 0.927 & 0.004 \\
\hline $\begin{array}{l}\text { Accredited university are higher } \\
\text { quality than non-accredited (reality) }\end{array}$ & 0.586 & 0.581 & -0.005 \\
\hline $\begin{array}{l}\text { All higher education institutions are } \\
\text { located in the } 5 \text { main cities of } \\
\text { Colombia (myth) }\end{array}$ & 0.602 & 0.608 & 0.006 \\
\hline $\begin{array}{l}\text { Public universities admit a lower } \\
\text { proportion of applicants compared to } \\
\text { private (reality) }\end{array}$ & 0.407 & 0.412 & 0.005 \\
\hline $\begin{array}{l}\text { Less than } 25 \% \text { of governmental loans } \\
\text { are granted to low-income students } \\
\text { (myth) }\end{array}$ & 0.365 & 0.394 & 0.029 \\
\hline
\end{tabular}

\footnotetext{
${ }^{13}$ Notice that the following variables are not reported in the administrative data, and statistics are taken from the study survey: live close to school, present orientation and overestimation of returns.
} 
Table 3.3 continued from previous page

\begin{tabular}{|c|c|c|c|}
\hline $\begin{array}{l}\text { Statement } \\
\text { (reduced version) }\end{array}$ & Treat. & Treat. & $\begin{array}{l}\text { Difference } \\
(\mathrm{T} 2-\mathrm{T} 1)\end{array}$ \\
\hline $\begin{array}{l}\text { The salary earn after higher education } \\
\text { is not enough to pay educational loan } \\
(\text { myth) }\end{array}$ & 0.497 & 0.540 & 0.043 \\
\hline $\begin{array}{l}\text { A subsidy of } 312,000 \mathrm{COP} \text { (108USD) } \\
\text { is not enough to cover living and board } \\
\text { (reality) }\end{array}$ & 0.830 & 0.802 & -0.028 \\
\hline $\begin{array}{l}\text { Graduates from accredited institutions } \\
\text { earn more salary than those who do } \\
\text { not (reality) }\end{array}$ & 0.511 & na & na \\
\hline $\begin{array}{l}\text { Percentage of low-SES students enrolled } \\
\text { in accredited institutions is less han } 10 \% \\
\text { (myth) }\end{array}$ & 0.552 & na & na \\
\hline $\begin{array}{l}\text { Preferential credits to students who enroll } \\
\text { accredited institutions (reality) }\end{array}$ & na & 0.705 & na \\
\hline $\begin{array}{l}\text { Tuition fees of accredited HEI cost more } \\
\text { than } 5,000,000 \mathrm{COP} \text { (1666 USD) per s } \\
\text { emester (myth) }\end{array}$ & na & 0.628 & na \\
\hline Number of correct answer $(\max =9)$ & 5.2730 & 5.5969 & 0.324 \\
\hline $\mathrm{N}$ & 1022 & 454 & \\
\hline
\end{tabular}

\subsubsection{Effect of information on student preferences}

Figure 3.4 shows the estimation results of Equation ${ }^{14} 2.1$ The results for the attribute-level coefficients are in line with the intuition. A scholarship has a positive sign, which suggests that students prefer packages that offer scholarships over those that do not, or over packages which offer a lower scholarship. In fact, for scholarships valued at over $36.2 \%$ of tuition, the scholarship coefficient surpasses the magnitude of all other coefficients. In addition, the higher the quality of the HEI (represented by stars), the higher the coefficient, which is consistent with the monotonicity assumption of the random utility model (see section 3.2). Moreover, public universities are preferred to private, and receiving stipend is preferred over not receiving one. Likewise, HEI located further away from home (10 hours or 14 hours away) are less preferred to those located near home. The difference between HEI located less than 0 hours from home and those located 2 hours and 4 hours away from home was insignificant.

\footnotetext{
${ }^{14}$ To check the consistency of the results obtained with the linear model, we performed an analysis using a conditional logit model and a mixed logit model and compared the results (Appendix 1). None of the models substantively change the results compared to the linear specification, which is why for the sake of simplicity of interpretation we chose to display only the linear probability.
} 
Due to the ordinal nature of the model, all else constant, we rank the attributes in the following order according to student preferences: scholarship ( 0.35 for a $50 \%$ scholarship), HEI quality (0.14 for 3 stars, 0.17 for 4 stars and 0.52 for 5 stars), receiving a stipend (0.23), public HEI (0.19) and distance to the HEI (-0.09 for 10 hours away and -0.19 for 14 hours away). It should be noted that, due to the ordinal nature of the model, one cannot interpret the magnitudes of coefficients. Figure 3.4 (and full regression results in Table 3.7 in Appendix) suggests that, on one hand the provision of information on the basics of higher education (such admission rates in public and private universities) with additional focus on returns and access (treatment one) have a modest effect on students preferences. On the other hand, provision of information on the basics of higher education with stress on available credits and costs of the sector does have a significant effect on students' preferences. In particular, compared to the control group, treated students are more likely to choose higher education options that contain higher quality universities.

Next, consider the effect of the treatments on preferences, that is, the interaction coefficients: $\beta_{1 k}$ (i.e. the effect of "demystifying" 9 higher education facts, the last two including returns to and enrollment rates in accredited universities) and $\beta_{2 k}$ (i.e. differing from treatment 1 in the last 2 facts, which include instead demystification of financial aid and university costs in accredited universities). Figure 3.4 (rows 11 and onwards) shows students reacting differently to some particular attributes compared to the control group, which is not exposed to information. Treating students with information on returns and access to accredited universities (Treatment 1) shifts students' preferences against public and further-away-from-home HEIs compared to the control group. Likewise, treating students with information on governmental loans and the cost of attending accredited universities (Treatment 2) results in a lower preference for public institutions. Nevertheless, students given treatment 2 show a strong preference for HEIs of higher quality, represented by significant coefficients in each one of the interactions between treatment 2 and the levels of the quality attribute (i.e. 3 stars, 4 stars and 5 stars). 
Figure 3.4: Effect of information on stated preferences for higher education attributes. Treatment 1: returns \& access. Treatment 2: credits \& costs.

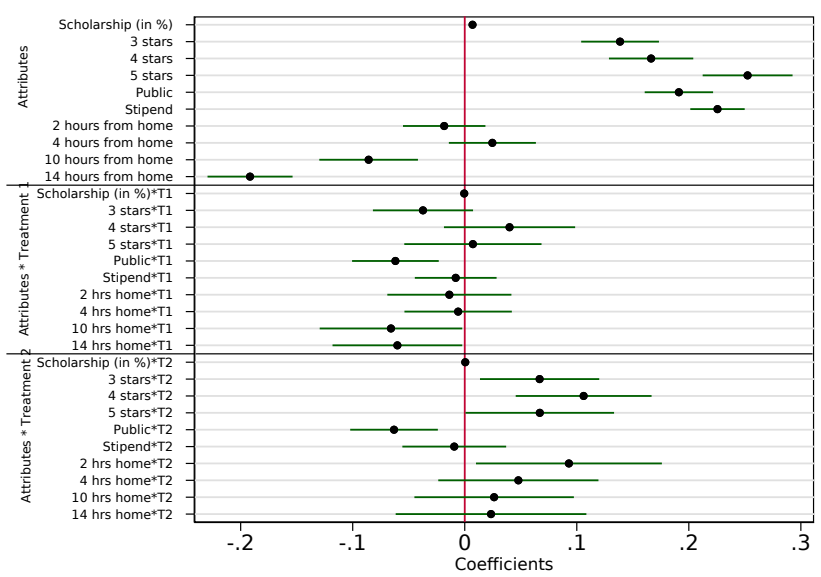

Note: dots with horizontal lines indicate point estimates with choice-set fixed effect, cluster standard error at school level and 90\% confidence intervals from least squares regression. Intervals falling in the zero line are not significantly different from the baseline category. The references categories for each attribute-level is: 2 stars, private HEI, no stipend, 0 hours away from home, and the interaction of those reference categories times each treatment. Attributes*Treatment1 refers to the interaction between each attribute-level and treatment 1 dummy. Attributes*Treatment2 refers to the interaction between each attribute-level and treatment 2 dummy. Appendix Table 3.7 displays the underlying regression results.

The willingness to give up analysis, presented in Figure 3.5 and Figure 3.6, displays how much of a presumably $100 \%$ tuition scholarship students are willing to give up in terms of the attribute levels (i.e.HEI quality, stipend, public institution and location). That is, assuming a baseline scenario where students hold a full scholarship to a 2-stars-private-HEI, with no stipend and in the same city as they live, everything else constant, the student is willing to give up $20 \%$ of a full scholarship in order to switch from a 2 star HEI to a 3 star HEI. Likewise, all else constant, he/she will 
Figure 3.5: Willingness to give up (WTGU) as a proportion of a full tuition scholarship. Coefficients of attributes and attributes*treatment 1 (returns \& access)

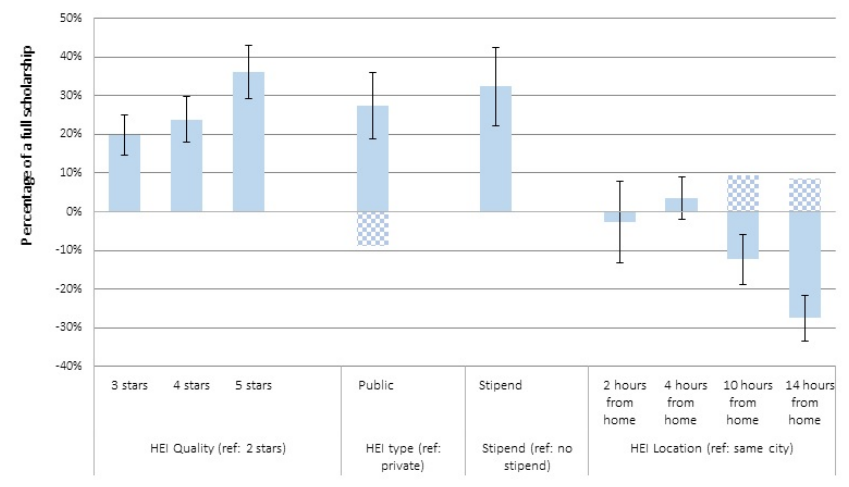

Note: solid color bars indicate WTGU from a $100 \%$ tuition scholarship. Of each attribute-level. Estimates include choice-set fixed effect, cluster standard error at school level and 90\% confidence intervals from least squares regression. The texture bars indicate the WTGU added by treatment 1 , and only significant point-estimates at the $90 \% \mathrm{CI}$ are shown. Note for interpretation: everything holding in the baseline category, students are on average willing to give up $27.5 \%$ of a $100 \%$ tuition scholarship in order to switch from a private to a public institution. Nevertheless, receiving information in treatment 1 (returns \& access) causes a drop in this coefficient by 8.9 percentage points. Appendix Table 3.7 displays the underlying regression results.

be willing to give up $24 \%$ of a full scholarship in order to be switched from a 3 stars HEI to a 4 stars HEI.

Figure 3.5 and Figure 3.6 display the effect in terms of willingness to give up caused by treatment 1 and treatment 2 , respectively. When exposed to basic awareness of financial aid offer to study in accredited universities, students were willing to give up an additional 10\%, $15 \%$ and $10 \%$ of a full scholarship to be switched from a 2 to a 3,4 or 5 star HEIs, respectively. In other words, treating students with information 
Figure 3.6: Willingness to give up (WTGU) as a proportion of a full tuition scholarship. Coefficients of attributes and attributes*treatment 2 (credits \& costs)

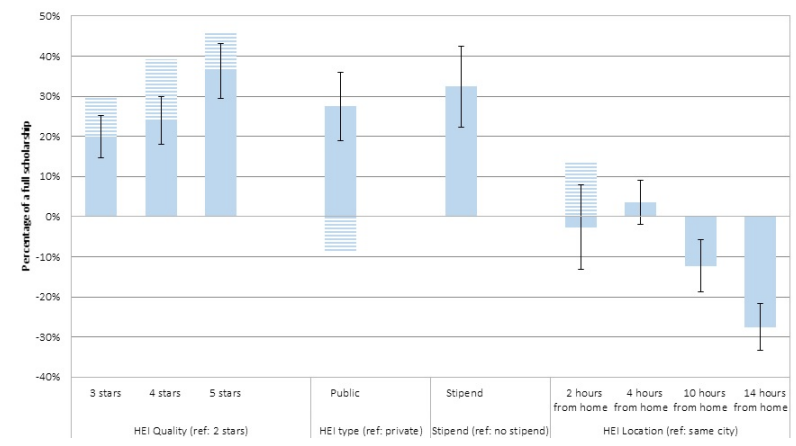

Note: solid color bars indicate WTGU from a 100\% tuition scholarship. Of each attribute-level. Estimates include choice-set fixed effect, cluster standard error at school level and $90 \%$ confidence intervals from least squares regression. The texture bars indicate the WTGU added by treatment 2, and only significant point-estimates at the $90 \% \mathrm{CI}$ are shown. Note for interpretation: everything holding in the baseline category, students are on average willing to give up $19.9 \%$ of a $100 \%$ tuition scholarship in order to switch from a 2 stars institution to a 3 stars institution. Nevertheless, receiving information in treatment 2 (credits \& costs) causes an increase in this coefficient by 9.6 percentage points. Appendix Table 3.6 displays the underlying regression results.

on governmental loans and the cost of attending accredited universities increases students' willingness to trade away some of their hypothetical scholarships for higher quality options. In contrast, in both treatments, students would need to be compensated by $9 \%$ of a full scholarship to switch from private to public HEIs, indicating that both treatments decrease the preference for public Institutions. Likewise, students treated with information on returns and access to accredited universities prefer to be even more compensated (between $2 \%$ and $9 \%$ ) for choosing faraway HEIs compared to the control group. ${ }^{15}$

\footnotetext{
${ }^{15}$ As a robustness check, we use the coarsened exact matching (CEM) methodology
} 


\subsubsection{Heterogeneous effects}

We explore the heterogeneous effects, as previous literature suggested that provision of information on higher education has a stronger effect on females (e.g. Avitabile et al., 2018) and on those from underprivileged socio-economic backgrounds (e.g. Peter, Rusconi, Solga, Spieß, \& Zambre, 2016) likely due to their lower prior expectations of attending higher education. Figures $3.7 \mathrm{a}$ and $3.7 \mathrm{~b}$ show how preferences vary across sex and socioeconomic status (SES), respectively. Female and low SES students treated with information on governmental loans and the cost of attending accredited universities (Treatment 2) react more strongly to quality compared to their counterparts. However, females and students from above-average SES backgrounds exhibit less preference for public universities in both treatment 1 and 2 .

Beyond demographic characteristics, personality features influence the results. Figure 3.7C explores whether information affects differently those who overestimate and underestimate salaries ${ }^{16}$. Students who overestimate returns show a significant response to treatment 2. Moreover, Figure 3.7d displays the preferences of students who have present orientation above and below the average reported in the survey. Students with greater present orientation react significantly to treatment 2, whereas others do not.

To test the strength of the results, several alternative model specifications have been estimated. First, over the premise that provision of information should affect the less informed more, we divided the sample according to the number of correct answers in the myths/reality activity. After excluding the control group (as the activity was not provided for them) we divided them into 3 groups according the number of correct answers regarding the 9 myths: less informed (less than 5 correct answers), moderately informed (between 5 and 6 answers) and well informed (more than 6 correct answer). The results in Table 3.3 confirm that the preferences of the less informed students change more than other groups, likely due to the awareness of higher education misperceptions.

proposed by Iacus, King \& Porro (2012) to control for imbalanced covariates. The analysis delivers similar results (see appendix).

${ }^{16}$ Perceived errors in returns were calculated by comparing students' guesses of returns from the desired program versus actual earnings for a particular program in the administrative records. 
Figure 3.7: Heterogeneous effect of provision of information on student's preferences, by subgroups. Treatment 1: returns \& access. Treatment 2 : credits \& costs.

(a) Effect by gender

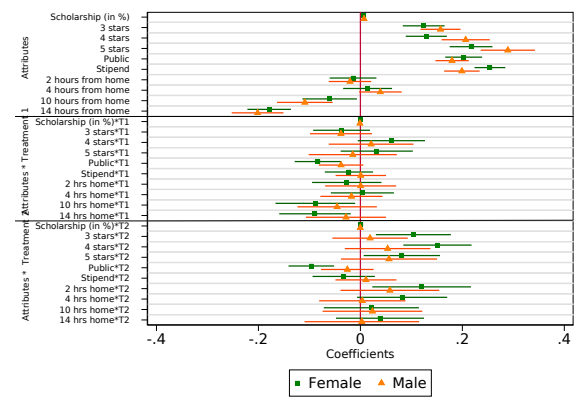

(c) Effect by overestimation of returns

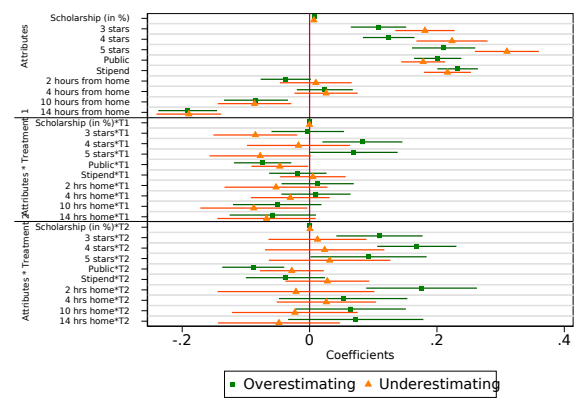

(b) Effect by SES

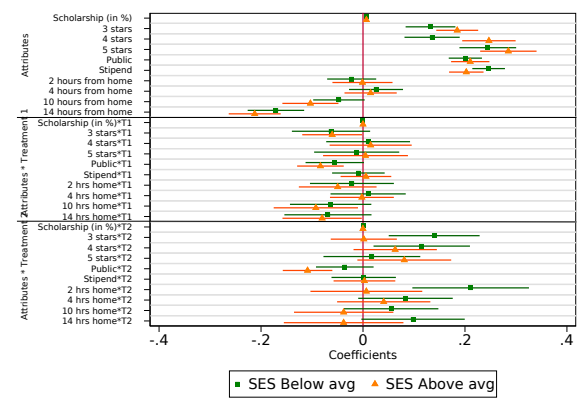

(d) Effect by present oriented characteristic

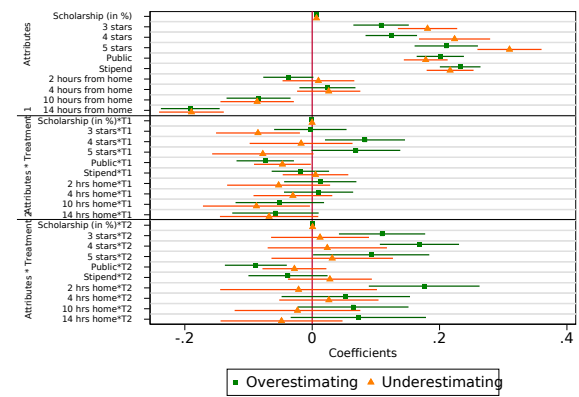

Note: dots with horizontal lines indicate point estimates with choice-set fixed effect, cluster standard error at school level and $90 \%$ confidence intervals from least squares regression. Intervals falling in the zero line are not significantly different from the baseline category. The references categories for each attribute-level is: 2 stars, private HEI, no stipend, 0 hours away from home, and the interaction of those reference categories times each treatment. Attributes*Treatment1 refers to the interaction between each attribute-level and treatment 1 dummy. Attributes*Treatment2 refers to the interaction between each attribute-level and treatment 2 dummy. Each panel represents two subgroups of the total sample. 
Table 3.4: Heterogeneous effect of provision of information on student's preferences, by their level of (miss)information on the statements

\begin{tabular}{|c|c|c|c|c|c|c|}
\hline & $\begin{array}{l}7,8 \text { or } 9 \\
\text { correct } \\
\text { Choice }\end{array}$ & s.e. & $\begin{array}{l}5 \text { or } 6 \\
\text { correct } \\
\text { Choice }\end{array}$ & s.e. & $\begin{array}{l}4 \text { or less } \\
\text { correct } \\
\text { Choice }\end{array}$ & s.e. \\
\hline \multicolumn{7}{|l|}{ ATTRIBUTES } \\
\hline \multirow{2}{*}{\multicolumn{7}{|c|}{ LEVELS }} \\
\hline \multicolumn{4}{|l|}{ Scholarship (\% of tuition) } & & & \\
\hline Scholarship (in \%) & $0.00564^{* * *}$ & $(0.0004)$ & $0.00649^{* * *}$ & $(0.0004)$ & $0.006^{* * *}$ & $(0.0004)$ \\
\hline \multicolumn{7}{|l|}{ HEI Quality (ref: 2 stars) } \\
\hline 3 stars & $0.138^{* * *}$ & $(0.0340)$ & $0.119^{* * *}$ & $(0.0277)$ & $0.0982^{* * *}$ & $(0.0298)$ \\
\hline 4 stars & $0.230^{* * *}$ & $(0.0441)$ & $0.243^{* * *}$ & $(0.0347)$ & $0.209 * * *$ & $(0.0313)$ \\
\hline 5 stars & $0.296^{* * *}$ & $(0.0426)$ & $0.307^{* * *}$ & $(0.0405)$ & $0.206 * * *$ & $(0.0328)$ \\
\hline \multicolumn{7}{|l|}{ HEI Location } \\
\hline 2 hours from home & -0.0221 & $(0.0358)$ & -0.00494 & $(0.0365)$ & -0.0225 & $(0.0359)$ \\
\hline 4 hours from home & 0.0465 & $(0.0358)$ & 0.0199 & $(0.0208)$ & 0.0374 & $(0.0285)$ \\
\hline 10 hours from home & $-0.234^{* * *}$ & $(0.0566)$ & $-0.195^{* * *}$ & $(0.0359)$ & $-0.208^{* * *}$ & $(0.0418)$ \\
\hline 14 hours from home & $-0.207 * * *$ & $(0.0419)$ & $-0.226 * * *$ & $(0.0406)$ & $-0.243^{* * *}$ & $(0.0411)$ \\
\hline \multicolumn{7}{|l|}{ HEI type (ref: private) } \\
\hline Public & $0.156^{* * *}$ & $(0.0308)$ & $0.119 * * *$ & $(0.0178)$ & $0.116^{* * *}$ & $(0.0178)$ \\
\hline \multicolumn{7}{|l|}{ Stipend (ref: no stipend) } \\
\hline Stipend & $0.189^{* * *}$ & $(0.0312)$ & $0.203^{* * *}$ & $(0.0228)$ & $0.193^{* * *}$ & $(0.0226)$ \\
\hline Constant & $-0.166^{* * *}$ & $(0.0401)$ & $-0.141 * * *$ & $(0.0296)$ & $-0.0738^{* *}$ & $(0.0334)$ \\
\hline \multicolumn{7}{|l|}{$\begin{array}{l}\text { Treatment } 2 \text { vs } \\
\text { treatment } 1 \text { effects }\end{array}$} \\
\hline \multicolumn{7}{|l|}{ Scholarship (\%tuition) } \\
\hline 852 & & & & & & \\
\hline Scholarship*T2 & $0.00251^{* * *}$ & $(0.0008)$ & 0.000739 & $(0.0006)$ & -0.0006 & $(0.0007)$ \\
\hline \multicolumn{7}{|l|}{ HEIs Quality \&3 T2 } \\
\hline 3 stars*T2 & $0.0975 *$ & $(0.0505)$ & 0.0859 & $(0.0537)$ & $0.123^{* *}$ & $(0.0534)$ \\
\hline 4 stars* ${ }^{*} 2$ & 0.0942 & $(0.0630)$ & 0.0149 & $(0.0575)$ & $0.101^{* *}$ & $(0.0459)$ \\
\hline 5 stars*T2 & 0.0154 & $(0.0656)$ & 0.0113 & $(0.0663)$ & $0.174^{* * *}$ & $(0.0559)$ \\
\hline \multicolumn{7}{|l|}{ HEIs Location \&S T2 } \\
\hline 2 hrs_home*T2 & 0.0943 & $(0.0639)$ & 0.0659 & $(0.0651)$ & $0.119 *$ & $(0.0666)$ \\
\hline 4 hrs_home*T2 & 0.0806 & $(0.0698)$ & 0.0423 & $(0.0515)$ & 0.0364 & $(0.0761)$ \\
\hline 10 hrs_home*T2 & 0.0472 & $(0.0740)$ & $0.111^{*}$ & $(0.0574)$ & 0.0936 & $(0.0807)$ \\
\hline 14 hrs_home*T2 & 0.0818 & $(0.0611)$ & 0.0815 & $(0.0732)$ & 0.0476 & $(0.0747)$ \\
\hline \multicolumn{7}{|l|}{ HEIs Type 85 T2 } \\
\hline Public*T2 & -0.0234 & $(0.0429)$ & 0.0362 & $(0.0294)$ & -0.0157 & $(0.0309)$ \\
\hline \multicolumn{7}{|l|}{ Stipend \& T2 } \\
\hline Stipend*T2 & -0.0335 & $(0.0534)$ & 0.00459 & $(0.0390)$ & 0.0202 & $(0.0479)$ \\
\hline Observations & 7.11 & & 10.998 & & 8.46 & \\
\hline Number of obsid & 3.555 & & 5.499 & & 4.23 & \\
\hline R-squared & 0.286 & & 0.286 & & 0.244 & \\
\hline
\end{tabular}

Significance levels report differences to the control group from least squared regression with choice -set fixed effects and standard errors clustered at school level, ${ }^{*} \mathrm{p}<0.1,{ }^{* *} \mathrm{p}<0.05,{ }^{* * *} \mathrm{p}<0.01$. Standard errors in parentheses.

In addition, we exploit that students could request additional information at the end of the survey. Students in both treatment groups were generally more interested in information regarding quality and loans (Table 3.4, top panel), and results are stronger for those who took the paper- 
based survey (Table 3.4, bottom panel). Interestingly, students in both treatment groups, but more pronounced among the students who were treated with information on governmental loans and the cost of attending accredited universities (Treatment 2), ask 7 to 12 percentage points more for the loan information, which corresponds to an increment of $21.7 \%$ to $40.8 \%$ compared to control groups.

Finally, we used the Coarsened Exact Matching (CEM) approach to control for maternal education and Sisben poverty index imbalances at the baseline. The results are in line as those found without the matching (see appendix, Figure 3.9c). 


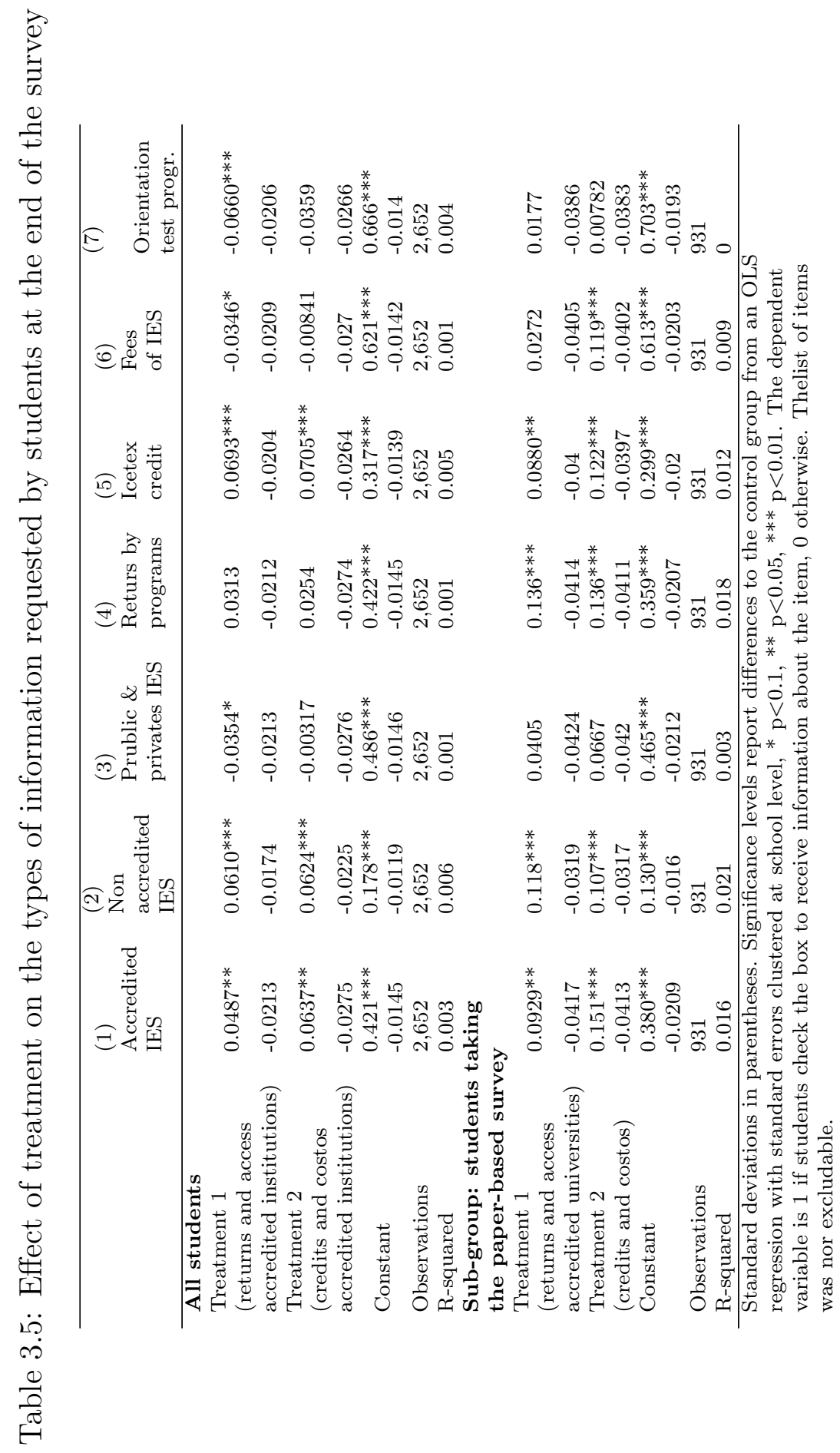




\subsection{Discussion and conclusion}

This paper observed that student preferences for higher education can be changed by correcting general misperceptions. This is especially true in a context where students lack information on fundamental aspects of higher education such as the definition of an accredited university, or the fact that admission to inscription rates are lower in public institutions. Using a combination of an information experiment with a discrete choice experiment, we overcome important limitations of earlier research that used choice records. Contrarily to earlier research, we examined how attributes are traded off against each other, and study lower income students' decisions, which are highly underrepresented in earlier work.

The results suggest a rank of student preferences over attributes: scholarships were valued most, followed by HEIs quality, the stipend, the HEIs type (public/private) and finally the HEIs location (far from home 10hours /14 hours). As also observed by Walsh et al. (2018) and Dunnett et al. (2012), quality and reputation play an important role in student preferences for higher education.

In terms of the impact of providing information, we find that students are susceptible to boost their preference for certain attributes by means of certain statements. Both a treatment with information on returns and access to accredited universities (treatment 1) and a treatment with information on governmental loans and the cost of attending accredited universities (treatment 2) boost preferences for private over public universities. This is probably due to one general statement presented to both groups in which we present that the admission rate was actually lower in public compared to private universities: "In a public HEI, for every 100 students that apply for admission, an average of 43 are admitted. In the private HEI, for every 100 that apply, an average of 76 are admitted". Providing this information to the two treatment groups explains the reduction in preference for public institutions in both groups compared to the control group. Importantly, this reduction does not entirely drop the general preference for public universities (the treatment effect is 0.06 compared to the coefficient for the preference of public universities of 0.19). Moreover, for the other six statements that were presented identically to both treatment groups (see Table 3.5), we do not find enough evidence to suggest the presence of a strong effect of any other shared 
piece of information on students' stated preferences.

Similarly, we do not find an effect of treating students additionally with information on returns to and enrollment rates in accredited universities, which are only presented to treatment 1 . This result is in line with Bonilla et al. (2019), who find no effect of providing information on the returns of higher education on the enrollment rates of treated Colombian students. They suggest initial overestimation of the returns as a possible explanation. Our study does not contradict this, but we identify having a greater orientation toward the present as a complementary explanation. This possible justification is also referred to by Golsteyn, Grönqvist \& Lindhal (2014), Cadena \& Keys (2015), and Sutter, Kocher, GlätzleRützler \& Trautmann (2013), among others studies, where a high discount factor makes youth pay more attention to immediate restrictions. In other words, students might have perceived future earnings as irrelevant to the immediate choice decision.

In contrast, students do react to information on governmental loans and the cost of attending accredited universities, which was exclusively provided in treatment 2 . This information refers to the preferential access to credit by students in accredited institutions and the range of fees of those institutions. Correcting misperceptions in these regards may have influenced students' immediate concerns over financial constraints to access to higher education. This finding is in line with the literature measuring the impact of providing financial aid information on students' decisions in developing countries (e.g. Avitabile et al., 2018; Busso et al., 2017; Hastings et al., 2015; Hastings, 2016; Rao, 2016). The idea that impatience drives the results is reinforced by the heterogeneous analysis, which identify the present oriented students as the ones who react the most to treatment 2 .

Subsample analysis suggests that students who are historically more likely not to attend college (i.e. those from the most vulnerable backgrounds) are the ones most likely to switch preferences in reaction to the provision of information. Their demand for higher education is yet less ambitious than their peers (less but still unprivileged students), after controlling for financial restrictions. Females and low-SES students were particularly likely to change preferences after receiving the information provided. 
Analyzing the effect of the provision of information on preferences rather than actual choices makes this research unique. Overcoming misperceptions over higher education can in fact change student's preferences for certain kinds of institutions. By contrast, the effect of information on actual student choices is not identifiable, due to factors including disproportionally large tuition costs or complicated application processes (Dynarski et al., 2018).

From a policy perspective, and for the particular case of the Colombian higher education system, there are many lessons. First, it is important to correct misperceptions about the basics of the higher education system as it changes students' preferences and, likely, their educational decisions. Second, compared to the canceled SPP program which switched enrolment of low-income students from low quality to high quality universities (Londoño-Velez et al., 2017), new scholarship programs could be less generous and still students would be willing to accept them. The SPP gave a 100\% scholarship, which encouraged low-income students to switch from a low-quality university into a high quality university. Our results suggest that low-income students are willing to bear part of the fees. In fact, there are other attributes, such as subsidies for study expenditures, that are "well worth" the sacrifice for future debt. Equally important is that students may be willing to take on even more debt if they are (more) aware of financial opportunities. Policies that inform students of the possibilities of accessing credit can be effective to increase their interest for higher education. Nevertheless, if tuition costs are excessively high, new preferences can be far from become feasible choices.

Further research will follow students who participated in the study through the higher education system (if they enroll), looking for long term effect of this intervention. Moreover, based on our findings and dataset, we intend in future research to simulate the effects of different higher education financial policies, adjusting for student's (mis)information, credit constrains and preferences (willingness to pay). In so doing we hope to discover more cost-effective, sustainable and equitable higher education policies. 


\section{References}

[1] Angrist, J. D., \& Pischke, J. S. (2010). The credibility revolution in empirical economics: How better research design is taking the con out of econometrics. Journal of economic perspectives, 24(2), 3-30.

[2] Avitabile, C., \& De Hoyos, R. (2018). The Heterogeneous effect of information on student performance: evidence from a randomized control trial in Mexico. Journal of Development Economics, 135, $318-348$.

[3] Bergerson, A. A. (2009). College choice and access to college: Moving policy, research, and practice to the 21st century. ASHE Higher Education Report, 35(4), 1-141.

[4] Bernal, G. Abadía, L., Alvarez, E., \& DeWitte, K. (Mimeo). When Chances For Higher Education Drop: The Cancellation Of Ser Pilo Paga Scholarship On Student Preferences For Higher Education.

[5] Bettinger, E. P., Long, B. T., Oreopoulos, P., \& Sanbonmatsu, L. (2012). The role of application assistance and information in college decisions: Results from the HR Block FAFSA experiment. The Quarterly Journal of Economics, 127(3), 1205-1242.

[6] Bleemer, Z., \& Zafar, B. (2018). Intended college attendance: Evidence from an experiment on college returns and costs. Journal of Public Economics, 157, 184-211.

[7] Bonilla-Mejía, L., Bottan, N. L., \& Ham, A. (2019). Information policies and higher education choices experimental evidence from Colombia. Journal of Behavioral and Experimental Economics, 83, 101468. 
[8] Booij, A. S., Leuven, E., \& Oosterbeek, H. (2012). The role of information in the take-up of student loans. Economics of Education Review, 31(1), 33-44.

[9] Busso, M., Dinkelman, T., Martínez, A. C., \& Romero, D. (2017). The effects of financial aid and returns information in selective and less selective schools: Experimental evidence from Chile. Labour Economics, 45, 79-91.

[10] Cadena, B., \& Keys, B. (2015). Human Capital and the Lifetime Cost of Impatience. American Economic Journal: Economic Policy, $7(3), 126-153$

[11] Czajkowski, M., Gajderowicz, T., Giergiczny, M., Grotkowska, G., \& Sztandar-Sztanderska, U. (2020). Choosing the future: economic preferences for higher education using discrete choice experiment method. Research in Higher Education, 61(4), 510-539.

[12] Dinkelman, T., \& Martínez A, C. (2014). Investing in schooling in Chile: The role of information about financial aid for higher education. Review of Economics and Statistics, 96(2), 244-257.

[13] Dunnett, A., Moorhouse, J., Walsh, C., \& Barry, C. (2012). Choosing a university: A conjoint analysis of the impact of higher fees on students applying for university in 2012. Tertiary Education and Management, 18(3), 199-220.

[14] DNP, CNC, \& UniAndes. (2016). Evaluación de Impacto de Corto Plazo del Programa Ser Pilo Paga. Bogotá, DC, Columbia: DNP.

[15] Dynarski, S., Michelmore, K., Libassi, CJ., \& Owen, S. (2018). Closing the Gap: The Effect of a Targeted, Tuition-Free Promise on College Choices of High-Achieving, Low-Income Students. National Bureau of Economic Research w25349.

[16] Freeman III, A. M., Herriges, J. A., \& Kling, C. L. (2014). The measurement of environmental and resource values: theory and methods. Routledge. Fryer Jr, R. G. (2016). Information, non-financial incentives, and student achievement: Evidence from a text messaging experiment. Journal of Public Economics, 144, 109-121. 
[17] Golsteyn, B., Grönqvist, H., \& Lindhal, L. (2014). Adolescent Time Preferences Predict Lifetime Outcome. The Economic Journal, 124, 739-761

[18] Hastings, J. S., Neilson, C. A., Ramirez, A., \& Zimmerman, S. D. (2016). (Un)informed college and major choice: Evidence from linked survey and administrative data. Economics of Education Review, 51, 136-151.

[19] Hastings, J., Neilson, C. A., \& Zimmerman, S. D. (2015). The effects of earnings disclosure on college enrollment decisions. National Bureau of Economic Research w21300.

[20] Hemsley-Brown, J. (2015). University choice: what do we know, what don't we know and what do we still need to find out? International Journal of Educational Management, 29(3), 254-274.

[21] Herber, S. P. (2018). The role of information in the application for highly selective scholarships: Evidence from a randomized field experiment. Economics of Education Review, 62, 287-301.

[22] Hurwitz, M., \& Smith, J. (2018). Student responsiveness to earnings data in the College Scorecard. Economic Inquiry, 56(2), 1220-1243.

[23] Iacus, S. M., King, G., \& Porro, G. (2012). Causal inference without balance checking: Coarsened exact matching. Political analysis, 124 .

[24] Kamargianni, M., \& Polydoropoulou, A. (2013). Hybrid choice model to investigate effects of teenagers' attitudes toward walking and cycling on mode choice behavior. Transportation research record, 2382(1), 151-161.

[25] Kerr, S. P., Pekkarinen, T., Sarvimäki, M., \& Uusitalo, R. (2020). Post-secondary education and information on labor market prospects: A randomized field experiment. Labour Economics, 66, 101888.

[26] Kruk, M. E., Johnson, J. C., Gyakobo, M., Agyei-Baffour, P., Asabir, K., Kotha, S. R., \& Dzodzomenyo, M. (2010). Rural practice preferences among medical students in Ghana: a discrete choice experiment. Bulletin of the World Health Organization, 88, 333-341. 
[27] Lambooij, M. S., Harmsen, I. A., Veldwijk, J., de Melker, H., Mollema, L., van Weert, Y. W., \& de Wit, G. A. (2015). Consistency between stated and revealed preferences: a discrete choice experiment and a behavioural experiment on vaccination behaviour compared. BMC medical research methodology, 15(1), 19.

[28] Lancaster, K. J. (1966). A new approach to consumer theory. Journal of political economy, 74(2), 132-157.

[29] Londoño-Velez, J., Rodriguez, C., \& Sánchez, F. (2017). The Intended and Unintended Impacts of a Merit-Based Financial Aid Program for the Poor: The Case of Ser Pilo Paga. Documento CEDE $2017 / 24$.

[30] Loyalka, P., Song, Y., Wei, J., Zhong, W., \& Rozelle, S. (2015). Information, college decisions and financial aid: Evidence from a cluster-randomized controlled trial in China. Economics of Education Review, 36, 26-40.

[31] Maestas, N., Mullen, K. J., Powell, D., Von Wachter, T., \& Wenger, J. B. (2018). The value of working conditions in the united states and implications for the structure of wages (No. w25204). National Bureau of Economic Research.

[32] Mas, A., \& Pallais, A. (2017). Valuing alternative work arrangements. American Economic Review, 107(12), 3722-59.

[33] McFadden, D. (1974). The measurement of urban travel demand. Journal of public economics, 3(4), 303-328.

[34] Mizala, A., \& Urquiola, M. (2013). School markets: The impact of information approximating schools' effectiveness. Journal of Development Economics, 103(1), 313-335.

[35] OECD, 2016. Education at glace. Retrieved from: https://www.oecd.org/education/skills-beyond-school/educationat-a-glance-2016-indicators.htm

[36] Oreopoulos, P., \& Dunn, R. (2013). Information and college access: Evidence from a randomized field experiment. The Scandinavian Journal of Economics, 115(1), 3-26. 
[37] Peter, F. H., \& Zambre, V. (2017). Intended college enrollment and educational inequality: Do students lack information? Economics of Education Review, 60, 125-141.

[38] Peter, F. H., Rusconi, A., Solga, H., Spieß, C. K., \& Zambre, V. (2016). Informationen zum Studium verringern soziale Unterschiede bei der Studienabsicht von AbiturientInnen. DIW-Wochenbericht, 83(26), 555-565.

[39] Phaneuf, D. J., \& Requate, T. (2016). A course in environmental economics: theory, policy, and practice. Cambridge University Press.

[40] Rao, T. (2016). Information, heterogeneous updating and higher education decisions: Experimental evidence from India. Unpublished manuscript.

[41] Ryan, M., Kolstad, J. R., Rockers, P. C., \& Dolea, C. (2012). How to conduct a discrete choice experiment for health workforce recruitment and retention in remote and rural areas: a user guide with case studies (No. 74489, pp. 1-94). The World Bank.

[42] Sutter, M., Kocher, M., Glätzle- Rützler, D., \& Trautmann, S. (2013). Impatience and Uncertainty: Experimental Decisions Predict Adolescents' Field Behavior. American Economic Review, 103(1), 510-531

[43] Walsh, C., Moorhouse, J., Dunnett, A., \& Barry, C. (2015). University choice: which attributes matter when you are paying the full price?. International Journal of Consumer Studies, 39(6), 670-681.

[44] Walsh, S., Flannery, D., \& Cullinan, J. (2018). Analysing the preferences of prospective students for higher education institution attributes. Education Economics, 26(2), 161-178.

[45] Wiswall, M., \& Zafar, B. (2018). Preference for the workplace, investment in human capital, and gender. The Quarterly Journal of Economics, 133(1), 457-507. 


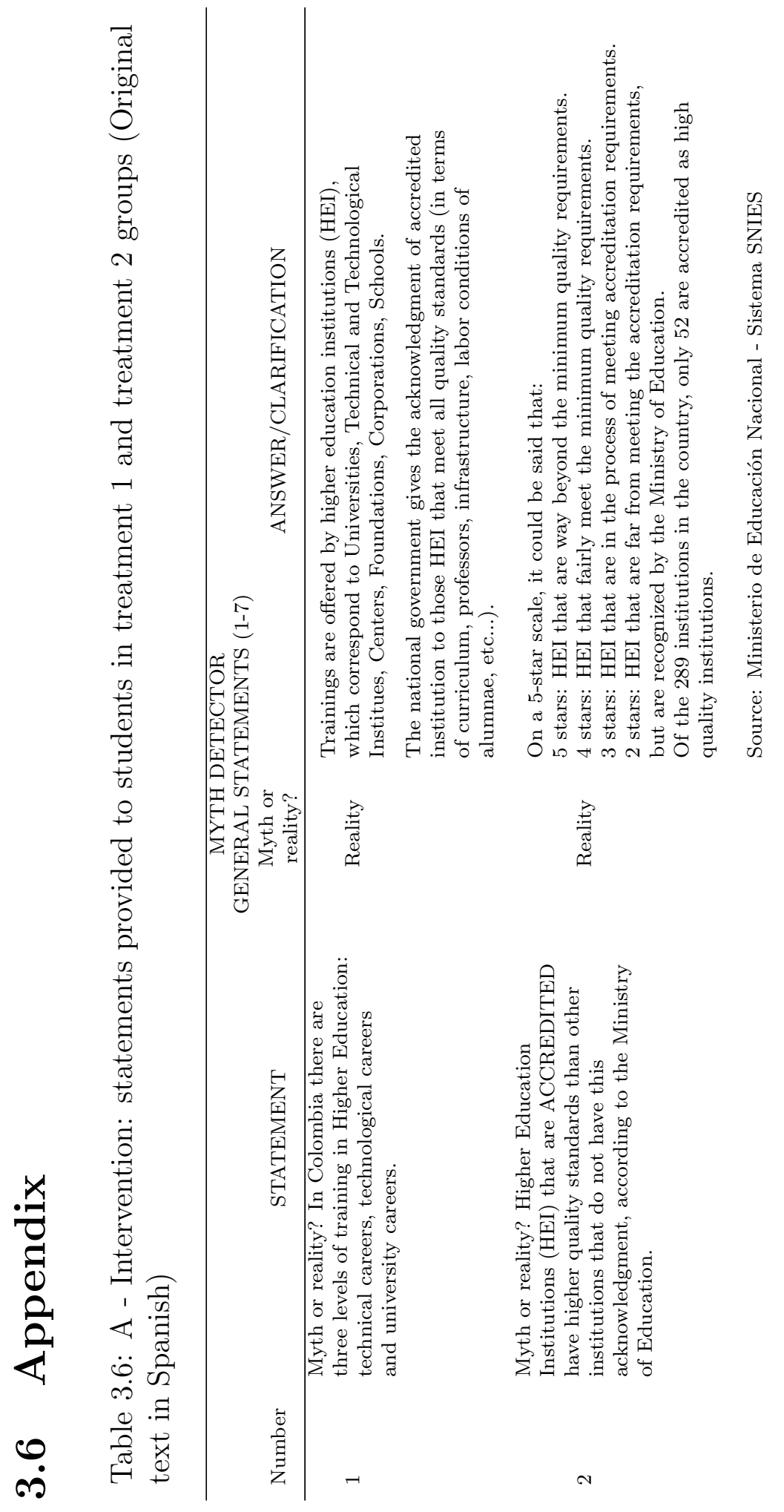




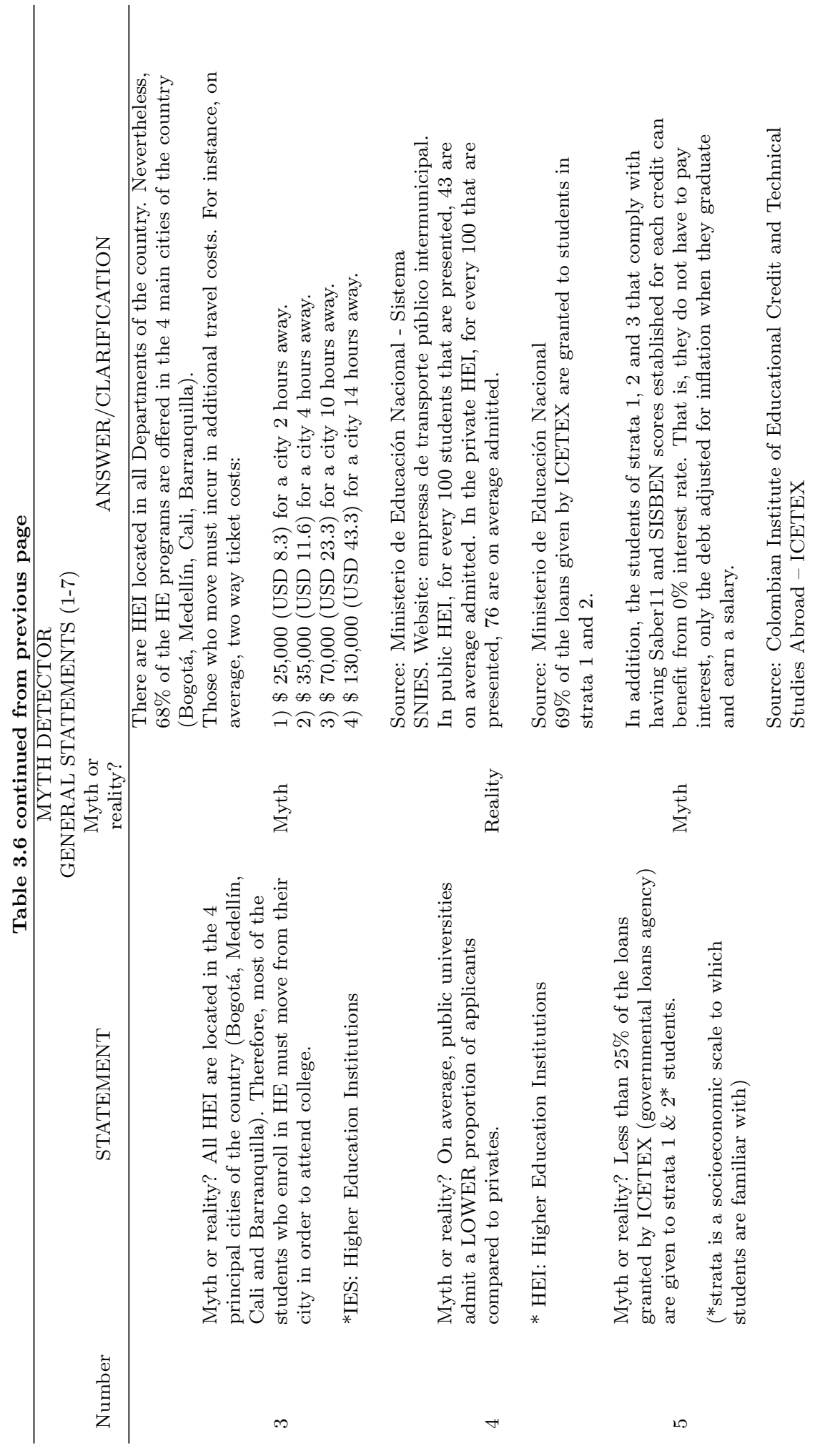




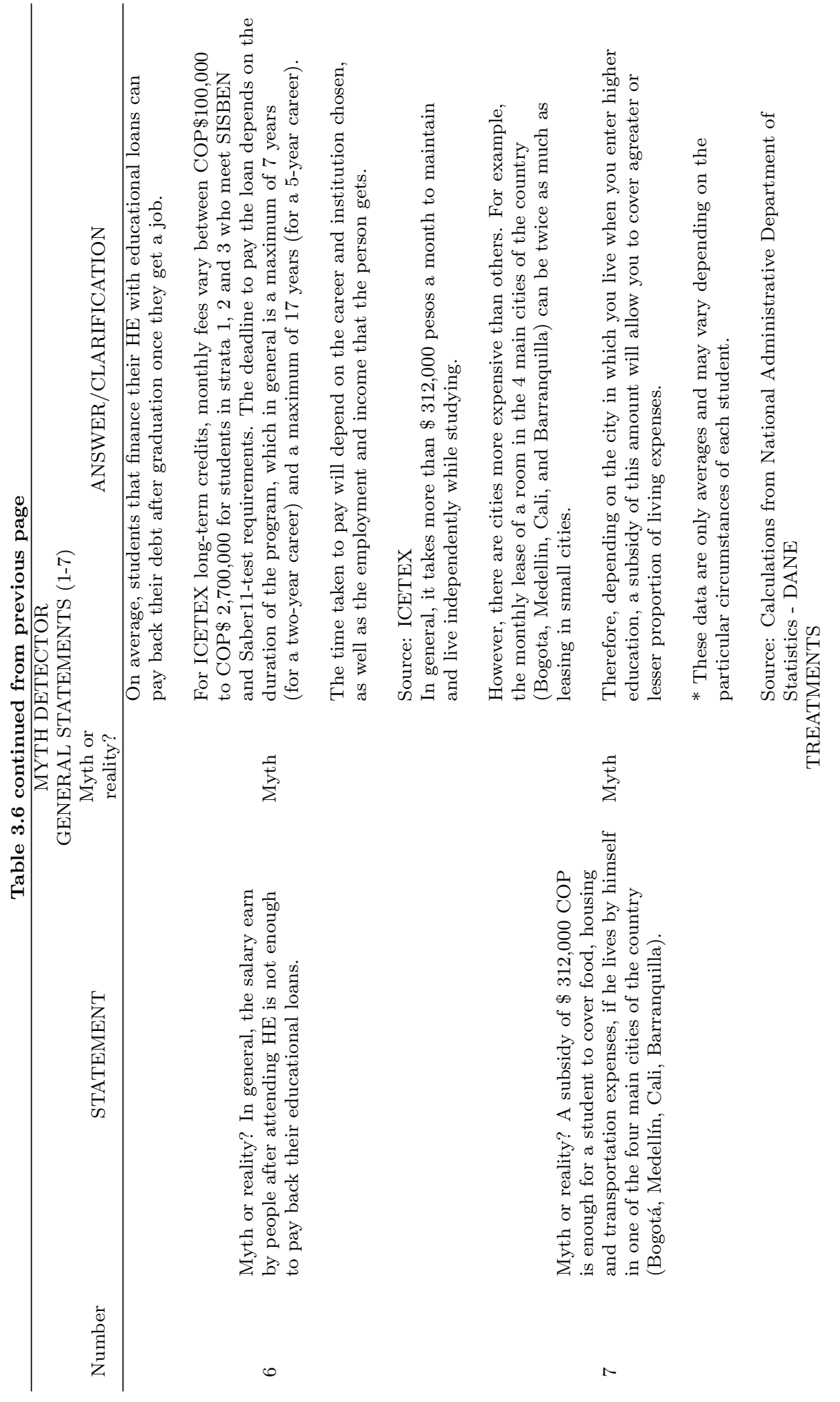




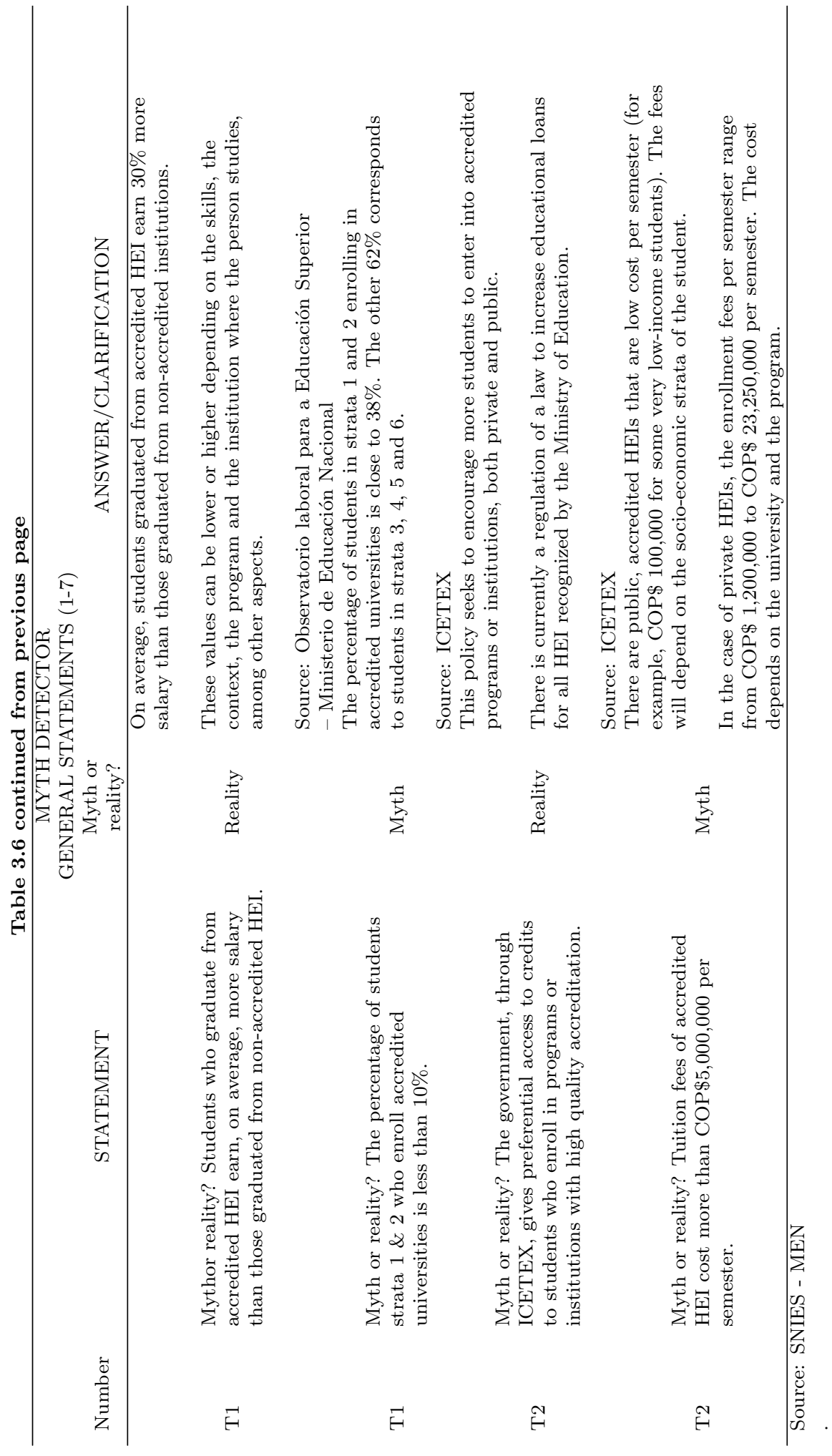


Figure 3.8: Survey sections

\begin{tabular}{|c|c|c|c|c|c|c|}
\hline \multicolumn{7}{|c|}{ SURVEY } \\
\hline $\mathbf{i}$ & ii & iii & iv & $\mathrm{v}$ & vi & vii \\
\hline CONSENT & INTERVENTION & $\begin{array}{c}\text { QUESTIONS PART } 1 \text { (18 } \\
\text { questions) }\end{array}$ & DCE & $\begin{array}{c}\text { QUESTIONS PART } 2 \text { (15 } \\
\text { questions) }\end{array}$ & OUTPUT & FINAL LINKS \\
\hline $\begin{array}{l}\text { If agree } \Rightarrow \\
\text { continue }\end{array}$ & \begin{tabular}{|c} 
Treatment 2 group: \\
9 statements (\# 8 \\
and \#9 differ from \\
treatment 1 )
\end{tabular} & $\begin{array}{l}\text { - personal characteristics } \\
\text { - location } \\
\text { - desire to study HE } \\
\text { - program, institution and city } \\
\text { they want to study HE (If } \\
\text { parents pay); assesment on } \\
\text { tuition fees \& returns } \\
\text { - program, institution and city } \\
\text { they want to study HE (If full } \\
\text { scholarship); assesment on } \\
\text { tuition fees \& returns } \\
\text { - assesment on returns of HS } \\
\text { only } \\
\text { - assesment in exit } \\
\text { examination score } \\
\text { - assesment on retuns }\end{array}$ & $\begin{array}{c}\text { Decision on the } \\
9 \text { discrete } \\
\text { choice sets. } \\
\text { Could be either } \\
\text { block } 1 \text { or block } \\
2 \text {, according to } \\
\text { blocks } \\
\text { randomization }\end{array}$ & $\begin{array}{l}\text { - discount factor } \\
\text {-socioeconomic status } \\
\text { - parents occupations } \\
\text { - family structure } \\
\text { - time \& transportation to } \\
\text { school } \\
\text { - classize } \\
\text { - altruism } \\
\text { - family levels of education } \\
\text { - books at home } \\
\text { - career orientation received } \\
\text { - knowledge on some } \\
\text { financial terms } \\
\text { - importance of some } \\
\text { attributes in HE decisions }\end{array}$ & $\begin{array}{l}\text { Check if you would like to } \\
\text { receive information on: } \\
\text { - carrier orientation test } \\
\text { - list of accredited } \\
\text { universities (by city) } \\
\text { - list of non-accredited } \\
\text { universities (by city) } \\
\text { - list of private and public } \\
\text { universities (by city) } \\
\text { - government loans (credit } \\
\text { simulator) } \\
\text { - wages of different } \\
\text { occupations } \\
\text { - enrollment fees in HE } \\
\text { programs }\end{array}$ & $\begin{array}{l}\text { Links } \\
\text { conducting to } \\
\text { official } \\
\text { websites on } \\
\text { HE } \\
\text { information } \\
\text { (same links } \\
\text { for all) }\end{array}$ \\
\hline
\end{tabular}

Table 3.7: B-Effect of information on student's preferences for higher education bundles. Willingness to give (WTGU) analysis.

\begin{tabular}{|c|c|c|c|c|}
\hline ATTRIBUTES & & & ( & \\
\hline LEVELS & Choice & s.e. & WTGU & s.e. \\
\hline Scholarship (\% of tuiti & & & & \\
\hline Scholarship (in \%) & $0.00696^{* * *}$ & $(0.000262)$ & & \\
\hline HEI Quality (ref: 2 sto & & & & \\
\hline 3 stars & $0.139 * * *$ & $(0.0210)$ & $19.91 \%$ & 0.1991 \\
\hline 4 stars & $0.166^{* * *}$ & $(0.0228)$ & $23.89 \%$ & 0.2389 \\
\hline 5 stars & $0.252^{* * *}$ & $(0.0243)$ & $36.25 \%$ & 0.3625 \\
\hline HEI type (ref: private) & & & & \\
\hline Public & $0.191 * * *$ & $(0.0185)$ & $27.45 \%$ & 0.2745 \\
\hline Stipend (ref: no stipen & & & & \\
\hline Stipend & $0.226^{* * *}$ & $(0.0147)$ & $32.40 \%$ & 0.3240 \\
\hline HEI Location (ref: sam & & & & \\
\hline 2 hours from home & -0.0183 & $(0.0223)$ & $-2.63 \%$ & 0.0263 \\
\hline 4 hours from home & 0.0247 & $(0.0235)$ & $3.54 \%$ & 0.0354 \\
\hline 10 hours from home & $-0.0858 * * *$ & $(0.0267)$ & $-12.32 \%$ & 0.1232 \\
\hline 14 hours from home & $-0.192^{* * *}$ & $(0.0230)$ & $-27.52 \%$ & 0.2752 \\
\hline Constant & $-0.124^{* * *}$ & $(0.0167)$ & & \\
\hline ATTRIBUT & EATMENT & 1 (returns & access) & \\
\hline Treatment 1 effects & & & & \\
\hline Scholarship (\%tuition) & & & & \\
\hline Scholarship (in \%)*T1 & -0.000441 & $(0.000366)$ & $-0.06 \%$ & 0.0006 \\
\hline HEIs Quality \& T1 & & & & \\
\hline 3 stars*T1 & -0.0373 & $(0.0271)$ & $-5.35 \%$ & 0.0535 \\
\hline 4 stars* $\mathrm{T} 1$ & 0.0400 & $(0.0354)$ & $5.74 \%$ & 0.0574 \\
\hline 5 stars*T1 & 0.00728 & $(0.0371)$ & $1.05 \%$ & 0.0105 \\
\hline HEIs Type \& T1 & & & & \\
\hline Public*T1 & $-0.0619 * * *$ & $(0.0234)$ & $-8.88 \%$ & 0.0116 \\
\hline Stipend \& T1 & & & & \\
\hline Stipend*T1 & -0.00806 & $(0.0221)$ & $-1.16 \%$ & 0.0888 \\
\hline
\end{tabular}


Table 3.7 continued from previous page

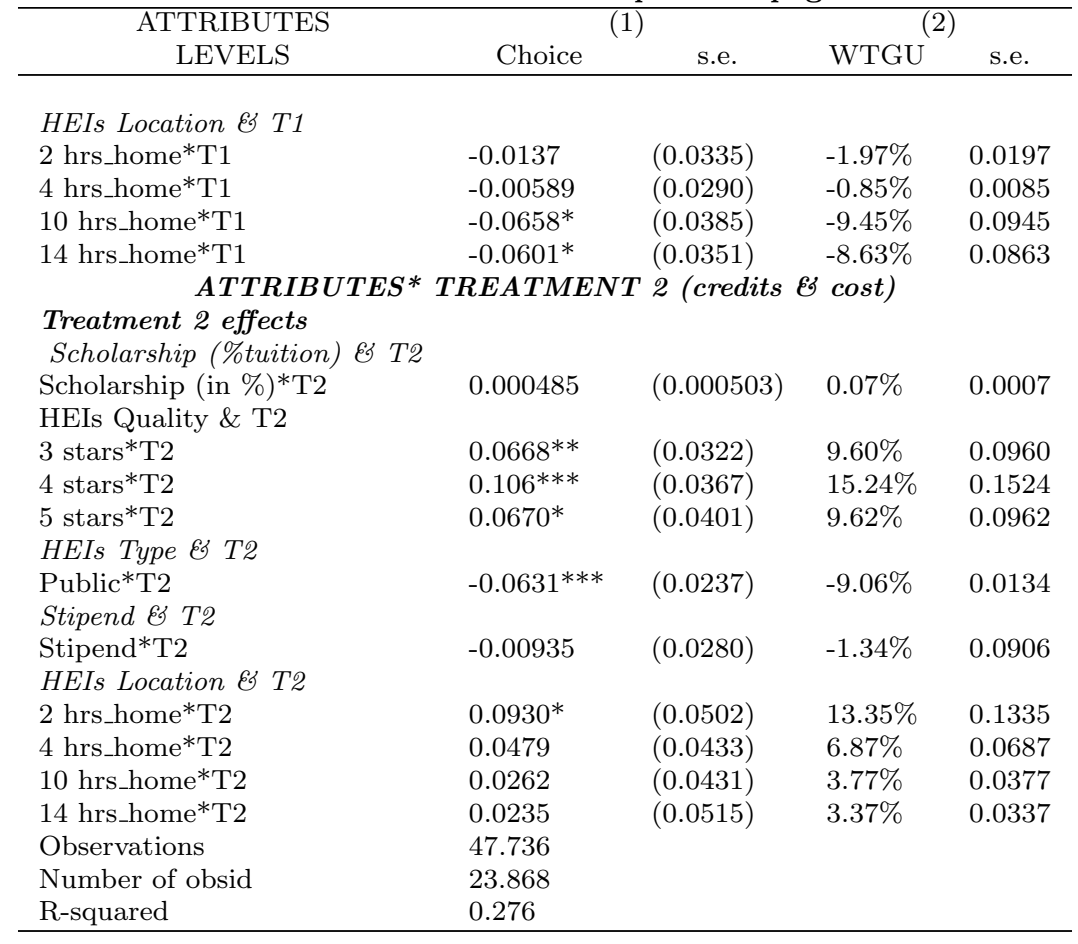


Figure 3.9: Robustness check

(a) B-Effect of information on student's preferences for higher education bundles. Estimations using Mixed Logit Model (MLM)

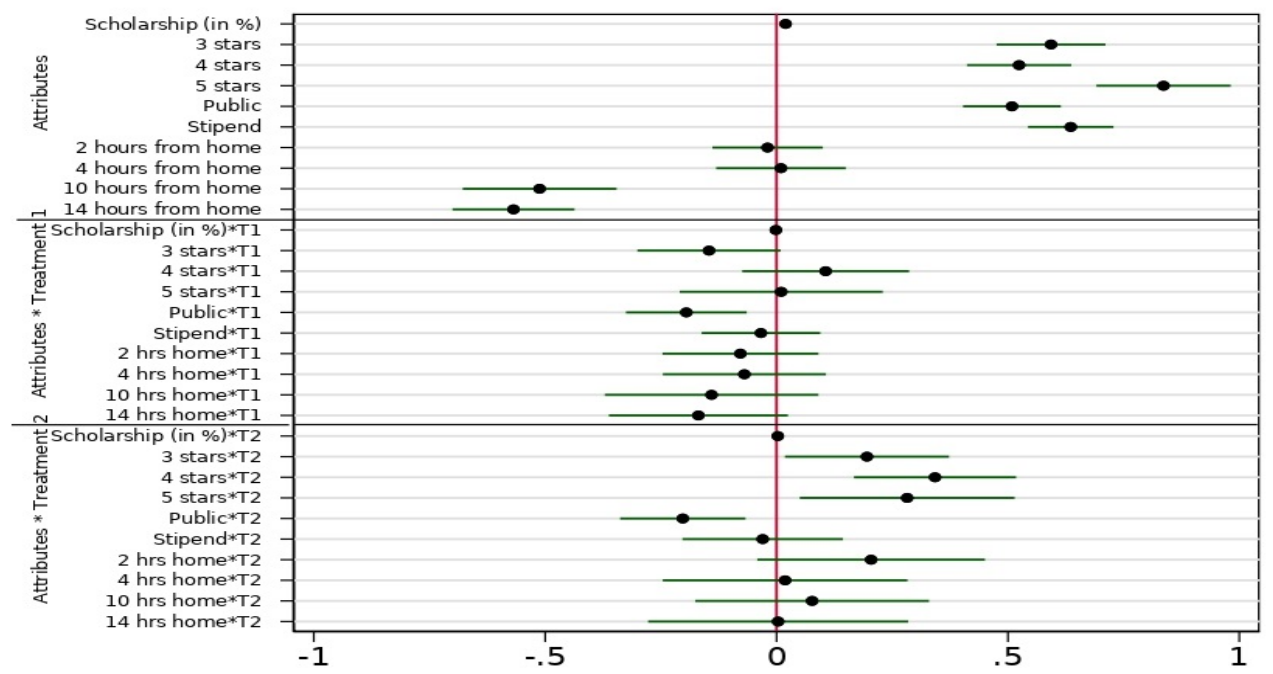

(b) C-Effect of information on student's preferences for higher education bundles, using CEM method

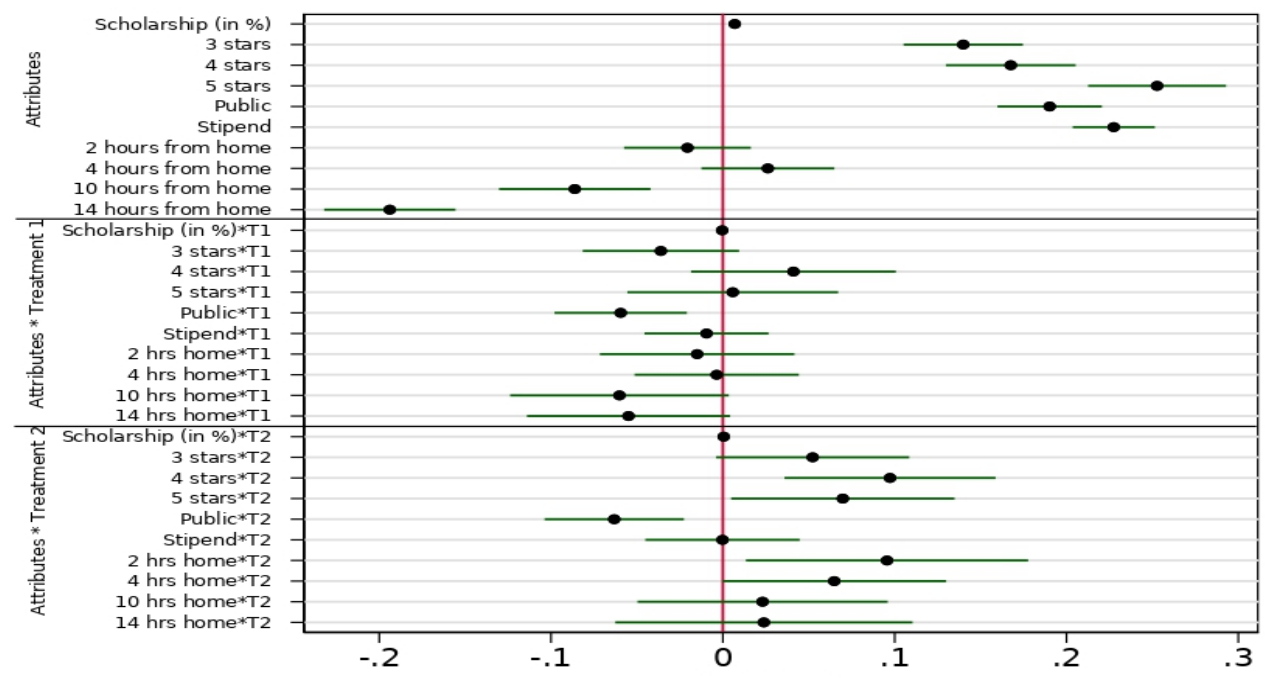




\section{Chapter 4}

\section{When Chances For Higher Education Drop: The Cancellation Of Ser Pilo Paga Scholarship On Student Preferences For Higher Education $* \dagger$}

\section{Abstract}

Low-income students' preferences for higher education might depend on the uncertainty of financial aid. Using a regression discontinuity design, we exploit the unanticipated cancellation of a nationwide Colombian merit and need-based scholarship, called Ser Pilo Paga, to study its consequences on students' preferences for higher education. Preferences

*Based on working paper: Bernal, G., Abadía, L., Alvarez, L. E. \& De Witte, K. (2020). When Chances For Higher Education Drop: The Cancellation Of Ser Pilo Paga Scholarship On Student Preferences For Higher Education.

${ }^{\dagger}$ Acknowledgements: We are also grateful to Mindel van de Laar, Wim Groot, and the seminar participants at the UNU-MERIT workshop for their valuable comments and suggestions. We are grateful to the ICFES for their constant support in this research. The analysis, views, and opinions expressed in this article are those of the authors and do not necessarily represent those of ICFES or Pontificia Universidad Javeriana. 
are measured by a discrete choice experiment administrated among senior high school students in 2018. The results show that the scholarship cancellation reduced the higher education ambitions and the interest in financial aid of prospective eligible students by diminishing preferences for high quality institutions and for financial aid.

\subsection{Introduction}

Understanding behavioral responses to educational opportunities is important for the successful design of higher education policies. Existing literature on the pre-college effect of opening educational opportunities for disadvantaged students has focused on outcomes such as their motivation and effort in high school or higher education enrollment (Hasting, Neilson \& Zimmerman, 2012; Alon \& Malamud, 2014). However, little is known on the underlying mechanisms of students' decisions. Identifying a possible channel through which the aspirations of low-income students can be modified is important in promoting investments in human capital among this population. The present study contributes to this literature by analyzing students' declared preferences and decision-making process for higher education by exploiting the unexpected cancellation of a nationwide merit and need-based scholarship program in Colombia: Ser Pilo Paga (SPP).

Making available educational aid opportunities might help targeted students to perceive higher education as attainable, and thus students are more likely to exert more effort to pursue such opportunities (Fryer \& Loury, 2005). Changes in opportunities to enroll higher education result in redirecting students' aspirations and their preferences for it (Kemptner \& Tolan, 2018), which in turn could alter their educational attainment (Boxer et al., 2011; Khattab, 2015; Ou \& Reynolds, 2008). For instance, in the presence of need-based scholarships, disadvantaged students may be more likely to choose higher quality education institutions than they would do otherwise (Dynarski, Libassi, Michelmore \& Owen, 2018), and they might be more willing to pay to develop their human capital. Conversely, the removal of such incentives can result in the reduction of aspirations for higher education, possibly leading to a behavioral poverty trap or self-perpetuation of poverty (Ross, 2019). 
In Colombia, the cancellation of the SPP scholarship directly reduced educational possibilities for low-income students to get into high quality colleges. The program, which roughly translates to "it pays to be smart", was the first highly publicized national large-scale university scholarship where eligible students were required to both have a very high performance on a standardized test and belong to a low socioeconomic status. The scholarship awarded 10,000 students annually and covered both tuition and living expenses. Although SPP has been shown to morethan-double the enrolment rate among eligible students (Londoño-Velez, Rodriguez \& Sanchez, 2020), and to have positive spillovers on increasing exit examinations scores (Bernal \& Penney, 2019), it was frequently criticized for its elevated cost and flow of public resources towards private universities. During the 2018 presidential elections in Colombia, SPP was a popular topic of discussion. The current Colombian President, Ivan Duque, was the only candidate out of six who supported the program as it was conceived. Yet, on September 6th, 2018 (one month after he took office), his ministry of education suddenly announced that the program would cease distributing new awards after 2018, and that in the future other higher education programs would take its place.

Given the unexpected and exogenous nature of the discontinuation of the SPP scholarship, the present study examines the extent to which grade 10 students switch choices on hypothetical higher education bundles as a result of the cancellation. Data stem from an online survey in which grade 10 students were asked for their plans for higher education and responded to a discrete choice experiment on higher education bundles. We use a discontinuity time design in which the sample is split by those responding before and after the shock. We also exploited the fact that not all students surveyed were eligible for SPP to examine differential effects according to students' eligibility status for SPP based on their poverty index score.

This study contributes to the literature in at least two aspects. First, we elicit and contrast students' declared preferences (henceforth preferences) for higher education before and after an exogenous event took place. These preferences are different from actual choices records in which observable preference for higher education are strongly correlated to students' characteristics. We use a discrete choice experiment (DCE) methodology that allows for orthogonality between the characteristics 
of the students and their choices for higher education under different scenarios. In other words, DCE allows one to separate the aspirational component for higher education from the economical and geographical constrains in which numerous low-SES students would base their actual decisions for education attainment (Carneiro \& Heckman, 2002; Parker et al., 2016). Second, we examine prior college outcomes when a negative shock on educational opportunity takes place. Most literature measuring high school students' reactions to higher education policies mainly focus on positive shocks such as the instauration of a scholarship (see for instance the examination of HOPE program in Pallais, 2009, and the Kalamazoo promise scholarship in Bartik \& Lachowska, 2014).

The closest related papers exploring decreases in higher education opportunities for disadvantaged students are those that examine how the banning of affirmative action affects prior college behavior among minorities. Antonovics \& Sander (2013), Furstenberg (2010), and Caldwell (2010) studied how minority students were discouraged from applying to University of California campuses after affirmative action policies were banned. Likewise, Dickson (2006) and Hinrichs (2012) evaluated whether the percentage of minority students applying to college decreased after banning 'affirmative action' in Texas. With the exception of Antonovics et al. (2013), who found no effects, these studies show evidence that minorities facing the ban became demotivated, which resulted in the reduction of applications of minorities to college in general, and to elite colleges in particular. However, the banning of affirmative action differs from the cancellation of SPP in several important ways. First, the cancellation of affirmative action in the USA was not a sudden and unexpected change, such that endogeneity issues might arise. In California and Texas, it took the Supreme Court between 1996 and 1998 to make a final decision on its elimination, which allows for anticipatory behavior on the part of affected students. Second, affirmative action is founded in increasing representation of racial minorities (Hispanic and black students), whereas SPP aims to increase representation of low-income students, which are a majority across Colombia (69\% of student population in 2018). ${ }^{1}$ Third, whereas affirmative action relied on the discretionary criteria of each university for admission, SPP had clear eligibility criteria for scores on both the exit examination and the poverty index. These criteria were the same for all accredited universities across time and region.

\footnotetext{
${ }^{1}$ Authors calculations based on Saber11 exit examinations in 2018.
} 
This study unfolds as follows. A brief overview of the Colombian higher education system and the SPP program is presented in Section 2. Section 3 details the methods whereas in Section 4 we estimate the causal effect of the cancellation of the SPP program using a time regression discontinuity design. Section 5 investigates the robustness of the results. The study concludes with a discussion of the public policy implications in Section 6.

\subsection{Context and Setting}

The Colombian Higher Education System is similar to that in the USA in several aspects. Application is decentralized, major-specific and most universities use performance in the high school exit examination (which serves a similar role as the American SAT or ACT) as the main admission criteria. Moreover, top private universities are expensive even by international standards (reaching up to $\$ 6,700$ USD per semester, not correcting for purchasing power parity) and top public universities are competitive (the average admission rate is $36.6 \%$ of applicants). ${ }^{23}$ These entrance criteria make low-income students (even high achievers) highly underrepresented in the system in general, and in top universities in particular.

In the Colombian context, high quality universities are defined as those that have passed the 'High Quality Accreditation' process, which is awarded by the National Accreditation Council (CNA, for its Spanish acronym). This award includes fulfilling minimum standards in terms of curriculum, academic staff, infrastructure and labor conditions of alumni, among others (CNA, 2015). By 2018, 52 out of 300 universities are accredited, 24 of which are public (Salazar, Mesa \& Correa, 2016). From approximately 500,000 high school graduates, roughly one-third enroll at an institution with the High Quality Accreditation. Only 5\% out of this third belong to the lowest socioeconomic strata. Correcting for the SES composition among all high school graduates, the percentage would need to be at least 5 times larger. Technical institutions offering vocational programs also coexist in this system. One-third of these programs offer

\footnotetext{
${ }^{2}$ Conversion using an Exchange rate of 3,400 COP per USD.

${ }^{3}$ Authors' calculations from SNIES 2018 database. This system officially follows up the number of applicants and admissions in higher education.
} 
higher education. Although vocational programs are low cost (on average $\$ 735$ USD per semester) and short term (maximum 4 semesters), a large proportion of low income students ( $77 \%$ in our survey) aspire to enroll in university programs rather than vocational programs.

Student loans are limited for low-income students. Arguably, reasons such as a co-debtor requirement, little financial literacy, distrust of governmental financial organizations such as ICETEX and high tuition fees in private universities make students reluctant to take a loan even in cases when it is worth the investment in terms of the expected future return. In 2000 and onwards, soft credit programs such as ACCES or Tú Eliges in 2015 (which roughly translates to "you choose") are offered by ICETEX targeting low socioeconomic strata students. While in 2000 only $2.5 \%$ of higher education students has ICETEX loans, in 2015 this percentage reached $20.8 \%$. In 2018, 70,4\% of ICETEX beneficiaries were given to the lowest two socioeconomic strata (ICETEX, 2018). ${ }^{4}$ Although this represents the majority of the loans, it is still a small proportion of low-income students who are willing to take up a loan to enroll higher education. Frequently, students in Colombia are sorted across institutions based on their access to financial resources rather than by their academic abilities.

\subsubsection{The Ser Pilo Paga Program}

In an attempt to increase the representativeness of high achieving lowincome students into high quality universities, the administration of President Santos administration created the Ser Pilo Paga (SPP) program, which roughly translates to "it pays to be smart". ${ }^{5}$ It was a merit and need-based scholarship launched on October 1st of 2014. Importantly, the scholarship covered 100\% tuition fees of any accredited university chosen by the student (after passing the admissions process). An additional stipend (approximately between $\$ 223$ USD and \$892 USD per semester) was offered based on where the student lives in reference to

\footnotetext{
${ }^{4}$ In Colombia, every households are divided in strata 1 to 6 according to their location (there is recently introduced 0 strata, but it is not yet common). Low-SES are 1 or 2, middle-SES are 3 and 4, and high SES are 5 and 6 .

5 "Pilo" is slang used only in Colombia to denote someone is smart or hardworking. "Paga" means to pay. These two words where only commonly used together after "Ser Pilo Paga" program.
} 
the chosen higher education institution. Strictly, the support provided by SPP came in the form of a loan that can be forgiven upon graduation within a stipulated period of study of five years on average. From 2015 to 2018, 10,000 scholarships were awarded annually, benefiting approximately 40,000 students over the four-year period. To become a beneficiary, students must fulfill two sharp eligibility criteria on both the exit examination scores measured by the Saber 11 examination $^{6}$, and the poverty index score measured by the Sisben index.

The Sisben score is a proxy of socioeconomic status and is critical variable in this study to distinguish the heterogeneous effects of the SPP scholarship cancellation. The government assigns the score to households based on housing quality, public utility services, possession of durables and human capital endowments, among others. As the index was designed to qualify low-income population to target social welfare program recipients, the medium and high class Colombians are usually not assigned to any score. The Sisben score includes decimal values and varies from 0 to 100, where lower numbers correspond to the poorest. For all fourth cohorts of SPP, the Sisben criteria was set using the same thresholds ${ }^{7}$.For most people, Sisben was determined in an initial assessment phase from 2009 to 2011, and the Sisben scores do not expire until a new version of the Sisben is released (which occurred in 2020, which is after the period considered in this study). It is worth noting that during data collection of this study, students were able to know their Sisben score in advance. Hence, students knew if they were need-eligible for SPP.

The SPP program was well known in the country. Government awareness campaigns were widespread during prime time on television, and scenes such as beneficiaries being congratulated by the president were also common. It was also widely covered in the press: for instance, accounting for only the 10 principal newspapers across regions in Colombia, we found 1.4 articles per day mentioning the phrase "Ser Pilo Paga". 8

\footnotetext{
${ }^{6}$ A score above the 91 st percentile of the overall distribution of Saber11 test scores for each year. Respectively, the cut-off for Saber11 were 310 in 2014, 318 in 2015, 342 in 2016 and 348 in 2017.

${ }^{7}$ Sisben has 3 cut-off depending on where the student lives: 57.21 for students who live in one of 14 major cities; 56.32 for students who live in other metropolitan areas, and 40.75 for students who live in rural areas.

${ }^{8}$ Using Python, we screened 10 principal newspapers between October 2014 and December 2018. The newspapers included in the search are: Diario del Sur, El
} 
The program was highly controversial. On the one hand, it was recognized to boost social mobility by increasing immediate enrolment of low-income high-achievers from $56.6 \%$ to $86.5 \%$ into high quality universities (Londoño et al., 2020). On the other hand, opponents to SPP pointed out that it was a costly program, covering only $3 \%$ of high school low-SES graduates, and indicated that the program resulted in relocation of public resources to private elite universities (Semana, 2018; DeZubiría, 2017). This statement was supported by the fact that $86 \%$ of beneficiaries chose private rather than public institutions. Yet, the program continued operating with no interruptions during the four years of president Santos's second term.

Figure 4.1: Timeline of electoral year in Colombia and survey administration

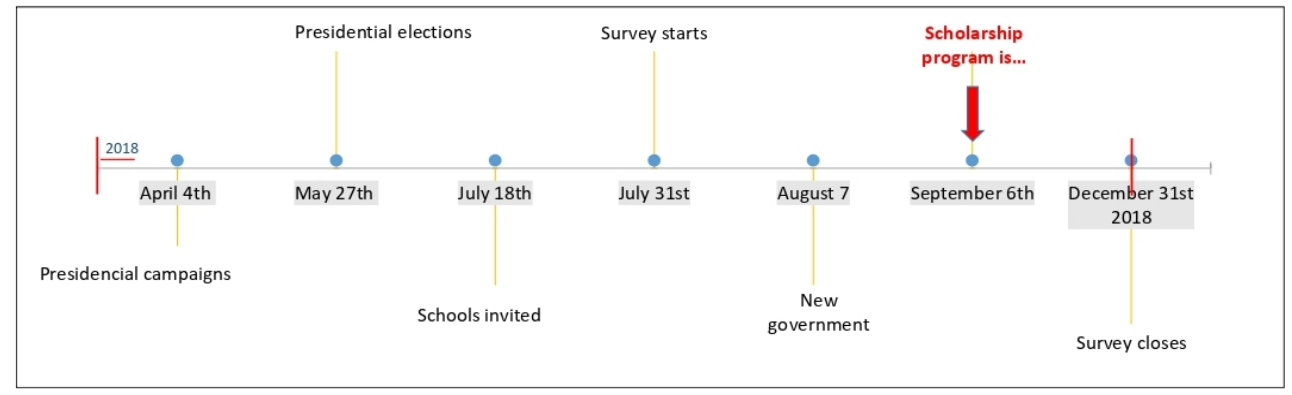

Nota: own elaboration.

\subsubsection{Exogenous shock}

Figure 4.1 shows the 2018 timeline of the events concerning SPP and its cancellation. In the first quarter of 2018, SPP was a central topic during the presidential campaigns. Out of the six presidential candidates, only one (i.e. Ivan Duque) promised to keep up the program as it was conceived. He won the election on May 27th, 2018, and took office on August 7th, 2018. During this period and the month after, an extensive media search does not reveal any sign of a cancellation of the program. However, on September 6th, the minister of education surprisingly announced that the Ser Pilo Paga program was no longer going to award additional scholarships (although resources for existing recipients were

Colombiano, El Diario, El Espectador, El país, El Tiempo, El Universal, La Nacion, La Opinion, Vanguardia. 
to be maintained), and he referred to the creation of another, different program with no details (El Espectador, 2018). The administration's main argument for the cancellation was costs overruns (El País, 2018).

Figure 4.2: Google trends exploration on 'ser pilo paga' searches

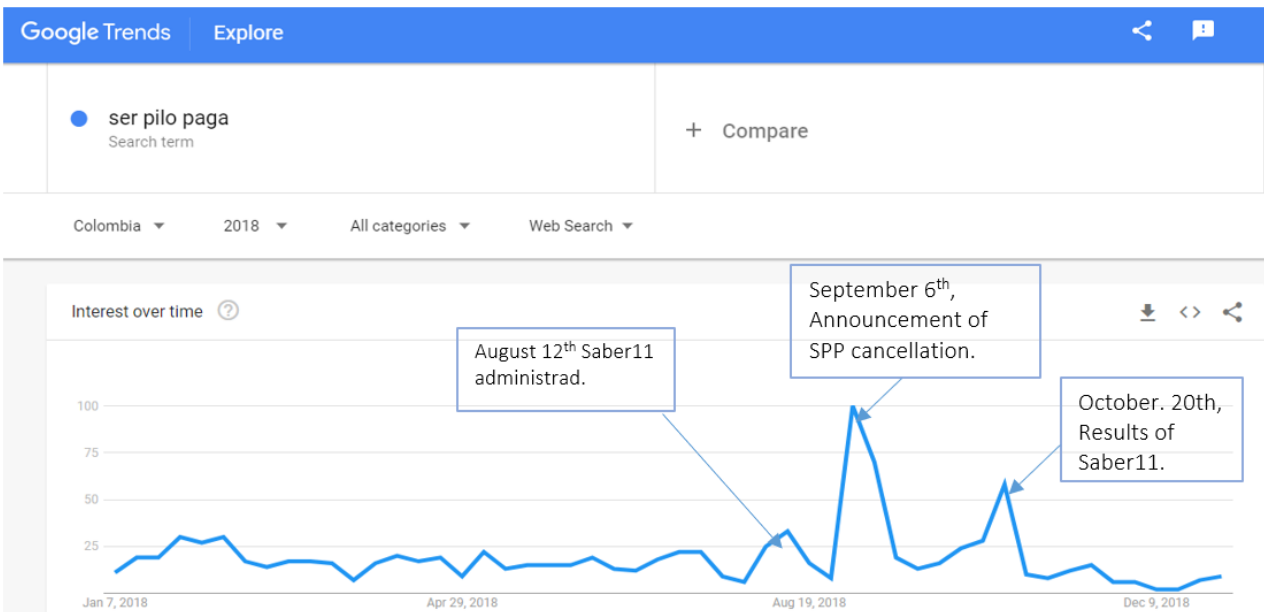

Source: Google Trends.

https://ahrefs.com/blog/how-to-use-google-trends-for-keyword-research/

Inspecting for the possible anticipation of the shock, Figure 4.2 displays Google trends concerning "ser pilo paga" searches in $2018^{9}$. Three spikes can be observed in the figure. The first peak is on August 12th, which is the date in which Colombian students take the exit examination, which arguably aroused a natural curiosity on the program and its requirements. The second peak is on September 6th, 2018, the day in which the government announced the cancellation of SPP. The sharp increase of interest in the topic suggests that news of the SPP program's cancellation was both a surprise and a call for attention. The third peak is on October 20th, 2018, when students received their exit examination results, and when the new higher education financial program "Generación E" was

\footnotetext{
${ }^{9}$ The Google Trends index is on a range of 0 to 100 . It shows the relative popularity of a search as the ratio of a query's search volume to the sum of the search volumes of all possible queries. A score of 100 corresponds to the highest popularity withing the queried time period. https://ahrefs.com/blog/how-to-use-google-trends-for-keywordresearch/
} 
launched without any specific details. ${ }^{10}$ Web searches for SPP when it no longer existed suggests some ignorance about its recent cancellation; if many students did not know about this, it would result in a lower bound estimation. Moreover, the fact that trend of Google searches on "ser pilo paga" was fairly stable before the cancellation (if something, searches actually decreased before the announcement) and no media mentions of any problem with the program supports the theory that there was no anticipatory behavior, and it is consistent with the classification of the shock as exogenous. Furthermore, results displaying a significant effect of the shock (mainly driven by Sisben-eligible students) are consistent with considering the shock as an exogenous event. For example, if there has been some degree of anticipation, it would have been expected that both groups of students - before and after - would react similarly to university bundles, which was not the case.

To empirically verify the exogenous nature of the shock, we performed a follow up survey during the holiday period of June 2019. The survey, which was answered by $35 \%$ of the students, indicated that $96 \%$ students knew about SPP and $86 \%$ knew about its cancelation in 2018. Interestingly, $76 \%$ of them anticipated using government scholarships in order to at least partially fund their higher education.

\subsection{Methods}

To examine how the sudden cancelation of the SPP program affected students' preferences for higher education, we administered a discrete choice model among 949 grade 10 students between July 31st and December 31st of 2018. The discrete choice model, which was part of a lager survey (Bernal et al., 2020), asks students to reveal their preference in hypothetical higher education bundles. In addition to these choices, we asked for personal identifiers such as age, gender, preferred major,

\footnotetext{
${ }^{10}$ According to the ministry of Education, Generación E is a program designed to strengthen access to higher education in Colombia. It has three components: equity, excellence and team. The equivalent replacement to SPP is the excellence component. It was less generous than SPP. Generacion E offers a partial scholarship to 4,000 students every year, where $50 \%$ of the expenses is assumed by the government, $25 \%$ by the higher education institution and $25 \%$ is from other funds (in some cases a student loan). When launched in October 20th, 2018, the government did not give many details on the criteria to be eligible.
} 
education of the parents, and occupation of parents ${ }^{11}$. As the sudden and exogenous cancelation of the SPP program happened in the middle of the data collection, we estimate a regression time discontinuity design around September 6.

The Discrete Choice Experiment (DCE). The DCE serves to evaluate the extent to which an individual values a good or a service by their choice of hypothetical scenarios. This technique has been applied in human capital scenarios, and the outcomes have revealed that DCE results have internal validity and consistency (Hemsley-Brown, 2015; Lambooij, Harmsen, Veldwijk, de Melker, Mollema, van Weert \& de Wit, 2015). There are few studies that have focused on students' preferences for higher education using a discrete choice experiment methodology (Walsh, Flannery \& Cullinan, 2018; Moorhouse, Dunnett \& Barry, 2015; Dunnett, Moorhouse, Walsh \& Barry, 2012; Czajkowski, Gajderowicz, Giergiczny, Grotkowska \& Sztandar-Sztanderska, 2020). None of those studies have examined the effect of an exogenous shock regarding educational opportunities that can eventually influence students' preferences.

To choose proper attributes for the choice sets, focus group discussions and pilots with grade 10 and 11 students were held, and administrative surveys on higher education choice were consulted. All participants thought that quality and school location was important, and most of them indicated that scholarships were an effective way to increase entrants despite career choice restrictions. Finally, five attributes were selected concerning quality, location, type (public versus private), scholarship (tuition fee/debt after graduation) and living expense stipend. The choices within the attributes (the levels) used realistic options. The attributes and levels included in the DCE are summarized in Figure 4.3.

1. Institution quality, represented by stars and ranging from 2 stars to 5 stars, with 5 stars being the highest rating. The 5 and 4 stars represent the accredited universities.

2. Location, which consists of 5 categories: 0, 2, 4, 10 and 14 (or more) hours travel from home. ${ }^{12}$ The length is set according to the

\footnotetext{
${ }^{11}$ Because the education levels of the parents are very highly correlated, we elect to use mother's education in the analysis.

${ }^{12}$ Students were way more familiar with the concept of time than distance according to the focus group.
} 
Figure 4.3: Attributes and levels in the discrete choice experiment

\begin{tabular}{|c|c|c|}
\hline Attribute & Categories & $\begin{array}{c}\text { Level } \\
\text { coding }\end{array}$ \\
\hline University quality & $\begin{array}{l}5 \text { stars (accredited) } \\
4 \text { stars (accredited) } \\
3 \text { stars (non-accredited) } \\
2 \text { stars (non-accredited) }\end{array}$ & $\begin{array}{l}5 \\
4 \\
3 \\
2\end{array}$ \\
\hline Location & $\begin{array}{l}\text { The city where your parents live. } \\
2 \text { hours by bus from where your parents live. You can choose to move or not. } \\
4 \text { hours by bus from where your parents live. You can choose to move or not. } \\
10 \text { hours by bus from where your parents live. You have to move. } \\
14 \text { hours or more by bus from where your parents live. You have to move. }\end{array}$ & $\begin{array}{l}0 \\
2 \\
4 \\
10 \\
14\end{array}$ \\
\hline University type & $\begin{array}{l}\text { Public } \\
\text { Private }\end{array}$ & $\begin{array}{l}1 \\
0\end{array}$ \\
\hline $\begin{array}{l}\text { Scholarship (tuition } \\
\text { fee) }\end{array}$ & $\begin{array}{l}\text { Scholarship of } 100 \% \text { of the tuition fee. } \\
\text { Scholarship of } 75 \% \text { of the tuition fee. The remaining } 25 \% \text {, you will be able to } \\
\text { pay back by giving up } 20 \% \text { of your salary received during } 3 \text { years after } \\
\text { graduation. } \\
\text { Scholarship of } 50 \% \text { of the tuition fee. The remaining } 50 \% \text {, you will be able to } \\
\text { pay back by giving up } 20 \% \text { of your salary received for } 5 \text { years after } \\
\text { graduation. } \\
\text { Scholarship of } 25 \% \text { of the tuition fee. The remaining } 75 \% \text {, you will be able to } \\
\text { pay back by giving up } 20 \% \text { of your salary received for } 7 \text { years after } \\
\text { graduation. } \\
\text { No scholarship. You will be able to pay the costs back by giving up } 20 \% \text { of } \\
\text { your salary received for } 9 \text { years after graduation. }\end{array}$ & $\begin{array}{l}100 \\
75\end{array}$ \\
\hline $\begin{array}{l}\text { Living expense } \\
\text { stipend }\end{array}$ & $\begin{array}{l}\text { Yes (COP } \$ 312.000 \text { monthly - about USD } \$ 100 \text { ) } \\
\text { No }\end{array}$ & $\begin{array}{l}1 \\
0\end{array}$ \\
\hline
\end{tabular}

most popular journeys students make to attend higher education. The information is obtained from the ICFES representative survey.

3. Type of universities. Students have to choose a bundle that differs in the public or private provision of education. The choice may represent perceptions of students about several variables, including for instance the cost of the tuition, and the risk of being affected by strikes (which is higher in public institutions).

4. Scholarship tuition fee, ranging from $0 \%$ to $100 \%$, with intervals of $25 \%$. The variable represents the percentage of tuition fee that students are hypothetically receiving. The values of salary and time students should give up in order to pay the remaining debt 
are calculated according to real information on returns combined with the credits calculator from ICETEX. ${ }^{13}$

5. Living expenses subsidy possibility. This attribute has only two options, yes or no. The subsidy was set at 312.000 COP per month (approximately $\$ 108 \mathrm{USD}$ ). The value of the living expenses is calculated based on the subsidy approved by the government in 2018 to SPP students who moved in order to attend college.

We used a statistically D-efficient design to choose the attribute-levels of the choice sets. To avoid students' fatigue we divide the 18 choice sets into two blocks, and one of the blocks was randomly assigned to a school. We do not assume prior information about the parameters to be estimated. Figure 4.4 shows an example of the binary choice framework. In each bundle, we asked respondents to choose their preferred bundle in a choice set of two possibilities, and the ability to skip was not permitted.

Figure 4.4: Activity instructions to the students before starting the DCE and an example of a DCE choice set. (Original text in Spanish)

\begin{tabular}{|c|c|c|}
\hline Attribute & Bundle 1 & Bundle 2 \\
\hline Quality of HEls & & \\
\hline Location of HEls & The city where you live & $\begin{array}{c}2 \text { hours in bus from where } \\
\text { you live. Move or not. }\end{array}$ \\
\hline Type of HEls & Private & Public \\
\hline Scholarship (\%) & $\begin{array}{l}\text { Scholarship: } 50 \% \\
50 \% \text { - The remaining } 50 \% \text {, } \\
\text { you will be able to pay } \\
\text { back by giving up } 20 \% \text { of } \\
\text { your salary received for } 5 \\
\text { years after graduation. }\end{array}$ & $\begin{array}{l}\text { Scholarship: } 0 \% \\
0 \% \text { - The } 100 \% \text {, you will be } \\
\text { able to pay back by giving } \\
\text { up } 20 \% \text { of your salary } \\
\text { received for } 9 \text { years after } \\
\text { graduation. }\end{array}$ \\
\hline Subsidy & NO & $\begin{array}{l}\text { yes }=\$ 312.000 \text { monthly } \\
(108 U S D)\end{array}$ \\
\hline
\end{tabular}

Which one do you prefer?

${ }^{13}$ The credits calculator can be found at the following address: http://aspirantes.ut.edu.co/simulador-puntaje.html 
Random Utility Model (RUM): In a classical RUM model, a decision maker $n$ out of $N$ individuals faces a choice among $J$ alternatives on $T$ repeated choice occasions. The decision maker $n$ btains from an alternative $j$ in a choice occasion $t$ a certain level of utility $U_{n j t}$. The model, $U_{n j t}=V_{n j t}+\varepsilon_{n j t}=x_{n j t} \beta+\varepsilon_{n j t} \forall j$ is equivalent to: $U_{n j t}^{*}=\lambda V_{n j t}+\lambda \varepsilon_{n j t}=x_{n j t}^{\prime}(\lambda \beta)+\lambda \varepsilon_{n j t} \forall j$ As we include two different subsamples into one model (to test the treatment differences) each group might have a different $\lambda s$ In this model, we assume a restricted version of the RUM in which $\lambda_{0}=\lambda_{1}=1$ Hence, we assume that the certainty of choosing an alternative does not vary between control and treatment.treatment. We also assumed that the independence of irrelevant alternatives in a DCE setting holds. In other words, we treat both control and treatment subsamples under the bases of a regular heterogeneous analysis of a classical RUM.

Statistical model. Based on a variation of the random utility model, the underlying utility function combined with the two treatment interactions can be expressed as:

$$
U_{n j t}=V_{n j t}+\varepsilon_{n j t}=\beta_{0}+\sum_{t=1}^{18} \beta_{j k}+A_{j k}+T_{1} * \sum_{t=1}^{18}\left(\beta_{j k}+A_{j k}\right)+\gamma_{t}+\varepsilon_{n j t}
$$

Where $j$ denotes a student's choice between one of the two bundles shown in each choice set $(t)$ The subscript $\mathrm{k}$ refers to the attribute-level (each level in all five attributes $(A)$, see Figure 4.4), sub-index 1 refers to students who answered the survey after the cancellation. Likewise, $\gamma_{t}$ epresents the choice set fixed effects to capture observed and unobserved heterogeneity at the individual level, and $\varepsilon_{n j t}$ is the idiosyncratic term. To account for peer effects, we clustered the standard errors at the school level. As a robustness check, we also include student fixed effects. The reference group for each attribute corresponds to a two-star university, same city as home, public institution, 0\% scholarship, and no stipend. The reference group for $T_{1}$.

The estimated coefficients $\beta_{j k}$ represent the preferences for the attributes. A positive sign of the coefficient implies that the attribute has a positive impact on the take-up of a given higher education bundle, conditional on treatment effects. Higher coefficients indicate a higher importance of the attribute on decision making. Interaction coefficients 
$\beta_{1 j k}$ estimate the causal effect of the cancellation on student's choices for the after-group. These coefficients identify the extent to which students' preferences are influenced by the cancellation of SPP compared to the control group. Significant and positive coefficients of these interactions suggest that the treatment was effective in modifying the importance of the attributes in the choice for higher education packages. For the estimation of the equation 1 parameters, we use a mixed logit model, which allows for random taste variation among individuals. We used here a simulation method for estimation by setting the number of repetitions to 50 .

Coarsened Exact Matching (CEM) approach: we accounted for confounding influence of covariates by using the Coarsened Exact Matching (CEM) approach proposed by Iacus, King \& Porro (2008). CEM enables the generation of covariate balance for the before and after group, which leads the comparison of preferences of similar students between the two groups. Comparing to other matching methods, CEM allows covariates to be coarsened into meaningful strata such that an 'exact matching' algorithm is applied to the coarsened data.

\subsection{Data}

Invitations to participate in the study were done by ICFES, the institution that administers exit examinations in Colombia. To increase participation, schools were contacted by telephone. Calls started on July, 2018 and ended on November 30th, 2018. As schools were contacted in random order, the date of cancellation is orthogonal to the date we invited them to participate (in fact, for $53 \%$ of the schools received their first call after the cancellation of SPP). This reduced possible selection biased (i.e. we have enthusiastic schools in either the before or the after group). Participation from both schools and students was voluntary. Schools were instructed to apply the survey to at least one complete grade 10 class. The survey was administrated during school hours. Data collection started on July 31st and ended in December 31st. From 1925 original surveys, we eliminated 555 observations for being paper-based since the surveys are not dated, 288 because participants did not responded the DCE section and 9 for failing the consistency test for the DCE. We also disregard 61 observations because those students declared 
not be interested in pursuing higher education.

In addition, we enriched our survey dataset by merging new variables reported by the student at the exit examination Saber11, 2019 (about one year after our survey took place). For instance, student's working activity, dietary habits, reading habits or internet access among other. The merge was successful in $81 \%$ of cases, and the correlations between the common variables in the two datasets were above $80 \%{ }^{14}$ We also merged the official Sisben score index updated to 2018 provided to ICFES by the National Department of Planning in Colombia. All merges were done by ICFES.

We use merged administrative dataset to identify and contrast the characteristics of the non-respondents to those in our sample. We found that from all students that graduate in 2019 from the schools we applied the survey; $31.6 \%$ answers the questionnaire. Nevertheless, this percentage is probably higher if we consider that the instruction to schools was to apply the survey to only one classroom (as supposed to the entire cohort) in grade 10 in 2018. Unfortunately, the 2019 exit examination does not have classroom identifier, so we cannot determine the real percentage or non-respondents within the classroom. In analysis performed on characteristics differences between respondents and non-respondents, we observed that non-respondents are oldest and have less educated mothers. Balance is achievement in the other covariant (see Table 4.1, column $5)$.

${ }^{14}$ The main reason for failing to match is due to students who reported an incomplete or invalid ID in our survey, which was the key variable used for merging. 
Table 4.1: Covariates balance of students in the sample and nonrespondents

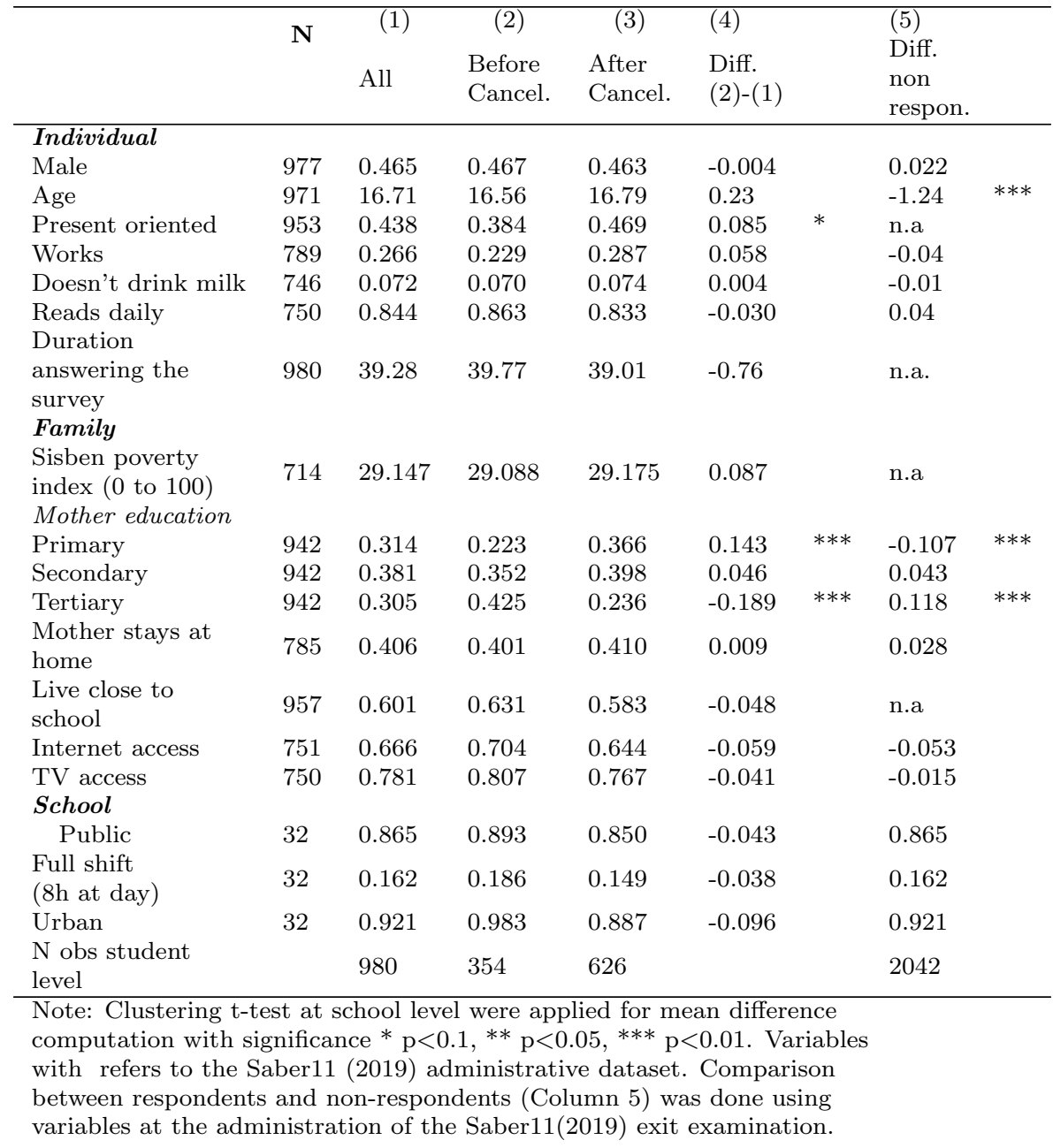

Our final sample comprises of 980 surveys administered to grade 10 students between July 31st and December 31st of 2018. Table 4.1 column 1 characterizes the full sample. Some of the statistics indicate that they are young students (16.7 years old), with some of them not having internet access (67\%), and most of them studying in urban areas $(92 \%)$. Their mothers have a low rate of tertiary level of education (31\%) and a high percentage of them are not in the labor force (41\%). Importantly, surveyed students are low-SES and highly likely to be eligible for SPP scholarships: $71 \%$ of them have Sisben index (which as previously noted are primarily carried by poor households), and $61 \%$ would have been 
Sisben-eligible for SPP according to their scores. The sample was split into two groups: students who answered before the cancellation $(\mathrm{n}=354)$ and those who answered afterwards $(n=626)$. When testing covariate balance (column 4), no differences in the eligibility criteria Sisben for SPP was found between the two groups, which gives us confidence to estimate the effect using raw data as part of the analysis. Nonetheless, as mother's education (a key variable for students' preferences on higher education) was imbalanced, we also used coarsened exact matching (CEM) data for balance the two groups in observables and for further estimation.

\subsection{Result}

To examine the impact of the sudden stop of a scholarship program targeting low-SES students on their preferences for higher education, we estimate equation (1) on both the raw data (Table 4.3 in the Appendix) and the coarsened data (Table 4.2). Given the similarities between the results with raw and coarsened data, we only discuss in what follows the CEM specification, which counters the unbalances at baseline. The results indicate that the scholarship cancellation reduced the higher education ambitions and financial aid interest of students who are more likely eligible for the scholarship. Compared to the group surveyed before the cancellation, the group after the cancellation reports lower preferences for high quality institutions and for financial aid. 


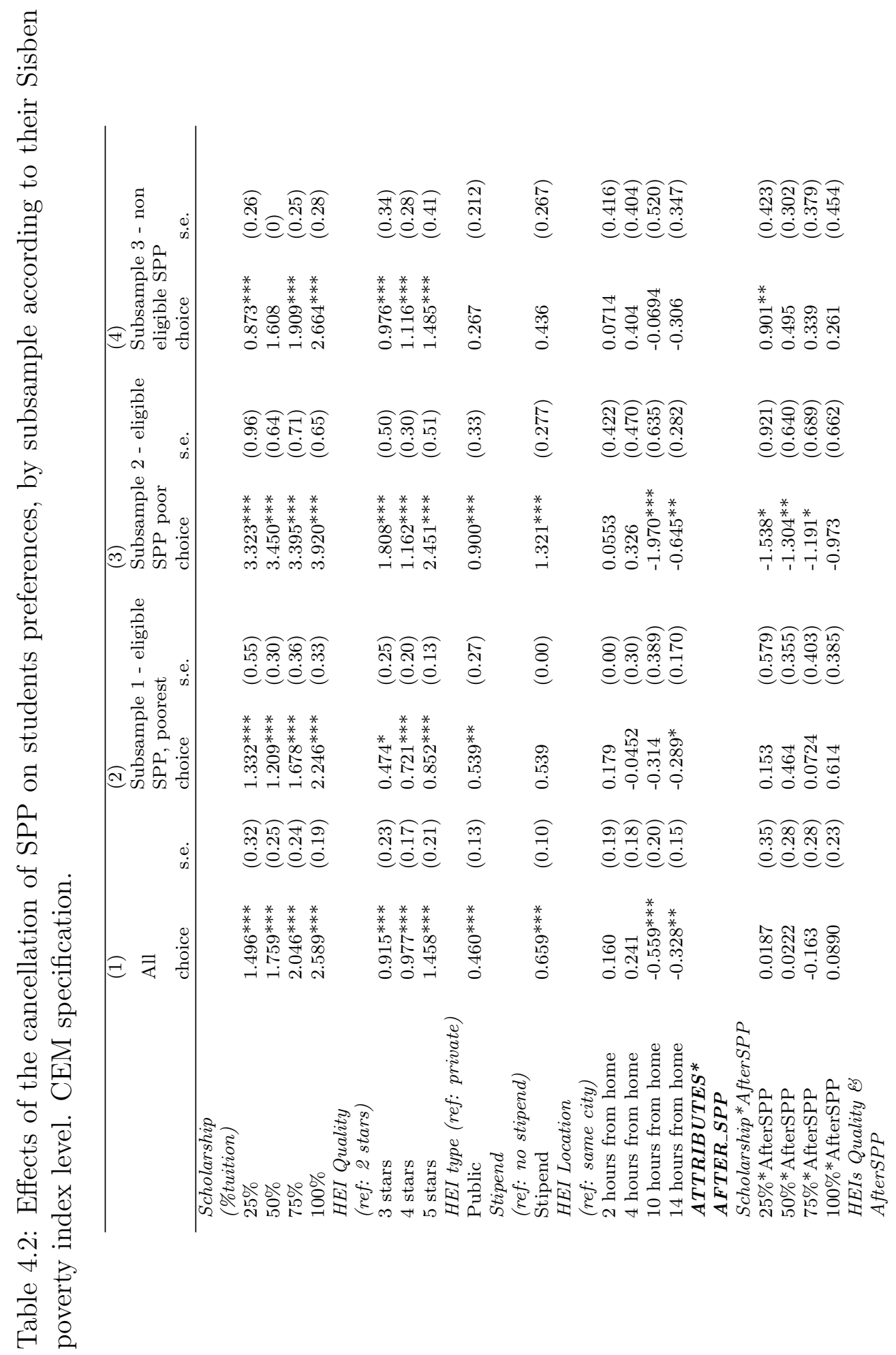




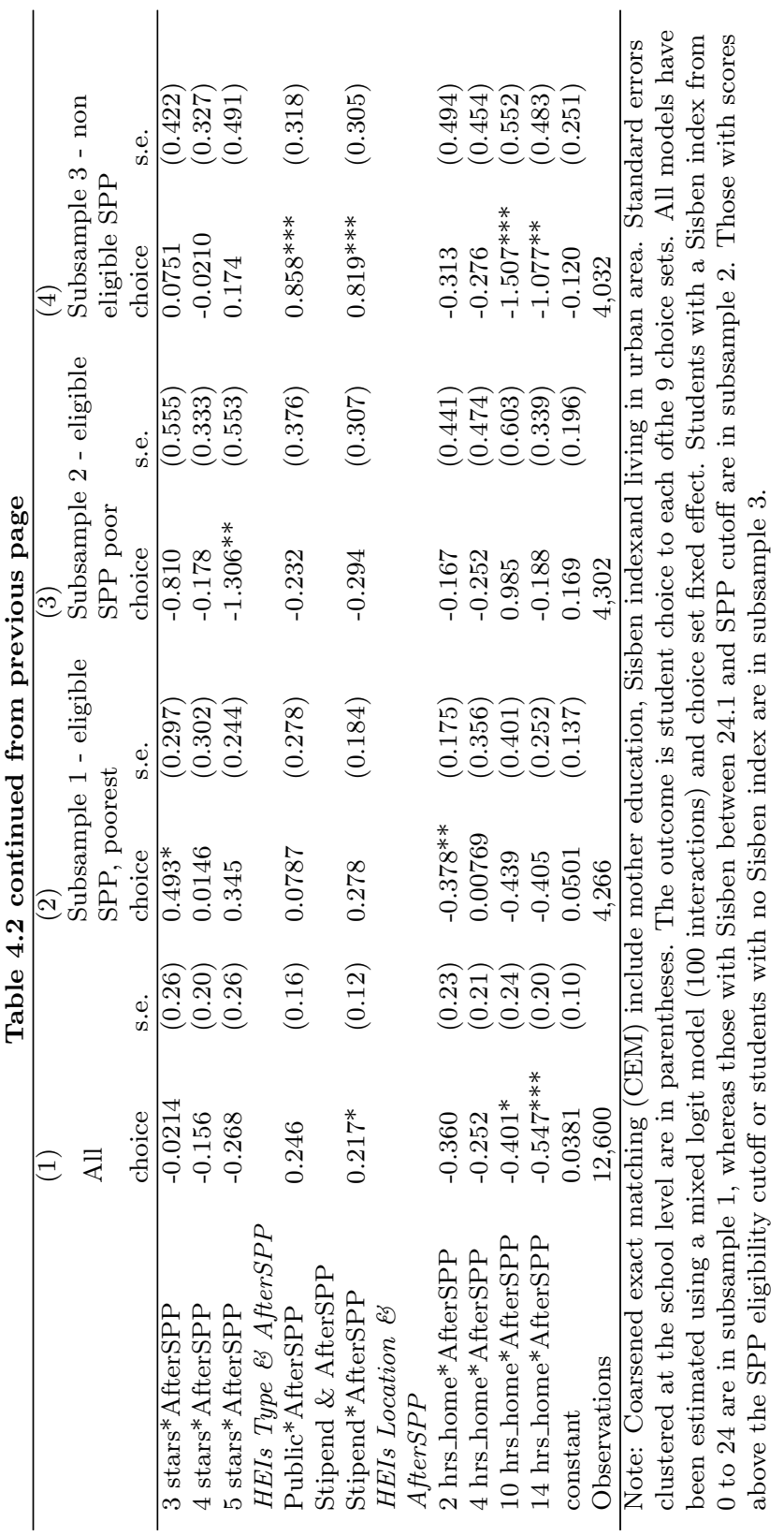


Table 4.2 shows the coefficients estimated in equation 1. Estimations of (levels of attributes) and $\beta_{1 k}$ (levels interacted with the treatment) are shown in top panel and bottom panel, respectively. Column 1 represents the results for the complete sample, whereas columns 2-4 display the results for the three subsamples according to Sisben index score classification. In the top panel, almost all coefficients are statistically significant at the $1 \%$ level, indicating that each one of these attributes are relevant to students when choosing bundles. Percentage of scholarship, HEI quality, being public and receiving a monthly stipend (approx. \$108 USD) are positively valued by the students. In contrast, HEI being located 10 or $14+$ hours from home is valued as a negative attribute. Given the ordinal nature of the model, we do not interpret the magnitudes of coefficients. We can only infer that higher coefficients represent stronger preferences for a particular attribute relative to the others. Hence, scholarship is the most important aspect for students to choose a higher education bundle (coefficients is 1.5 for a tuition scholarship of $25 \%$ and 2.59 for a full scholarship $)^{15}$. The higher the scholarship, the more weight the students give to a particular higher education bundle, which validates the monotonic assumptions of the preferences. In addition, students quality of the HEI the second most important attribute (for a 3 stars university coefficient is 0.9 , and for a 5 stars it is 1.5 ). The other attributes (i.e. public IES, have a subsidy and location from the HEI) are less important to the students (with coefficients being lower than 0.7). These results are in line with previous studies eliciting preferences for higher education in which quality/reputation have a predominant role in the choices of the students, and students from disadvantaged backgrounds are particularly sensitive to higher fees (Walsh et al., 2018; Dunnett et al., 2012).The main focus of this research is through the influence of the cancellation of a scholarship on students' preferences for higher education packages. The bottom panel of Table 4.2 , column 1 show all attributes interacted with either being or nor being exposed to the shock at the moment of answering the survey. Results suggests only a modest effect of SPP cancellation on expenditure (0.22) and distance (-0.55). However, the results change when analyzing heterogeneous effects.

Compared to their counterparts, students in subsample 2 (Sisbeneligible but not in the bottom of income distribution) react the most to the shock by reducing their preferences for scholarship and quality of the

${ }^{15}$ Units should be interpretated as ordinal. 
HEI in significant amounts (between 1.0 and 1.5 reduction for scholarship, and 1.3 reduction for quality). By contrast, subsample 1 (the poorest) and subsample 3 (not Sisben-eligible) had few significant coefficients. The termination of the scholarship causes students to put less importance to quality and financial aid that they would have otherwise. In line with previous findings on the negative impact of banning affirmative action (e.g. Antonovics et al., 2013; Furstenberg, 2010), the cancellation of a scholarship leads to lower educational aspirations for low-income students.

Robustness checks: four robustness checks were conducted in this study. First, out of the DCE preference setting, we test if variables related to aspirations for higher education asked in the survey were subject of change due to the event. Figure 4.5 shows that after the cancellation of the scholarship, students prefer less costly universities and they are more reluctant to receive information about accredited universities or governmental loans. Students are also less willing to use a governmental loan compared to the group who completed the survey before the cancellation. Altogether, students are less interested in high quality universities and ways to finance tertiary education. Second, Figure 4.6 plots the mean of several socioeconomic variables unrelated to the cancellation of the scholarship (a placebo test). In contrast to Figure 5.1, Figure 4.6 shows several variables across time: Sisben index, proxy of altruism, knowledge of financial terms and will use family sources for further education do not differ between the control and treated group. Third, we run a more restricted CEM analysis in which we conditioned the matching to four more variables: gender, age, altruism, and present oriented. Results indicate similar coefficients, although less statistical significance. Loss of statistical power is attributable to the drop of almost half of the observations after performing the more restricted matching (Appendix, Table 4.4). Fourth, we run the model with a random allocation of the treatment condition. The level of the coefficients are robust along specifications (i.e. regardless the available information, students still value scholarships more over other attributes). Nevertheless, the heterogeneous effect (i.e. the negative reaction of SPP's cancellation on most eligible students) vanished in this placebo test (Appendix, Table 4.5). The former robustness check supports our finding of diminishing educational attainment is not due to chance. 
Heterogeneous Effects. We run heterogeneous analyses for three subsamples according to socioeconomic status. Students with a Sisben index from 0 to 24 are in subsample 1, whereas those with Sisben between 24.1 and SPP cutoff are in subsample 2. Those with scores above the SPP eligibility cutoff or students with no Sisben index are in subsample 3. The two first subsamples are eligible for SPP. However, historical data on beneficiaries pointed that those in the second group are 2.5 times more likely than the first group to get the scholarship (probably correlated to better living conditions). Therefore, students in subsample 2 are expected to actually be the most affected by the SPP program's cancellation.

Figure 4.5: Robustness checks - Testing time discontinuity in variables related to aspirations for higher education (Raw dataset)
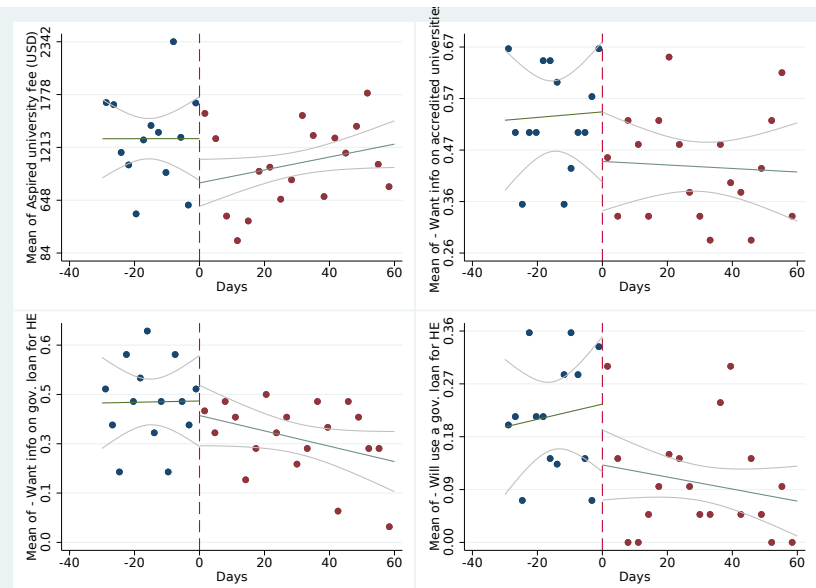

Note: The figures plot the mean of several variables related to aspirations for higher education such as: fees of the university they are pursuing, interest in receiving information of accredited universities or governmental loans or intentions to use a governmental loan for higher education. The temporary running variable is days, where 0 is identified as the day of the cancellation: September 6th, 2018. Raw dataset (not coarsened) is used. 
Figure 4.6: Robustness checks - Testing time discontinuity in variables unrelated to aspirations for higher education (Raw dataset)

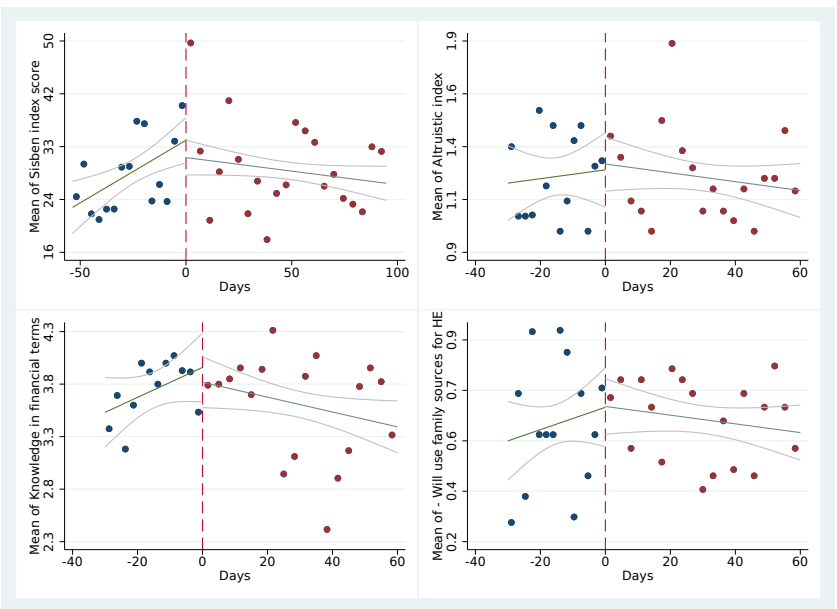

Note: The figures plot the mean of several variables unrelated to the cancellation of the scholarship: Sisben (poverty) index (100 points is the maximum, lower numbers imply more impoverished), altruism index (02 ), knowledge about financial terms index (0-5) and the perceived probability that family helps with sources for higher education. The temporary running variable is days, where 0 is identified as the day of the cancellation: September 6th, 2018. Raw dataset (not coarsened) is used.

\subsection{Discussion and conclusions}

This study aimed to estimate the impact of the cancellation of the nationwide low-income targeted scholarship on students' preferences for higher education. Two exogenous sources of variation distinguish this study from others. First, the exogenous variation in the higher education bundles offered to students to elicit their preferences (i.e. exogenous arrangements overcome the limitations of real choices records where the choice is usually endogenous to students' characteristics). Second, we exploit the fact that the news of the cancellation of the scholarship were unexpected and thus exogenous to all participants, including low-income students. Earlier literature has studied pre-college outcomes such as student attendance and test scores in high school in the presence of scholarships (Pallais, 2009; Bartik \& Lachowska, 2014) or when an affirmative action is banned (Antonovics et al., 2013; Furstenberg, 2010). We add to this 
literature by being the first to research what happens to students' preferences and aspirations by means of a discrete choice experiment when facing changes in educational opportunities.

The results show that the cancellation of the full scholarship reduced educational ambition (i.e. decreased preferences for high quality institutions) and decreased interest in financial aid for higher education among income-eligible students. This is of particular importance given that changes in perceptions (aspirations) are a strong predictor of schooling outcomes, and that low-SES students are particularly responsive to changes in credit constrains (Kaufmann, 2014).

Given that higher aspirations can significantly affect investments in human capital (Macours \& Vakis, 2009), and consequently affect labor supply, reducing educational opportunities to minorities can have disastrous losses for human capital accumulation among affected students and for society. Some consequences can include diminishing college enrolment, placing into lower-quality universities (both public and private), diminishing applications in STEM fields, declining potential earnings, and the deterring of well qualified students from applying to high quality colleges (Bleemer, 2020). In turn, decreasing the funding opportunities of low-SES students not only affects them to reach selective universities, but also has negative consequences on economic success and intergenerational mobility for the nation (Zimmerman, 2019; Chetty, Friedman, Saez, Turner \& Yagan, 2020).

Furthermore, if our findings are to apply to most of low-income students in Colombia (which are $72 \%$ of high school students), the spillover effects are tremendous. Even though scholarships like SPP benefit few (10,000 out of nearly 300,000 need-based eligible) and most of them would not meet the score requirement (being above the 91th percentile), spillover effects are feasible. For instance, improvements on exit examination of potential eligible students after the creation of SPP (Bernal \& Penney, 2019) can be reversed after the SPP program is cancelled.

From a policy perspective, helping the poor to enhance their aspirations can have a positive effect on reducing poverty (Chiapa, Garrido \& Prina, 2012). Scholarships could be created to promote increasing investments in human capital for low-income students, as it can be a powerful 
means to increase educational ambition and interest for pre-college students with of lower socioeconomic backgrounds. The mere existence of scholarship programs can increase effort and aspirations of a wider number of students than those that would be ultimate beneficed. When making decisions, policymakers should internalize these spillover effects. Furthermore, these policies must be cost-sustainable, as its cessation will carry a step back for students that were enthusiastic for the existence of the possibility of financial support for higher education. 


\section{References}

[1] Alon, S., \& Malamud, O. (2014). The impact of Israel's class-based affirmative action policy on admission and academic outcomes. Economics of Education Review, 40, 123-139.

[2] Antonovics, K. L., \& Sander, R. H. (2013). Affirmative action bans and the "chilling effect". American law and economics review, 15(1), 252-299.

[3] Bartik, T. J., \& Lachowska, M. (2014). The short-term effects of the Kalamazoo Promise scholarship on student outcomes. In New Analyses of Worker Well-Being (pp. 37-76). Emerald Group Publishing Limited.

[4] Bernal, G. L., \& Penney, J. (2019). Scholarships and student effort: Evidence from Colombia's Ser Pilo Paga program. Economics of Education Review.

[5] Blackwell, M., Iacus, S., King, G., \& Porro, G. (2009). cem: Coarsened exact matching in Stata. The Stata Journal, 9(4), 524-546.

[6] Bleemer, Z. (2020). Affirmative Action, Mismatch, and Economic Mobility after California's Proposition 209. Mismatch, and Economic Mobility after California's Proposition, 209.

[7] Boxer, P., Goldstein, S. E., DeLorenzo, T., Savoy, S., \& Mercado, I. (2011). Educational aspiration-expectation discrepancies: Relation to socioeconomic and academic riskrelated factors. Journal of adolescence, 34(4), 609-617.

[8] Caldwell, R. (2010). The effects of university affirmative action policies on the human capital development of minority children: Do expectations matter? (No. 200812). University of Kansas, Department of Economics. 
[9] Carneiro, P., \& Heckman, J. J. (2002). The evidence on credit constraints in post-secondary schooling.The Economic Journal, 112(482), 705-734.

[10] Chetty, R., Friedman, J. N., Saez, E., Turner, N., \& Yagan, D. (2020). Income segregation and intergenerational mobility across colleges in the united states. The Quarterly Journal of Economics, 135(3), 1567-1633.

[11] Chiapa, C., Garrido, J. L., \& Prina, S. (2012). The effect of social programs and exposure to professionals on the educational aspirations of the poor.Economics of Education Review, 31(5), 778-798.

[12] CNA. (2015) Retrived: http://www.cna.gov.co/1741/articles186359_Acuerdo_3_2014_Lin_Acr_IES.pdf

[13] Czajkowski, M., Gajderowicz, T., Giergiczny, M., Grotkowska, G., \& Sztandar-Sztanderska, U. (2020). Choosing the future: economic preferences for higher education using discrete choice experiment method.Research in Higher Education, 61(4), 510-539.

[14] De Zubiría, J. (13 de marzo de 2017). Ser Pilo Paga: Un programa que hay que reestructurar. Revista Semana.

[15] Dickson, L. M. (2006). Does ending affirmative action in college admissions lower the percent of minority students applying to college? Economics of Education Review,25(1), 109-119.

[16] Dunnett, A., Moorhouse, J., Walsh, C., \& Barry, C. (2012). Choosing a university: A conjoint analysis of the impact of higher fees on students applying for university in 2012. Tertiary Education and Management, 18(3), 199-220.

[17] Dynarski, S., Libassi, C. J., Michelmore, K., \& Owen, S. (2018). Closing the gap: The effect of a targeted, tuition-free promise on college choices of high-achieving, low-income students (No. w25349). National Bureau of Economic Research.

[18] El Espectador. Redacción Vivir. (6 de septiembre de 2018). Gobierno reemplazará el programa Ser Pilo Paga en octubre.

[19] El País. (6 de septiembre de 2018). 'Ser pilo paga' tiene un déficit económico y será replanteado, dice Mineducación. El País. 
[20] Fryer Jr, R. G., \& Loury, G. C. (2005). Affirmative action and its mythology. Journal of Economic Perspectives,19(3), 147-162.

[21] Furstenberg, F. F. (2010). Diverging development: The not-soinvisible hand of social class in the United States. Grau, N. (2018). The impact of college admissions policies on the academic effort of high school students. Economics of Education Review, 65, 58-92.

[22] Hastings, J. S., Neilson, C. A., \& Zimmerman, S. D. (2012). The effect of school choice on intrinsic motivation and academic outcomes (No. w18324). National Bureau of Economic Research.

[23] Hemsley-Brown, J. (2015). University choice: what do we know, what don't we know and what do we still need to find out? International Journal of Educational Management, 29(3), 254-274.

[24] Hinrichs, P. (2012). The effects of affirmative action bans on college enrollment, educational attainment, and the demographic composition of universities.Review of Economics and Statistics, 94(3), 712-722.

[25] ICETEX. Informe de resultados 2018. (2018). Ministerio de Educación.

[26] Kaufmann, K. M. (2014). Understanding the income gradient in college attendance in Mexico: The role of heterogeneity in expected returns. Quantitative Economics,5(3), 583-630.

[27] Kemptner, D., \& Tolan, S. (2018). The role of time preferences in educational decision making. Economics of Education Review, 67, 25-39.

[28] Khattab, N. (2015). Students' aspirations, expectations and school achievement: What really matters? British Educational Research Journal, 41(5), 731-748.

[29] Lambooij, M. S., Harmsen, I. A., Veldwijk, J., de Melker, H., Mollema, L., van Weert, Y. W., \& de Wit, G. A. (2015). Consistency between stated and revealed preferences: a discrete choice experiment and a behavioural experiment on vaccination behaviour compared. BMC medical research methodology, 15(1), 19. 
[30] Londoño-Vélez, J., Rodríguez, C., \& Sánchez, F. (2020). Upstream and Downstream Impacts of College Merit-Based Financial Aid for Low-Income Students: Ser Pilo Paga in Colombia. American Economic Journal: Economic Policy, 12(2), 193-227.

[31] Pallais, A. (2009). Taking a Chance on College Is the Tennessee Education Lottery Scholarship Program a Winner?. Journal of Human resources, 44(1), 199-222.

[32] Parker, P. D., Jerrim, J., Anders, J., \& Astell-Burt, T. (2016). Does living closer to a university increase educational attainment? A longitudinal study of aspirations, university entry, and elite university enrolment of Australian youth. Journal of youth and adolescence, 45(6), 1156-1175.

[33] Ross, P. H. (2019). Occupation aspirations, education investment, and cognitive outcomes: Evidence from Indian adolescents. World Development, 123, 104613.

[34] Salazar, N., Mesa, C. A., \& Correa, C. (2016). Financiación de la educación superior a través del ICETEX: estimación de necesidades de recursos a futuro y propuestas de mecanismos de fondeo. Fedesarrollo.

[35] Semana. (Abril 19 de 2018). Solo Iván Duque mantendría "Ser Pilo Paga"; Semana. (8 de septiembre de 2018). El pasado no perdona: Cuando Iván Duque dijo que mantendría 'Ser Pilo Paga'.

[36] Walsh, S., Flannery, D., \& Cullinan, J. (2018). Analysing the preferences of prospective students for higher education institution attributes. Education Economics, 26(2), 161-178.

[37] Walsh, C., Moorhouse, J., Dunnett, A., \& Barry, C. (2015). University choice: which attributes matter when you are paying the full price?. International Journal of Consumer Studies, 39(6), 670-681.

[38] Zimmerman, S. D. (2019). Elite colleges and upward mobility to top jobs and top incomes. American Economic Review, 109(1), 1-47. 


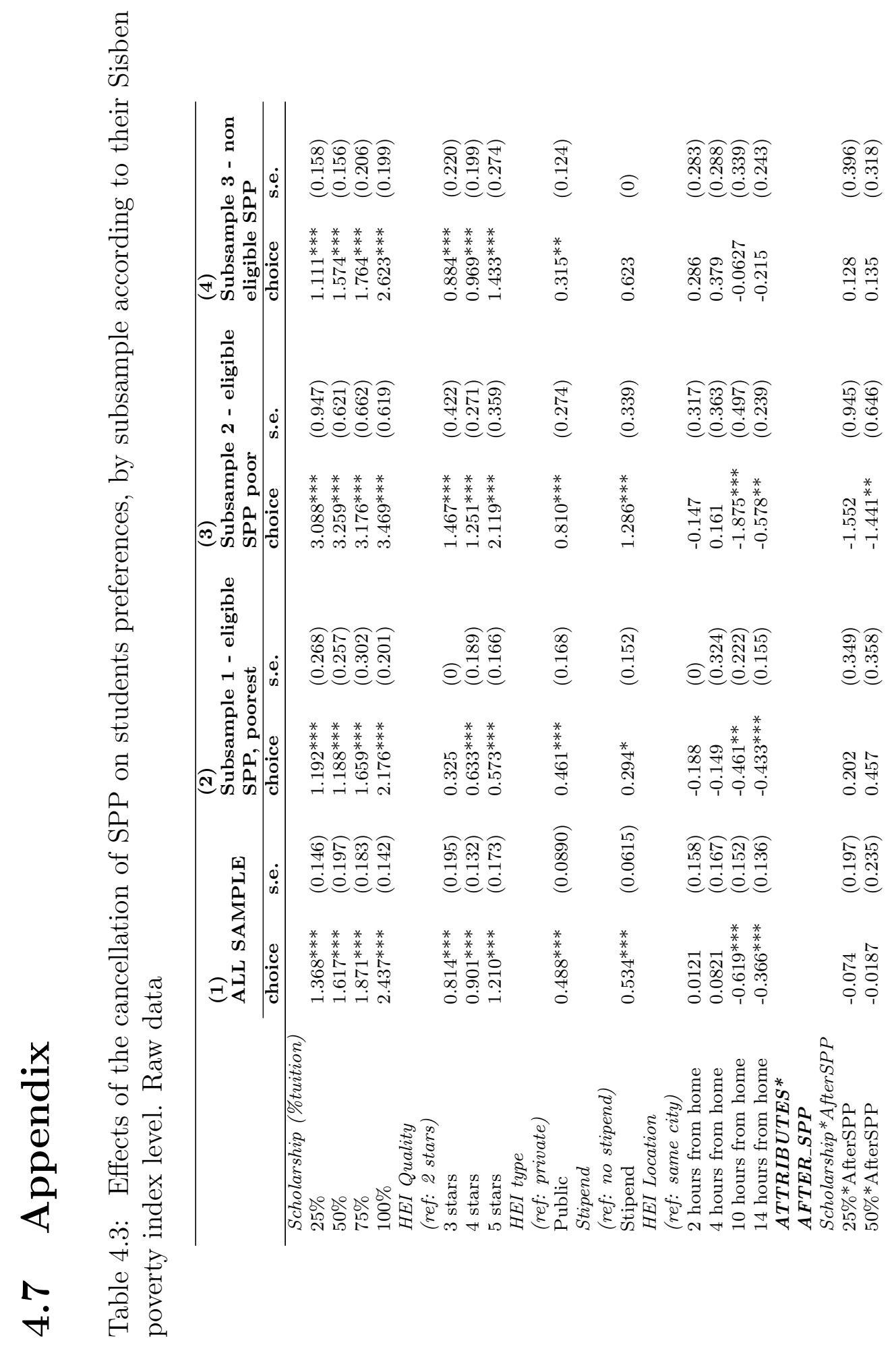




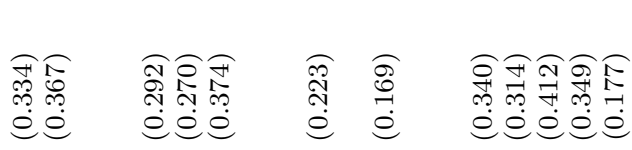

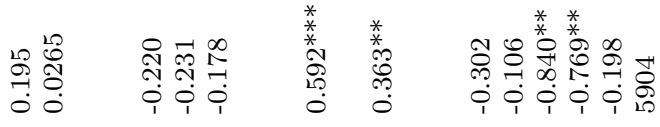

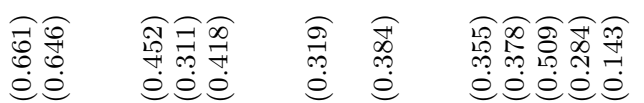

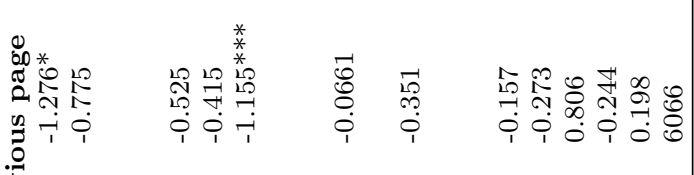

范

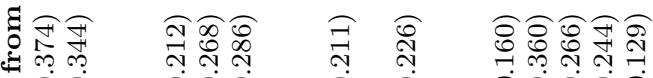

- é

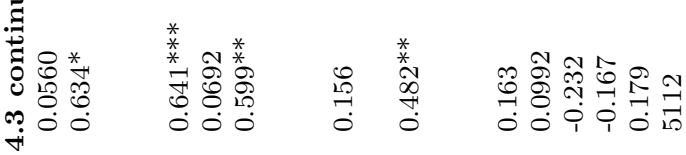

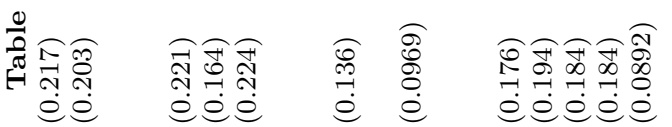

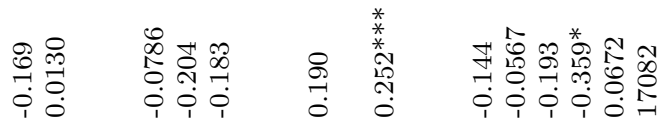

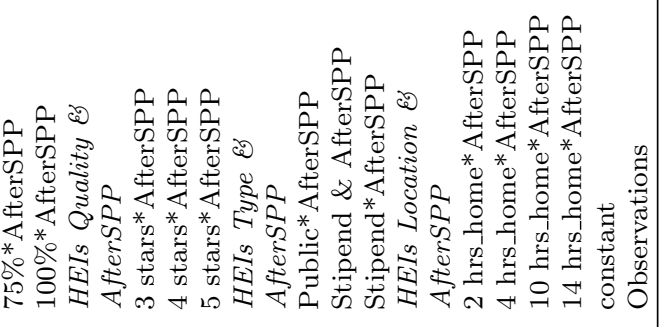




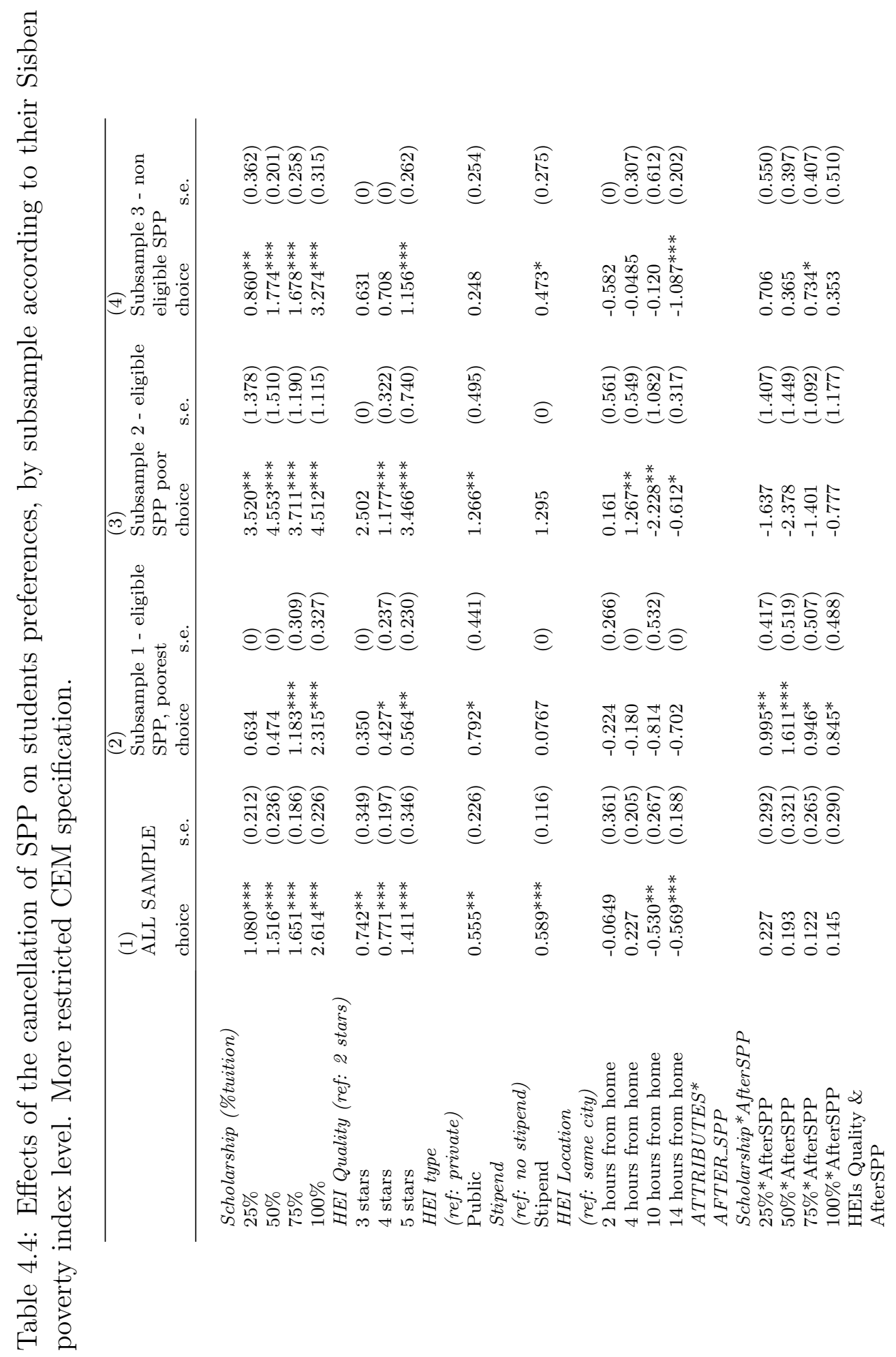




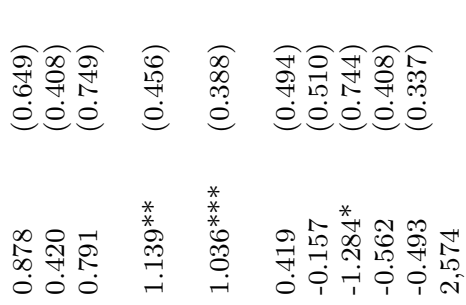

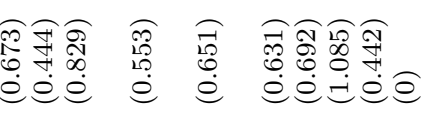

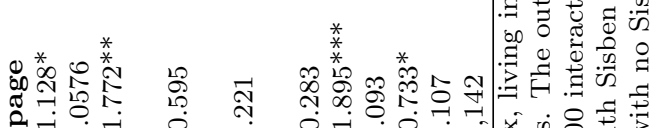

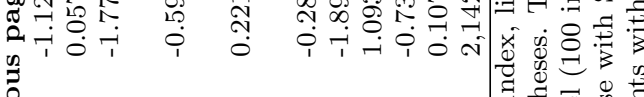

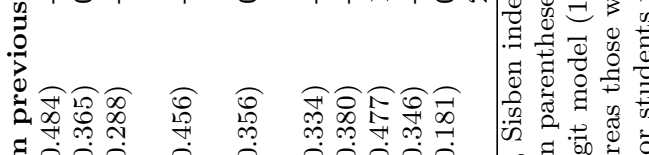

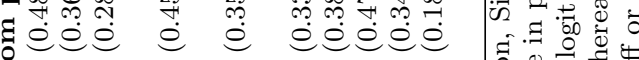

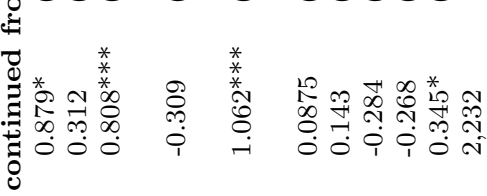
H্

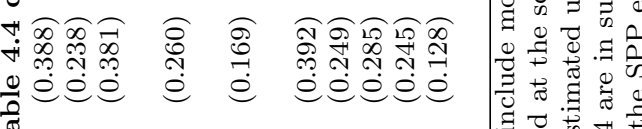
ब

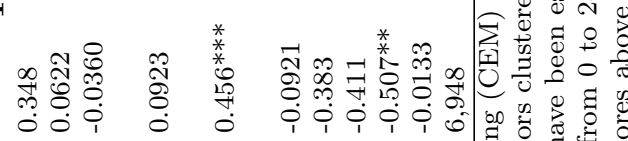

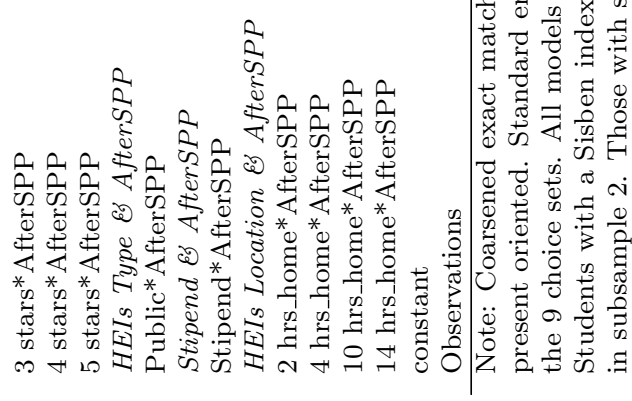




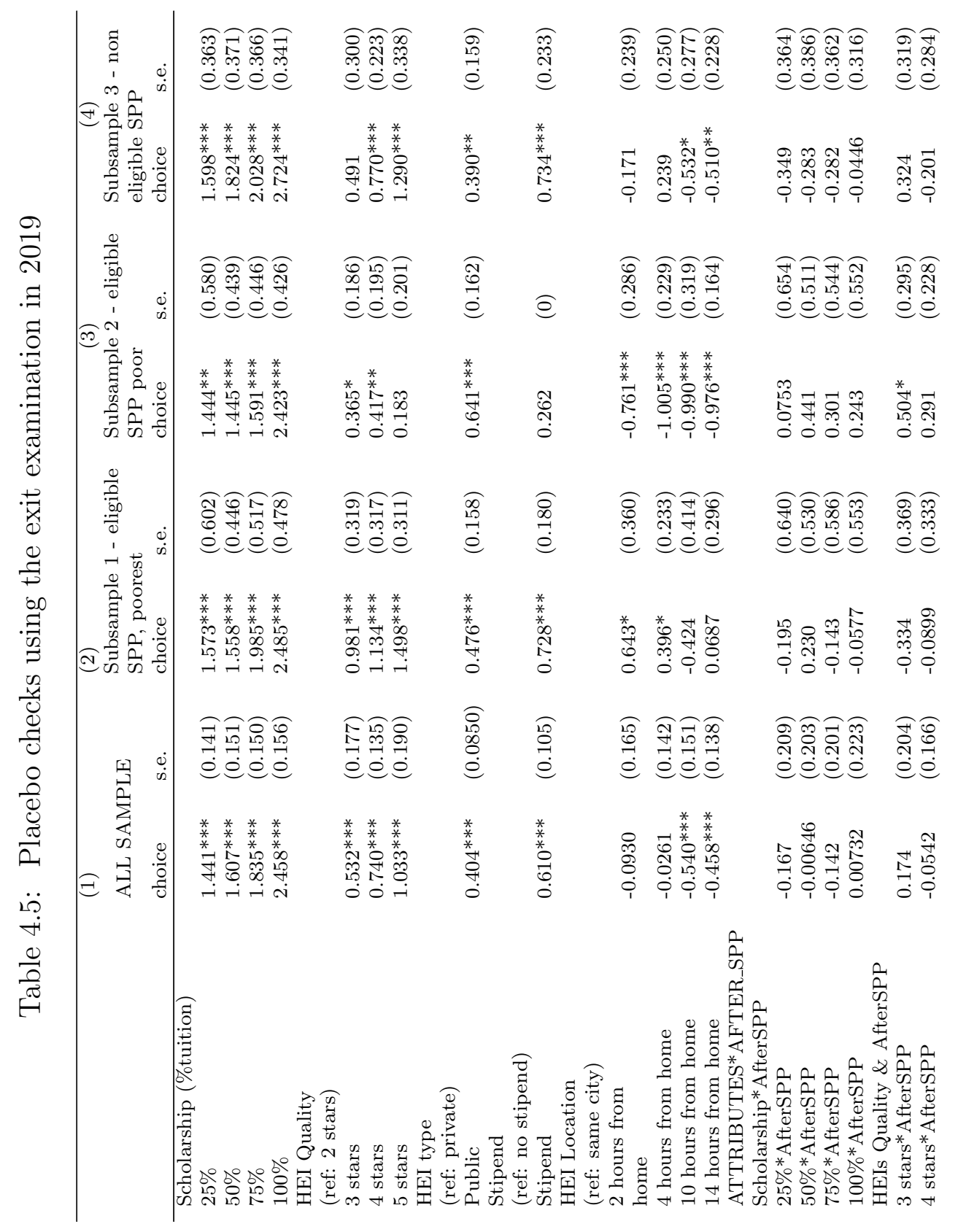




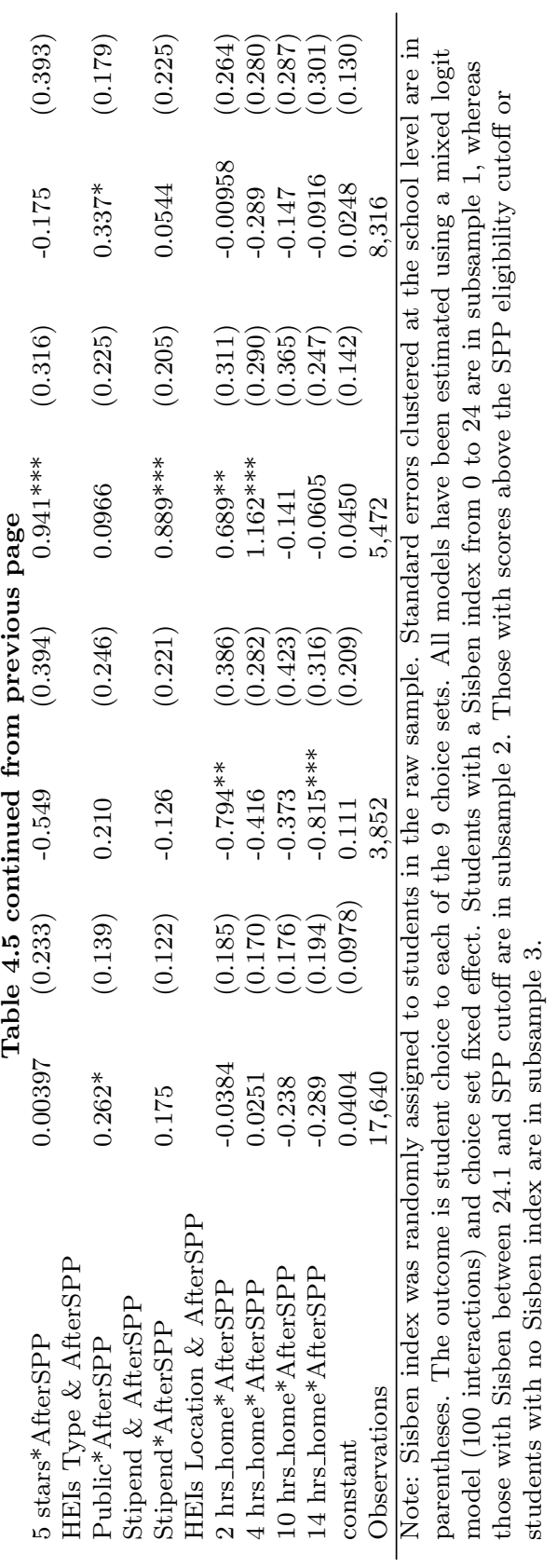




\section{Chapter 5}

\section{The Effect Of Converting Single-sex Schools to Coeducational:}

\section{Quasi-experimental Evidence From Colombia $* \dagger$}

\section{Abstract}

There has long been a debate about the effect of coeducational (coed) settings on pupils' academic achievement in schools. Exploiting quasiexperimental evidence from Colombia, this study examines the effects of the conversion of single-sex to coed schools on students' performance. Using a time varying difference-in-differences strategy, we exploit the conversion of 78 male-only and 168 female-only schools to coed schools in a period of 17 years. The results suggest that males attending former maleonly (ex-male) schools decreased their performance. In contrast, females attending former female-only (ex-female) schools increased achievement.

${ }^{*}$ This chapter is based on: Bernal, G. \& De Witte, K. (2020). The Effect of Converting Single-sex Schools to Coeducational: Quasi-experimental Evidence from Colombia.

†We are grateful to Mindel van de Laar and seminar participants at the $5^{\circ}$ the LEER Workshop on Education Economic, the UNU-MERIT workshop 2018 for their valuable comments and suggestions. 
Moreover, female students attending ex-male schools outperform females in coed, ex-female and current female-only schools. Our findings support the hypothesis that a masculine schooling environment (i.e. on average, characterized as more competitive, and with a stronger math focus) may be beneficial for females' performance, although this is to the expense of males' achievement.

\subsection{Introduction}

The convenience of converting single-sex schools to coeducational (coed) schools (or the other way around) has been widely discussed without a consensus (Title IX of the federal Education Amendments, 2006; Department for Education and Skills UK, 2007). Theoretical arguments state that both male and female students perform better in a single sex-school academic environment; for example, because of the adaptation to different learning mechanisms, or the development of competitive-related skills (Schneeweis \& Zweimuller, 2012; Booth \& Nolen, 2012). In contrast, other theories favor coeducation as a mechanism to improve performance of both genders, e.g. due to undesirable behavior such as sex-segregation and gender stereotypes (Halpern, et al., 2011; Hilliard et al. \& Liben, 2010). The debate on the effects of gender composition on educational performance is particularly relevant in developing countries, which are generally characterized by low academic achievement, notorious gender gaps (OECD, 2018) and little causal evidence on the effects of mix-gender composition on achievement. In this study, we exploit a rich longitudinal dataset and the unique quasi-experimental case of Colombia to examine the extent to which the conversion from single-sex schools to coed schools affects the academic achievement of male and female students.

Empirical studies have stressed the benefits of single-sex schools over coed schools, when looking at the impact on academic performance. However, a number of these studies suffer from self-selection bias (see the meta-analysis by Pahlke et al., 2014). That is, single-sex schools and their students may differ in unobservable characteristics from coed schools and the students attending them. Therefore, the estimates obtained when comparing single-sex to coed schools cannot be interpreted as causal effects. Nevertheless, two studies used a causal framework to investigate the impact of converting single-sex schools to coed on aca- 
demic achievement, however, they suffer from low power. Lee \& Park (2017), and Dustmann \& Kwak (2018) exploited the conversion of a few (7 males-only) private, single-sex schools to coed, and the random assignment of middle-school graduates to different high schools in Seoul, South Korea. Both investigations indicate that the conversion leads to worse academic outcomes for boys. ${ }^{1}$

Using a similar research question and methodology as Lee \& Park (2017) and Dustmann \& Kwak (2018), we contribute to the literature on the conversion of single-sex schools to coed in three aspects. First, we exploit a large-scale natural experiment, where numerous single-sex schools (78 male-only and 168 female-only) converted to coed facilities, during the 1990s and 2000s in Colombia. Second, we exploit the unique significant variation in the share of opposite sex students -from 1 former single-sex schools and across cohorts within the same school, thus allowing to teased out the gender peer effect from the possible endogenous responses of teachers and parents right after the change. Third, given that the causal evidence of single-sex schools versus coeducational in general, and the conversion of single-sex schools to coed in particular, has been almost exclusively examined for high income countries (e.g. South Korea, England, or the USA), this research contributes to the literature in analyzing the conversion of single-sex to coed system in the context of a developing nation characterized by low performance and high gender academic gap. ${ }^{2}$ These academic conditions are fundamentally different from other developed nations such as South Korea. ${ }^{3}$

\footnotetext{
${ }^{1}$ Dustmann et al. (2018) studied in addition 4 female-only schools and find a negative effect on girls'performance in ex-female-only schools.

${ }^{2}$ While South Korea consistently occupies a top 10 position in international rankings of math (and occasionally reading) assessments, Colombia consistently ranks in the bottom 10, and has amongst the largest gender gap in math (and amongst the lowest gender advantage in reading) across PISA-participating countries (OECD, 2018). In Colombia, boys outperformed girls in mathematics by 20 score points, which is 4 times larger than the average gender gap in mathematics across OECD countries. In addition the advantage for girls in reading is 3 times lower than the OECD average. Moreover, while girls slightly outperformed boys in science overall, in Colombia boys outperformed girls in science by 12 score points. w www.oecd.org/pisa/publications/PISA2018_CN_COL.pdf

${ }^{3}$ According to Smyth (2010) the societal context within which coeducational and single-sex education take place can influence the processes at play and it is usually neglected by researchers.
} 
Two main reasons triggered the schools to change their gender composition status: (1) the explicit recommendation in the Colombian National Education Plan (1996-2005) to switch single-sex schools to coed; and (2) the worldwide idiosyncratic trend considering coed schools favorable for children development (UNICEF \& United Nations, 1993). Selection into coed regimen was not mandatory but highly recommended. As long as selection is based on time-invariant school characteristics (observed and unobserved) this shall not affect the causal interpretation of the Differencein-differences with fixed effects estimates. This, combined with the high cost or the mere impossibility to transfer students to another single-sex school, allows this setting for a natural experiment consideration. ${ }^{4}$ Using the 2001-2017 panel data from compulsory high school exit examinations along with a time varying Difference-in-differences (DiD) methodology and school fixed effects capturing observed and unobserved heterogeneity at school level, we aim to answer the following question: Does this conversion of single-sex schools to coed affect academic performance of incumbent students? Moreover, using a coarsened exact matching (CEM) approach, we aim to answer the question: Does this conversion has differential effects on the performance of incoming opposite-sex students in converting schools? i.e. females in ex-male schools and males in ex-female schools.

This study contributes to the extensive literature that claims that nurture over nature is a decisive element of academic success regardless of the students' gender (Guiso et al., 2008). Unobservable learning dynamics and school environments, such as those pursued in masculine and in feminine environments, are possible determinants of academic success (Van De Gaer et al., 2004). In addition, the present study contributes to the literature that analyzes the interactions between male and female students in school environments (e.g. Welch et al., 2014), and to the scarce literature of gender peer effects on performance in developing countries.

The results suggest that, when females join an ex-male school, the

\footnotetext{
${ }^{4}$ Students' residence $(86 \%$ of the municipalities did not have another single-sex school to transfer) and high cost of single-sex private schools prevent students transferring to another single-sex school. Even in the case that moving from the converting school occurs, our estimates will be bias downwards as parents will transfer those students that would be negatively affected by the presence of the opposite-sex in their classes.
} 
decrease in the performance of males is proportional to the percentage of females that newly enroll in the school. This decrease in performance is already quite pronounced at even a $10 \%$ share, where males see a decrease in their academic performance of 0.1 standard deviations. In contrast, when males join an ex-female school, the increase in the performance of females is proportional to the percentage of males entering to the school. Conditional on observed characteristics, females in ex-male schools score the highest among other types of schools (i.e. mixed, ex-female or femaleonly schools). In contrast, males in ex-female schools perform worse than ex-male and male-only schools, and yet better than in coed schools. Our findings support the hypothesis that a masculine schooling environment, which has typically been characterized by more competitive, and with a stronger math focus, may be beneficial for females' performance, but this might be at the expense of males' achievement. Furthermore, the hypothesis that boys may lose focus on their studies and/or experience disruptive behavior, as shown in the South Korean studies, is also a possible explanation to the reduction in boys' performance.

The remaining of the study is structured as follows: Section 2 and 3 provides a review of the literature and a description of the Colombian educational system, respectively. The dataset and the difference-indifferences model framework is described in Section 4. Section 5 presents the results, and various robustness checks; and Section 6 discusses the results and concludes.

\subsection{Literature review}

In the late 19th and early 20th centuries, coeducation became more widely accepted in different nations such as the USA, China, UK, and the Soviet Union countries. In fact, under the arguments of gender inclusion, equal education opportunity and diversity many nations required their public schools to be coeducational by mandate. By the early 21 st century, coeducational education became the rule with most of the countries in the world having lower than two percent single-sex schools (Wiseman, 2008). ${ }^{5}$ However, there is still an opened debate over the benefits on non-

\footnotetext{
${ }^{5}$ Using Mathematics and Science Study (TIMSS), Wiseman (2008) identified that nations with more than $15 \%$ of the schools being single-sex included: Chile, Singapore, England, Israel, Hong Kong, Israel, New Zealand, Australia, South Korea, and Muslim
} 
cognitive and cognitive outcomes of keep students separated by gender (in some classes for instance).

The large theoretical and empirical literature in the area of educational psychology and economics observes mixed and inconclusive evidence on the effects of mixing boys and girls in the classroom on learning. On the one hand, some theoretical studies show that students perform relatively better in singlegender classes. This literature shows that the higher levels of performance could be explained by the following factors: teachers can easily focus on the needs and ways of learning of each sex (Sax, 2010; Lee Marks \& Byrd, 1994); the development of competitiverelated skills (Booth \& Nolen, 2012); and more concentration of students on academics rather than on appearance and popularity (Riordan et al., 2008). It is also argued that girls may perform better in girls' schools because they have more self-confidence, and there are fewer gender stereotypes (Eisenkopf et al., 2015; Shapka \& Keating, 2003). On the other hand, some other theoretical studies argue that stereotypes are in fact strengthened in girls' schools (Bigler \& Liben, 2007; Halpern et al., 2011) and that girls in female-only schools are less likely to pursue careers in science and technology (Oakes, 1990; Thompson, 2003).

In terms of academic achievement, the literature is not conclusive either. Single sex schools tend to show higher performance but this advantage is small or even disappear after properly control for individual factors such as socio-economic status, ethnicity or school factors as leadership and teacher expertise (Smithers et al., 2006; Pahlke et al., 2014). Empirical evidence using causal research designs tends to find positive effects of attending single sex schools over coed. Using random assignment of pupils to either single sex or mixed schools to assess performance, Park et al. (2013) find that attending a coed (versus single-sex) school lowers achievement and decreases the likeliness to apply to higher education for both boys and girls in Seoul, South Korea. Moreover, the benefits on achievement of a single-sex school over coed in the United States are also highlighted by Choi, Hyungsik \& Geert (2014), whereas Jackson (2012) finds for Trinidad and Tobago that only the girls with a revealed preference for girls' schools before their assignment experienced benefit of single-sex schooling. In contrast to the other studies, and conditional in nearly random assignment, Doris, O'Neill \& Sweetman (2013)

nations. 
do not find that single-sex schooling reduces the significant gender gap in performance favoring boys in Ireland. The mentioned studies compared mixed-always with single-sex-always schools, which relates to but is different to the present study. In the present study, we compare the same school under two regimes of gender composition, which avoids large school heterogeneity in the comparison and allows for a better control of time-invariant unobservable characteristics of the school (such as school management, culture, believes, organization, teacher composition, etc.).

Lee et al. (2017) and Dustmann et al. (2018) are closely related to the present study. Both studies exploited school transitions from single-sex to coed schools in South Korea to identify the effects of single-sex schooling on academic achievement, using a Difference-in-differences (DiD) approach with school fixed effects. Lee (2017) focuses on the transition of seven boys-only schools, whereas Dustmann et al. (2018) analyzed these seven schools and another four female-only schools that were converted to a coed setting. Although the latter focuses more on comparing single-sex schooling to coed schooling, both studies compared cohorts in the same school that were exposed to either a single-sex or a coed environment at two different levels: within-high-school and within-class level. They find that the conversion of single-sex schools to coed leads to worse academic outcomes for boys (and girls in Dustmann's paper). While Lee et al. (2017) suggest that this negative effect disappeared after two years when the school transition was completed, Dustmann et al. (2018) conclude that the negative effects are more persistent.

\subsection{Institutional background}

Colombia performs significantly below the OECD average in international tests such as the PISA assessment, and the academic gender gap is among the largest in the world. Compared to all countries participating in the 2018 PISA assessment, males outperform females in math by the widest margin, but at the same time, girls outperform boys in reading by the lowest margin (OECD, 2018). Although policy discussions focus on ways to increase achievement - including teaching each gender separately in mixed schools - there is limited research exploring the gender peer effect on academic achievement. 
In Colombia, compulsory education begins when children are 5 years old and it lasts until children turn 15 years old (grade 9). In addition, students must study two more years to graduate from high school (grade 11). Two academic calendars are used simultaneously: one starts in February (A calendar) and one in August (B calendar). Most national schools, hosting approximately $95 \%$ of the students are in A calendar. ${ }^{6}$ Up to the 1950's, separate schooling for boys and girls was the rule. However, in 2019 only the minority of schools (about 7\%) are singlesex schools, and those are often managed by a religious organization. Although conversion was implemented by many schools in the last six decades, tests scores to measure the consequences of this phenomenon are only available from year 2000 onwards.

Reasons for conversion of each particular school are unknown. However, two events likely trigger the schools decisions: (a) it was highly recommended (albeit not obligatory) by the government National Education Plan (1996-2005) to deliver coed rather than single-sex schooling arguing gender equalization, and (b) there were trend changes regarding idiosyncratic beliefs of parents and school administrators about mixing students in classes following worldwide trends (UNICEF \& United Nations, 1993). According to newspapers articles, parents who these days choose single-sex schools usually argue that single sex favors values, customs, discipline, non-discrimination and culture (Semana, 2019). These reasons are consisted with parents in other countries such as the USA (Heather, 2002).

Colombian parents have relative freedom to choose the school for their children compared to parents in other nations. In public schools, students are by default assigned based on their home location. However, there are no legal impediments for a student living in some district area to enroll a school in another district area (as it is the case in the USA or in South Korea). Although the dropout rate in secondary education is high (at roughly $4.09 \%$ annually, for the year 2019), a transfer from one school to another is a rather uncommon practice due to the high transactional costs of switching schools and the strict entrance limitations (e.g. in public schools it is difficult to find another available spot, and private high-quality schools do not often receive students from another school

\footnotetext{
${ }^{6}$ Many B calendar are international schools in Colombia which align with international calendars.
} 
unless the student has outstanding credentials). Adding to this, in case students desired a relocation from one single-sex school to another one in the same municipality, in $86 \%$ of the cases there was no other school left to transfer to in 2001. While private schools have more autonomy (and on average have students with higher SES) than public schools, a similar number of private and public schools converted in our sample.

\subsection{Data and Method}

Data. We use administrative data of the national exit examination in Colombia, Saber $11^{\circ}$. The exam can be thought of as analogous to the SAT and ACT exams in the United States. It is administrated to all students who graduated from high schools in Colombia by the Colombian governmental agency in charge of measuring the quality of education: ICFES. ${ }^{7}$ In 2014, the Saber $11^{\circ}$ exam switched from evaluating eight subjects to five subjects. We examine math and reading sections not only because they are transversally evaluated in all versions, but also because they are high-stake subjects in which historically male and female respectively outperform the other sex. In its sampling strategy ICFES targets each subject to have a mean of approximately 50 and a standard deviation of about 10. We also examined the overall performance of the students' global score, as this score serves to enter to the university. The average of the student scores per school then makes up the school score, which is also the measure used for ranking schools. For each year, we standardized scores using z-score in the final sample and averaged students' scores to the school level. In addition to test scores, Saber $11^{\circ}$ also reports information on school characteristics and, since 2008, it also reports information on students' demographics such as socioeconomic (SES) strata. This strata measure is particularly unique in Colombia and lead the possibility to adequately know if the students belong to a low, middle or high income household. ${ }^{8}$ Approximately $97 \%$ for senior high school students take the exam.

The final sample consists of 3,962 Colombian secondary schools (which include mixed schools, single sex schools and converting schools). In the

\footnotetext{
${ }^{7}$ ICFES stands for "Instituto Colombiano para el Fomento de la Educación Superior".

${ }^{8}$ Low-SES are 1 or 2 , middle-SES are 3 and 4 , and high SES are 5 and 6 . For more details see Bernal and Penney (2019).
} 
period 2001-2017, we observed that 78 male-only and 168 female-only schools have converted to a mix their gender composition. ${ }^{9}$ Schools may have started its conversion in k-grade, which gives a time span from 1990 onwards. We excluded schools with fewer than 14 out of 18 possible registers in the study period. This leads to the inclusion of schools that graduate cohorts regularly during the study period. We also exclude schools with average cohorts size of less than 30 students. This eligibility rule leads to an exclusion of mostly mixed rural schools, which usually differ in curriculum practices. ${ }^{10}$ Figure 5.1 shows the number of converting schools observed at exit examination, by gender-type, during the period of analysis. ${ }^{11}$

Although there might be multiple reasons for a school to convert (see Section 3), our identification requires only that the decision to switch is based on time-invariant school characteristics (which we account for by school fixed effects) or time-trends (which we account for by year fixed effects). As long this mild assumption holds, the DiD estimates will identify the combined effects of a school's gender type and possible schoollevel changes that accompany the school-type conversion. The summary

statistics of the sample schools are displayed in Table 5.1. Standardized math and reading scores by year are nearly zero for mixed schools that have been always in this condition (Column 1). By contrast, maleonly and female-only schools significantly outperform mixed schools in math (reading) by 2.10 and 0.93 (1.69 and 1.30) SDs (Columns 2 and 4). Similarly, converted schools outperformed coed schools (Columns 3 and 5), but in lower magnitudes ranging from 0.43 to 1.4 SDs ( 0.5 to $1.5 \mathrm{SDs}$ ) in math (reading). It is noticeable that, after conversion, the absolute achievement of students in ex-male schools dropped roughly $2 / 3$ of a standard deviation, whereas students in ex-female increases by $1 / 3$

\footnotetext{
${ }^{9}$ This is approximately $6 \%$ of the total number of schools in the sample.

${ }^{10}$ Example of rural practice is the program "escuela nueva" in which students in different grades seat in the same room with one or two instructors. Each student follows a different guideline or book depending on the grade. Moreover, in inspection of rural schools, some of them did have single sex cohorts although they were mixed schools. This is because when graduating few students (one student in some cases), chances are that a particular small cohort has girls only or boys only.

${ }^{11}$ We observe that schools that adopted early the conversion were more likely to be public schools, in small cities, with low or no fees compared to those who adopt later the regimen. The nature and time invariant characteristics of schools are controlled under the school and school-trend fixed effects.
} 
Figure 5.1: Number of single-sex schools that converted to coeducational observed in exit examination over time.

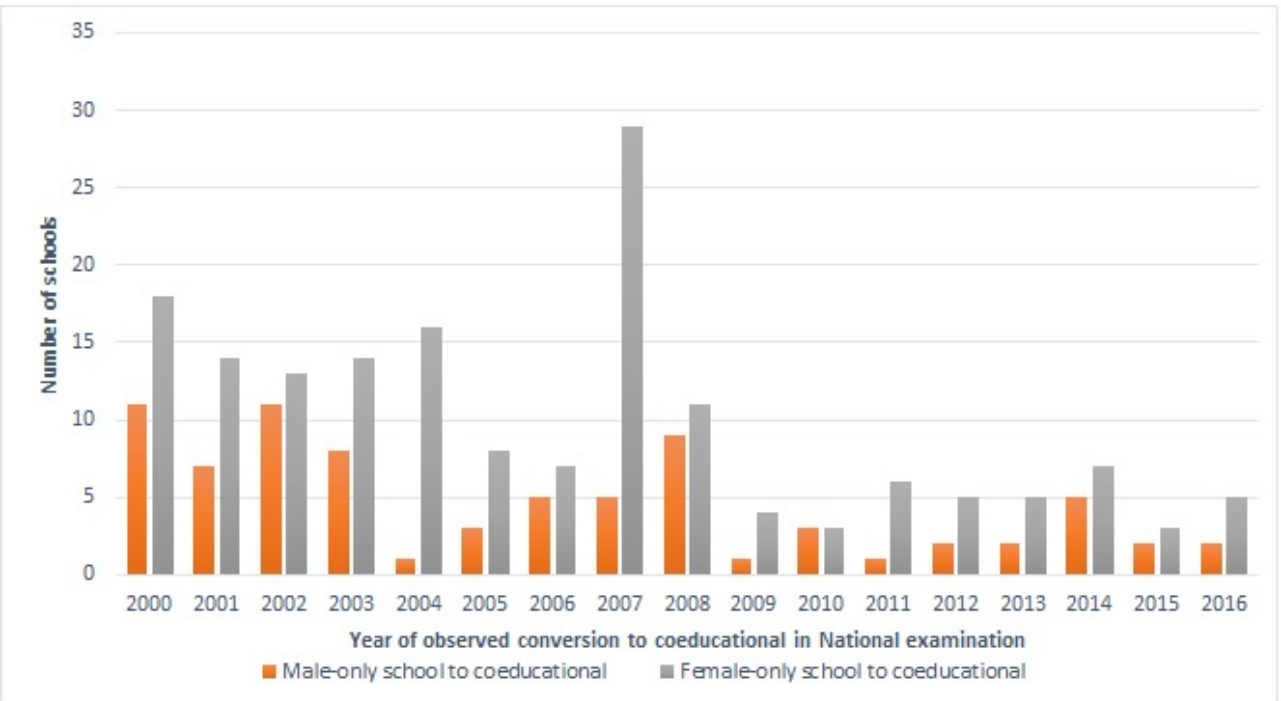

Note: We excluded schools with fewer than 14 out of 18 possible registers in the study period and schools with average cohorts with fewer than 30 students. The former lead for schools that are regularly active during the study period, whereas the latest excluded mostly co-ed rural schools. Total schools in the sample:3962.

of a standard deviation (Column 3 and 4). Nevertheless, these losses cannot be attributed to causal effect of the transition from single-sex to coed system because of the possible influence of other observable and unobservable factors such as trends over time, school academic culture or idiosyncrasies or school particular trend. The empirical analysis will account for the mentioned elements. 


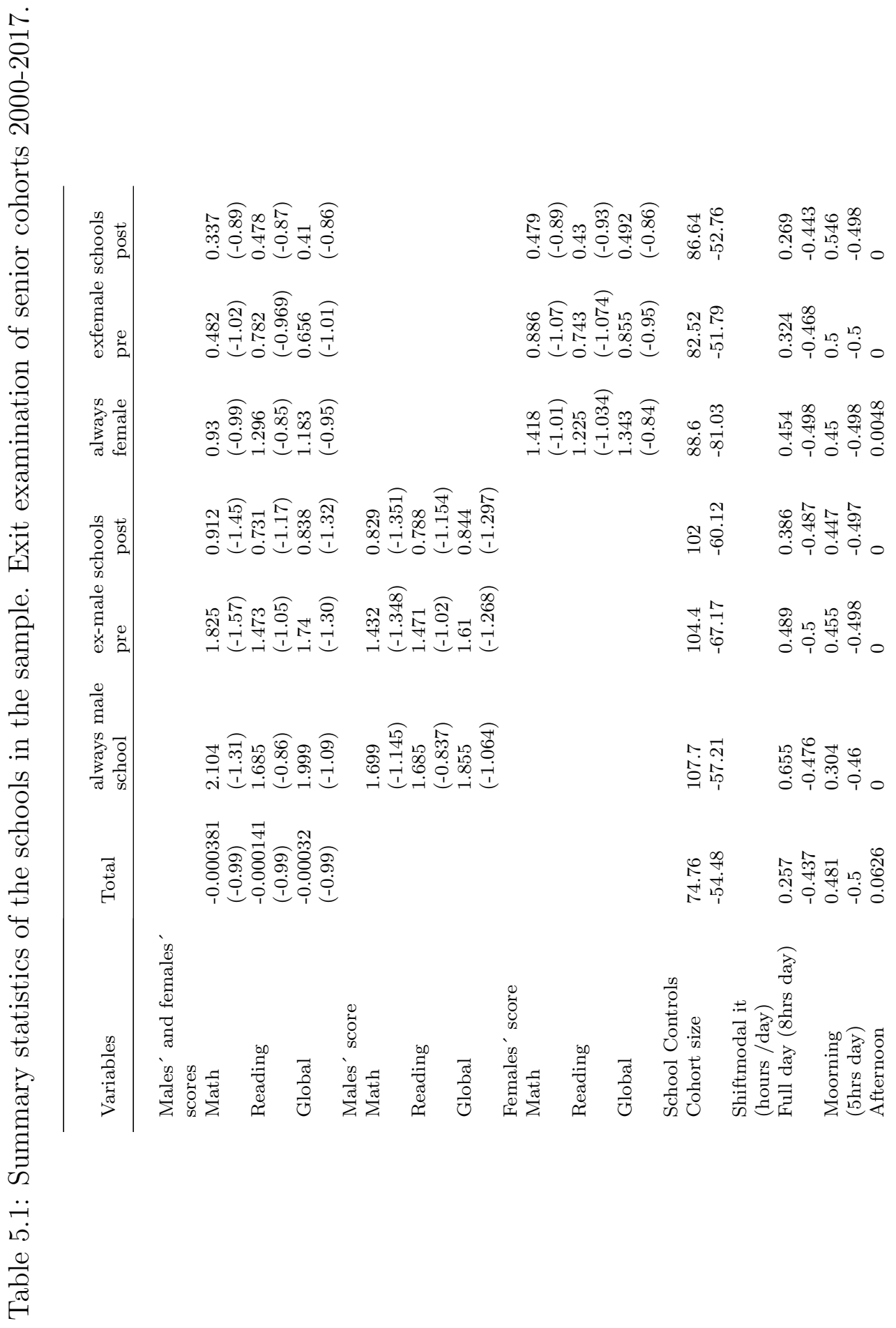




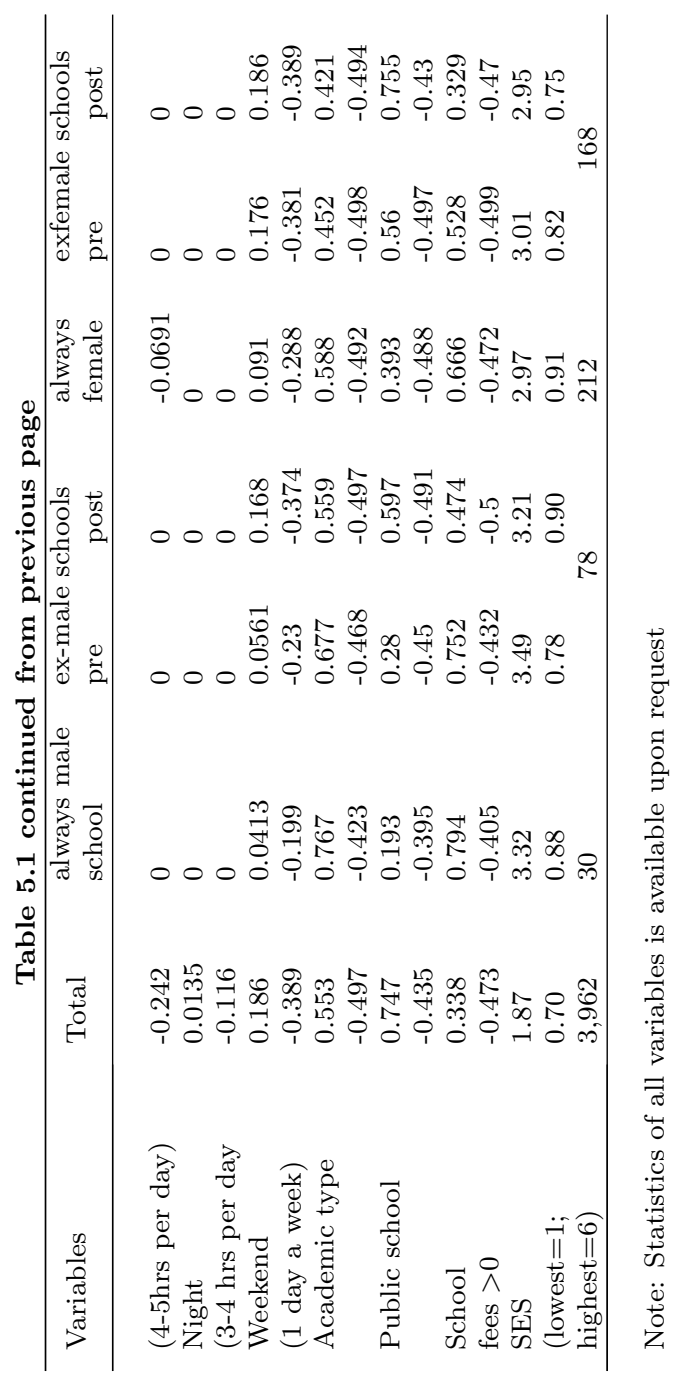


Figure 5.2: Example of a boys-only school that converts to coeducational in $\mathrm{K}$ grade, observed in 11th grade at t period.

\begin{tabular}{|c|c|c|c|c|c|c|c|c|c|c|c|c|c|c|c|c|c|c|c|}
\hline \multicolumn{19}{|c|}{ observed conversion } & \multirow[b]{3}{*}{ observed outcome } \\
\hline & $t-12$ & $t-11$ & $t-10$ & $t-9$ & $t-8$ & $t-7$ & $t-6$ & $t-5$ & $t-4$ & $t-3$ & $t-2$ & $t-1$ & $t$ & $t+1$ & $t+2$ & $t+3$ & $t+4$ & $t+5$ & \\
\hline $11^{\circ}$ & Boys & Boys & Boys & Boys & Boys & Boys & Boys & Boys & Boys & Boys & Boys & Boys & B\&G & B\&G & $B \& G$ & B\&G & $B \& G$ & B\&G & \\
\hline $10^{\circ}$ & Boys & Boys & Boys & Boys & Boys & Boys & Boys & Boys & Boys & Boys & Boys & B\&G & B\&G & B\&G & $B \& G$ & $B \& G$ & B\&G & B\&G & \\
\hline $9^{\circ}$ & Boys & Boys & Boys & Boys & Boys & Boys & Boys & Boys & Boys & Boys & $B \& G$ & B\&G & B\&G & B\&G & $B \& G$ & $B \& G$ & B\&G & B\&G & \\
\hline $8^{\circ}$ & Boys & Boys & Boys & Boys & Boys & Boys & Boys & Boys & Boys & B\&G & $B \& G$ & B\&G & B\&G & B\&G & $B \& G$ & B\&G & B\&G & $B \& G$ & \\
\hline $7^{\circ}$ & Boys & Boys & Boys & Boys & Boys & Boys & Boys & Boys & $B \& G$ & B\&G & $B \& G$ & $B \& G$ & B\&G & $B \& G$ & $B \& G$ & $B \& G$ & B\&G & $B \& G$ & \\
\hline $6^{\circ}$ & Boys & Boys & Boys & Boys & Boys & Boys & Boys & B\&G & B\&G & B\&G & $B \& G$ & B\&G & B\&G & $B \& G$ & $B \& G$ & B\&G & B\&G & B\&G & \\
\hline $5^{\circ}$ & Boys & Boys & Boys & Boys & Boys & Boys & B\&G & B\&G & B\&G & B\&G & $B \& G$ & $B \& G$ & B\&G & $B \& G$ & $B \& G$ & B\&G & B\&G & $B \& G$ & \\
\hline $4^{\circ}$ & Boys & Boys & Boys & Boys & Boys & B\&G & $B \& G$ & B\&G & $B \& G$ & B\&G & $B \& G$ & $B \& G$ & B\&G & $B \& G$ & $B \& G$ & $B \& G$ & B\&G & $B \& G$ & \\
\hline $3^{\circ}$ & Boys & Boys & Boys & Boys & B\&G & $B \& G$ & $B \& G$ & B\&G & $B \& G$ & $B \& G$ & $B \& G$ & B\&G & B\&G & B\&G & $B \& G$ & $B \& G$ & B\&G & $B \& G$ & \\
\hline $2^{\circ}$ & Boys & Boys & Boys & $B \& G$ & $B \& G$ & B\&G & $B \& G$ & $B \& G$ & $B \& G$ & $B \& G$ & B\&G & $B \& G$ & $B \& G$ & B\&G & $B \& G$ & $B \& G$ & $B \& G$ & $B \& G$ & \\
\hline $1^{\circ}$ & Boys & Boys & $B \& G$ & B\&G & $B \& G$ & $B \& G$ & B\&G & B\&G & $B \& G$ & B\&G & $B \& G$ & B\&G & B\&G & $B \& G$ & $B \& G$ & $B \& G$ & B\&G & $B \& G$ & \\
\hline$\overline{\mathrm{K}}$ & Boys & $B \& G$ & B\&G & B\&G & B\&G & B\&G & $B \& G$ & B\&G & $B \& G$ & B\&G & $B \& G$ & B\&G & B\&G & B\&G & $B \& G$ & B\&G & B\&G & B\&G & \\
\hline
\end{tabular}

Note: grades are represented in the right side. Score is observed in 11 grade. $t$ is the cohort that we observe converting to coeducation; $t+1$ is the subsequent cohort, whereas $t-1$ is the previous to the change cohorts. Notice that this is an extreme case where school decided to converted in $K$ grade. Other schools might decide to switch in different cohorts, or all school at once.

We observe the students' achievement in the high school exit examination. Nevertheless, the conversion and thus the exposure to a new regime may have started several years prior for most schools. Figure 5.2 shows an example of the transition process for an ex-male school to coed school. In this extreme case the transition started with kindergarten inflows (from boys only to allowing mixed classes to start), and it was done one cohort at the time for incoming classes only. ${ }^{12}$ The observed outcome is at 11th grade. That is, we observe conversion to mix gender composition in t period. However, this cohort could have been exposed to girls presence in the school for a period as long as 11 years. The cohort in t-1 did not have girl peers at class level, but they did at school level because the precedent cohort was gender mixed. That is, the $\mathrm{t}-1$ cohort experienced exposure to mix gender composition environment at school-level (although not class-level) for the last 10 out of 11 years of their compulsory education. The year of change to mixed regime at time $\mathrm{t}$ is labelled by 0 . It should be noticed that the proportion of females has monotonically increase (decrease) along transition for ex-male (exfemale) schools (see Figure 5.3). Therefore, nonlinearities in peer effects are further tested. A similar transitional processes in gender composition was experienced in ex-female' schools.

\footnotetext{
${ }^{12}$ Unfortunately, it is no possible to identify from the dataset which schools star doing the conversion cohort by cohort from $\mathrm{K}$ grade.
} 
Figure 5.3: Example of a boys-only school that converts to coeducational in $\mathrm{K}$ grade, observed in 11th grade at $\mathrm{t}$ period.

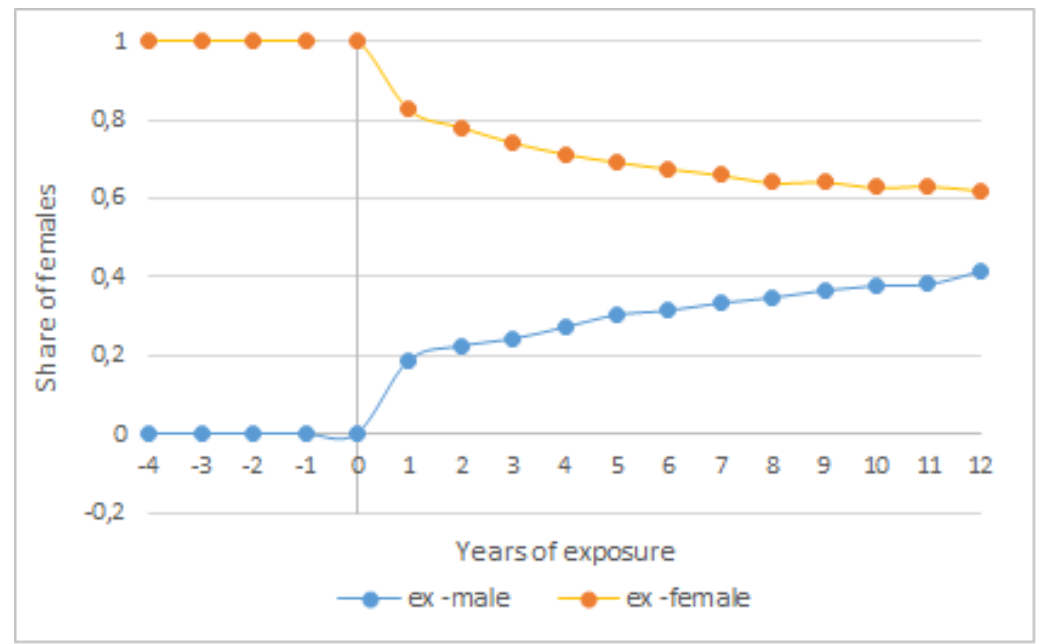

Note: $t$ is the year of conversion from single-sex to coeducational. The share of students from the other sex in ex-single sex schools fails monotonically.

Empirical model. Our goal is to determine the effect of school conversion from single sex to coed schools on students' academic performance. Moreover, we are interested in identifying the intensity effect (proportion of girls in the cohort) after the conversion. We use a differencein-differences identification strategy with time varying implementation (following Bertrand, Duflo \& Mullainathan, 2004) to compare schools' performance before and after the conversion from single-sex to mix. As treated schools later become the controls, this method controls better for differences across time (i.e. pre-trends and post-trend) compared to standard DiD method. We also include school fixed effects to control for time-invariant observed and unobserved school characteristics. The OLS model is formulated as follows:

$$
y_{s g t}=\alpha_{s}+\gamma_{t}+\beta_{1} e_{\text {male } * \text { post }}{ }_{s t}+\beta_{2} e x_{f e m * p o s t}{ }_{s t}+\delta X_{s g t}+\varepsilon_{s g t}+\phi_{s t}
$$

where $y_{s g t}$ is the standardized test score of high school $s$ in municipality $g$, who sat for the test in year $t$.Ex $x_{\text {male*Post }}$ is a dummy indicating whether ex-male school $s$ admitted females in year $t ; E x_{\text {female*Post }}$ is a dummy indicating whether female school $s$ admitted boys in year $t$. The 
year of change to coed regime at time $t$ is labelled by 0 . Moreover, $\alpha_{s}+\gamma_{t}$ are school and year fixed effects respectively, which controls for time invariant school characteristics and time trends. Moreover, $\phi_{s t}$ represents school time-trends at school level dummies (such that every single school has a different slope depending on period), $X_{\text {sgt }}$ represents time-variant controls (cohort size, instructiontime -some school extended their shift-, public or private school, school fee) and $\varepsilon_{s g t}$ is the error term. School and year fixed effects together with school time-trend allow to control for other changes in the schools and legislative framework. We cluster standard errors at the municipal level. The omitted comparison group includes students who are in the cohorts prior the conversion ( $\mathrm{t}-1$ or earlier). The coefficient $\beta_{1}$ is the effect on school performance of converting male schools to mixed, while $\beta_{2}$ will be the effect of converting female schools to mixed.

Due to the gender gap in math, ex-male schools could decrease performance after including girls merely because of girls math test scores are lowering the average of the school s scores. To account for this composition effect, the dependent variable, $y_{\text {sgt }}$ is male-only scores when analyzing ex-male schools and female-only scores when analyzing ex-female schools. Analysis for males in ex-male schools and females in ex-female schools are run separately.

To measure the intensity to the treatment, we exploit the variation induced by the monotonic increase in the share of girls among converted schools. Therefore, we replaced the dummy time-treatment indicator for continuous variables indicating the proportion of girls of the school $s$ at time $t$. Given that we include school fixed effects, differentials in gender composition induce different intensities of the treatment under the new coed regime.

Difference-in-Differences (DiD) assumptions. The DiD framework relies on several assumptions (Rubin, 1980) which also holds after including time varying implementation. First, the stable unit treatment value assumption (SUTVA): if conversion causes parents to change students from one school to another, selection occurs and SUTVA is not met. Due to data limitations, we do not observe if a particular student switches from one school to another. Nevertheless, methodologically, we mitigated possible selection effects by including school-time trends, which 
accounts for tendencies that a particular school experiences over time, including for instance, changes in class size or changing reputation of the schools. In practice, however, due to high transaction costs, parents are not likely to move to another schools, which mitigates the dissatisfaction of this assumption by 11th grade. In addition, if selective attrition occurred, students who are to be transferred are likely to be the ones who would perform worst in mixed schools environments, which would biased estimates toward zero.

Second, the DiD framework is built on the assumption that the change in school gender composition should be unrelated to the performance outcome at baseline. As argued in Section 3, the motivations for conversion are mainly related to inclusion and not to improvements in performance. In fact, observed performance (public rankings) of schools show the majority of mixed schools perform worse than single-sex schools, and the transformed schools eventually performing even worse than before (Herrera, 2016). Therefore, improving performance is unlikely to be a reason to convert.

Third, the parallel trends assumption (PTA) is tested by examining the possibility of anticipation effects and phase-in effects. Leads and lags were included in the equation (1) following Autor (2003). The model can be formulated as follows:

$$
\begin{array}{r}
Y_{s g t}=\alpha_{s}+\gamma_{t}+\phi_{s t}+\sum_{t=-q}^{-1} \beta s t * \text { exmale }_{g t}+\sum_{t=0}^{m} \beta s t * \text { exmale }_{p t}+ \\
\sum_{t=-q}^{-1} \beta s t * \text { exfem }{ }_{p t} \sum_{t=0}^{m} \beta g t * \text { exfem } \text { ert }_{t}+\delta X_{s g t}+\varepsilon_{s g t}
\end{array}
$$

In equation (5.2), q represents the number of leads or the anticipatory effects, while $m$ denotes the number of lags or the post treatment effects. Lead coefficients close to zero indicate no anticipatory effects, fulfilling the PTA assumption. Lag coefficients measure the effects of the policy occurring $\mathrm{m}$ periods after adoption. 


\subsection{Results}

\subsubsection{Effect of conversion from single-sex school to coed on performance}

Our results indicate that converted female-only or male-only schools perform differently after converting to a coed regime. Table 5.2 displays the effects of the change on student performance. The performance of boys in ex-male schools decreased in $0.13 \mathrm{SD}$ in math and in $0.16 \mathrm{SD}$ in reading (columns 3 and 4). This finding is in line with the findings from Dustman et al. (2018) and Lee et al. (2017) in terms of direction and magnitude. The results are also consistent with the academic advantage that male-only schools used to have over males in coed schools in the US (0.14 SDs in math) according to meta-analysis by Pahlke (2014). In contrast, we observe insignificant positive effect of $0.06 \mathrm{SD}$ in math and $0.03 \mathrm{SD}$ in reading for girls in ex-female schools (Columns 5 and 6 ). This finding does not fit the previous literature for the US as this suggested that female-only schools tend to perform better (0.14 SDs) than coed. However, nonlinear positive effects are visible when exploring marginal effects of the share of females. The results for the average effect are robust to the absent of different controls (see Appendix A).

The composition effect -taking the z-score of the school over time without observing the score of a particular gender- shows that, on average, ex-male schools decreased their performance (-0.4 SD in math and $-0.2 \mathrm{SD}$ in reading). In contrast, ex-female schools have, on average, higher test scores after conversion (0.18 SD in math and 0.06 SD in reading). All results are significant at the $1 \%$-level. The magnitude of the effect can be due merely to the mixed gender composition of the new cohorts as in Colombia girls generally underperform boys in math (and boys do fairly similar to girls in reading). Therefore, the inflow of girls lowers the average scores of ex-male schools whereas the inflow of boys increases the average score of ex-female schools. The historic gender academic gap automatically decreases the performance of ex-male schools and increases the performance of ex-female schools after the conversion. This is not of particular importance for other countries such as South Korea, where girls scored similar to boys in math and significantly better in reading (OECD, 2018). Absolute ranking supports our findings that ex-male schools do not benefit from conversion. In exploring the top 100 ranked 
schools over the last two decades, we found three of the ex-male schools and none of the ex-female schools sampled in this study. Although the composition effect is important to evaluate the overall performance of schools, henceforth, we will focus on the peer effect of conversion. 
Table 5.2: Effect on performance of single-sex schools converting to coeducational

\begin{tabular}{|c|c|c|c|c|c|c|}
\hline & \multicolumn{2}{|c|}{ Composed score } & \multicolumn{2}{|c|}{ Males'score } & \multicolumn{2}{|c|}{ Females'score } \\
\hline VARIABLES & $\begin{array}{l}\text { (1) } \\
\text { math }\end{array}$ & $\begin{array}{l}(2) \\
\text { reading }\end{array}$ & $\begin{array}{l}\text { (3) } \\
\text { math }\end{array}$ & $\begin{array}{l}(4) \\
\text { reading }\end{array}$ & $\begin{array}{l}(5) \\
\text { math }\end{array}$ & $\begin{array}{l}(6) \\
\text { reading }\end{array}$ \\
\hline ex_male*post conversion & $\begin{array}{l}-0.394^{* * *} \\
(0.0652)\end{array}$ & $\begin{array}{l}-0.197^{* * * *} \\
(0.0568)\end{array}$ & $\begin{array}{c}-0.126^{* *} \\
(0.0602)\end{array}$ & $\begin{array}{l}-0.156^{* * *} \\
(0.0601)\end{array}$ & & \\
\hline ex_female*post conversion & $\begin{array}{l}0.181^{* * *} \\
(0.0372)\end{array}$ & $\begin{array}{l}0.0559 * * \\
(0.0240)\end{array}$ & & & $\begin{array}{l}0.0591 \\
(0.0426)\end{array}$ & $\begin{array}{l}0.0337 \\
(0.0259)\end{array}$ \\
\hline Constant & $\begin{array}{l}-0.0639 \\
(0.174)\end{array}$ & $\begin{array}{l}0.0907 \\
(0.0839)\end{array}$ & $\begin{array}{c}-0.0163 \\
(0.142)\end{array}$ & $\begin{array}{l}0.114 \\
(0.0779)\end{array}$ & $\begin{array}{l}-0.256 \\
(0.243)\end{array}$ & $\begin{array}{l}0.0257 \\
(0.117)\end{array}$ \\
\hline Observations & 68,758 & 68,758 & 63,849 & 63,849 & 67,697 & 67,697 \\
\hline R-squared & 0.799 & 0.862 & 0.721 & 0.775 & 0.695 & 0.800 \\
\hline School controls & yes & yes & yes & yes & yes & yes \\
\hline School FE & yes & yes & yes & yes & yes & yes \\
\hline Year FE & yes & yes & yes & yes & yes & yes \\
\hline Cluster_Mun & yes & yes & yes & yes & yes & yes \\
\hline School time trend & yes & yes & yes & yes & yes & yes \\
\hline
\end{tabular}

Note: This table reports the estimates of Equation 1. School control variables include: cohort size, instruction time (some school extended their shift), public or private school, school fee (categorical up to 2011 public schools became 0 cost), and years of exposure to the change. Variable ex_male school*post conversion (ex_female school*post) is a dummy indicating whether a male (female) school admitted females (males) in year. School fixed effects and year fixed effects are included. Robust standard errors clustered by municipality are in parentheses. ${ }^{* * *}$ represent significance at $1 \%$-level, ${ }^{* *}$ at $5 \%$-level, and ${ }^{*}$ at $10 \%$-level.

Figure 5.4 presents the regression result described in Equation 2, which tests the parallel trend assumption, and the impact of the conversion in the years before after the change. We find no evidence of anticipatory behaviors during the pre-conversion period for either ex-male or ex-female schools. Panel A and B shows how the general performance of the schools decreases in male schools (due to the increment of the share of females with historical underperformance) and increases in ex-female schools (due to historic over-performance of males). Panel C and E shows the effect on incumbent students' performance in ex-male schools. Reactions in reading are immediate and sustained over time. The effects on math are negative but not significant over the first years of changes. No average effect was found on females' performance in ex-female schools.

\subsubsection{Intensity Effect and Marginal effects}

Given potential nonlinearities in the effect of classroom composition by gender, we exploit the monotonic increase of students from the other sex in the single sex schools. Figure 5.5 shows the marginal effect on 
Figure 5.4: Parallel trend assumption

(a) Composed, global score-exmale (b) Composed, global score-exfemale schools schools
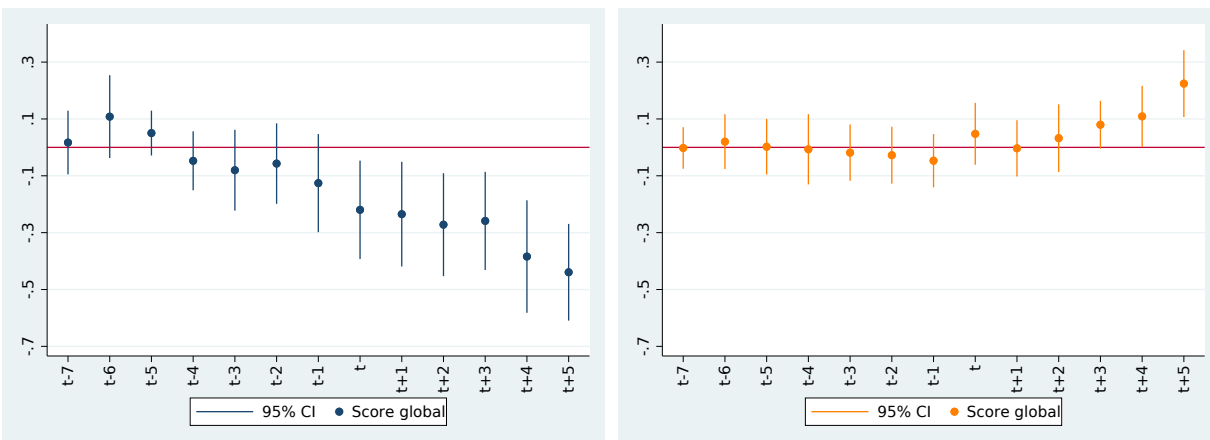

(c) males, math score-exmale schools

(d) females, math score-exfemale schools
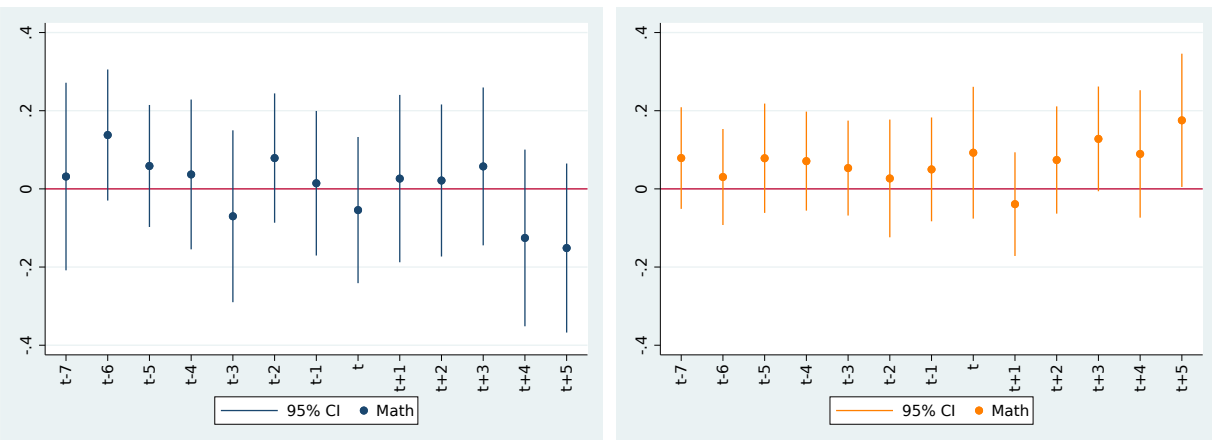

(e) males, math score-exmale schools

(f) females, math score-exfemale schools

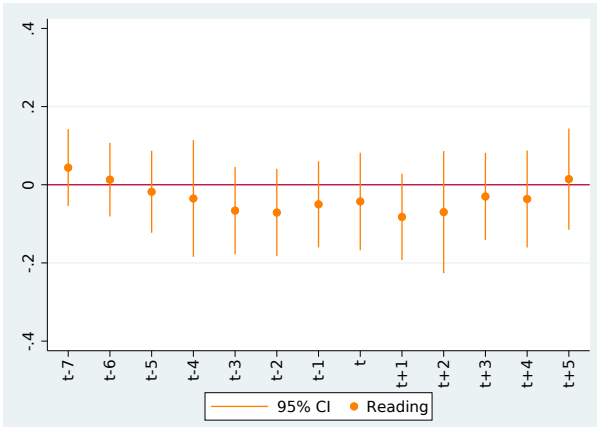

This figure plots the coefficients from estimating Equation 2.Scores in math and reading subjects are the dependent variable. Panel A shows the results for ex-male schools and panel B for ex-female. All coefficients are normalized in the event year t. Regressions include school controls, school fixed effects and year fixed effects are included. Robust standard errors clustered by municipality are in parentheses. ${ }^{* * *}$ represent significance at $1 \%$-level, ${ }^{* *}$ at $5 \%$-level, and $*$ at $10 \%$-level. 
performance of the proportion of girls on ex-male and ex-female schools. In marginal terms, our findings are partially in line with previous finding documented by Hoxby (2000), lavy \& Schlosser (2011) and Schneeweis \& Zweimuller (2012). As documented before, an increase in the proportion of girls decreases male test scores when the fraction is lower than $1 / 3$, and this drop is followed by a marginal recovery in test scores when the share of females increases. However, our estimates show that this recover does not surpass the initial score losses (either in math or reading) as in previous literature. ${ }^{13}$ By contrast, female students in ex-female schools experienced positive effects in math (not in reading) after the share of male students started to increase (read the Figure 5.5 from left to right for proportion of males). This marginal effect is hidden when only looking at average effect (Table 5.2).

These results suggest the prevalence of the peer effects over the endogenous response of the teachers facing the change (such as changing attitudes or teaching techniques). As shown by Duflo et al. (2011) and Pop-Eleches \& Urquiola (2013), teachers adjust attitudes and teaching techniques after gender mixed classes. This behavior would likely hold as soon as gender composition includes students from both sexes instead of one sex, and it will be absorbed by the school fixed effects. Therefore, small changes in marginal effect from variation on the proportion of female may be present (and if so, they should be linear if nor related to the gender composition). Instead, we observe a $U$ shape in marginal effects, which suggests that gender composition is driven by changes in performance. If teacher's need to adjust her (new) teaching techniques due to indiscipline, these changes will be via gender composition and less likely to endogenous response to the change per-se.

\subsubsection{Sub-analysis for females in ex-male schools and males in ex-female schools}

Single-sex schools that convert to coed conserve several features (e.g. routines, academic culture, etc..) that can have differential impact on the academic achievement of the opposite-sex students, compared to other non-converted schools. Thus, we explore the performance of females in ex-male schools and males in ex-female schools. Using OLS and Coarsened Exact Matching Methods (CEM), we explore the post conversion

\footnotetext{
${ }^{13}$ Note that none of the ex-male schools have a share of females higher than 0.7 . In ex-female this share is never lower than 0.43 .
} 
Figure 5.5: Intensity effect: changes in the share of students from the opposite sex in schools converted from single-sex to coed

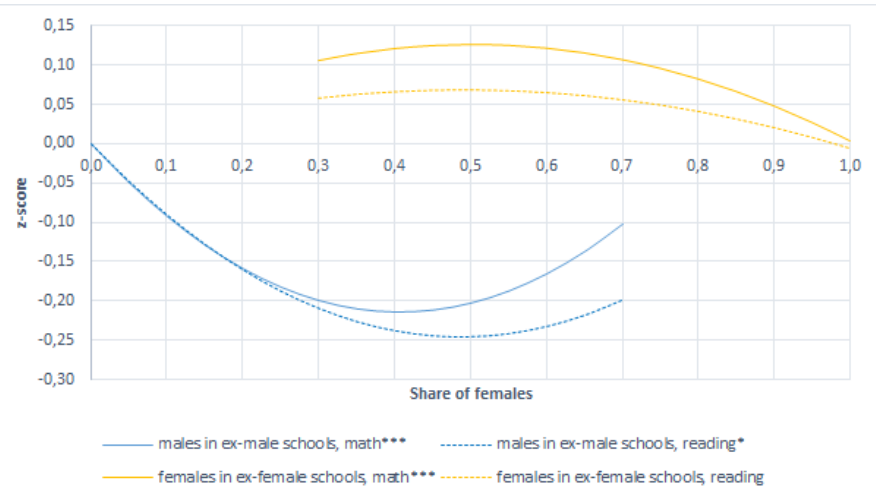

Note: This Figure reports the estimates of Equation 1, but focusing in the intensity effect. We replaced the treatment dummy (when equals 1 ) for the share of female students in the converted schools allowing for marginal effect interpretation. While for ex-male schools interpretation should be read from left to right: marginal increments on female share on marginal changes on performance; for females the interpretation should be from left to right, as the share of girls was initially 1 and then $\mathrm{t}$ diminished. Notice that none of the converted schools has a share higher than 0.7 students from the incumbent sex. Regression includes school controls, years (and years ${ }^{2}$ ) of exposure controls, School fixed effects and year fixed effects are included. Robust standard errors clustered by municipality are in parentheses. *** represent significance at $1 \%$-level, **at $5 \%$-level, and * at $10 \%$ level.

period of schools to analyze the performance of students, under different gender type of the schools (coed, male-only, ex-male, female-only, and exfemale), conditional on the available observables as presented in Table 5.1. ${ }^{14}$ The results, presented in Table 5.3, show that the CEM specifica-

\footnotetext{
${ }^{14}$ Notice that DiD or fixed effects are no longer useful to analyze the subsequent periods after the conversion as the converted schools do not change their coed status, thus gender-type school is dropped from the estimation. Coarsened Exact Methods is a matching method that improves the estimation of causal effects in observational studies by reducing imbalance in covariates between treated and control groups (Blackwell, Iacus, King \& Porro, 2009). Compared to other matching techniques such as propensity score matching, Mahalanobis distance matching and fine stratification by propensity score (FS), it generally achieved the best covariate balance and is recommended over others when having fewer than 10 covariates which is our case (Ripollone
} 
tion (Columns 4 and 8) delivers fairly similar results to OLS coefficients using controls (Column 3 and 7).

et al., 2020). 


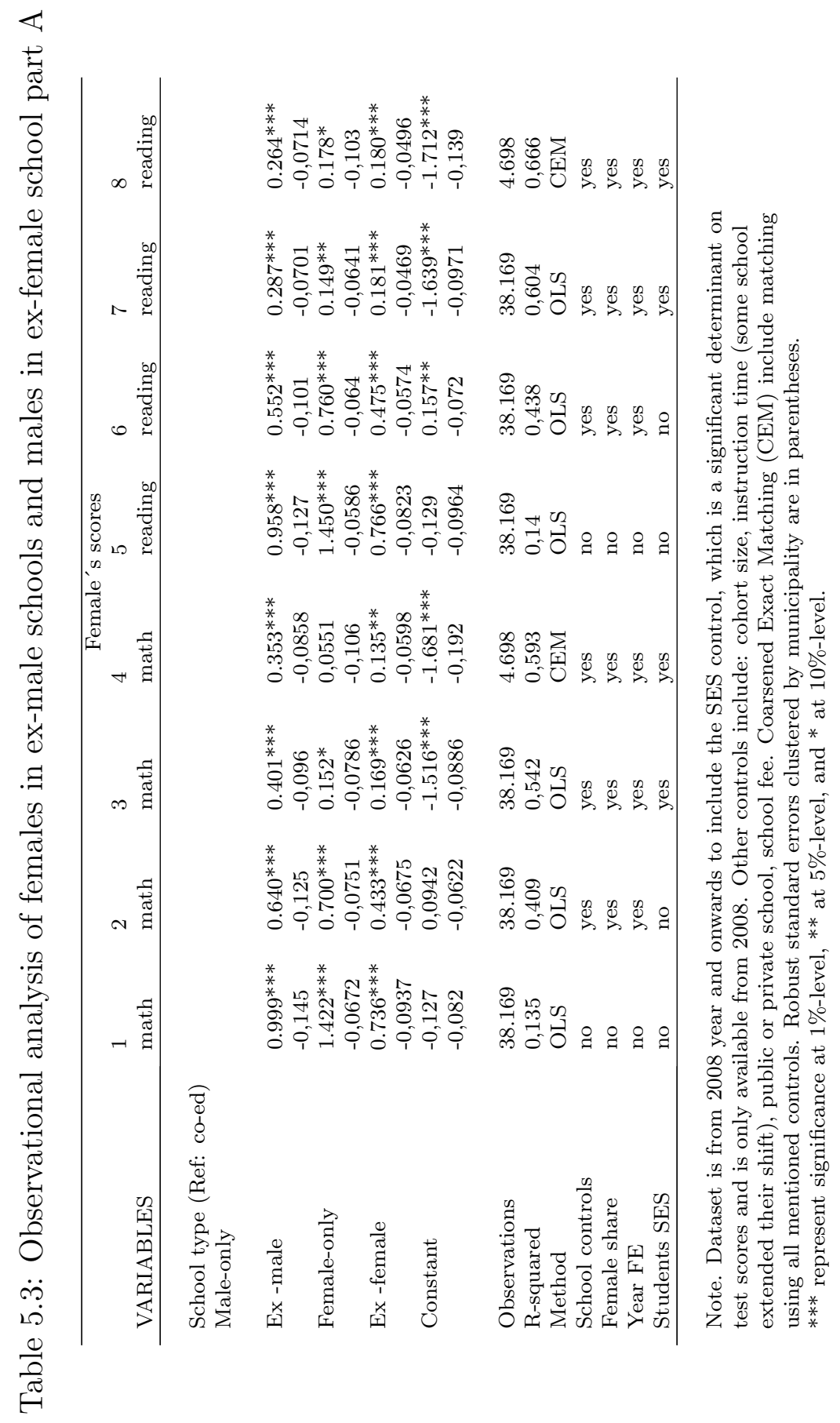




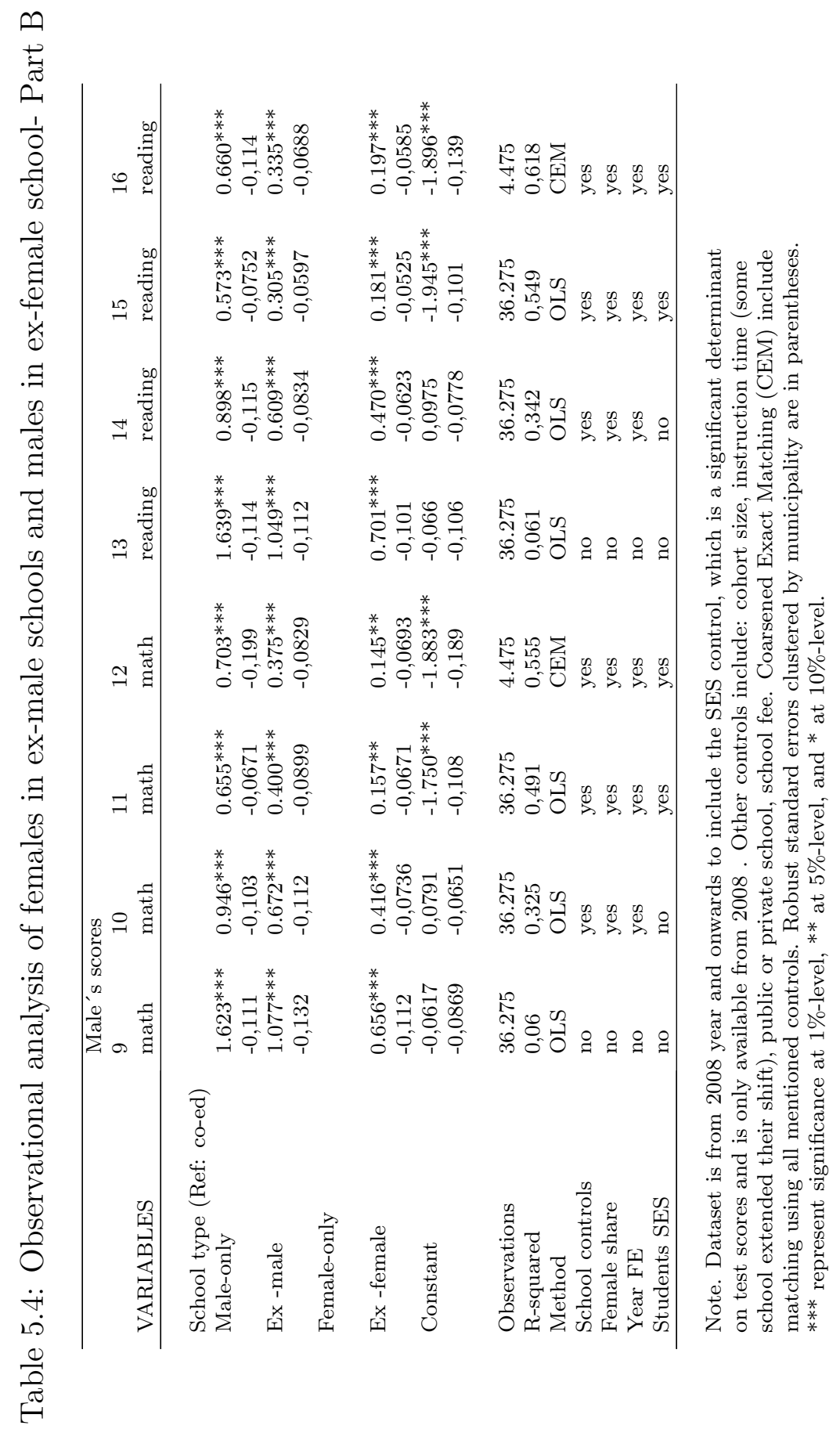


We include observations from 2008 onwards given that the student socioeconomic questionnaire was implemented only since then. Table 5.3 shows that without controls, females perform the highest in math and reading in female-only schools (1.4 SDs higher than females in coed schools). This is consistent with raw performance of female-only schools presented in other studies (Pahlke et al., 2014). However, conditional on school controls, and particularly on socioeconomic status (SES), females perform the highest in ex-males schools: 0.35 and 0.26 SDs in math and reading relatively to the reference group of coed. Interestingly, girls in exfemale schools perform better than those in female-only schools (Columns 4 and 8 ); and the difference is particularly high for math (0.35 versus 0.06 SDs). Although SES accounts for most of the success of females in allfemale schools (also documented in Perry \& McConney, 2010), it is not the case for females in ex-male schools. Alternative variables beyond SES, like school strong academic math culture or peer effects, might explain this phenomenon. Moreover, conditional on SES, females in ex-female schools also surpass females-only schools' performance. Here, as shown before, the peer effects are a key determinant (having males at school might push females to do better in math).

A different pattern is observed for males (Table 5.4, Column 8). Males in male-only schools always outperform any other type of schools in both math and reading regardless the controls (always-coed schools is the reference group). The second best type of schools in males' performance is ex-male schools followed by ex-female schools. Here, conditional on controls and SES (which is recognized as the main determinant of school's performance along with pupil ability (Smithers \& Robinson, 2006), students in ex-female schools do fairly better than coed schools $(0.15$ and 0.2 SDs in math and reading), but do worse than those in ex-male schools (0.38 and $0.34 \mathrm{SDs}$ ) or male only (0.70 and 0.66 SDs). The significant advantage of male-only schools over coed is not explained by SES differences, but rather other characteristics of these schools (which do not allows for female peer effects) are determining their outstanding performance. 


\subsection{Robustness checks}

As a first robustness test, we perform the parallel trend assumption using time-varying school characteristics as a placebo test. Figure 5.6 shows that there is no evidence of significant changes by the time of the conversion of time-variant school characteristics.

As a second robustness test, we show in Table 5.5 in the Appendix that the results are robust after adding several controls. In fact, after clustering standard errors at municipality level, adding year fixed effects, observable variables controls, and school time-trends, the coefficients increase. Particularly, we disregard some concerns about schools' trends jeopardizing the DiD assumptions (like possible massive transition of students from the incumbent sex). As mentioned before, it seems that if attrition selection occurred, the DiD and Fixed effect estimates would be a lower bound, likely because students who are expected to perform worse in coed schools are the ones who would be transferred out.

\subsection{Discussion and conclusions}

Exploiting a rich longitudinal dataset and the unique quasi-experimental case of Colombia, this research studied the effect of converting of singlesex schools to coed on students' performance. Different from previous studies, our database accounted for a large set of converting schools (78 male-only and 168 female-only schools), and an extended variation in the proportion of opposite sex students. Time varying implementation over the period 2001-2017 allows us to control for time and school (un)observed heterogeneity. This also allows for rich variation in gender composition to test the marginal effect of the inflow of opposite-sex students. We find that boys in male-only schools do not benefit from the change (in line with Dustmann et al., 2018; Lee et al., 2017; Park, 2013). On the contrary, we find that girls in ex-female schools can benefit from the conversion. Our results partially confirm Hoxby (2000) findings: when boys outnumber girls (higher than 3:1), the performance of both marginally decreases, and this loss starts recovering when girls outnumber boys. Nevertheless, we do not find, as in previous literature, that the magnitude of the recovery does compensate the losses for the ex-male schools: male students are worst off in academic achievement terms after the conversion, even if females outnumber them. Moreover, for ex-female schools it seems to be beneficial for girls' math performance to increase 
up to half of boys in the class. In this research, the masculine or feminine environment of the schools (which remains at least partially after the change), as well as the context of a developing country, can play an important role. Contrary to mentioned literature that refers to developed countries, this research studied school gender composition in an environment where female highly underperform males in math (with the highest gender gap in math in PISA test), and gender stereotypes referring to females as less prompt for school are highly prevalent (Duryea et al., 2012). As far as we know, this is the first referent of causal evidence of converting single-sex schools into coed in a developing country.

Various mechanisms may explain why the inflow of girls decreases male performance. Our results support the hypothesis that boys may experience less competitiveness, disruptive behavior, or lose focus on their studies when girls are present in their academic environment (Nagengast et al., 2013). Other possible mechanisms include that teachers might change their teaching style in a way that does not favor boys when having girls in the same classroom. They may become less strict regarding math or reading subjects as they used to be before the conversion to avoid leaving behind girls joining the classes with average lower starting competence in these areas (Jackson, 2010). Teachers in ex-male schools might also have dedicated more attention to girls to the expense of less attention for boys after the conversion (Farrell, 2007). In contrast, positive spillover effects from peers are observed for incumbent females in ex-female schools. They experienced progress in math and not significant changes in reading. Boys could have boost girls' interest in math as historically they have performed better than females in this area, particularly in developing country contexts.

Conditional on observables, including SES as the most relevant determinant on performance, we observed that male-only and ex-male schools outperform the other schools (female-only, ex-female and coed type). It is also worth noticing the outstanding achievement of females in ex-male schools over the other gender-type schools (i.e. female-only, ex-female and always-coed schools). This suggests that unobservable variables, such as the masculine environment idiosyncrasies or practices (on average, males' schools tend to be more competitive, and with a stronger math focus; Gibb et al., 2008), might help boost the potential of the females. In contrast, feminine schooling environments for males (which are 
less competitive than others gender-type schools, and in some cases have more behavioral classes in the curriculum $)^{15}$ may not significantly boost males' academic achievement. It may be that the previous performance or cultural willingness of incoming male students in ex-female schools is not capable of producing peer pressure, or that the traditions of teaching methods less focused on average on math in the ex-female schools remain the same when the conversion occurs. Our findings support the hypothesis that a masculine schooling environment may be beneficial for females' performance, but this might be at the expense of males' achievement.

This study also contributes to the need for causal evidence of peer effects in Latin-American countries, where the educational system has had a significant presence of gender discrimination and gender stereotypes (Duryea et al., 2012), which prevents female students to achieve their potential. This study adds to the immense literature indicating that nurture excels over nature (e.g. Guiso et al., 2008; Schiltz et al., 2019): peer effects as well as certain academic practices can reshape the performance of students. Although our study does not speak for possible collateral benefits such as gains in soft skills that occur in the face of the coexistence of men and women in the classroom (Musiimenta et al., 2019), or potential downsides such as higher teenage pregnancy in mix gender environments (Cortés et al., 2019), it does inform policymakers on the vulnerability of male students facing changes in the gender composition of their schools' peers. It also suggests that, at least in the context of a developing country, a dose of competitiveness in the schools' environment is beneficial for girls, while boys need to be instructed to manage distraction in mixed-gender classes. Further research can test the incidence of peer effect on non-cognitive outcomes, and the effect of having single-sex classes in coed schools on several outcomes. It is also worth to explore the learning environments in single-sex-schools (especially in male-only schools), as compared to other schools type, they added the most to female students in terms of math.

In the aim to reach academic-gender equalization as driven educational policy, we suggest that policymakers need to pay special attention to the gender peer effects which are large and significant (particularly of

\footnotetext{
${ }^{15}$ We randomly selected 5 male-only schools and 5 female-only schools for which curriculums were available in the website and compared them. Female schools included $8 \%$ more classes related to ethics and religion than male schools.
} 
females over males' performance). In coeducation environments, efforts need to be done in diminishing males' proclivity to distractions and females' proclivity to not exploit their academic potential, particularly in math. A dose of competitiveness environment accompanied to reduction of gender stereotypes in schools can be beneficial for girls to reduce the pronounced gender academic gap, which at present restricts their access to higher education, and particularly to STEM careers (AbadÍa \& Bernal, 2017).

Moreover, assuming the benefits of single-sex education occur at the classroom level, implementing single-sex classes for some subjects within coed schools can be an alternative for preserving the advantages in both single-sex and coed environments. On the one hand, male-only schools tend to considerably strengthen males' academic performance, which can produce positive spillover effects towards females when mixed in some other classes. ${ }^{16}$ Likewise, female-only classes are also associated with increases in self-esteem (Eisenkopf et al., 2015), which in a mixed gender environment can serve to improve the academic performance of girls. On the other hand, one important element of coeducational schools is that they allow for the development of a broader range of behaviors and attitudes within students (Wong, Shi, \& Chen, 2018) and inclusion with children of the other gender. One consequence of reverting coed schools to single-sex schools is that the number of schools children can enroll in decreases, which deprives parents of the scale economies of having opposite-sex siblings in the same school; this will particularly harm lowincome parents who are highly sensitive to transport costs in education (Murnane \& Willett, 2010).

\footnotetext{
${ }^{16}$ These spillover effects will be particularly beneficial when boys do not outnumber girls in a class, as previously shown.
} 
Figure 5.6: Robustness checks: parallel trend assumption using control variables

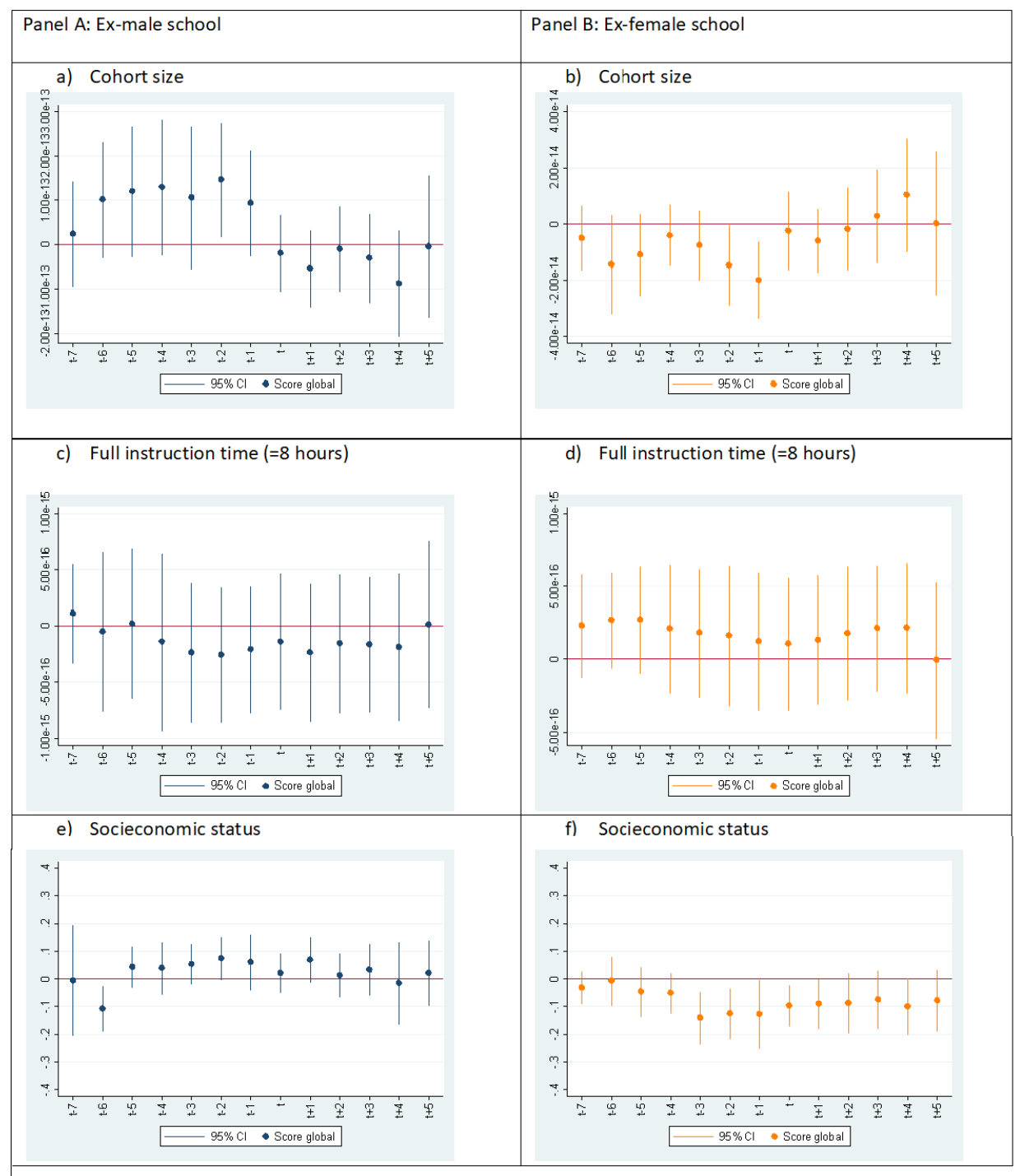

Notes: This figure plots the coefficients from estimating Equation 2. Cohort size (in ln), full instruction time and socioeconomic strata (SES has a scale from 1-6) are the dependent variable. SES only from 2008 onwards. Panel A shows the results for ex-male schools and panel B for ex-female. All coefficients are normalized in the event year t. Regressions include school controls, school fixed effects years of exposure and year fixed effects are included. Robust standard errors clustered by municipality are in parentheses. ${ }^{* * *}$ represent significance at $1 \%$-level, ${ }^{*}$ at $5 \%$-level, and * at $10 \%$-level. 


\section{References}

[1] Abadía, L. K., \& Bernal, G. (2017). A widening gap? A genderbased analysis of performance on the Colombian high school exit examination. Revista de economía del Rosario, 20(1), 5-31.

[2] Autor, D. H. (2003). Outsourcing at will: The contribution of unjust dismissal doctrine to the growth of employment outsourcing, Journal of Labor Economics, 21(1), 1-42.

[3] Bernal, G. \& Penney, J. (2019). Scholarships and student effort: Evidence from Colombia's Ser Pilo Paga program. Economics of Education Review, Volume 72, Pages 121-130, https://doi.org/10.1016/j.econedurev.2019.04.008.

[4] Bertrand, M., Duflo, E., \& Mullainathan, S. (2004). How Much Should We Trust Differences-In-Differences Estimates?. The Quarterly Journal of Economics, Volume 119, Issue 1, Pages 249-275,https://doi.org/10.1162/003355304772839588

[5] Blackwell, M., Iacus, S., King, G., \& Porro, G. (2009). cem: Coarsened exact matching in Stata. The Stata Journal, 9(4), 524-546.

[6] Booth, A. \& Nolen, P. (2012). Choosing to compete: How different are girls and boys?. Journal of Economic Behavior \& Organization, Volume 81, Issue 2, 2012, Pages 542-555, ISSN 0167-2681, https://doi.org/10.1016/j.jebo.2011.07.018.

[7] Choi, E. J., Hyungsik, R. M., \& Geert, R. (2014)."Estimation of an Education Production Function under Random Assignment with Selection." American Economic Review, 104 (5): 206-11.DOI: 10.1257/aer.104.5.206 
[8] Cortés, D., Cote, H., \& Pulido, G. (2019). Determinantes del embarazo temprano en Colombia: diferencias entre mujeres y hombres. In Embarazo temprano: evidencias de la investigación en Colombia. https://ezproxy.uniandes.edu.co:8443/login?url=http://search. ebscohost.com/login.aspx?direct $=$ trueanddb=edsvlxand $A N=$ edsvlx. 845672229 andlang $=$ esandsite $=$ eds-liveandscope $=$ site

[9] Department for Education and Skills. (2007). 2020 Vision. Report of the Teaching and Learning in 2020 Review Group.

[10] Doris, A., O’Neill, D., \& Sweetman, O. (2013). Gender, single-sex schooling and maths achievement. Economics of Education Review, 35, 104-119.

[11] Duflo, E., Dupas, P., \& Kremer, M. (2011). Peer Effects, Teacher Incentives, and the Impact of Tracking: Evidence from a Randomized Evaluation in Kenya. Amer- ican Economic Review 101 (5), 1739-1774.

[12] Duryea, S., Galiani, S., Nopo, H., \& Piras, C. C. (2012). The Educational Gender Gap in Latin America and the Caribbean. SSRN Electronic Journal, April. https://doi.org/10.2139/ssrn.1820870

[13] Dustmann, C., Ku, H., \& Kwak, D. W. (2018). Why Are Single-Sex Schools Successful?. Labour Economics, 54, 79-99.

[14] Eisenkopf, G., Hessami, Z., Fischbacher, U., \& Ursprung, H. W. (2015). Academic performance and single-sex schooling: Evidence from a natural experiment in Switzerland. Journal of economic behavior and organization, 115, 123-143.

[15] Farrell, J. (2007). Class divide: Single-sex schoolrooms take off. Hartford Courant.

[16] Gibb, S., Fergusson, D., \& Horwood, J. (2008). Effects of single-sex and coed schooling on the gender gap in educational achievement. Australian Journal of Education, 52(3), 301-317. https://ezproxy.uniandes.edu.co:8443/login?url=http://search.ebsco host.com/login.aspx? direct $=$ trueanddb $=a 9$ hand $A N=34999608$ and lang $=$ esandsite $=$ eds-liveandscope $=$ site

[17] Guiso, L., Monte, F., Sapienza, P., \& Zingales, L. (2008). Culture, Gender, and Math. Science Magazine, Volume 320. 
[18] Halpern, Diane F., Lise Eliot, Rebecca S. Bigler, Richard A. Fabes, Laura D. Hanish, Janet Hyde, Lynn S. Liben, \& Carol Lynn Martin. "The Pseudoscience of Single-Sex Schooling." Science 333 (No.6050 2011): 1706-07.

[19] Heather, B. (2002). "Constructions of gender in parents choice of a single-sex school for their daughters". In Gender in policy and practice: Perspectives on single-sex and coeducational schooling, Edited by: Datnow, A. and Hubbard, L. 304-22. New York: RoutledgeFalmer.

[20] Herrera, M. B. H. C. P. (2016). Colegio Mixtos o de un Solo Sexo : ¿ Qué nos dice la Evidencia ? Universidad Del Desarrollo, Facultad de Gobierno Centro de Politícas Públicas, 11(N/A), 23. http://gobierno.udd.cl/cpp/

[21] Hilliard, L. J., \& Liben, L. S. (2010). Differing levels of gender salience in preschool classrooms: Effects on children's gender attitudes and intergroup bias. Child development, 81(6), 1787-1798.

[22] Hoxby, C. (2000). Peer Effects in the Classroom: Learning from Gender and Race Variation. NationaL Bureau of Economic Research. DOI $10.3386 / \mathrm{w} 7867$

[23] Jackson, C. K. (2012). Single-sex schools, student achievement, and course selection: Evidence from rule-based student assignments in Trinidad and Tobago. Journal of Public Economics, 96(1-2), 173187.

[24] Jackson, J. (2010). 'Dangerous presumptions': how single-sex schooling reifies false notions of sex, gender, and sexuality. Gender and education, 22(2), 227-238.

[25] Lavy, V., \& Schlosser, A. (2011). Mechanisms and Impacts of Gender Peer Effects at School. American Economic Journal: Applied Economics, 3 (2): 1-33.

[26] Lee, J. \& Park, H. Y. (2017). School Gender Composition and Academic Performance: Evidence from Transition from Single-Sex to Coed Schools. Seoul Journal of Economics, 30(4). 
[27] Lee, V., Marks, H., \& Byrd, T. (1994). Sexism in Single-Sex and Coeducational Independent Secondary School Classrooms. Sociology of Education, 67(2), 92-120. doi:10.2307/2112699

[28] Murnane, R. J., \& Willett, J. B. (2010). Methods matter: Improving causal inference in educational and social science research. Oxford University Press.

[29] Musiimenta, A., Tumuhimbise, W., Bangumya, E., Mugaba, A. T., Mugonza, R., Kobutungi, P., \& Nankunda, M. J. (2019). Exploring the Gender Gap in Science, Technology, Engineering, and Mathematics (STEM), and Soft Skills, and Knowledge of Role of Models Among Students in Rural Uganda. Journal of Education and Development, 3(3), 31. https://doi.org/10.20849/jed.v3i3.621

[30] Nagengast, B., Marsh, H.W., \& Haw, K. (2013). Effects of SingleSex Schooling in the Final Years of High School: A Comparison of Analysis of Covariance and Propensity Score Matching. Springer Science+Business Media New York. DOI 10.1007/s11199-013-0261-8

[31] Oakes, J. (1990). Chapter 3: Opportunities, Achievement, and Choice: Women and Minority Students in Science and Mathematics. Review of Research in Education, 16(1), 153-222. https://doi.org/10.3102/0091732X016001153

[32] OECD. (2018). Country note. South Korea. https://www.oecd.org/pisa/publications/ PISA2018_CN_KOR.pdf

[33] Pahlke, E., Hyde, J. S., \& Allison, C. (2014). The effects of singlesex compared with coeducational schooling on students' performance and attitudes: A meta-analysis. Psychological Bulletin, 140, 1042-1072. doi:10.1037/a0035740

[34] Park, H., Behrman, J. R., \& Choi, J. (2013). Causal Effects of SingleSex Schools on College Entrance Exams and College Attendance: Random Assignment in Seoul High Schools. Population Association of America. DOI 10.1007/s13524-012-0157-1

[35] Perry, L. \& McConney, A. (2010). Does the SES of the school matter? Teachers College Record, 112(4), 1137-1162. https://www.researchgate.net/publication/266602181 
[36] Pop-Eleches, C. \& Urquiola, M. (2013). Going to a Better School: Effects and Be- havioral Responses. American Economic Review 103 (4), 1289-1324.

[37] Riordan, C., Faddis, B. J., Beam, M., Seager, A., Tanney, A., DiBiase, R., ... \& Valentine, J. (2008). Early Implementation of Public Single-Sex Schools: Perceptions and Characteristics. US Department of Education.

[38] Ripollone, J. E., Huybrechts, K. F., Rothman, K. J., Ferguson, R. E., \& Franklin, J. M. (2020). Evaluating the utility of coarsened exact matching for pharmacoepidemiology using real and simulated claims data. American journal of epidemiology, 189(6), 613-622.

[39] Rubin, D. B. (1980). Bias reduction using Mahalanobis metric matching. Biometrics, 36, 293-298. doi:10.2307/2529981.

[40] Sax, L. (2010). Sex differences in hearing: Implications for best practice in the classroom. Advances in Gender and Education, 2, 13-21.

[41] Schiltz, F., Mazrekaj, D., Horn, D. \& De Witte, K. (2019). Does It Matter When Your Smartest Peers Leave Your Class? Evidence from Hungary. Labour Economics 59, pp. 79-91.

[42] Schneeweis, N., \& Zweimüller, M. (2012). Girls, girls, girls: Gender composition and female school choice. Economics of Education review, 31(4), 482-500.

[43] Semana. (2019). Colegios de un solo género: ¿cuáles son los pros y los contra? Retrieved: January 2021. https://www.semana.com/educacion/articulo/colegios-de-unsolo-genero-que-ventajas-tienen/644324/

[44] Shapka, J. D., \& Keating, D. P. (2003). Effects of a GirlsOnly Curriculum During Adolescence: Performance, Persistence, and Engagement in Mathematics and Science. American Educational Research Journal, 40(4), 929-960. https://doi.org/10.3102/00028312040004929

[45] Smithers, A. \& Robinson, P. (2006). The paradox of single-sex and co-educational schooling, Liverpool, England: Crown Printing Company. 
[46] Thompson, J. S. (2003). The Effect of Single-Sex Secondary Schooling on Women's Choice of College Major. Sociological Perspectives, 46(2), 257-278. https://doi.org/10.1525/sop.2003.46.2.257

[47] Van De Gaer, E., Pustjens, H., Van Damme, J., \& De Munter, A. (2004). Effects of single-sex versus coed classes and schools on gender differences in progress in language and mathematics achievement. British Journal of Sociology of Education, 25(3), 307-322.

[48] Welch, G. A., Cakir, M., \& Peterson, C. (2014). The relationship between gender and classroom environment in Turkish science classrooms. Educational Research and Reviews, 9(20), 893-903. https://doi.org/10.5897/err2014.1839

[49] Wiseman, A. W. (2008). A Culture of (in)Equality?: A CrossNational Study of Gender Parity and Gender Segregation in National School Systems. Research in Comparative and International Education, 3(2), 179-201. https://doi.org/10.2304/rcie.2008.3.2.179

[50] Wong, W. I., Shi, S. Y., \& Chen, Z. (2018). Students from single-sex schools are more gender-salient and more anxious in mixed-gender situations: Results from high school and college samples. PloS one, 13(12), e0208707. 


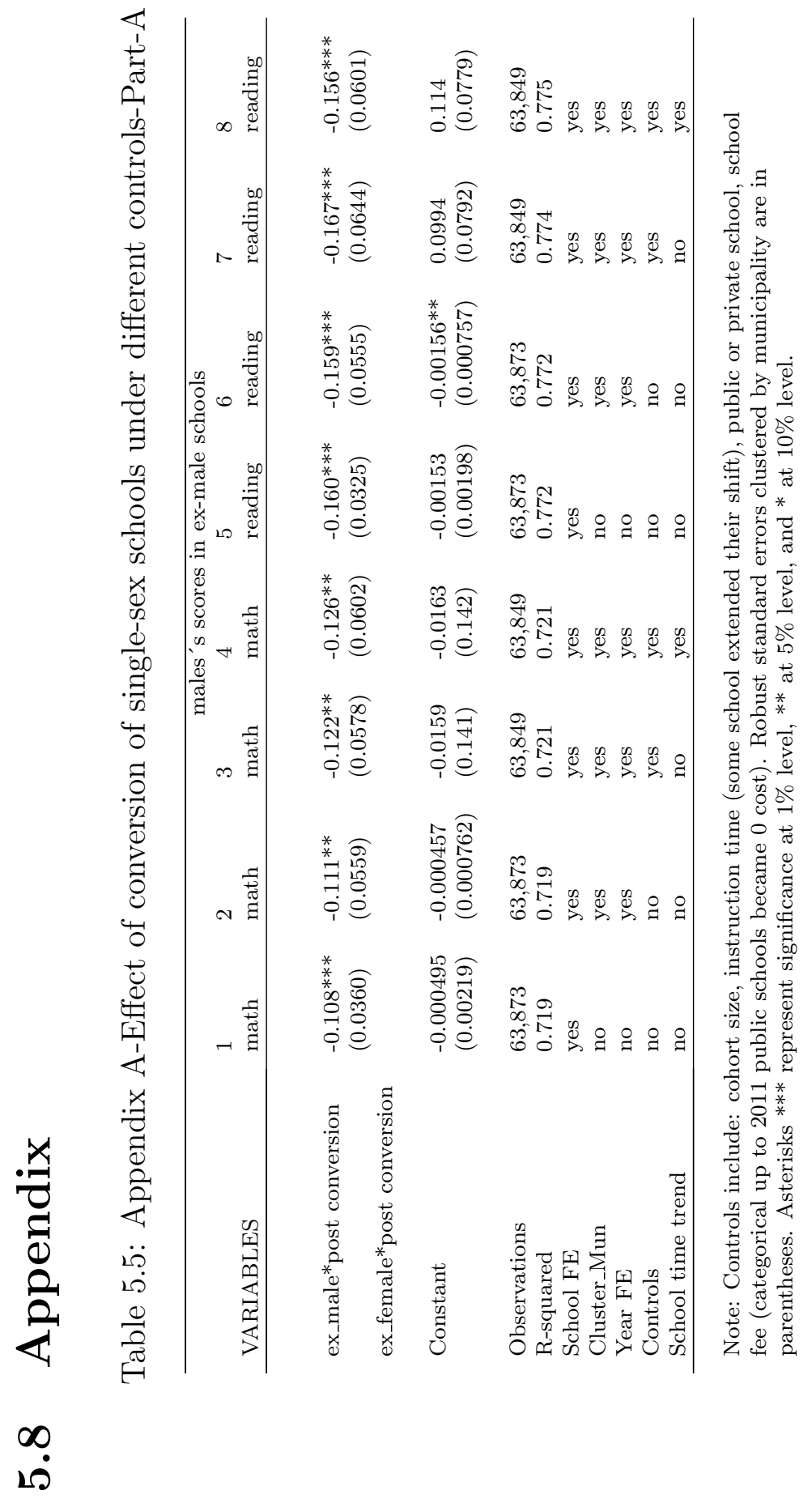




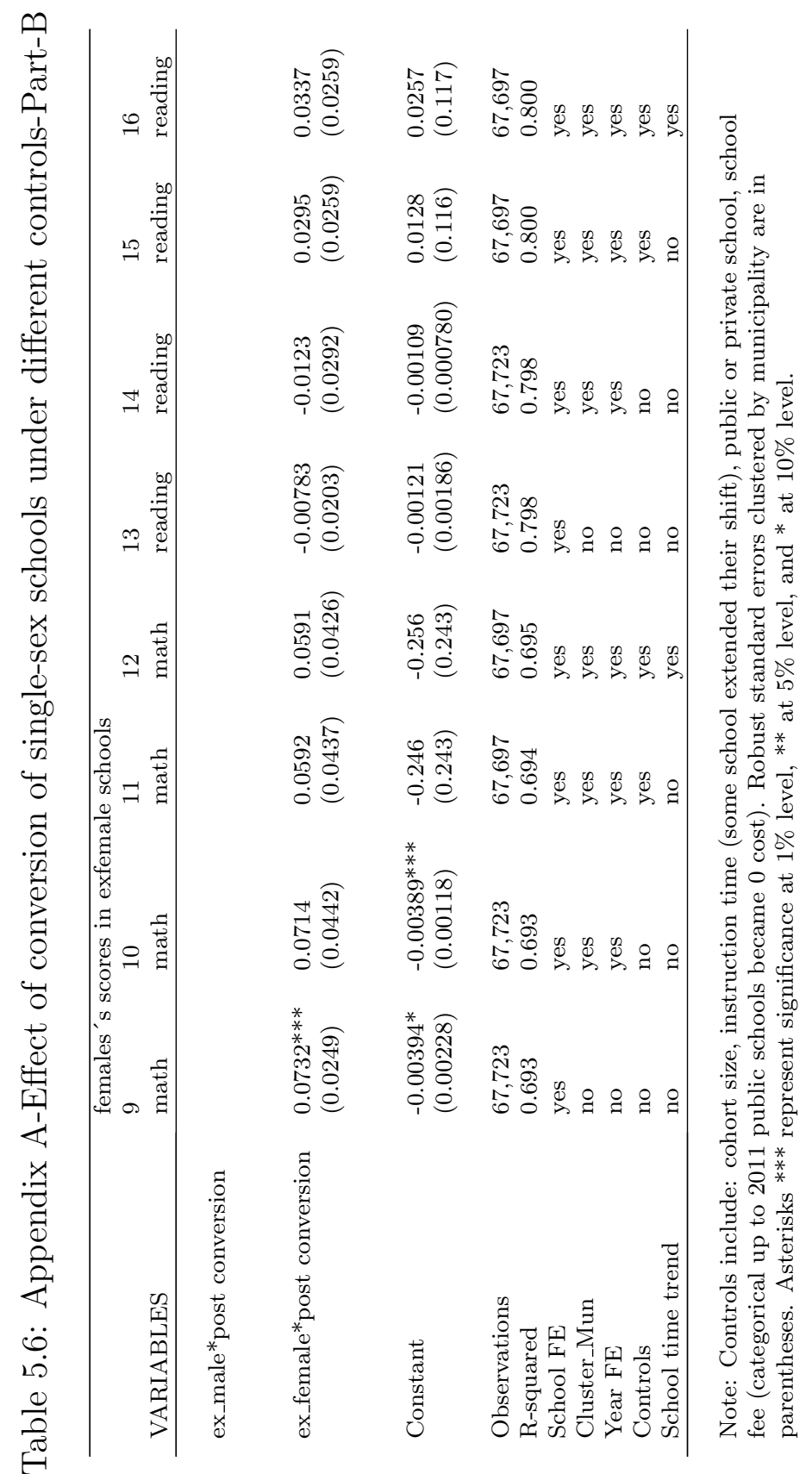




\section{Chapter 6}

\section{Conclusion and Discussion}

\subsection{Overview}

United Nations Sustainable Development Goal 4 identifies educational opportunities as a top priority. Improving educational opportunities for disadvantaged students is essential to increasing a society's inclusion, educational aspirations, and capital accumulation (United Nations, 2017). Worldwide, low-income youths have considerably less access to higher education opportunities than their high-income counterparts, due in part to a lack of both money and information about existing opportunities (Dynarski, Michelmore, Libassi \& Owen, 2018). This dissertation focuses on low-income students who frequently struggle to access higher education systems and thus are not included in official higher education records. We analyzed original data as well as large administrative databases assembled from different sources to address the questions posed in each chapter.

Many questions about the most effective channels to increase access, financing, quality and inclusion in education remain unanswered (UNICEF, 2018). In higher education, these channels largely relate to understanding how information drives students' preferences and efforts, as well as the effects of specific educational programs (Kaufmann, 2014). For instance, past research investigates how introducing financial aid opportunities, such as income-based scholarships, affects high school students' academic effort and further college enrollment (Cornwell, Lee \& Mustard, 2005). Identifying such effects is particularly important when they have the potential to generate massive spillovers to other low-income 
students.

Considering the external benefits that educational opportunities bring to (and costs they impose on) students is crucial for the design of efficient and inclusive programs that deliver such opportunities. Merit- and needbased scholarships can improve academic effort and increase aspirations to pursue higher education among pre-college students in socioeconomically disadvantaged positions. These benefits accrue not only to the students who are ultimately awarded, but also to many other students in similar socioeconomic conditions. Likewise, the curtailing of educational opportunities can yield severe negative repercussions that go beyond students who did not receive scholarships. Educational opportunities and information have the power to rapidly and enormously influence the behavior of students who usually have low chances of pursuing tertiary education.

This thesis assesses how students' exposure to various situations (i.e. introducing a scholarship, providing information, cancelling a scholarship and changing the school's gender composition) can affect their educational outcomes. It makes contribution to two strands of literature. First, in Chapter 3, we use new approaches to causally study students' decision-making processes. To the best of our knowledge, this study is the first to use a discrete choice experiment as an outcome in a randomized control trial in the economics of education literature. Second, in Chapters 2, 4 and 5 we exploit the framing of three novel natural experiments: the implementation of large-scale scholarship program with particular eligibility criteria, the sudden cancellation of that program, and the conversion of a large number of single-sex schools into coeducational (coed) schools. These natural experiments help us understand how students react to changes in their educational environments. In Chapters 2 and 4 the changes are related to financial opportunities, whereas in Chapter 5 the change is related to mixing the gender composition of single-sex schools. The situations under study and the large samples employed are unique in the literature and provide key insights into how students may react to changes in the education system. The results of the thesis can help guide decision makers on how best to motivate students to pursue higher education. Understanding a student's reaction to information on higher education, their willingness to take a loan and their aspirations when facing different financial scenarios is useful information to policy- 
makers in at least two ways. First, it helps to anticipate the behavior of and spillover effects on students when a particular policy such a nationwide scholarship takes place. Second, it helps in the design of more efficient higher education policies that are not only more adjusted to the target population but also policies that can achieve similar outcomes using fewer financial resources. These insights are particularly valuable to governments who wish to achieve their policy goals in education but are experiencing budgetary strain.

\subsection{Findings and conclusions of each chapter}

In this section we present the research questions explored in each chapter and briefly discuss the main results and related policy implications.

\section{Chapter 2: To what extent does a merit-based scholarship program for college affect pre-college students' academic effort?}

To test the spillover effects of the Ser Pilo Paga (SPP) scholarship program on potential eligible students, we use a dataset combining data from the Colombian assessment organization, Colombian Institute for the Promotion of Higher Education for 2014 and 2015. Since eligibility for the scholarship program is based on a numerical cutoff on the Sisben (poverty index) score, we use a regression discontinuity approach to estimate the effects of the program's introduction on student achievement. We also use quantile regression to examine the effects of the program at different points in the distribution, as well as a survey to explore changes in the level of effort of eligible students.

We hypothesized that merit-based scholarships improve pre-college student performance. The results support this hypothesis. We find that students who were eligible for the scholarship scored about 0.09 standard deviations higher on the test than those who were not. Moreover, we find that the program increased the representation of the poorest students in the top $9 \%$ of test takers, and that spillover effects were less evident for female students and for those in rural areas. The existence of the nationwide program itself increased students' scores in the exit examination of high school students. Our findings support those of previous studies on the positive and spillover effects of introducing scholarships on student 
effort (e.g. Hasting et al., 2012; Bartik \& Lachowska, 2014; Akhtari, Bau \& Laliberté, 2017).

This chapter provides new information regarding the extent of the positive effects on high school exit examination scores that can be expected from a highly publicized scholarship program. Our findings have key implications for scholarship program design. Policymakers should pay particular attention to males and students in rural areas, as they tend to be less influenced by scholarship opportunities. Perhaps even larger incentives could be targeted at specific populations. In addition, these programs should be accompanied by verifications that the main messages of the scholarship program are being fully delivered in specific regions.

Chapter 3: To what extent does the provision of information on financial aid and tuition costs affect students' preferences for higher education?

We developed a randomized control trial involving 2,652 low-income 10th grade students, approximately $71 \%$ of whom were eligible for the SPP program based on their income level. Students were randomly assigned to two intervention groups and one control group. Both intervention groups received basic information about higher education in Colombia. The information provided to treatment group one stressed the returns to higher education and enrollment rates, whereas financial aid and tuition costs in high-quality universities were emphasized for treatment group two.

We hypothesized that providing information affects students' preferences for higher education. Our results partly support this hypothesis. Provision of information regarding financial aid and tuition costs, increase educational aspiration of low-income, pre-college students. In contrast, provision of information regarding returns and access rates to higher education did not have effect on student's preferences. Unfolding the findings of this research, we highlight four main results. First, providing information reduced students' preferences for public institutions, perhaps because one of the statements revealed that public institutions have lower admission rates. Second, students increased their preferences for higher-quality institutions after being given information about financial aid and tuition costs. However, information that stressed the returns 
to education did not produce significant changes. Third, information is most likely to affect the decisions of low socioeconomic status (SES) students who are female, present-oriented or who overestimate the returns to education. Fourth, students are willing to give up $24-36 \%$ of a $100 \%$ scholarship to switch from a low-quality to a high-quality institution. This last result suggests that even though scholarships can switch students' preferences for high-quality institutions, offering a full scholarship is not necessary to achieve this aim: students are willing to take out a small loan to allow them to switch to a better-quality institution. We contribute to the literature by estimating the causal influence of providing information on students' preferences and decisions regarding their higher education options. This research enhances our understanding of what type of information can change students' preferences, trade-offs and decision-making process related to higher education.

We find that correcting misperceptions, particularly those related to financial aid, influences students' preferences, making them conscious of the trade-off between quality and financial concerns. This type of information emphasizes the importance of making information available about student loans and the meaning of quality in higher education. The government should implement campaigns to educate students about the meaning of quality in local contexts and to facilitate comparisons of higher education institutions. Providing information about financial aid and how students can access it is a crucial aspect of this process. Government authorities can make information on students searching for high-quality education in specific areas more easily available to universities, so that universities can actively offer opportunities to students. Our results also emphasize that high-quality universities can reassess their plans to attract more high-profile students by providing partial scholarships targeted at specific populations with different levels of financial capacity (i.e. price discrimination).

\section{Chapter 4: To what extent does the cancellation of a merit- based scholarship affects students' aspirations for higher edu- cation?}

We administered a survey to 980 low-income, 10th grade students about their preferences for higher education. Many of them would have been eligible for the highly publicized SPP scholarship program before it was cancelled. Using a regression discontinuity design, we exploited 
the SPP's unanticipated cancellation and sharp eligibility criteria. The outcome was students' preferences for higher education measured using a discrete choice experiment administered in 2018.

We hypothesized that cancelling a merit- and need-based scholarship would decrease students' aspirations for higher education. The results supported this hypothesis. We find that the program's cancellation reduced educational ambitions mainly for low-income students who were more likely to be awarded an SPP scholarship among the individuals in the sample. Compared to the control group (i.e. students who completed the survey before the cancellation of the scholarship), informed students (i.e. those who completed the survey after the cancellation) reported lower levels of interest in the quality of higher education institutions and financial aid. We conclude that ending educational opportunities for minorities (or lower SES students in the Colombian case) can significantly decrease human capital accumulation among affected students, which deprives low-income students of social mobility. Governments should consider the large potential spillover effects on educational opportunities generated by announcements about financial aid. Such announcements can cause a large number of students (including those not awarded by the program) to modify their aspirations for higher education, which previous evidence has shown is linked to actual choices for higher education (Kaufmann, 2014).

\section{Chapter 5: To what extent does the conversion of single-sex schools into coed schools affect academic achievement?}

In this chapter we assessed, for the first time using a large nation-wide sample, the effect of converting 78 male-only and 168 female-only schools into coed schools on high school exit examination scores over a period of 17 years in Colombia. Using a time-varying difference-in-differences strategy along with school fixed effects, we assessed the benefit or harm for incumbent students caused by the inflow of opposite-sex students to the school.

We hypothesized that converting single-sex schools into coed schools would increase academic achievement for both females and males. This hypothesis was rejected for males in former male-only schools, and supported for females in former female-only schools. In particular, males 
in former male-only schools experienced a decrease in their performance, up to -0.25 standard deviations, particularly when the share of females was less than a half. Moreover, females in former female-only schools slightly benefited, up to +0.12 standard deviations, from the change. This gender peer effect is large in magnitude even in the presence of the endogenous reactions of parents and teachers to the change. Although it was not contemplate by the hypothesis, we also find that, conditional on SES, females have the best performance in former male-only schools compared to other types of schools.

This result suggests that a masculine school environment (i.e. on average characterized as more competitive and math focused) can enhance females' academic performance. Fourth, the conversion from single-sex to coed schools has important effects, especially when there is a small proportion of female students in former male-only schools. However, as the proportion of female students grows, male students seem to partially recover their performance, while female students continue to improve their performance. We conclude that gender peers have a significant influence on students' performance, and males do not benefit from the mixing. While we cannot recommend that high schools return to a single-sex status, we do recommend that changes to coed schools consider revising and studying closely aspects such as concomitant expected changes in culture of the school and pedagogy to avoid or minimize male decreases in performance and maximize corresponding increases in female performance.

\subsection{Summary of the findings}

This thesis explores how students' exposure to different situations (i.e. launching of a scholarship, provision of information, cancellation of a scholarship and changes in the gender composition of the school) can affect students' performance, decisions and preferences, which can ultimately influence their opportunities in higher education. Using various approaches, we find that low-income students are very sensitive to changes in expectations regarding financial aid for higher education (Chapters 1, 2 and 3), and that gender peer effects are high, and in some cases negative, when aiming to improve overall performance in high school (Chapter 5). Altogether, we find that incentives such as financial aid are powerful tools to increase academic effort and to change low- 
income students' decision-making process. This work goes beyond confirming existing information regarding the importance of financial aid. It proposes ways to deliver information to achieve better results with the available, often restricted, resources. However, it also finds that ending financial aid programs can reduce vulnerable students' educational aspirations, which can in turn slow the formation of human capital. Not accounting for real, well-known, reliable and reasonable achievable chances to study in a high-quality higher education institution will represent a high cost in terms of social mobility and the accumulation of human capital.

\subsection{Policy implications}

Chapters 1, 2 and 3 examine high school students' reactions to various higher education scenarios. Chapters 1 and 2 exploit a natural experiment related to the creation and then cessation of the SPP scholarship program. Chapter 3 recreated, in a hypothetical higher education choice set, the presence or absence of a (partial) scholarship and varied higher education attributes. Throughout the three chapters, information was the key driver of students' reactions, even under conditions of high uncertainty about whether they would be able to go to college. The studies jointly yield four implications.

1. More well-informed scholarships/financial aid directed towards specific populations is required, even if they are not full scholarships. Low-income students respond significantly and positively to scholarship incentives. In both the real event of the creation of the SPP program and in our study's artificial setting of a higher education choice set, where scholarships exogenously varied from 0 to $100 \%$, introducing or increasing financial opportunities generated positive spillover effects on low-income students. Providing more scholarships - in a coordinated effort with other actors in the educational system, with complete and understandable information provided to students, and with an emphasis on specific disadvantaged students - enriches the educational outcomes and ambitions of disadvantaged students.

2. A scholarship does not necessarily need to cover $100 \%$ of tuition fees to motivate low-income students to enroll in 
high-quality universities. Although financial aid is the most important incentive to encourage low-income students to attend college, students appear to be willing to take out a loan (of approximately $30 \%$ ) to switch from a low-quality to a high-quality institution. Moreover, students appear to be willing to give up an extra $30 \%$ of scholarship to instead receive a stipend. These insights are an important consideration when designing financial aid programs, since partial scholarships could be provided to a much larger group of students at a lower cost. Price discrimination in fees in costly universities (along with publicity) will also be an effective strategy to attract talent from low-income populations.

3. Disadvantaged groups require extra attention. Opportunities for education are more often denied to disadvantaged groups (particularly low SES students) than to others. For the lowest SES and female students, college scholarships improve their performance on the high school exit examination. However, the effect is modest compared to their counterparts. At the same time, providing information has the greatest effect on the decisions of female students and those in the lowest SES. A combination of higher education financial opportunities and proper information campaigns, especially those that target disadvantaged groups, can increase the opportunities' take-up among these groups.

\section{Changes from single-sex to coed schools require prepara-} tion and should consider large peer effects. While several practical reasons may lead schools to move to coed environments, the impact on student performance is mixed. It may be argued that the coed strategy is worth pursuing considering the potential benefits, even if small, of closing the gap between males and females, even if this is at the expense of reducing males' performance. Introducing single-sex classes for some subjects within coed schools could help preserve the advantages of both environments: it may retain the benefits of a competitive environment while empowering females and avoiding distractions for males. Well-implemented, female-only classes encourage female self-esteem (Eisenkopf, et al., 2015), which could eventually enhance their performance. Given that the mechanisms behind these results are still uncertain, a pilot of this single-sex class within a coed school should be conducted before this policy is fully implemented. 


\subsection{Directions for future research}

This dissertation suggests ways in which educational systems can more efficiently use resources by providing more motivation and access to lowincome students. These findings can be applied to many other contexts in which there are large socioeconomic challenges. However, these results should be confirmed and extended to find innovative ways to motivate and provide students with better opportunities for higher education.

In Colombia, a natural continuation of this research is to test the possible adverse consequences of cancelling a scholarship on students' performance in exit examinations. As the first cohort of SPP students is now in the labor market, there is a unique opportunity to study the SPP's effects on returns to education and social mobility. Moreover, the study of the impact of scholarships and mixed-gender environments should be extended to additional outcomes, such as the effects on socioemotional conditions. Students with better socioemotional conditions are most likely to succeed academically, socially, and in the labor force (Boston, 2013; Graven, 2014).

Pilots of novel policies that pursue inclusion and academic improvements among students who have been academically left behind require causal testing. This is important to launch small-scale innovative programs to explore and exploit students' potential. The pandemic has popularized multiple new ways to deliver knowledge at a very low cost; thus introducing changes will be easier than before. Even at the risk of failure, it is worth testing new approaches to increase inclusion and quality in education. Such measures could include: (i) testing practices such as delivering high-quality online classes to low-income high school students, to better target college financial aid; (ii) allocating small or single-sex classes in times where re-sorting students has become normal practice; and (iii) launching educational platforms for those unable to attend in-person classes. 


\section{References}

[1] Akhtari, M., Bau, N., \& Laliberté, J. W. (2017). Affirmative Action and Student Effort. Working Paper.

[2] Bartik, T. J., \& Lachowska, M. (2014). The short-term effects of the Kalamazoo promise scholarship on student outcomes. New analyses of worker well-being. Emerald Group Publishing Limited. 37-76.

[3] Boston, J. (2013). Improving educational performance: Why tackling child poverty must be part of the solution. In Symposium on the Poverty Impacts on Learning, Wellington, New Zealand. Retrieved from http://igps. victoria. ac. nz/staff/team/Education\% 20and\% 20ch ild\% 20poverty \% 20V4.pdf

[4] Cornwell, C., Mustard, D. B., \& Sridhar, D. J. (2006). The enrollment effects of merit-based financial aid: Evidence from Georgia's HOPE Program. Journal of Labor Economics, 24(4), 761-786. https://doi.org/10.1086/506485

[5] Dynarski, S., Libassi, C. J., Michelmore, K., \& Owen, S. (2018). Closing the gap: The effect of a targeted, tuition-free promise on college choices of high-achieving, low-income students (No. w25349). National Bureau of Economic Research.

[6] Eisenkopf, G., Hessami, Z., Fischbacher, U., \& Ursprung, H. W. (2015). Academic performance and single-sex schooling: Evidence from a natural experiment in Switzerland. Journal of economic behavior and organization, 115, 123-143

[7] Graven, M. H. (2014). Poverty, inequality and mathematics performance: The case of South Africa's post-apartheid context. ZDM, 46(7), 1039-1049 
[8] Hastings, J. S., Neilson, C. A., \& Zimmerman, S. D. (2012). The effect of school choice on intrinsic motivation and academic outcomes (No. w18324). National Bureau of Economic Research.

[9] Kaufmann, K. M. (2014). Understanding the income gradient in college attendance in Mexico: The role of heterogeneity in expected returns. Quantitative Economics, 5(3), 583-630.

[10] UNICEF. (2018). Gobal Area 2 Every child learns. https://www.unicef.org/media/55331/file

[11] United Nations. (2017). Goal 4: Ensure inclusive and equitable quality education and promote lifelong learning opportunities for all. 


\section{Appendix - Selected literature}

This section present a comparative table of selected literature, in the context of the topics of this dissertation. Table 6.1 summarizes some aspects of selected papers on the effect of Scholarships on several precollege and college outcomes. Moreover, Table 6.2 summarizes some aspects of selected papers that assess the impact of provision of information to pre-college students regarding either earnings and/or financial aid on different outcomes. All the papers carried out are randomized control trials (RCT). The tables serves to easily compare the selected existing literature with the findings in this dissertation, in the perspective of the broader empirical analysis proposed.

Table 6.1: Selected literature - Scholarships provision

\begin{tabular}{|c|c|c|c|c|c|}
\hline \multicolumn{6}{|c|}{ Criteria: 1) need-based grats 2)pre-college students; 3) Quasi-experimental or RCT design. } \\
\hline $\begin{array}{l}\mathrm{Au}- \\
\text { tors }\end{array}$ & $\begin{array}{l}\text { Coun- } \\
\text { try, } \\
\text { popula- } \\
\text { tion }\end{array}$ & $\begin{array}{l}\text { De- } \\
\text { sign } \\
\text { (RCT, } \\
\text { DiD, } \\
\text { RD) }\end{array}$ & $\begin{array}{l}\text { Sholarship pro- } \\
\text { vided... }\end{array}$ & Outcome & Results \\
\hline $\begin{array}{l}\text { Bar- } \\
\text { tik, } \\
\text { Her- } \\
\text { sh- } \\
\text { bein } \\
\& \text { } \\
\text { La- } \\
\text { chowskk } \\
(2021)\end{array}$ & $\begin{array}{l}\text { The } \\
\text { USA }\end{array}$ & DID & $\begin{array}{l}\text { Kalamazoo } \\
\text { Promise. College } \\
\text { scholarships }\end{array}$ & $\begin{array}{l}\text { Stu- } \\
\text { dents' } \\
\text { perfor- } \\
\text { mance } \\
\text { in sec- } \\
\text { ondary } \\
\text { school }\end{array}$ & $\begin{array}{l}\text { Positive. Increase in the probability of } \\
\text { earning any credits and one less suspen- } \\
\text { sion day per year. Larger increases in } \\
\text { GPA among African American students. }\end{array}$ \\
\hline $\begin{array}{l}\text { Dy- } \\
\text { narski, } \\
\text { Libassi } \\
\text { Michel- } \\
\text { more } \\
\& \\
\text { Owen } \\
(2018) .\end{array}$ & $\begin{array}{l}\text { Michi- } \\
\text { gan, } \\
\text { the } \\
\text { USA }\end{array}$ & $\mathrm{RCT}$ & $\begin{array}{l}\text { HAIL Scholar- } \\
\text { ship, University } \\
\text { of Michigan, } \\
\text { merit-based, } \\
\text { pays full tuition. }\end{array}$ & $\begin{array}{l}\text { Appli- } \\
\text { cation } \\
\text { and en- } \\
\text { rollment } \\
\text { rates }\end{array}$ & $\begin{array}{l}\text { The offer substantially increased appli- } \\
\text { cation and enrollment rates. }\end{array}$ \\
\hline
\end{tabular}




\begin{tabular}{|c|c|c|c|c|c|}
\hline $\begin{array}{l}\text { Londoñ } \\
\text { Velez, } \\
\text { Ro- } \\
\text { driguez } \\
\& \\
\text { Sancheq, } \\
2020\end{array}$ & $\begin{array}{l}\text { Colom- } \\
\text { bia }\end{array}$ & $\begin{array}{l}\text { RD, } \\
\text { DID }\end{array}$ & $\begin{array}{l}\text { Ser Pilo Paga } \\
\text { in Colombia. A } \\
\text { large-scale pro- } \\
\text { gram available to } \\
\text { high-achieving, } \\
\text { low-income } \\
\text { students for } \\
\text { attending high- } \\
\text { quality colleges } \\
\text { in Colombia }\end{array}$ & $\begin{array}{l}\text { postsec- } \\
\text { ondary } \\
\text { enroll- } \\
\text { ment, } \\
\text { college } \\
\text { choice, } \\
\text { and } \\
\text { student } \\
\text { composi- } \\
\text { tion }\end{array}$ & $\begin{array}{l}\text { Positive. Raise enrollment by } 56.5 \text { to } \\
86.5 \text { percent, depending on the complier } \\
\text { population. Increase matriculation at } \\
\text { private, high-quality colleges Diversity } \\
\text { increased } 46 \text { percent at private, high- } \\
\text { quality colleges. }\end{array}$ \\
\hline $\begin{array}{l}\text { Bernal } \\
\& \\
\text { Pen- } \\
\text { ney } \\
(2019)\end{array}$ & $\begin{array}{l}\text { Colom- } \\
\text { bia, } \\
11 \text { th } \\
\text { (last) } \\
\text { grade } \\
\text { stu- } \\
\text { dents }\end{array}$ & $\mathrm{RD}$ & $\begin{array}{l}\text { Ser Pilo Paga, } \\
\text { national, income } \\
\text { and merit-based. } \\
\text { Pays full tuition. }\end{array}$ & $\begin{array}{l}\text { Stan- } \\
\text { dardized } \\
\text { test and } \\
\text { effort. }\end{array}$ & $\begin{array}{l}\text { Positive. students who qualify for the } \\
\text { scholarship score about } 0.09 \text { test score } \\
\text { standard deviations higher than those } \\
\text { who do not. Students spent more time } \\
\text { and money preparing for the test. }\end{array}$ \\
\hline $\begin{array}{l}\text { De } \\
\text { Hoyos, } \\
\text { At- } \\
\text { tana- } \\
\text { sio \& } \\
\text { Meghir } \\
(2019)\end{array}$ & $\begin{array}{l}\text { Mex- } \\
\text { ico, } \\
\text { upper } \\
\text { sec- } \\
\text { ondary } \\
\text { school } \\
\text { stu- } \\
\text { dents } \\
\text { from } \\
\text { poor } \\
\text { back- } \\
\text { grounds }\end{array}$ & $\begin{array}{l}\text { Quasi- } \\
\text { ex- } \\
\text { peri- } \\
\text { ment. } \\
\text { Ran- } \\
\text { dom } \\
\text { allo- } \\
\text { cation } \\
\text { into } \\
\text { the } \\
\text { pro- } \\
\text { gram. }\end{array}$ & $\begin{array}{l}\text { PROBEMS, } \\
\text { a scholarship } \\
\text { program in } \\
\text { Mexico }\end{array}$ & $\begin{array}{l}\text { Test } \\
\text { scores } \\
\text { and } \\
\text { grad- } \\
\text { uation } \\
\text { rates } \\
\text { three } \\
\text { years } \\
\text { later in } \\
2012\end{array}$ & $\begin{array}{l}\text { No effect. On average, the program } \\
\text { has no discernible impact on graduation } \\
\text { rates or math or Spanish test scores. }\end{array}$ \\
\hline $\begin{array}{l}\text { Holmes, } \\
\text { Mills } \\
\& \\
\text { Wolf } \\
(2019)\end{array}$ & $\begin{array}{l}\text { Louisiana } \\
\text { the } \\
\text { USA }\end{array}$ & PSM & $\begin{array}{l}\text { Louisiana Schol- } \\
\text { arship Program }\end{array}$ & $\begin{array}{l}\text { college } \\
\text { entrance. }\end{array}$ & $\begin{array}{l}\text { Not effect. no differential treatment ef- } \\
\text { fects when considering student enroll- } \\
\text { ment in two- or four-year post-secondary } \\
\text { institutions. }\end{array}$ \\
\hline $\begin{array}{l}\text { Fack } \\
\& \\
\text { Grenet } \\
(2015)\end{array}$ & France & $\mathrm{RD}$ & need-based grant & $\begin{array}{l}\text { enroll- } \\
\text { ment } \\
\text { deci- } \\
\text { sions, } \\
\text { persis- } \\
\text { tence, } \\
\text { and } \\
\text { grad- } \\
\text { uation } \\
\text { rates } \\
\text { of low- } \\
\text { income } \\
\text { students }\end{array}$ & $\begin{array}{l}\text { Positive. Need-based grants have pos- } \\
\text { itive effects on student persistence and } \\
\text { degree completion. Provision of } 1,500 \\
\text { euros cash allowances increases their col- } \\
\text { lege enrollment rates by } 5 \text { to } 7 \text { percent. }\end{array}$ \\
\hline
\end{tabular}




\begin{tabular}{|c|c|c|c|c|c|}
\hline $\begin{array}{l}\text { Alon } \\
\& \\
\text { Mala- } \\
\text { mud, } \\
2014\end{array}$ & Israel & $\mathrm{RD}$ & $\begin{array}{l}\text { Offer admission } \\
\text { to academically } \\
\text { borderline appli- } \\
\text { cants who were } \\
\text { above a certain } \\
\text { threshold of dis- } \\
\text { advantage }\end{array}$ & $\begin{array}{l}\text { admis- } \\
\text { sion and } \\
\text { enroll- } \\
\text { ment } \\
\text { out- } \\
\text { comes as } \\
\text { well as } \\
\text { academic } \\
\text { achieve- } \\
\text { ment }\end{array}$ & $\begin{array}{l}\text { Positive. Increase probability of admis- } \\
\text { sion and enrollment. Higher rates of ad- } \\
\text { mission to the most selective majors. }\end{array}$ \\
\hline $\begin{array}{l}\text { Scott- } \\
\text { Claytop } \\
(2011)\end{array}$ & $\begin{array}{l}\text { West } \\
\text { Vir- } \\
\text { ginia, } \\
\text { the } \\
\text { USA }\end{array}$ & $\mathrm{RD}$ & $\begin{array}{l}\text { PROMISE pro- } \\
\text { gram, offers free } \\
\text { tuition to stu- } \\
\text { dents who main- } \\
\text { tain a minimum } \\
\text { GPA and course } \\
\text { load }\end{array}$ & $\begin{array}{l}\text { GPA and } \\
\text { course } \\
\text { load }\end{array}$ & Positive. Academic outcomes. \\
\hline $\begin{array}{l}\text { Pal- } \\
\text { lais } \\
(2009)\end{array}$ & $\begin{array}{l}\text { Ten- } \\
\text { nessee, } \\
\text { the } \\
\text { USA }\end{array}$ & $\begin{array}{l}\text { Quasi- } \\
\text { ex- } \\
\text { peri- } \\
\text { ment. } \\
\text { Ran- } \\
\text { dom } \\
\text { allo- } \\
\text { cation } \\
\text { into } \\
\text { the } \\
\text { pro- } \\
\text { gram. }\end{array}$ & $\begin{array}{l}\text { Broad-based } \\
\text { merit scholar- } \\
\text { ship. Tennessee } \\
\text { Education } \\
\text { Lottery Scholar- } \\
\text { ships. HOPE }\end{array}$ & $\begin{array}{l}\mathrm{ACT} \text { ex- } \\
\text { ams }\end{array}$ & $\begin{array}{l}\text { Positive. Increases in performance on } \\
\text { the ACT. }\end{array}$ \\
\hline $\begin{array}{l}\text { Corn- } \\
\text { well } \\
\text { et al. } \\
(2006) \text {, }\end{array}$ & $\begin{array}{l}\text { Univer- } \\
\text { sity of } \\
\text { Geor- } \\
\text { gia, } \\
\text { The } \\
\text { USA }\end{array}$ & $\begin{array}{l}\text { Quasi- } \\
\text { exper- } \\
\text { iment }\end{array}$ & $\begin{array}{lr}\begin{array}{l}\text { Georgia's } \\
\text { Program }\end{array} & \text { spon- } \\
\text { sors a merit- } \\
\text { based } & \text { scholar- } \\
\text { ship } & \end{array}$ & $\begin{array}{l}\text { enroll- } \\
\text { ment }\end{array}$ & $\begin{array}{l}\text { HOPE increased freshmen enrollment by } \\
5.9 \% \text {, or } 2,889 \text { students per year, which } \\
\text { amounts to only } 15 \% \text { of freshmen schol- } \\
\text { arship recipients. Four-year colleges ac- } \\
\text { count for most of the gain; a reduc- } \\
\text { tion in students leaving the state ex- } \\
\text { plains two-thirds of the } 4 \text {-year-school ef- } \\
\text { fect attributable to freshmen who have } \\
\text { recently graduated from high school. } \\
\text { White and black enrollments increased } \\
\text { because of HOPE. }\end{array}$ \\
\hline
\end{tabular}

\section{Table 6.2: Selected literature - Provision of information}

\begin{tabular}{|c|c|c|c|c|}
\hline \multicolumn{5}{|c|}{$\begin{array}{l}\text { Criteria: 1) Design }=\text { RCT 2) Intervention = Provision of information to pre-college students } \\
\text { regarding either "earnings" and/or "financial aid" }\end{array}$} \\
\hline Autors & Country & $\begin{array}{l}\text { Treatment - provi- } \\
\text { sion of information } \\
\text { regarding... }\end{array}$ & Outcome & Result \\
\hline $\begin{array}{l}\text { Bernal, } \\
\text { Abadía, } \\
\text { Arango } \\
\& \text { De- } \\
\text { Witte } \\
(2020)\end{array}$ & $\begin{array}{l}\text { Colombia, } \\
\text { 10th grade } \\
\text { students, } \\
\text { low-income. }\end{array}$ & $\begin{array}{l}\text { Statements on re- } \\
\text { turns and financial } \\
\text { aid }\end{array}$ & $\begin{array}{l}\text { Students } \\
\text { preferences } \\
\text { measured } \\
\text { as a Dis- } \\
\text { crete Choice } \\
\text { Experiment }\end{array}$ & $\begin{array}{l}\text { Positive. Students increase prefer- } \\
\text { ences for higher quality higher ed- } \\
\text { ucation institution }\end{array}$ \\
\hline
\end{tabular}




\begin{tabular}{|c|c|c|c|c|}
\hline $\begin{array}{l}\text { Bonilla, } \\
\text { Bottan } \\
\& \text { Ham } \\
(2017)\end{array}$ & $\begin{array}{l}\text { Colombia, } \\
\text { 11th grade } \\
\text { students. }\end{array}$ & $\begin{array}{l}\text { Labor market } \\
\text { statistics (earnings) } \\
\text { and financial aid } \\
\text { options }\end{array}$ & $\begin{array}{l}\text { Beliefs about } \\
\text { earnings, } \\
\text { test scores, } \\
\text { college } \\
\text { enrollment }\end{array}$ & $\begin{array}{l}\text { No effect. Students learn about } \\
\text { financial aid but do not change } \\
\text { their beliefs about earnings asso- } \\
\text { ciated with college degrees. Test } \\
\text { scores and college enrollment are } \\
\text { unchanged. Although more stu- } \\
\text { dents to choose to attend selective } \\
\text { colleges. }\end{array}$ \\
\hline $\begin{array}{l}\text { Ehlert, } \\
\text { Finger, } \\
\text { Rus- } \\
\text { coni \& } \\
\text { Solga } \\
(2017) \\
\end{array}$ & $\begin{array}{l}\text { Germany, } \\
\text { Berlin }\end{array}$ & $\begin{array}{l}\text { costs of and returns } \\
\text { to higher education }\end{array}$ & $\begin{array}{l}\text { Application } \\
\text { to college }\end{array}$ & $\begin{array}{l}\text { Positive. Increases the likelihood of } \\
\text { treated less-privileged students to } \\
\text { apply to college }\end{array}$ \\
\hline $\begin{array}{l}\text { Ab- } \\
\text { biati \& } \\
\text { Barone } \\
(2017)\end{array}$ & $\begin{array}{l}\text { Italy, Four } \\
\text { Italian } \\
\text { provinces } \\
\text { students } \\
\text { from the } \\
\text { working } \\
\text { class }\end{array}$ & Returns and costs & $\begin{array}{l}\text { Enrollment } \\
\text { in higher } \\
\text { education } \\
\text { (strong } \\
\text { fields) }\end{array}$ & Mixed. \\
\hline $\begin{array}{l}\text { Peter, } \\
\text { Frauke, } \\
\text { Zam- } \\
\text { bre \& } \\
\text { Vaishali } \\
(2016)\end{array}$ & $\begin{array}{l}\text { Berlin, Ger- } \\
\text { many. Pre- } \\
\text { college stu- } \\
\text { dents. }\end{array}$ & $\begin{array}{l}\text { On the benefits and } \\
\text { financing of college } \\
\text { education }\end{array}$ & $\begin{array}{l}\text { Intend to en- } \\
\text { roll in college }\end{array}$ & $\begin{array}{l}\text { Positive. Increases the likelihood } \\
\text { that they intend to enroll in college- } \\
\text { particularly for students whose par- } \\
\text { ents have no academic background. } \\
\text { Increases the likelihood that the } \\
\text { students will carry out these plans, } \\
\text { which means that they will actually } \\
\text { apply to college }\end{array}$ \\
\hline $\begin{array}{l}\text { Rao } \\
(2016)\end{array}$ & $\begin{array}{l}\text { India, } \\
12 \text { th grade } \\
\text { students. }\end{array}$ & $\begin{array}{l}\text { on population earn- } \\
\text { ings }\end{array}$ & $\begin{array}{l}\text { College at- } \\
\text { tendance } \\
\text { and college } \\
\text { track }\end{array}$ & $\begin{array}{l}\text { No significant effect of information } \\
\text { on decision regarding college atten- } \\
\text { dance and college track (technical, } \\
\text { academic, vocational) conditional } \\
\text { on attendance. }\end{array}$ \\
\hline $\begin{array}{l}\text { Fryer } \\
(2016)\end{array}$ & $\begin{array}{l}\text { Oklahoma, } \\
\text { the USA. }\end{array}$ & $\begin{array}{l}\text { daily information } \\
\text { about the link } \\
\text { between human } \\
\text { capital and future } \\
\text { outcomes via text } \\
\text { message (giving } \\
\text { free cellular phones } \\
\text { or minutes to talk) }\end{array}$ & $\begin{array}{l}\text { Student } \\
\text { effort, at- } \\
\text { tendance, } \\
\text { suspensions, } \\
\text { and state } \\
\text { test scores }\end{array}$ & $\begin{array}{l}\text { No effect. No measurable changes } \\
\text { in student effort, attendance, sus- } \\
\text { pensions, or state test scores, } \\
\text { though there is evidence that scores } \\
\text { on college entrance exams four } \\
\text { years later increased. }\end{array}$ \\
\hline $\begin{array}{l}\text { Busso, } \\
\text { Dinkel- } \\
\text { man \& } \\
\text { Martínez } \\
\& \\
\text { Romero } \\
(2016)\end{array}$ & $\begin{array}{l}\text { Chile, grade } \\
12 \text { students }\end{array}$ & $\begin{array}{l}\text { financial aid and } \\
\text { average earnings } \\
\text { and employment } \\
\text { probabilities for } \\
\text { schools and careers }\end{array}$ & \begin{tabular}{lr}
\multicolumn{2}{l}{ enrollment } \\
and & deci- \\
sions & for \\
higher & edu- \\
cation &
\end{tabular} & $\begin{array}{l}\text { No effect on enrollment in the se- } \\
\text { lective or in the less selective sec- } \\
\text { tor. But, do find effect in the } \\
\text { intensive margin: choose careers } \\
\text { and schools with lower expected } \\
\text { wages, lower employment probabil- } \\
\text { ities, but with higher quality rela- } \\
\text { tive to their baseline preferences. }\end{array}$ \\
\hline $\begin{array}{l}\text { Avitabile } \\
\& \quad \text { De } \\
\text { Hoyos } \\
(2015)\end{array}$ & $\begin{array}{l}\text { Mexico, } \\
\text { 10th grade } \\
\text { students. }\end{array}$ & $\begin{array}{lr}\text { average } & \text { earnings } \\
\text { associated } & \text { with } \\
\text { different educa- } & \text { tional attainments, } \\
\text { life expectancy, } \\
\text { and obtaining } \\
\text { funding for higher } \\
\text { education }\end{array}$ & $\begin{array}{l}\text { High school } \\
\text { completion, } \\
\text { test scores } \\
\text { and self- } \\
\text { reported } \\
\text { effort }\end{array}$ & $\begin{array}{l}\text { Mixed. No effects on a proxy } \\
\text { for on-time high school completion, } \\
\text { but a positive and significant im- } \\
\text { pact on standardized test scores } \\
\text { and self-reported measures of effort } \\
\text { (larger effects for girls). }\end{array}$ \\
\hline
\end{tabular}




\begin{tabular}{|c|c|c|c|c|}
\hline $\begin{array}{l}\text { Pekkala- } \\
\text { Kerr } \\
\text { et al } \\
(2015)\end{array}$ & $\begin{array}{l}\text { Finland, } \\
\text { high schools }\end{array}$ & $\begin{array}{l}\text { on the labor mar- } \\
\text { ket prospects asso- } \\
\text { ciated with detailed } \\
\text { post-secondary pro- } \\
\text { grams }\end{array}$ & $\begin{array}{l}\text { Beliefs of la- } \\
\text { bor market }\end{array}$ & $\begin{array}{l}\text { Effects only in the margin. A third } \\
\text { of the students report that the in- } \\
\text { tervention led them to update their } \\
\text { beliefs. The least informed stu- } \\
\text { dents are the most affected. }\end{array}$ \\
\hline $\begin{array}{l}\text { Herber } \\
(2015)\end{array}$ & $\begin{array}{l}\text { Germany, } \\
\text { pre-college } \\
\text { students. }\end{array}$ & $\begin{array}{l}\text { federally funded } \\
\text { scholarships or } \\
\text { additionally to tai- } \\
\text { lored information } \\
\text { on details of the } \\
\text { application process. }\end{array}$ & $\begin{array}{l}\text { Application } \\
\text { for financial } \\
\text { aid }\end{array}$ & $\begin{array}{l}\text { Positive Effect. Increase non- } \\
\text { academic and male students' ap- } \\
\text { plication probabilities for feder- } \\
\text { ally funded merit-based scholar- } \\
\text { ships. Providing general informa- } \\
\text { tion on the scholarship system trig- } \\
\text { gered participants' own informa- } \\
\text { tion search for alternative funding } \\
\text { sources and increased application } \\
\text { rates for other scholarships. }\end{array}$ \\
\hline $\begin{array}{l}\text { Hoxby } \\
\& \\
\text { Turner } \\
(2015)\end{array}$ & $\begin{array}{l}\text { The USA, } \\
\text { high school } \\
\text { seniors }\end{array}$ & $\begin{array}{l}\text { colleges' net prices, } \\
\text { resources, curric- } \\
\text { ula, students, and } \\
\text { outcomes }\end{array}$ & $\begin{array}{l}\text { changes } \\
\text { students' } \\
\text { knowl- } \\
\text { edge and } \\
\text { decision- } \\
\text { making }\end{array}$ & $\begin{array}{l}\text { Positive. raises students' applica- } \\
\text { tions to, admissions at, enrollment, } \\
\text { and progress at selective colleges. }\end{array}$ \\
\hline $\begin{array}{l}\text { Hast- } \\
\text { ings, } \\
\text { Neilson } \\
\text { \& Zim- } \\
\text { mer- } \\
\text { man } \\
(2015)\end{array}$ & Chile & Earnings & $\begin{array}{l}\text { degrees } \\
\text { choice. }\end{array}$ & $\begin{array}{l}\text { Positive. Treatment causes low- } \\
\text { income students to reduce their } \\
\text { demand for low-return degrees by } \\
4.6 \% \text {, and increases the likelihood } \\
\text { they remain in college for at least } \\
\text { four years. }\end{array}$ \\
\hline $\begin{array}{l}\text { Rosinger } \\
(2015)\end{array}$ & $\begin{array}{l}\text { United } \\
\text { States }\end{array}$ & $\begin{array}{l}\text { Financial aid award } \\
\text { notification }\end{array}$ & $\begin{array}{l}\text { admission to } \\
\text { universities }\end{array}$ & $\begin{array}{l}\text { No effect. Receipt of the shopping } \\
\text { sheet had a limited effect on enroll- } \\
\text { ment and borrowing decisions. }\end{array}$ \\
\hline $\begin{array}{l}\text { Dinkel- } \\
\text { man \& } \\
\text { Martínez } \\
2014\end{array}$ & $\begin{array}{l}\text { Chile, } \\
\text { medium- } \\
\text { and high- } \\
\text { grade } \\
\text { students, } \\
\text { low-income } \\
\text { students. }\end{array}$ & $\begin{array}{l}\text { financial aid for } \\
\text { higher education } \\
\text { for students and } \\
\text { their parents }\end{array}$ & $\begin{array}{l}\text { Preparatory } \\
\text { high school } \\
\text { enrollment, } \\
\text { primary } \\
\text { school atten- } \\
\text { dance, and } \\
\text { financial aid } \\
\text { knowledge }\end{array}$ & $\begin{array}{l}\text { Positive. Increase college prepara- } \\
\text { tory high school enrollment, pri- } \\
\text { mary school attendance, and fi- } \\
\text { nancial aid knowledge. Parental } \\
\text { involvement did not significantly } \\
\text { magnify these effects }\end{array}$ \\
\hline $\begin{array}{l}\text { Loy- } \\
\text { alka, } \\
\text { Song, } \\
\text { Wei, } \\
\text { Zhong } \\
\& \\
\text { Rozelle } \\
(2013) \\
\end{array}$ & $\begin{array}{l}\text { China, } \\
\text { high school } \\
\text { students } \\
\text { in poor } \\
\text { regions of } \\
\text { northwest } \\
\text { China }\end{array}$ & $\begin{array}{l}\text { on college costs and } \\
\text { financial aid }\end{array}$ & $\begin{array}{l}\text { Financial aid } \\
\text { recipients } \\
\text { and college } \\
\text { choice }\end{array}$ & $\begin{array}{l}\text { Positive. Information increases } \\
\text { the likelihood that students receive } \\
\text { some types of financial aid. Infor- } \\
\text { mation also positively affects the } \\
\text { choice to attend college. }\end{array}$ \\
\hline $\begin{array}{l}\text { Booij, } \\
\text { Leu- } \\
\text { ven \& } \\
\text { Oost- } \\
\text { erbeek, } \\
2012\end{array}$ & $\begin{array}{l}\text { The } \\
\text { Nether- } \\
\text { lands, }\end{array}$ & $\begin{array}{l}\text { Loans for higher ed- } \\
\text { ucation }\end{array}$ & $\begin{array}{l}\text { Take up } \\
\text { rates of } \\
\text { financial aid }\end{array}$ & $\begin{array}{l}\text { No effect. The treatment has no } \\
\text { impact on loan take-up. }\end{array}$ \\
\hline
\end{tabular}




\begin{tabular}{|c|c|c|c|c|}
\hline $\begin{array}{l}\text { Bet- } \\
\text { tinger, } \\
\text { Long, } \\
\text { Ore- } \\
\text { opoulos } \\
\text { \& San- } \\
\text { bon- } \\
\text { matsu } \\
(2012)\end{array}$ & $\begin{array}{l}\text { the USA, } \\
\text { high school } \\
\text { seniors }\end{array}$ & $\begin{array}{l}\text { tax prepara- } \\
\text { tion, immediate } \\
\text { assistance to com- } \\
\text { plete the FAFSA } \\
\text { form. Tuition cost } \\
\text { amounts for nearby } \\
\text { colleges. }\end{array}$ & $\begin{array}{l}\text { FAFSA sub- } \\
\text { missions, } \\
\text { college at- } \\
\text { tendance, } \\
\text { persistence, } \\
\text { and aid } \\
\text { receipt. }\end{array}$ & $\begin{array}{l}\text { Positive. Higher FASA submissions } \\
\text { and higher college competition for } \\
\text { those assisted with the FASA. No } \\
\text { effect for those who received aid in- } \\
\text { formation but no assistance with } \\
\text { the FAFSA. }\end{array}$ \\
\hline $\begin{array}{l}\text { Jensen } \\
(2010) \text {; }\end{array}$ & $\begin{array}{l}\text { Dominican } \\
\text { Republic, } \\
\text { 8th grade }\end{array}$ & $\begin{array}{l}\text { Returns to educa- } \\
\text { tion }\end{array}$ & $\begin{array}{l}\text { School com- } \\
\text { petition }\end{array}$ & $\begin{array}{l}\text { Positive. Treated students com- } \\
\text { pleted on average more years of } \\
\text { school over the next four years. }\end{array}$ \\
\hline $\begin{array}{l}\text { Nguyen } \\
(2008)\end{array}$ & $\begin{array}{l}\text { Mada- } \\
\text { gascar, } \\
\text { 4th grade } \\
\text { students. }\end{array}$ & $\begin{array}{l}\text { Returns to educa- } \\
\text { tion by statistics } \\
\text { versus using a role } \\
\text { model }\end{array}$ & Test score & $\begin{array}{l}\text { Positive. Increase test scores. Roll } \\
\text { model has larger effect. }\end{array}$ \\
\hline
\end{tabular}




\section{Bio}

Gloria Lucía Bernal Nisperuza is an assistant professor of the Department of Economics at Pontificia Universidad Javeriana (Javeriana University) in Bogota, Colombia. She is also the cofounder and codirector of the Laboratory of Economics of Education (LEE) at the same university (2020). At LEE, she leads and conduct rigorous analysis and evidence-based opinions regarding education. LEE has reached a significant attention from media, governmental institutions, and private organizations interested in Education in Colombia in one year since launched. It has become one of the most cited source of educational analysis in the country and a tool to generate real impact on Colombians education.

Gloria's recent research focuses on testing solutions directed towards improving education opportunities, and reducing gap gender, especially to socio-economic vulnerable students. She is passionate about applying her knowledge in the design of educational policies that have real impact in our society. She intersects research with actions by promoting small-scale programs that look to increase educational opportunities to low-income students in Colombia. In addition, she enjoys teaching motivating lectures for my students, gaining close to perfect scores from students evaluations. She earned an A.B. and M.A. in Economics from Javeriana University (2005 and 2008), and a Master of Public Policy from New York University (2014). More recently (2017), she engaged the Ph.D. program in Policy in Governance and Policy Analysis to obtain the degree of Doctor at the Maastricht University (2021).

After studying abroad, and inspired by generating transformations of the educational sector in her country, Gloria resides and works in Bogotá-Colombia, where she was born (1983). She lives with her beloved husband, Lope, and their two adorable children, Santiago (7) and María Lucía (6). 



\section{UNU-MERIT/MGSoG Dissertation Series}

2021

\section{Philip Drauz}

Who calls the shot and why?

The role of actors and instructions in

the response to the sovereign debt

crises in the euro area

UNU-MERIT/MGSoG Dissertation

Series № 261

\section{Bart Kleine Deters}

A Quantitative approach to the right to education: Concept, Measurement, and Effects

UNU-MERIT/MGSoG Dissertation

Series № 260

\section{Eliana Rubiano-Matulevich}

Essays on Conflict-Induced

Displacement and Gender in Colombia

UNU-MERIT/MGSoG Dissertation

Series № 259

\section{Njagi Purity Muthoni}

Financial Risk, Vulnerability and

Equity of Access to Healthcare Services in Kenya

UNU-MERIT/MGSoG Dissertation

Series № 258

\section{María José Espinosa-Romero}

The Shadow of Hierarchy in Marine

Fisheries Governance

UNU-MERIT/MGSoG Dissertation

Series № 257

\section{Lorena Rivera León}

Unveiling the Determinants of Scientific

Productivity in Middle-Income Countries:

An Economics of Science Perspective

UNU-MERIT/MGSoG Dissertation

Series № 256

\section{Racky Balde}

Essays on Informal versus formal Economy Choices

UNU-MERIT/MGSoG Dissertation

Series № 255

\section{Caio Torres Mazzi}

Learning, Capabilities and Governance in Global Value Chains

UNU-MERIT/MGSoG Dissertation

Series № 254

\section{Giulia Rossello}

Social Transformations and Labour Market

Entry

An Investigation into University Systems in Emerging Economies

UNU-MERIT/MGSoG Dissertation

Series № 253

2020

\section{Rose Camille Vincent}

Essays in Public Economics

Multi-Layer Tax Structure and

Implications

UNU-MERIT/MGSoG Dissertation

Series № 252 


\section{Emmanuel Mensah}

Structural change in developing countries:

patterns, causes, and consequences

UNU-MERIT/MGSoG Dissertation

Series № 251

\section{Ornsaran Manuamorn}

Governance of International Adaptation

Finance for Local Climate Change

Adaptation: An Analysis of Adaptation

Fund Projects

UNU-MERIT/MGSoG Dissertation

Series № 250

\section{Gillian McFarland}

Doing policy in Further Education

An exploration of the enactment of the

GCSE resits policy in Further Education

colleges in England

UNU-MERIT/MGSoG Dissertation

Series № 249

\section{Omar Rodriguez Torres}

Essays on Entrepreneurship in Colombia UNU-MERIT/MGSoG Dissertation

Series № 248

\section{Elaine Lebon-McGregor}

International Organizations and Global

Migration Governance

UNU-MERIT/MGSoG Dissertation

Series № 247

\section{Janyl Moldalieva}

Playing the 'Game' of Transparency and

Accountability in Kyrgyzstan's Resource

Governance

UNU-MERIT/MGSoG Dissertation

Series № 246

\section{Kaleab Kebede Haile}

Essays on Rural Household Decision-

Making under Climate Risk

UNU-MERIT/MGSoG Dissertation

Series № 245

\section{Nora Jasmin Ragab}

Diaspora Mobilisation in a Conflict Setting

UNU-MERIT/MGSoG Dissertation

Series № 244

\section{Mary Kaltenberg}

From Micro to Macro: Essays on

Technological Change and Income

Divergence

UNU-MERIT/MGSoG Dissertation

Series № 243

\section{Ayla E. Bonfiglio}

Student migrant, refugee or both?

Exploring Refugee Agency and Mobility

through Tertiary Education in Kenya,

South Africa and Uganda

UNU-MERIT/MGSoG Dissertation

Series № 242

\section{Danilo Sartorello Spinola}

Cycles, Economic Structures and External Constraints.

A Structuralist study on the causes of economic volatility in Latin America UNU-MERIT/MGSoG Dissertation

Series № 241

2019

Jemal Adem

Livelihood Vulnerability to Shocks,

Behaviour and Investment in Education:

Essays in Behavioural Development

Economics

UNU-MERIT/MGSoG Dissertation

Series № 240

\section{Davina Osei}

Corrupt or corrupted networks?

An empirical enquiry

UNU-MERIT/MGSoG Dissertation

Series № 239 


\section{Patima Chongcharoentanawat}

Beyond Static Inequality

Public policies and economic mobility in

Thailand

UNU-MERIT/MGSoG Dissertation

Series № 238

\section{Charlotte Guillard}

Rethinking economic growth

and structural change.

The role of boundaries and linkages between industries

UNU-MERIT/MGSoG Dissertation

Series № 237

\section{Nicolas Echarti}

Employment Effects or Vocational

Rehabilitation in Germany:

A quantitative analysis

UNU-MERIT/MGSoG Dissertation

Series № 236

\section{Shellie E. Solomon}

Neighborhoods Matter:

Crime, collective efficacy and foreclosures

in Miami

UNU-MERIT/MGSoG Dissertation

Series № 235

\section{Michał Kazimierczak}

Regional Innovation and Entrepreneurship

Patents, trade marks, entry and entrants' growth in European manufacturing

industries

UNU-MERIT/MGSoG Dissertation

Series № 234

\section{Fernanda Soares}

The Influence of Within School and Across Schools' Collaborative Practices on Student Learning and Teaching Outcomes in West Africa

UNU-MERIT/MGSoG Dissertation

Series № 233

\section{Mira Bierbaum}

New Mindsets to Innovate Activation UNU-MERIT/MGSoG Dissertation

Series № 232

\section{Norman Dytianquin}

Technology in the Asian Miracle and Crisis Debates: Applications of and Insights from the Field of Influence Approach to InputOutput Analysis

UNU-MERIT/MGSoG Dissertation

Series № 231

\section{Nga Le}

The implications of health insurance for the labour market and patient satisfaction with medical care in Vietnam

UNU-MERIT/MGSoG Dissertation

Series № 230

\section{Jinhyuck Park}

Intellectual Property right protection and cross-border RED investments by multinational enterprises

UNU-MERIT/MGSoG Dissertation

Series № 229

\section{Richard de Groot}

Show me the Money:

Essays on the Impact of Cash Transfers on Child Nutrition and the Role of Intra-

Household Dynamics

UNU-MERIT/MGSoG Dissertation

Series № 228

\section{Catie Lott}

Diamonds are a Women's Best Friend Broadening Measures of Women's Access to Formal Political Decision-Making UNU-MERIT/MGSoG Dissertation Series № 227 


\section{Ana Cristina Calderon Ramirez}

Public Management Reforms

Three stories about public procurement agencification in Latin America UNU-MERIT/MGSoG Dissertation

Series № 226

\section{Camilo Nicanor Carrillo Purin}

Teachers' in-service training and student achievement:

The effect of in-service training of Peruvian teachers on student achievement UNU-MERIT/MGSoG Dissertation

Series № 225

\section{Hugo Confraria}

Developing scientific capacity in the Global South

UNU-MERIT/MGSoG Dissertation Series № 224

\section{Alison Cathles}

Educational Pathways and Skills:

Past, Present, and Future

UNU-MERIT/MGSoG Dissertation

Series № 223

\section{Ibrahima Sory Kaba}

Aggregate Fluctuations and Development:

Essays on Macroeconomic Volatility and

Economic Growth

UNU-MERIT/MGSoG Dissertation

Series № 222

\section{Charlotte Keijser}

Firm Participation, Learning and

Innovation in Heterogenous Value Chains

of IT-enabled Services

UNU-MERIT/MGSoG Dissertation

Series № 221

\section{Salih Çevikarslan}

Innovation Strategies and Their

Implications for Technological Change and

Market Outcomes:

An Evolutionary Multi-Agent Based

Modelling Approach

UNU-MERIT/MGSoG Dissertation

Series № 220

\section{Wondimagegn Mesfin Tesfaye}

Essays on the Impacts of Climate-Smart

Agricultural Innovations on Household

Welfare

UNU-MERIT/MGSoG Dissertation

Series № 219

\section{Tatevik Poghosyan}

How Board Networks Affect Firm

Performance and Innovation Incentives in

Transition Economies: The Case of

Armenia

UNU-MERIT/MGSoG Dissertation

Series № 218

\section{Arip Muttaqien}

Essays on Inequality and Polarization:

Empirical Studies in Developing Asia

UNU-MERIT/MGSoG Dissertation

Series № 217

\section{8}

\section{Katrin Marchand}

Essays on Forced Migration and Labour

Market Participation in Developing

Countries

UNU-MERIT/MGSoG Dissertation

Series № 216

\section{Ortrun Merkle}

The Myth of Gender Neutral Power:

Corruption and Gender Norms

UNU-MERIT/MGSoG Dissertation

Series № 215 


\section{Biljana Meshkovska}

Life after Trafficking:

(re)integration processes of women that have been trafficked for the purpose of sexual exploitation in Europe UNU-MERIT/MGSoG Dissertation Series № 214

\section{Vincenzo Vinci}

The Relevance of Institutions and People's Preferences for Social Protection UNU-MERIT/MGSoG Dissertation Series № 213

\section{Silke Heuser}

The Effectiveness of Environmental Policies on Reducing Deforestation in the Brazilian Amazon

UNU-MERIT/MGSoG Dissertation Series № 212

\section{Jennifer Waidler}

Social Assistance and Remittances and Their Role in the Fight Against Poverty UNU-MERIT/MGSoG Dissertation Series № 211

\section{Choolwe Muzyamba}

The role of community mobilization in the promotion of maternal health of women living with HIV in Zambia

UNU-MERIT/MGSoG Dissertation Series № 210

\section{Juan Carlos A. Castillo Sánchez}

Assessing the Role of the Export Sector in Mexican Economic Development,19652014

UNU-MERIT/MGSoG Dissertation Series № 209

\section{Tareq Abuelhaj}

Food Security Policy Impact Analysis: The Econometrics of Cash and Food Assistance Cost Effectiveness

UNU-MERIT/MGSoG Dissertation

Series № 208

Marta Férnandez de Arroyabe Arranz

Essays on MEAS and Innovation

UNU-MERIT/MGSoG Dissertation

Series № 207

\section{Clotilde Mahé}

Essays on Migration and Occupational Choice

UNU-MERIT/MGSoG Dissertation

Series № 206

\section{Simone Sasso}

Talent on the move. Essays on Human Capital, Graduate Mobility and Economic Development

UNU-MERIT/MGSoG Dissertation Series № 205

\section{Khaled Walid Rajab}

Strategic Planning under Fragility

UNU-MERIT/MGSoG Dissertation

Series № 204

\section{Mutinta Hambayi Nseluke}

A Tall Order: Improving Child Linear Growth

UNU-MERIT/MGSoG Dissertation Series № 203

\section{Elvis Korku Avenyo}

Innovations and Firm Performance in sub-Saharan Africa: Empirical Analyses UNU-MERIT/MGSoG Dissertation

Series № 202 
Ni Zhen

Employment Dynamics, Firm Performance and Innovation Persistence in the Context of Differentiated Innovation Types:

Evidence from Luxembourg

UNU-MERIT/MGSoG Dissertation

Series № 201

\section{Caroline Wehner}

Too Scared to Achieve: The Relation

Between Neuroticism, Conscientiousness

and Socioeconomic Outcomes

UNU-MERIT/MGSoG Dissertation

Series № 200

Stefania Innocenti

On Institutional Persistence

UNU-MERIT/MGSoG Dissertation

Series № 199

\section{Hassen Abda Wako}

Economic Globalization, Institutions and Development: Essays on Aid, Foreign

Direct Investment and Trade

UNU-MERIT/MGSoG Dissertation

Series № 198

2017

\section{Hans-Erik Edsand}

Winds of Change

UNU-MERIT/MGSoG Dissertation

Series № 197

\section{Ana Patricia Silva Vara}

Redressing the Gender Gap

UNU-MERIT/MGSoG Dissertation

Series № 196

\section{Andrés Iván Mideros Mora}

Essays on the Economic Effects of Noncontributory Social Protection

UNU-MERIT/MGSoG Dissertation

Series № 195
Tobias Broich

New Actors in the Global Economy UNU-MERIT/MGSoG Dissertation

Series № 194

\section{Bernard Nikaj}

From No-government to E-government

UNU-MERIT/MGSoG Dissertation

Series № 193

\section{Ali Safarnejad}

Prioritizing the HIV Response

UNU-MERIT/MGSoG Dissertation

Series № 192

\section{Clovis Freire}

Diversification and Structural Economic

Dynamics

UNU-MERIT/MGSoG Dissertation

Series № 191

\section{Michael Verba}

Innovation and Knowledge Dynamics:

Essays on the Knowledge Economy

UNU-MERIT/MGSoG Dissertation

Series № 190

\section{Pui Hang Wong}

The Hearts and Minds in Conflict and

Peace: The Economics of

Counterinsurgency and the Psychology of

Reconstruction

UNU-MERIT/MGSoG Dissertation

Series № 189

\section{Brenda Yamba}

Schooling Despite All Odds: Evidence from

Lesotho on Female Child Carers who Stayed in School

UNU-MERIT/MGSoG Dissertation

Series № 188 


\section{Sheng Zhong}

Moving towards An Energy Efficient

Future: Essays on Energy Efficiency,

Technology and Development

UNU-MERIT/MGSoG Dissertation

Series № 187

\section{Julieta Marotta}

Access to Justice and Legal Empowerment of Victims of Domestic Violence through Legal Organizations in the City of Buenos Aires: A Qualitative Empirical Legal Study UNU-MERIT/MGSoG Dissertation

Series, № 186

\section{Andrea Franco-Correa}

On the Measurement of Multidimensional Poverty as a Policy Tool: Empirical

Applications to Chile, Colombia, Ecuador and Peru

UNU-MERIT/MGSoG Dissertation

Series, № 185

\section{6}

Yesuf Awel

Insurance for Growth: Empirical Essays on Insurance Demand and Impacts in Africa UNU-MERIT Dissertation Series, № 108

\section{Tigist Mekonnen Melesse}

Grow More Food using Fewer Resources: Agricultural Technology Adoption and Innovation Practices for Inclusive and Sustainable Development UNU-MERIT Dissertation Series, № 107

\section{Eleni Yitbarek}

Getting Ahead or left Behind? Essays on Poverty Dynamics and Social Mobility in Africa UNU-MERIT Dissertation Series, № 106
Thuy Dieu Nguyen

Firm-Level Theory and Evidence of

Corruption

UNU-MERIT Dissertation Series, № 105

\section{Raquel Tsukada Lehman}

Essays on Household Production with

Labor-Saving Technology

UNU-MERIT Dissertation Series, № 104

\section{Eva Barteková}

Multi-Problem Challenges for a Renewable Future: Empirical Studies on Competitive Disadvantages from Electricity Price Differentials and Mineral Supply Risk in an Open Economy

UNU-MERIT Dissertation Series, № 103

\section{Jocelyn Olivari}

Entrepreneurial Traits and Innovation:

Evidence from Chile

UNU-MERIT Dissertation Series, № 102

\section{Muhammad Shafique}

Essays on the role of knowledge, $R \mathcal{E} D$, and Technology-based Firms in the Evolution of Socio-techno-economic System UNU-MERIT Dissertation Series, № 101

\section{Serdar Türkeli}

Governance of Innovation Policy: Empirical Studies on Applied Political Economy by Multi-Methods Analysis UNU-MERIT Dissertation Series, № 100 


\section{Ayokunu Adedokun}

Pathways to Sustainable Peace building in Divided Societies: Lessons and Experiences from Mozambique

MGSoG Dissertation Series, № 75

\section{Luiz Rothier Bautzer}

Organizing Concurrent Engineering

through ICT Platforms

Blueprinting Product Lifecycle

Management Platforms across Disciplinary

Agencies

MGSoG Dissertation Series, № 74

\section{Natalia Popova}

Migration in the Periphery of the European Union:

Determinants of Successful and

Sustainable Labour Market Integration of

Return Migrants in Albania, Egypt,

Moldova and Tunisia

MGSoG Dissertations Series, № 73

\section{Richard A. Martina}

Uncertainty and Resource Constraint in the Small Island Developing States:

Essays in Entrepreneurial Cognition

MGSoG Dissertations Series, № 72

\section{Cécile Cherrier}

The Expansion of Basic Social Protection in Low-income Countries:

An Analysis of Foreign Aid Actors' Role in the Emergence of Social Transfers in SubSaharan Africa

MGSoG Dissertations series, № 71

\section{Paul Caldron}

The Tacit Bargain in Short-Term Medical Missions: Why U.S. physicians go and what it costs

MGSoG Dissertation Series, № 70

\section{Mahmut Kobal}

Customs \& Excellence: A Comparative

Approach on Administrative and

Regulatory Compliance Perspectives of the

EU-Turkey Customs Union

MGSoG Dissertation Series, № 69

\section{Craig Loschmann}

Essays on Conflict-related Migration and Development in the Case of Afghanistan

MGSoG Dissertations Series, № 68

\section{Andrea Milan}

Rural Livelihoods, Location and Vulnerable Environments: Approaches to Migration in Mountain areas of Latin America

MGSoG Dissertation Series, № 67

\section{Farida Lada}

On Guarding the Welfare of Clinical Trial Subjects While Promoting Novel Drug Innovation

A Game Theoretical Approach

MGSoG Dissertation Series, № 66

2015

\section{Hibret Belete Maemir}

Dissecting Aggregate Productivity: International Integration and Growth with Heterogeneous Firms

UNU-MERIT Dissertation Series, № 96

\section{Giorgio Triulzi}

Looking for the Right Path: Technology

Dynamics, Inventive Strategies and

Catching-up in the Semiconductor

Industry

UNU-MERIT Dissertation Series, № 95

\section{Abdul Baseer Qazi}

Knowledge flows and networks in the ICT sector: The case of Pakistan

UNU-MERIT Dissertation Series, № 94 
Ajay Thutupalli

Technology Paradigm Shifts in

Agriculture: Drivers of Sustainability and

Catch up

UNU-MERIT Dissertation Series, № 93

\section{Eduardo Urias}

Improving access to HIVIAIDS treatment in Brazil: When are Compulsory Licenses

effective in Price Negotiations?

UNU-MERIT Dissertation Series, № 92

\section{Francesca Guadagno}

Why have so few Countries Industrialised?

UNU-MERIT Dissertation Series, № 91

\section{Daniel Opolot}

The Evolution of Beliefs and Strategic

Behaviour

UNU-MERIT Dissertation Series, № 90

Alejandro Lavopa

Structural Transformation and Economic

Development: Can Development Traps be

Avoided

UNU-MERIT Dissertation Series, № 89

\section{Jinjin Zhao}

Urban water management reform: The Case of China

UNU-MERIT Dissertation Series, № 88

\section{Simona Vezzoli}

Borders, Independence and Post-colonial

Ties: the Role of the State in Caribbean

Migration

MGSoG Dissertation Series, № 65

\section{Silvia Consuelo Gómez Soler}

Civil Conflict and Education: How Does

Exposure to Civil Conflict Affect Human

Capital Accumulation? Evidence from

Standardized Exit Exams in Colombia

MGSoG Dissertation Series, № 64
Paula Nagler

Occupational Choice in the Developing

World

MGSoG Dissertation Series, № 63

\section{Jasmin Kientzel}

Determinants of Professional Commitment

to Environmental Sustainability

MGSoG Dissertation Series, № 62

\section{Mehmet Güney Celbiş}

Regional Policies: Convergence, Trade, and the Allocation of Public Capital

MGSoG Dissertation Series, № 61

\section{Florian Henning}

Living Up to Standard: Interoperability

Governance and Standards Adoption in

Government Information Networks

MGSoG Dissertation Series, № 60

\section{Niels P. Groen}

The Never-Ending Project

Understanding E-Government Project

Escalation

MGSoG Dissertation Series, № 59

\section{Derek Copp}

Teacher-Based Reactivity to Provincial Large-scale Assessment in Canada

MGSoG Dissertation Series, № 58

\section{Michaella Vanore}

Family-Member Migration and the Psychosocial Health Outcomes of Children in Moldova and Georgia

MGSoG Dissertation Series, № 57

\section{Sonja Fransen}

The Economic and Social Effects of Remittances and Return Migration in Conflict-Affected Areas: The Case of Burundi

MGSoG Dissertation Series, № 56 
Ibrahim Khalil Conteh

The Impact of Floods on Primary School

Education in Zambia

MGSoG Dissertation Series, № 55

\section{Richard Bluhm}

Growth Dynamics and Development

Essays in Applied Econometrics and

Political Economy

MGSoG Dissertation Series, № 54

\section{Nevena P. Zhelyazkova}

Work-Family Reconciliation and Use of

Parental Leave in Luxembourg: Empirical

Analysis of Administrative Records

MGSoG Dissertation Series, № 53

\section{4}

\section{Dirk Crass}

The Impact of Brands on Innovation and

Firm Performance: Empirical Evidence

from Germany

UNU-MERIT Dissertation Series, № 87

\section{Samyukta Bhupatiraju}

The Geographic Dimensions of Growth and Development

UNU-MERIT Dissertation Series, № 86

\section{François Lafond}

The Evolution of Knowledge Systems

UNU-MERIT Dissertation Series, № 85

\section{Annalisa Primi}

Promoting Innovation in Latin America:

What Countries Have Learned (and What

They Have Not) in Designing and

Implementing Innovation and Intellectual

Property Policies

UNU-MERIT Dissertation Series, № 84
Fatoumata Lamarana Diallo

Evaluation of Meal and Deworming

Programs for Primary Schools in Rural

Senegal

UNU-MERIT Dissertation Series, № 83

\section{Sachin Kumar Badkas}

Metachoice and Metadata: Innovating with Environmental Policy Analysis in Europe MGSoG Dissertation Series, № 52

\section{Irina S. Burlacu}

An Evaluation of Tax-Benefit Systems Impact on the Welfare of Frontier Worker: The Case of Luxembourg and Belgium MGSoG Dissertation Series, № 51

\section{Özge Bilgili}

Simultaneity in Transnational Migration Research: Links Between Migrants' Host and Home Country Orientation MGSoG Dissertation Series, № 50

\section{Yulia Privalova Krieger}

Reshaping the Big Agenda: Transnational Politics and Domestic Resistance Financial crisis and social protection reform in Bosnia and Herzegovina

MGSoG Dissertation Series, № 49

\section{Marieke van Houte}

Moving Back or Moving Forward? Return migration after Conflict

MGSoG Dissertation Series, № 48

\section{Oxana Slobozhan}

Global Governance in the Management of Natural Resources: The Case of the Extractive Industries Transparency Initiative (EITI)

MGSoG Dissertation Series, № 47 
Luis Bernardo Mejia Guinand

The Changing Role of the Central Planning Offices in Latin America: A Comparative

Historical Analysis Perspective (1950-

2013)

MGSoG Dissertation Series, № 46

\section{Cheng Boon Ong}

Ethnic Segregation in Housing, Schools and Neighbourhoods in the Netherlands MGSoG Dissertation Series, № 45

\section{Luciana V. Cingolani}

Bureaucracies for Development: Oxymoron or Reality? Studies on State Capacity in Challenging Governance Contexts MGSoG Dissertation Series, № 44

\section{Carlos Cadena Gaitán}

Green Politics in Latin American Cities -

Sustainable Transport Agendas

MGSoG Dissertation Series, № 43

\section{Katie Kuschminder}

Female Return Migration and

Reintegration Strategies in Ethiopia

MGSoG Dissertation Series, № 42

Metka Hercog

Highly-Skilled Migration and New

Destination Countries

MGSoG Dissertation Series, № 41

\section{Margaret Agaba Rugadya}

Can Remittances Influence the Tenure and Quality of Housing in Uganda?

MGSoG Dissertation Series, № 40

\section{Ilire Agimi}

New Governance Under Limited Statehood:

The Case of Local Government Reform in Kosovo

MGSoG Dissertation Series, № 39
2013

Anant Kamath

Information Sharing through Informal Interaction in Low-Tech Clusters

UNU-MERIT Dissertation Series, № 82

\section{Flavia Pereira de Carvalho}

What we talk about when we talk about Brazilian Multinationals: An Investigation on Brazilian FDI, Economic Structure, Innovation and the Relationship between them

UNU-MERIT Dissertation Series, № 81

\section{Jun Hou}

Complementarity in Innovation and

Development: A Cross-country

Comparison

UNU-MERIT Dissertation Series, № 80

\section{Rufin Baghana}

Impacts of Government Incentives to RED, Innovation and Productivity:

A Microeconometric Analysis of the

Québec Case

UNU-MERIT Dissertation Series, № 79

\section{Lilia I. Stubrin}

High-Tech Activities in Emerging

Countries: A Network perspective on the

Argentinean Biotech Activity

UNU-MERIT/MGSoG Dissertation

Series, № 78

\section{Kristine Farla}

Empirical Studies on Institutions, Policies and Economic Development

MGSoG Dissertation Series, № 38

\section{Marina Petrovic}

Social Assistance and Activation in the Pursuit of Happiness: Shedding New Light on Old Policy Solutions to Social Exclusion MGSoG Dissertation Series, № 37 


\section{Laura Torvinen}

Assessing Governance Assessments: The

Case of Mozambique: Governance

Assessments in the Context of Aid

Effectiveness Discourse

MGSoG Dissertation Series, № 36

\section{Biniam Egu Bedasso}

Institutional Change in the Long Shadow of

Elite: Essays on Institutions, Human

Capital and Ethnicity in Developing

Countries

MGSoG Dissertation Series, № 35

\section{Sepideh Yousefzadeh Faal Deghati}

Childhoods Embargoed: Constructing and

Reconstructing Multidimensional Child

Poverty in Iran 1984-2009

MGSoG Dissertation Series, № 34

\section{Robert Bauchmüller}

Investing in Early Childhood Care and

Education: The Impact of Quality on

Inequality

MGSoG Dissertation Series, № 33

\section{Martin Rehm}

Unified Yet Separated: Empirical Study on the Impact of Hierarchical Positions within Communities of Learning

MGSoG Dissertation Series, № 32

2012

\author{
Abdul Waheed \\ Innovation Determinants and Innovation \\ as a Determinant: Evidence from \\ Developing Countries \\ UNU-MERIT Dissertation Series, № 77
}

\section{Bilal Mirza}

Energy Poverty and Rural Energy Markets in Pakistan

UNU-MERIT Dissertation Series, № 76

\section{Benjamin Engelstätter}

Enterprise Software and Video Games: An Empirical Analysis

UNU-MERIT Dissertation Series, № 75

\section{Fulvia Farinelli}

Natural Resources, Innovation and Export Growth: The Wine Industry in Chili and Argentina

UNU-MERIT Dissertation Series

\section{Rodolfo Lauterbach}

Innovation in Manufacturing: From

Product Variety and Labor Productivity

Growth to Economic Development in Chile

UNU-MERIT Dissertation Series

\section{Kirsten Wiebe}

Quantitative Assessment of Sustainable Development and Growth in Sub-Saharan Africa

UNU-MERIT Dissertation Series, № 74

\section{Julio Miguel Rosa}

Organizational Strategies, Firms'

Performance and Spatial Spillovers: The

Canadian Case in Research and

Development.

UNU-MERIT Dissertation Series, № 73

\section{Johannes Wilhelmus Marie Boels}

Joseph Schumpeter, Honderd Jaar

Economische Ontwikkeling: Een

Historisch-theoretische Beschouwing.

UNU-MERIT Dissertation Series

\section{Dorcas Mbuvi}

Utility Reforms and Performance of the

Urban Water Sector in Africa

MGSoG Dissertation Series, № 31 


\section{Lina Salanauskaite}

Distributional Impacts of Public Policies:

Essays in Ex-Ante and Ex-Post Evaluation

MGSoG Dissertation Series, № 30

\section{Esther Schüring}

To Condition or not - is that the Question? An Analysis of the Effectiveness of Ex-Ante and Ex-Post Conditionality in Social Cash Transfer Programs

MGSoG Dissertation Series, № 29

Joe Abah

Strong Organisations in Weak States:

Atypical Public Sector Performance in

Dysfunctional Environments

MGSoG Dissertation Series, № 28

\section{Zina Samih Nimeh}

Social Citizenship Rights: Inequality and

Exclusion

MGSoG Dissertation Series, № 27

2011

Daniel Vertesy

Interrupted Innovation: Emerging

Economies in the Structure of the Global

Aerospace Industry

UNU-MERIT Dissertation Series, № 72

\section{Tina Saebi}

Successfully Managing Alliance Portfolios:

An Alliance Capability View

UNU-MERIT Dissertation Series, № 71

\section{Nora Engel}

Tuberculosis in India: A Case of Innovation and Control

UNU-MERIT/MGSoG Dissertation

Series, № 70

\section{Evans Mupela}

Connectivity and growth in Sub-Saharan

Africa: The Role of Communication

Satellites

UNU-MERIT Dissertation Series, № 69

\section{Nantawan Kwanjai}

Cross Cultural Intelligence amid Intricate

Cultural Webs: A Tale of the

UnDutchables in the Land of 1002 Smiles

UNU-MERIT Dissertation Series, № 68

\section{Lina Sonne}

Innovation in Finance to Finance

Innovation: Supporting Pro-poor

Entrepreneur-based Innovation

UNU-MERIT Dissertation Series, № 67

\section{Lenka Eisenhamerová}

Legitimacy of 'Humanitarian Military

Intervention'

MGSoG Dissertation Series, № 26

\section{Sonila Tomini}

Informal Payments for Health Care

Services in Albania

MGSoG Dissertation Series, № 25

\section{Jinjing Li}

Dynamic Microsimulation in Public Policy

Evaluation

MGSoG Dissertation Series, № 24

\section{Aziz Atamanov}

Rural Nonfarm Employment and International Migration as Alternatives to Agricultural Employment: The Case of Kyrgyzstan

MGSoG Dissertation Series, № 23

\section{Frieda Vandeninden}

Poverty Alleviation: Aid and Social Pensions

MGSoG Dissertation Series, № 22 
Juliana Nyasha Tirivayi

The Welfare Effects of Integrating AIDS

Treatment with Food Transfers: Evidence from Zambia

MGSoG Dissertation Series, № 21

\section{Agnieska Ewa Sowa}

Who's Left Behind? Social Dimensions of

Health Transition and Utilization of

Medical Care in Poland

MGSoG Dissertation Series, № 20

\section{Emmanaouil Sfakianakis}

The Role of Private Actors in the Provision of Public Goods with Applications to Infrastructure and Financial Stability

MGSoG Dissertation Series, № 19

\section{Siu Hing Lo}

White Collars Green Sleeves: An Interorganizational Comparison of

Determinants of Energy-Related Behaviors among Office Workers

MGSoG Dissertation Series, № 18

\section{Treena $\mathbf{W u}$}

Constraints to Human Capital Investment in Developing Countries:

Using the Asian Financial Crisis in

Indonesia as a Natural Experiment

MGSoG Dissertation Series, № 17

\section{Henry Espinoza Peña}

Impact Evaluation of a Job-Training

Programme for Disadvantaged Youths:

The Case of Projoven

MGSoG Dissertation Series, № 16
2010

\section{Fernando Santiago}

Human Resources Management Practices

and Learning for Innovation in Developing

Countries: Pharmaceutical Firms in

Mexico

UNU-MERIT Dissertation Series, № 66

\section{Zakaria Babutsidze}

Essays on Economies with Heterogeneous Interacting Consumers

UNU-MERIT Dissertation Series, № 65

\section{Bertha Vallejo}

Learning and Innovation Under Changing Market Conditions: The Auto Parts

Industry in Mexico

UNU-MERIT Dissertation Series, № 64

\section{Donatus Ayitey}

Technical Change, Competitiveness and

Poverty Reduction: A Study of the

Ghanaian Apparel Industry

UNU-MERIT Dissertation Series, № 63

\section{Sergey Filippov}

Multinational Subsidiary Evolution:

Corporate Change in New EU Member

States

UNU-MERIT Dissertation Series, № 62

\section{Asel Doranova}

Technology Transfer and Learning under the Kyoto Regime: Exploring the

Technological Impact of CDM Projects in Developing Countries

UNU-MERIT Dissertation Series, № 61

\section{Florian Tomini}

Between Family and Friend:

Understanding the Interdependency of

Private Transfers

MGSoG Dissertation Series, № 15 


\section{Michał Polalowski}

The Institutional Transformation of Social Policy in East Central Europe: Poland and Hungary in Comparative and Historical Perspective

MGSoG Dissertation Series, № 14

\section{Maha Ahmed}

Defining, Measuring and Addressing Vulnerability: The Case of Post Conflict

Environments

MGSoG Dissertation Series, № 13

\section{Pascal Beckers}

Local Space and Economic Success: The

Role of Spatial Segregation of Migrants in the Netherlands

MGSoG Dissertation Series, № 12

\section{Victor Cebotari}

Conflicting Demands in Ethnically Diverse Societies: Ethno political Contention and Identity Values in Europe

MGSoG Dissertation Series, № 11

\section{Dennis Gyllensporre}

Competing and Complementary

Perspectives on the EU as a Crisis

Management Actor:

An Examination of the Common Security and Defence Policy through the Lenses of Idealism and Realism

MGSoG Dissertation Series, № 10

\section{Judit Vall Castello}

Business Cycle and Policy Effects on Labour Market Transitions of Older and Disabled Workers in Spain

MGSoG Dissertation Series, № 9

\section{Keetie Roelen}

False Positives or Hidden Dimensions: The Definition and Measurement of Child Poverty

MGSoG Dissertation Series, № 8

\author{
Denisa Maria Sologon
}

Earning Dynamics in Europe

MGSoG Dissertation Series, № 7

\section{Melissa Siegel}

Money and Mobility: Migration and

Remittances

MGSoG Dissertation Series, № 6

Jessica S. Hagen-Zanker

Modest Expectations: Causes and Effects of Migration on Migrant Households inSource Countries

MGSoG Dissertation Series, № 5

2009

\begin{abstract}
Alexis Habiyaremye
From Primary Commodity Dependence to Diversification and Growth: Absorptive Capacity and Technological Catch Up in Botswana and Mauritius.
\end{abstract}

UNU-MERIT Dissertation Series, № 60

\section{Yoseph Getachew}

The Role of Public Capital in Economic

Development

UNU-MERIT Dissertation Series, № 59

\section{Sandra Leitner}

Embodied Technological Change and

Patterns of Investment in Austrian

Manufacturing

UNU-MERIT Dissertation Series, № 58

\section{Semih Akçomak}

The Impact of Social Capital on Economic and Social Outcomes

UNU-MERIT Dissertation Series, № 57

\author{
Abraham Garcia \\ The Role of Demand in Technical Change \\ UNU-MERIT Dissertation Series, № 56
}




\section{Saurabh Arora}

Coherence in Socio-technical Systems: A

Network Perspective on the Innovation

Process

UNU-MERIT Dissertation Series, № 55

\section{Mirtha R. Muniz Castillo}

Human Development and Autonomy in

Project Aid: Experiences from four bilateral projects in Nicaragua and El Salvador

MGSoG Dissertation Series, № 4

\section{Christiane Arndt}

Governance Indicators

MGSoG Dissertation Series, № 3

\section{Britta Augsburg}

Microfinance: Greater Good or Lesser Evil? MGSoG Dissertation Series, № 2

\section{8}

\section{Rutger Daems}

Medicines for the Developing World

UNU-MERIT Dissertation Series, № 54

\section{Johannes Hanel}

Assessing Induced Technology: Sombart's Understanding of Technical Change in the History of Economics

UNU-MERIT Dissertation Series, № 53

\section{Rifka Weehuizen}

Mental Capital: the Economic Significance of Mental Health

UNU-MERIT Dissertation Series, № 52

\section{Danielle Cloodt}

The Relationship between RED

Partnership Formation, Social

Embeddedness and Innovative Performance UNU-MERIT Dissertation Series, № 51

\section{Sabine Fuss}

Sustainable Energy Development under Uncertainty

UNU-MERIT Dissertation Series, № 50

\section{Geranda Notten}

Measuring and Managing Poverty Risks

MGSoG Dissertation Series, № 1

2007

\section{Tobias Kronenberg}

Reconciling Environmental Conservation with Economic Prosperity: The Feasibility

of Double Dividends in the Short and Long Run

UNU-MERIT Dissertation Series, № 49

\section{Viktoria Kravtsova}

Assessing the Impact of Foreign Direct Investment in Transition Economies UNU-MERIT Dissertation Series, № 48

\section{Suhail Sultan}

The Competitive Advantage of Small and Medium Sized Enterprises: The Case of Jordan's Natural Stone Industry UNU-MERIT Dissertation Series, № 47

2006

\section{Bulat Sanditov}

Essays on Social Learning and Imitation UNU-MERIT Dissertation Series, № 46

\section{Mamata Parhi}

Dynamics of New Technology Diffusion: A Study of the Indian Automotive Industry UNU-MERIT Dissertation Series, № 45

\section{Andreas Reinstaller}

Social Structures and the Innovation Process: Their Role in the Demand of Firms and Consumers

UNU-MERIT Dissertation Series, № 44 


\section{Rose Kiggundu}

Innovation systems and Development: The Journey of a Beleaguered Nile Perch Fishery in Uganda

UNU-MERIT Dissertation Series, № 43

\section{Thomas Pogue}

The Evolution of Research Collaboration in South African Gold Mining: 1886-1933

UNU-MERIT Dissertation Series, № 42

\section{Geoffrey Gachino}

Foreign Direct Investment, Spillovers and Innovation: The Case of Kenyan

Manufacturing Industry

UNU-MERIT Dissertation Series, № 41

\section{Önder Nomaler}

Technological Change, International Trade and Growth: An Evolutionary, Multi-

Agents-Based Modeling Approach

UNU-MERIT Dissertation Series, № 40

2005

\section{Samia Satti Osman Mohamed-Nour}

Change and Skill Development in the Arab Gulf Countries

UNU-MERIT Dissertation Series, № 39

\section{Elad Harison}

Intellectual Property Rights: Economics and Policy Analysis

UNU-MERIT Dissertation Series, № 38

\section{Daniel Dalohoun}

Learning to innovate: agricultural innovation and entrepreneurship: the case of Songhaï farmers in Benin

UNU-MERIT Dissertation Series, № 37

\section{Bas Straathof}

Product Variety and Economic Growth: The Counteracting Effects of Scale and Idiosyncrasy

UNU-MERIT Dissertation Series, № 35

\section{Wilfred Schoenmakers}

Knowledge Flows between Multinational Companies: A Patent Data Analysis UNU-MERIT Dissertation Series, № 34

\section{Myriam Cloodt}

Mergers and Acquisitions ( $M$ and $A s$ ) in High-Tech Industries: Measuring the Post$M$ and $A$ Innovative Performance of Companies

UNU-MERIT Dissertation Series, № 33

\section{4}

\section{Paola Criscuolo}

RED Internationalisation and Knowledge Transfer: Impact on MNEs and their Home Countries

UNU-MERIT Dissertation Series, № 32

\section{Maarten Verkerk}

Trust and Power on the Shop Floor UNU-MERIT Dissertation Series, № 31

\section{Gottfried Leibbrandt}

Adoption, Harmonization and Succession of Network Technologies across Countries UNU-MERIT Dissertation Series, № 30

\section{Mark Sanders}

Skill Biased Technical change: Its Origins, the Interaction with the Labour Market and Policy Implications

UNU-MERIT Dissertation Series, № 29

\section{Müge Ozman}

Networks, Organizations and Knowledge UNU-MERIT Dissertation Series, № 36 
2003

\section{Nadine Roijakkers}

Inter-firm Cooperation in High-tech

Industries: a Study of RED Partnerships

in Pharmaceutical Biotechnology

UNU-MERIT Dissertation Series, № 28

\section{Viki Sonntag}

Speed, Scale and Sustainability

UNU-MERIT Dissertation Series, № 27

\section{Masaru Yarime}

From End-of-Pipe Technology to Clean

Technology

UNU-MERIT Dissertation Series, № 26

\section{Stéphane Malo}

The Combinatorial Chemistry Revolution:

Sustaining a Superior Performance

Position through Technological Learning

UNU-MERIT Dissertation Series, № 25

2002

\section{Annelies Hogenbirk}

Determinants of Inward Foreign Direct Investment: the Case of the Netherlands

UNU-MERIT Dissertation Series, № 24

\section{Bastiaan Johan terWeel}

The Computerization of the Labour Market UNU-MERIT Dissertation Series

2001

\section{John Adeoti}

Technology Investment in Pollution

Control in Sub-Saharan Africa: The Case of the Nigerian Manufacturing Industry

UNU-MERIT Dissertation Series, № 23

\section{Edward Huizenga}

Innovation Management: How

Frontrunners Stay Ahead: An Empirical

Study on Key Success Factors in the ICT

sector

UNU-MERIT Dissertation Series, № 22

2000

\section{Machiel van Dijk}

Technological Change and the Dynamics of Industries: Theoretical Issues and

Empirical evidence from Dutch

Manufacturing

UNU-MERIT Dissertation Series, № 21

\section{9}

\section{Jan Cobbenhagen}

Managing Innovation at the Company

Level: A Study on Non-Sector-Specific

Success Factors

UNU-MERIT Dissertation Series, № 20

\section{Marjolein Caniëls}

Regional Growth Differentials: The Impact of Locally Bounded Knowledge Spillovers

UNU-MERIT Dissertation Series, № 19

\section{8}

\section{Aldo Geuna}

Resource Allocation and Knowledge production: Studies in the Economics of University Research UNU-MERIT Dissertation Series, № 18

1996

\section{Reinoud Joosten}

Dynamics, Equilibria, and Values

UNU-MERIT Dissertation Series, № 17 


\section{Hugo Kruiniger}

Investment, $R \mathcal{E} D$, and the Financing

Decisions of the Firm

UNU-MERIT Dissertation Series, № 16

1995

\section{Hans van Meijl}

Endogenous Technological Change: The

Case of Information Technology,

Theoretical Considerations and Empirical

Results

UNU-MERIT Dissertation Series, № 15

\section{René Kemp}

Environmental Policy and Technical

Change: A Comparison of the Technological Impact of Policy Instruments

UNU-MERIT Dissertation Series, № 14

\section{Rohini Acharya}

The Impact of New Technologies on

Economic Growth and Trade: A Case Study of Biotechnology

UNU-MERIT Dissertation Series, № 13

\section{Geert Duysters}

The Evolution of Complex Industrial

Systems: The Dynamics of Major IT

Sectors

UNU-MERIT Dissertation Series, № 12

\section{Marjan Groen}

Technology, Work and Organisation: A

Study of the Nursing Process in Intensive

Care Units

UNU-MERIT Dissertation Series, № 11

1994

\section{Huub Meijers}

On the Diffusion of Technologies in a

Vintage Framework: Theoretical

Considerations and Empirical Results

UNU-MERIT Dissertation Series, № 10

\section{Theon van Dijk}

The Limits of Patent Protection: Essays on the Economics of Intellectual Property

Rights

UNU-MERIT Dissertation Series, № 9

\section{Hans Voordijk}

Naar Integrale Logistiek in Bedrijfsketens:

Ontwikkelingen in de Bouw

UNU-MERIT Dissertation Series, № 8

1993

\section{Paul Diederen}

Technological Progress in Enterprises and Diffusion of Innovation: Theoretical

Reflections and Empirical Evidence

UNU-MERIT Dissertation Series, № 7

\section{Ben Dankbaar}

Economic Crisis and Institutional Change: The Crisis of Fordism from the Perspective of the Automobile Industry

UNU-MERIT Dissertation Series, № 6

\section{Hanno Roberts}

Accountability and Responsibility: The Influence of Organisation Design on

Management Accounting

UNU-MERIT Dissertation Series, № 5

\section{2}

\section{Bart Verspagen}

Uneven Growth between Interdependent

Economies: An Evolutionary View on

Technology Gaps, Trade and Growth

UNU-MERIT Dissertation Series, № 4

\section{Sjoerd Romme}

A Self-organization Perspective on Strategy

Formation

UNU-MERIT Dissertation Series, № 3 
1989

\section{John Spangenberg}

Economies of Scale, and Atmosphere in Research Organisations

UNU-MERIT Dissertation Series, № 2

1988

\section{John Hagedoorn}

Evolutionary and Heterodox Innovation Analysis: A Study of Industrial and Technological Development in Process Control and Information Technology

UNU-MERIT Dissertation Series, № 1 